\title{
INTEGRATING RENEWABLE ENERGY IN PACIFIC ISLAND COUNTRIES
}

\author{
by
}

\author{
Marie Marconnet \\ A thesis \\ submitted to the Victoria University of Wellington \\ in fulfillment of the \\ requirements for the degree of \\ Master of Commerce and Administration \\ in Economics
}

Victoria University of Wellington

(2007) 


\section{Abstract}

The purpose of this thesis is to investigate the entry of renewable energy technologies into Pacific Islands' electricity markets, with particular focus on a new technology: the Pelamis, a wave energy converter. Pacific Islands are endowed with various types of renewable energy resources, yet they remain highly dependent on expensive fuel imports for their energy requirements, using little renewable energy. This paradox is investigated by studying the characteristics of Pacific Islands' electricity markets, including a casestudy on the entry of a new renewable energy technology, the Pelamis, into the electricity market of Hawaii. The integration of renewable energy technologies into Pacific Islands' electricity systems is then analysed from the point of view of an energy planner. The recent application of portfolio analysis to energy planning has provided a new framework to evaluate the different electricity generating options available to energy planners. Taking both the generating cost and financial risk of each technology into account, portfolio theory has been applied to various European countries, by comparing actual generation portfolios to an efficient frontier showing the trade-off between energy security and the cost of electricity generation. This framework has clear relevance to Pacific Island Countries. However, the characteristics inherent to Pacific Island Countries have important implications on the operation of their electricity systems, which are not necessarily taken into account in portfolio analysis. In particular, geographical isolation inhibits these countries from connecting to larger intercontinental grids, which emphasizes the importance of reliability of supply. This thesis presents a mathematical model which establishes a method for computing an optimal intertemporal path for introducing renewable energy into a pre-existing electricity system. The model explicitly allows for the cost of maintaining reliability of supply as intermittent generators are integrated. The framework also incorporates concepts from Integrated Resource Planning and portfolio analysis. Finally, policies for accelerating renewable energy development are reviewed, and a discussion is provided on the policies which are likely to be most suitable to Pacific Islands. One of the main conclusions of this thesis is that the amount of backup capacity for renewable energy can be optimally minimized by diversifying the mix of renewable energy resources in each island. In practice, this would require studying the complementarities and loading curves of the various renewable resources available, 
and comparing their total potential production, and the variability of this production, to electricity demand. This would allow energy planners to model the inclusion of a maximum amount of renewable energy using a minimum of backup capacity to maintain system reliability, potentially leading to a more efficient implementation and formulation of policies aimed at developing renewable energy generation in Pacific Islands. 


\section{Acknowledgements}

I would like to express my most sincere gratitude to my supervisor, Dr. Geoffrey Bertram, for his guidance, insight and support during the preparation of this thesis. I would also like to thank my second supervisor, Dr. Peter Chang, for his crucial input and guidance on the development of the model, and for his patience during the long debates held between Geoff and I. Special thanks to Société de Recherche du Pacifique and especially Barbara Vlaeminck for their financial support and insightful collaboration. I am also grateful to the School of Economics and Finance at Victoria University for funding my field research in Hawaii. Thanks to the team at Castalia, SOPAC and SPREP for providing me with useful comments and information. Last but not least, I wish to thank my parents, Philippe and Pascale Marconnet, for their unconditional encouragement and patience. 


\section{Contents}

Chapter One: Introduction

p. 1

Chapter Two: Analysis of the Key Patterns and Trends of Electricity Production and Consumption in Pacific Island Countries................................ 3

1) Sources of Electricity Generation in Pacific Island

Countries........................................................ 3

2) Electricity Supply in the Main

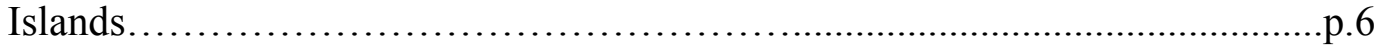

3) Electricity Supply in Outer Islands and Remote Areas..........................p.12

4) International Aid for Electricity Supply in Pacific Islands..................... p.13

5) Electricity Consumption in Pacific Islands................................. 16

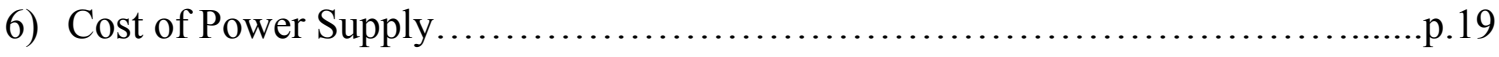

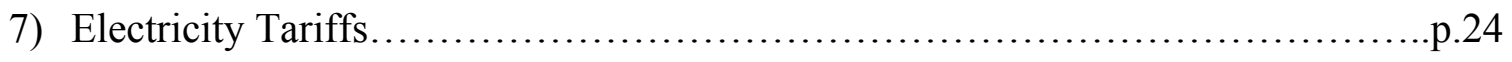

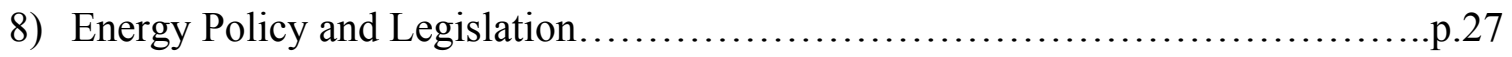

Chapter Three: Renewable Energy and Electricity Supply: Integrating Wave

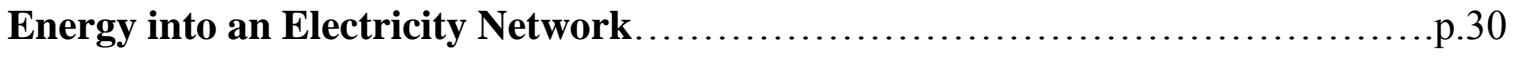

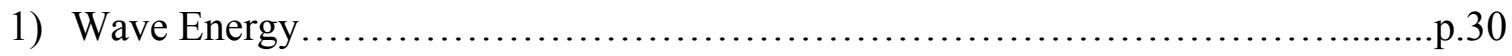

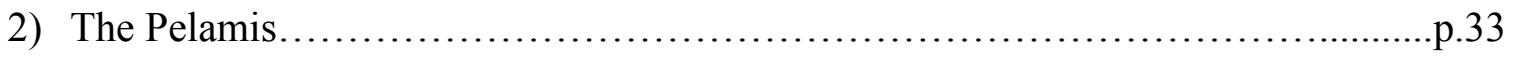

3) Accomodation of Renewable Energy by Electric Utilities......................p.36

4) Application of Portfolio Theory to Electricity Generation....................... 40

Chapter Four: Entry of a Wave Energy Technology into the Electricity Market of a Pacific Island - Case Study of the Pelamis in Hawaii.........................p.50

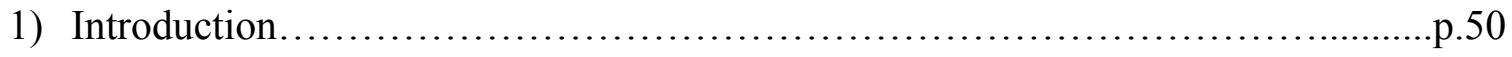

2) Electric Utilities, Current Regulation and Requirements.......................p.51

3) Barriers to Renewable Energy Development in Hawaii..........................p.58 
4) Feasibility and Potential for the Implementation of a Wave Energy Tecnology in

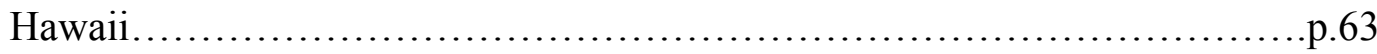

5) Using Insights from the Case-Study of Hawaii to Develop a Mathematical Model for the Integration of Renewables into Pacific Islands Electricity Systems..........p.67

Chapter Five: A Model for the Integration of Renewable Energy into an Existing

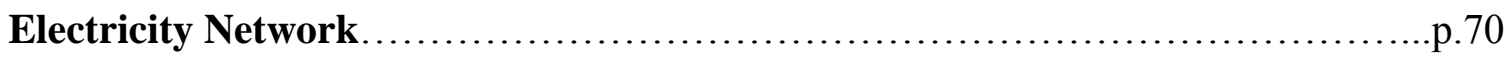

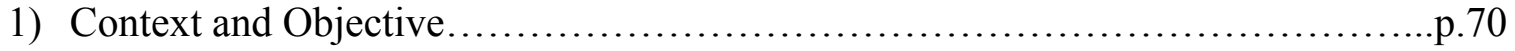

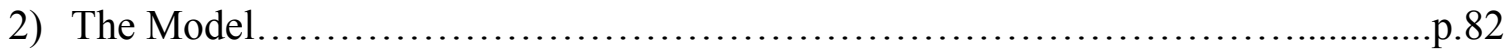

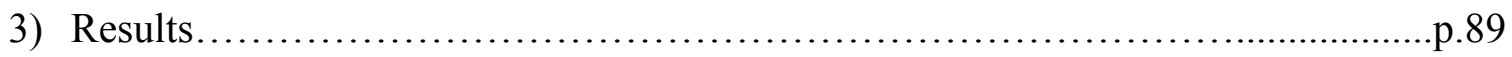

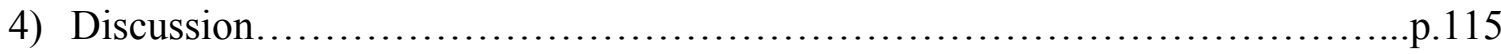

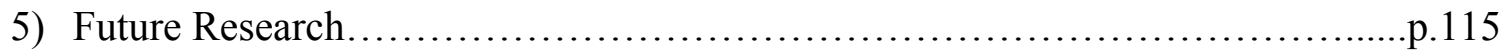

Chapter Six: Policies and Market Instruments to Promote Renewable Energy in

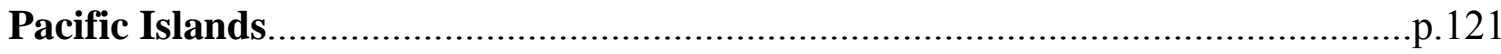

1) Barriers to the Development of Renewable Energy in Pacific Islands..............p.121

2) Policies and Instruments to Facilitate Renewable Energy Development............p.131

a). Mandated Market Policies: a Renewed Debate on Prices vs. Quantities...p.131

i) Price-setting policies: feed-in laws .............................. 132

ii) Quantity-based policies...................................... 135

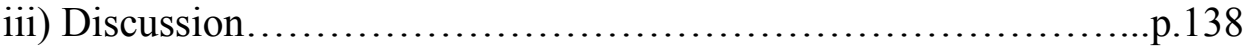

b). Cost-reduction policies: financial incentives..........................p. 142

c). Public investment and market facilitation activities......................p. 143

d). Power grid access policies............................................... 144

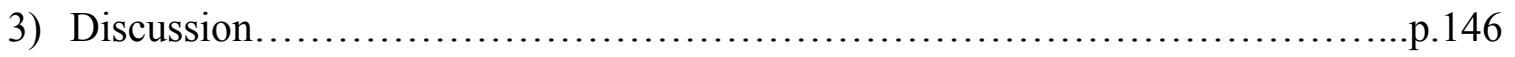

Chapter Seven: Conclusion.................................................. 149

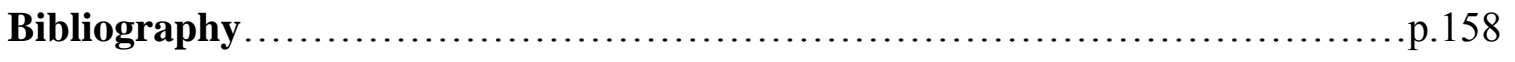




\section{List of Tables}

Table 2.1: Electricity Generation in Pacific Islands............................... 10

Table 2.2: Cost of Electricity Supply in some Pacific Islands.........................p.21

Table 4.1: Electricity Supply in Hawaii from Hawaiian Electric Industries.............p.53

Table 4.2: Percentage of Total Installed Capacity held by Independent Producers......p.53

Table 4.3: Cost of electricity generated by a wave farm.......................... p.67

Table 5.1: Base Case Scenario Parameters and Values.............................p.89

Table 5.2: Investment in Renewable and Non-Renewable Energy Plants (Scenario1)..p.95

Table 6.1: Overview of PIC National Energy Office Staffing and Authority (2004)...p.125

Table A1: Sources of electricity generation in Pacific Island Countries...............p.150

Table A2: Main electricity utilities in the Pacific Islands.......................... 154

Table B1: List of Interviews in Hawaii (August 2006)............................ 155

\section{List of Figures}

Figure 2.1: Percentage of electricity generated from diesel plants

(main electricity providers) ...................................... 4

Figure 2.2: Access to Electricity in Pacific Islands............................... .8

Figure 2.3: Electricity per Capita in Pacific Islands.............................. 11

Figure 2.4: Electricity as a Percentage of Non-transport Energy Consumption in

Pacific Islands................................................ 18

Figure 2.5: System Loss in Pacific Islands.................................. 20

Figure 2.6: Cost of Electricity Supply in the Cook Islands........................p.22

Figure 2.7: Economies of Scale in the Cook Islands............................. 23

Figure 2.8: Residential Electricity Tariffs in Pacific Islands and the United States, 2003-

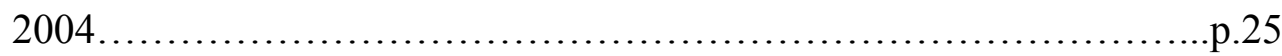

Figure 3.1: The Pelamis................................................... 34

Figure 3.2: EU Efficient Frontier (Awerbuch and Berger, 2003).................... 43

Figure 3.3: Scotland's Efficient Frontier (Awerbuch, 2005) .........................44

Figure 3.4: Switzerland's Efficient Frontier (Krey and Zweifel, 2006)................45

Figure 4.1: Electricity Generation Sources in Hawaii (2005) ......................p.58 
Figure 5.1: Indifference Curves and Budget Constraints for Electricity Quality New

Zealand and Rural Papua New Guinea..............................p. 72

Figure 5.2: Trade-off between Price and Intermittency of Electricity................p. 72

Figure 5.3: Trade-off between 'Renewability' and Reliability of Electricity............p.74

Figure 5.4: Choice of Technique with Two Technologies.......................... 75

Figure 5.5: Framework for the Integration of Renewables into an Existing Electricity

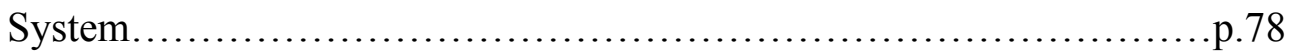

Figure 5.6: Integrating Renewables with Unlimited Backup Resources...............p.80

Figure 5.7: Possible Future Shape of Iso-Reliability Curves.......................p.81

Figure 5.8: Model Output for Scenario 1.................................... 93

Figure 5.9: Desired Vs. Actual Output for Scenario 1............................p.97

Figure 5.10: Model Output for Scenario 2 .................................... 99

Figure 5.11: Model Output for Scenario 3................................ 102

Figure 5.12: Model Output for Scenario 4-Increasing the Renewable Portfolio Standard from $20 \%$ to $30 \%$ and $40 \%$...........................................................p. 106

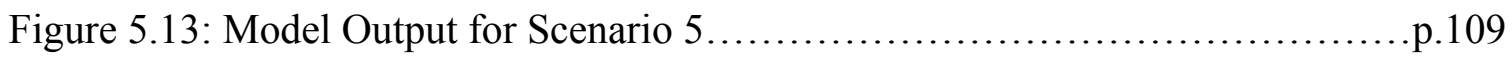

Figure 5.14: Model Output for Scenario 6................................. 112

Figure 5.15: Framework for Reliability with a Portfolio of Renewable Energy.........p.118

\section{Appendices}

Appendix A: Electricity Generation in Pacific Island Countries.................... 150

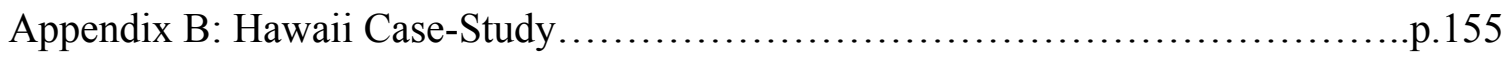

Appendix C: Model for the Integration of Renewables into Pacific Islands' Electricity Systems - First Order Conditions............................p.156 



\section{Chapter One: Introduction}

The purpose of this thesis is to investigate the entry of renewable energy technologies into Pacific Islands' electricity markets, with particular focus on a new technology: the Pelamis, a wave energy converter. The case of Pacific Islands is considered because these countries are endowed with various types of renewable energy resources, yet they remain highly dependent on expensive fuel imports for their energy requirements, using little renewable energy (Jafar, 2000, p.306; Yu and Gilmour, 1996, p.698; World Bank, 1992). This paradox is investigated by studying the characteristics of Pacific Islands' electricity markets: how are the electricity systems operated in these islands, and how are technology choices made? After examining the characteristics of Pacific Islands' electricity systems, a case-study is provided on the entry of a wave energy technology, the Pelamis, into the electricity market of Hawaii. This case study provides information on Hawaii's electricity market and its regulation, highlighting the presence of conflicting objectives between policy-makers and market-oriented electric utility stakeholders. It also provides information on the Pelamis, including its generating costs (Previsic, M. et al., 2005 b), and the potential for its entry in the electricity market of Hawaii.

Following this study of Pacific Islands' electricity markets, the integration of renewable energy technologies is analysed from the point of view of an energy planner. The recent application of portfolio analysis to energy planning has provided a new framework to evaluate the different electricity generating options available to energy planners. Taking both the generating cost and financial risk of each technology into account, portfolio theory has been applied to various European countries (Awerbuch and Berger, 2003; Jansen et al., 2006), finding evidence that energy security can be significantly improved by diversifying the generating mix without incurring any cost, if the EU were to move onto its efficient frontier. Applying this framework to Pacific Island Countries is likely to yield similar results. However, the characteristics inherent to Pacific Island Countries have important implications on the operation of their electricity systems, which are not necessarily taken into account in portfolio analysis. In particular, geographical isolation inhibits these countries from connecting to larger intercontinental grids, which emphasizes the importance of 
reliability of supply (Mayer, 2000). This thesis presents a model which examines the implications of increasing renewable energy in the electricity generating mix of Pacific Island Countries. The model establishes a method for computing an optimal intertemporal path for introducing renewable energy into a pre-existing electricity system, with explicit allowance for the cost of maintaining reliability of supply as intermittent generators are integrated. The framework incorporates concepts from Integrated Resource Planning and portfolio analysis.

The thesis is organized as follows. Chapter 2 provides information on electricity supply and renewable energy in Pacific Island Countries. Chapter 3 presents information on wave energy generation and the Pelamis wave energy converter. In addition, the technical problems and economic benefits associated with introducing renewable energy into existing electricity systems are discussed. Chapter 4 provides a case-study of the entry of renewable energy technologies into the electricity market of Hawaii, and the potential for the entry of a wave energy technology in this market. In chapter 5, a model for the integration of renewable energy technologies in Pacific Islands is developed. Chapter 6 reviews policies available for accelerating renewable energy development, and provides a discussion on the policies which are likely to be most suitable to Pacific Islands. Finally, chapter 7 concludes. 


\section{Chapter Two: Analysis of the Key Patterns and Trends of Electricity Production and Consumption in Pacific Island Countries}

\section{1) Sources of Electricity Generation in Pacific Island Countries}

Pacific Islands all benefit from abundant resources in renewable energy, whether it is hydroelectricity, geothermal, solar, or wind energy. Despite an increase in the use of such resources for electricity generation in the last three decades, virtually all Pacific Island Countries generate most of their electricity using oil-fuelled generators (except for Fiji and Samoa, which have significant hydro resources). This section provides a brief overview of the energy sources used for electricity production in Pacific Islands. For more detailed information, a table displaying the sources of electricity generation in each country can be found in the appendix (Table A1).

Diesel combustion plants can be found on each main island in the Pacific, mostly providing the bulk of electricity generation in all islands ${ }^{1}$. This pattern is depicted in figure 2, which shows the supply technology for electricity generated by the main electricity provider of each country ${ }^{2}$. The share of renewable energy use, such as solar home systems often found in outer islands, is thus understated in figure 2.1. However, diesel generators can also be found in remote areas and villages which are not connected to the main electricity grids.

\footnotetext{
${ }^{1}$ In Tonga, the Marshall Islands, Guam, FSM, Niue and Palau, there are some small-scale, off-grid renewable energy systems such as solar photovoltaic and wind power. Note that in the discussion which follows, distillate-fuelled turbines have been included in the "diesel" category.

${ }^{2}$ The use of off-grid systems is not represented in Figure 2.
} 
Figure 2.1: Percentage of Electricity Generated from Diesel Plants (Main electricity providers) $^{3}$

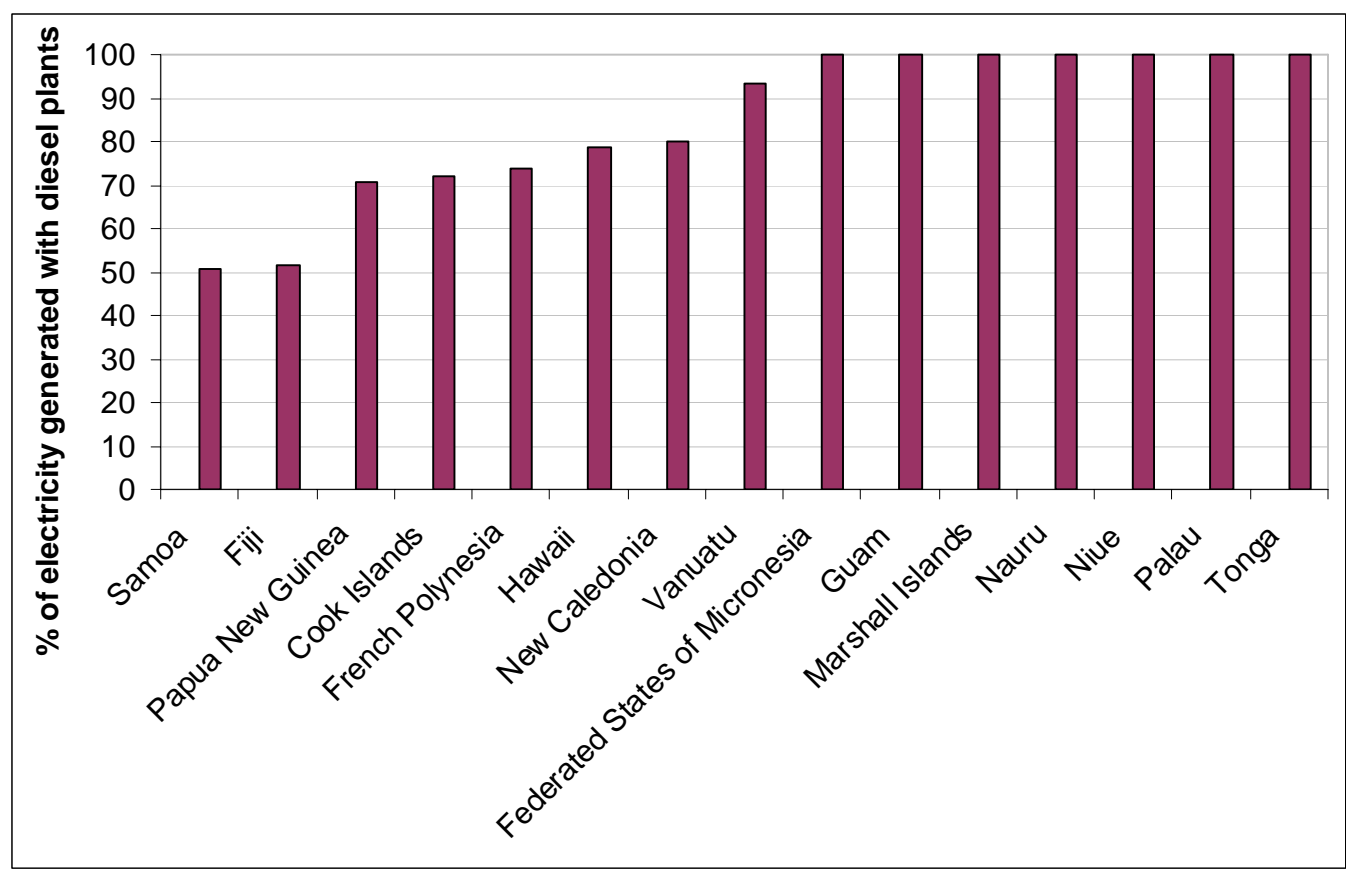

Most electricity in New Caledonia is generated by gas turbines or internal combustion engines. However, it could not be determined how much electricity was generated from each plant, so the amount of diesel generation in New Caledonia displayed in figure 2.1 includes generation from gas turbines.

In Fiji, hydropower is the main source of electricity, and in French Polynesia, New Caledonia, Papua New Guinea, Samoa, Solomon Islands, and Vanuatu, hydropower represents the second largest source. However, the share of hydropower has been decreasing in the past years, notably in Fiji and New Caledonia. In Fiji, the share of hydropower decreased from 92 percent in 1995 to 80 percent in 2000 and to 55 percent in 2003 due to a drought. However, this share is likely to have increased again because new hydropower plants have been constructed since 2003 (Wade, H. et al., 2005 Volume 4, p. 23). In New Caledonia, the contribution of hydropower to total generation has slightly increased over the years (from about 16 percent in 1995 to

\footnotetext{
${ }^{3}$ Sources: French Polynesia-Electricité de Tahiti; New Caledonia-Institut de la Statistique des Etudes Economiques de Nouvelle Caledonie (2004) Bilan Energie 2004; Hawaii-Hawaiian Electric Company (http://www.heco.com); Guam, Marshall Islands_-Pacific Power Association (2006) United States of America Insular Areas Energy Assessment Report; Remainder-Wade, H. et al. (2005).
} 
more than 19 percent in 2004) to the detriment of diesel generation, but the installation of both a gas turbine in 2003 (Institut de la Statistique des Etudes Economiques de Nouvelle-Calédonie (ISEE), 2003) and a coal combustion plant in 2006 to respond to growing industrial needs may have reversed this trend. There is also hydropower potential in the Federated States of Micronesia, including an existing run-of-river hydropower plant in the state of Pohnpei (Pacific Power Association, p.236).

Wind turbines have been installed in the Cook Islands, Fiji, New Caledonia, French Polynesia, Hawaii and Papua New Guinea, but they typically do not contribute much to the total electricity generation as there is little installed capacity. For example, in New Caledonia in 2006, the installed capacity of wind turbines exceeded 19 megawatt (MW) but wind energy represented 3 percent of total electricity production.

Solar energy is widely used in Pacific Islands (except in Nauru ${ }^{4}$ ), particularly in outer islands and remote villages which do not have access to a main electricity grid. Solar photovoltaic and solar water heating systems have often been installed in the context of lending and donor programmes for rural electrification. Although such programmes were not always successful, the experience they provided led to substantial improvements in solar energy use, and organisations are now more informed on the institutional approaches that are suitable to introduce and maintain solar systems in Pacific Islands (Liebenthal, A. et al., 1994). In Hawaii, there are a large number of grid-connected solar panels since cash rebates, state and federal tax credits on solar water heaters and solar photovoltaics have provided incentives for households to invest in such systems (Wade et al., 2005, Volume 4 pp. 61-62).

There are also hybrid power plants combining solar and wind energy with diesel generation in Fiji and French Polynesia (solar/diesel hybrid). However, the Fiji plant has been using less and less renewable energy: the wind and solar components contributed over 60 percent of the hybrid generation in 1997, but their contribution fell steadily to less than 15 percent in 2002, due to a lack of technical support and component failures (Wade et al., 2005, Volume 4, pp.61-62).

\footnotetext{
${ }^{4}$ It is unclear why there are no solar systems installed in Nauru.
} 
Biomass gasification has been used in a few islands, notably in Papua New Guinea for commercial copra, cocoa, coffee and tea drying. In late 2002, 52 gasifiers were still used by coffee processors in Papua New Guinea (Wade et al., 2005, Vol.1 p.47). A few plants are also operating in Fiji, Cook Islands, and the Federated States of Micronesia; however these plants have not typically been used for energy production. In Micronesia, for example, the gas is bled off because people find the concept of using biogas from manure for cooking offensive (Wade, H. et al., 2005, Vol.3, p. 26). Gasifiers for power generation were installed in Vanuatu (between 1982 and 1994) and Samoa (in the early 80s), but these systems are no longer operating.

In summary, although most Pacific Island Countries have some experience with diverse renewable energy technologies, the contribution of renewable energy sources remains relatively low. Apart from hydropower in some islands with a suitable resource such as Fiji and Samoa, diesel generators remain the biggest source of power generation.

\section{2) Electricity Supply in the Main Islands}

There are three types of electricity supply arrangements in Pacific Islands: regulated monopolies, government-owned utilities and public service concessions. In most countries, main grid electricity is provided by a government-owned utility, which is often the sole electricity provider. Most of these utilities used to be government departments and have become corporate state-owned enterprises. In the Solomon Islands and Samoa, the utility has been commercialised and is meant to operate as a business. A list of the main electric utilities in Pacific Islands is provided in Table A2 of appendix 1.

Regulated monopolies supply the bulk of electricity in Tonga and Hawaii. In Vanuatu and the French Territories of the Pacific (French Polynesia, New Caledonia, Wallis and Futuna), private electricity companies are providing electricity in the context of (long-term) public service concessions. These concessions allow the electricity companies to operate within specified geographical areas as part of a contract with the government. For example, UNELCO (Vanuatu) has the concession to generate and distribute electricity in Port Vila, Luganville, Malekula and Tanna (Wade, H. et al., 
2005, Vol. 16, p. 8). Anybody can produce and supply their own electricity outside the specified areas and on other islands ${ }^{5}$. UNELCO (Vanuatu) and the electricity supply companies in French territories are all subsidiaries of the same company ELYO, from the international group SUEZ ${ }^{6}$.

Only in Hawaii, Tonga, Vanuatu, Wallis and Futuna, French Polynesia and New Caledonia are the electric utilities privately owned or managed (although Shoreline, the company which supplies electricity in Tonga, has been in the process of becoming nationalized again ${ }^{7}$ ).

In some Pacific Island Countries, different power supply arrangements apply for different groups of islands. For example, in the Federated States of Micronesia there is a different public electric power system in the principal island of each of the four states, so that each state manages its own power supply. In some countries, there is more than one supplier on a given island. In New Caledonia, for instance, both EEC and ENERCAL hold concessions for the production and distribution of electricity. In Kiribati, there is a public utility responsible for power, but the Solar Energy Company (SEC), an incorporated company owned by the government, is involved in the sale and lease of solar electric systems and relevant components (Wade et al., 2005, Vol. 5, p. 10). The country with the highest number of electricity providers is Papua New Guinea: while PNG Power (PNGP) is responsible for the generation, transmission and distribution of electricity throughout the country, operating three main interconnected systems and nineteen smaller provincial systems, there are a large number of private electricity producers whose total installed capacity is comparable to that of PNGP (Wade et al., 2005, Vol. 10, pp. 12-13).

All the electric utilities in Pacific Islands are responsible for not only electricity generation, but also the transmission and distribution of electricity ${ }^{8}$. Vertical integration is common because of economies of scope and scale (Domah, 2002). In some islands, the electric utilities supply both electricity and water (American Samoa

\footnotetext{
${ }^{5}$ www.investinvanuatu.com/vanuatu/infrastru.htm

${ }^{6} \mathrm{http}: / /$ www.elyo.com/business-uk/filiales/default.htm

${ }^{7}$ http://www.matangitonga.to/article/tonganews/business/article print northpower070806.shtml

${ }_{8}$ Except for EEC in New Caledonia, which does not ensure electricity transmission on the main island (electricity distribution is provided by Enercal, another electric utility).
} 
Power Authority in American Samoa, Public Utilities Board in Kiribati, Nauru Phosphate Corporation, and EEWF in Wallis and Futuna).

In most islands, the main electric utility only serves the main island or largest islands. Only the Solomon Islands Electricity Authority (in the Solomon Islands), the Tuvalu Electric Corporation (in Tuvalu) and Electricité De Tahiti (French Polynesia) extend their services to all or a large number of populated islands. Some utilities have recently expanded to provide electricity to smaller islands: Shoreline in Tonga, and UNELCO in Vanuatu (Wade et al., 2005, Vol. 1, p. 29). Nevertheless, in most Pacific Island Countries the percentage of households electrified in outer islands and rural areas is lower than in the main islands and urban areas. As displayed in figure 2.2 below, the total percentage of households with access to electricity ranges from under 20 percent (in Papua New Guinea, Solomon Islands, and Vanuatu) to close to 100 percent (Wade et al., 2005, Vol. 1, p. 30).

Figure 2.2: Access to Electricity in Pacific Islands ${ }^{9}$

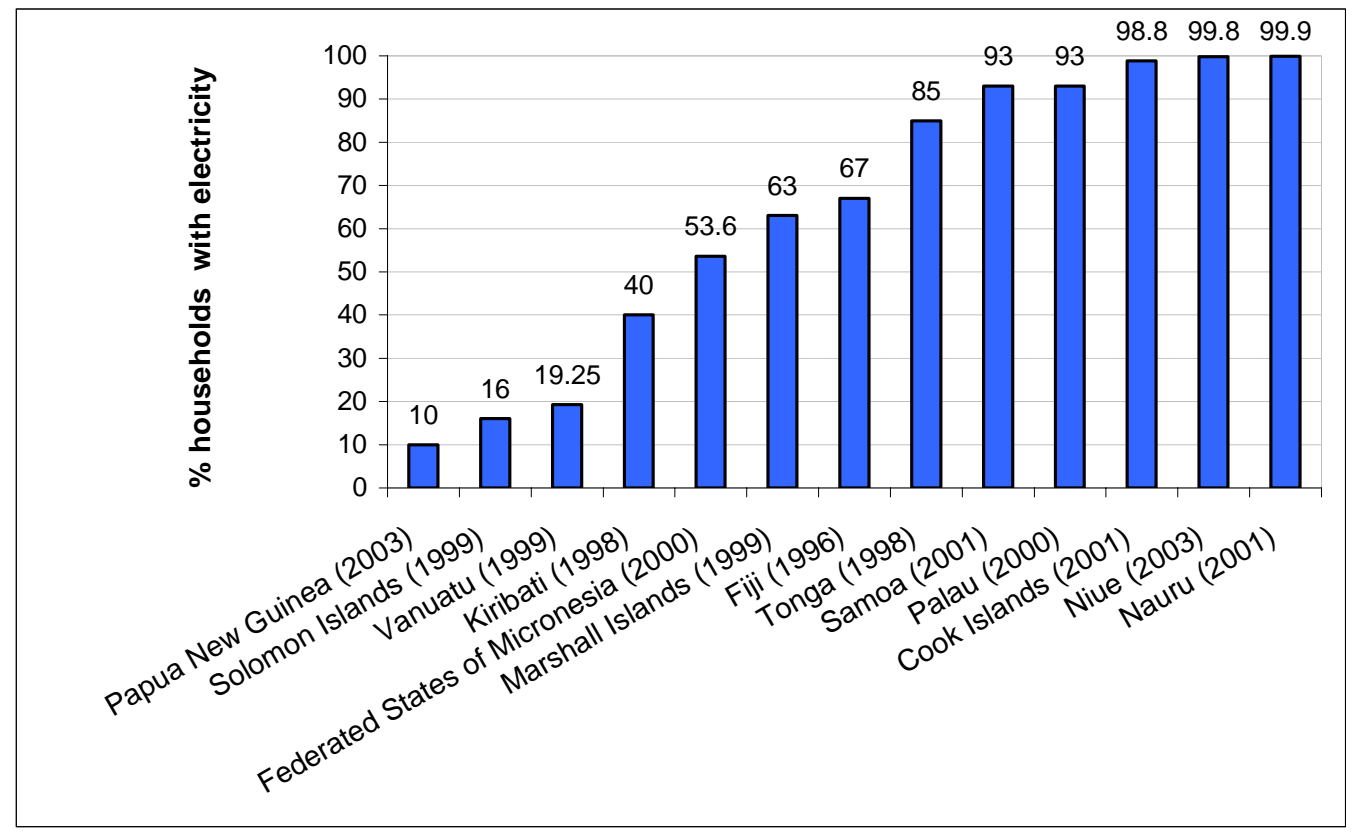

\footnotetext{
9 Sources: Kiribati and Tonga-Meritec (2001) Private Participation in Infrastructure in Pacific Island Countries annex 1 p.5.; Remainder-Wade et al. (2005) Vols. 2-4, 6-12 and 16. Note: The figure for Papua New Guinea is only an estimate from the PIREP report; it does not come from an official census.
} 
Electric utilities of Pacific Islands vary dramatically in size, from 2.4 MW of installed capacity in Niue (with less than 2000 customers) to about 614 MW in Papua New Guinea (Wade et al., 2005, Vol. 1, p. 32). Table 2.1 displays the annual amount of electricity generated by the main electric utility in 19 Pacific Island Countries. Generation in recent years remains below 200 GWh per year in most Pacific Islands except for Fiji, French Polynesia, Guam, New Caledonia, and Papua New Guinea. One may expect the difference in electricity generation to be caused by differences in population levels, which would explain why electricity generation is higher in Papua New Guinea than anywhere else. However, although domestic consumers constitute the largest category of customers for most islands utility grids, they generally account for well under half of the total consumption of electricity. 
Table 2.1: Electricity Generation in Pacific Islands

\begin{tabular}{|c|c|c|c|}
\hline Country & $\begin{array}{c}\text { Capacity, } \\
\text { MW } \\
\text { (year) }\end{array}$ & $\begin{array}{c}\text { Electricity } \\
\text { Generated, } \\
\text { MWh } \\
\text { (year) }\end{array}$ & Source \\
\hline American Samoa & $\begin{array}{r}93.75 \\
(2005)\end{array}$ & $\begin{array}{r}188,975 \\
(2005)\end{array}$ & $\begin{array}{l}\text { American Samoa Power Authority }{ }^{10} \text {, Pacific } \\
\text { Power Association (2006) }\end{array}$ \\
\hline Cook Islands & $\begin{array}{r}10.66 \\
(2002) \\
\end{array}$ & $\begin{array}{l}29,758 \\
(2002) \\
\end{array}$ & $\begin{array}{l}\text { Pacific Islands Renewable Energy Project Vol.2 } \\
\text { table } 7.2\end{array}$ \\
\hline Federated States of Micronesia & $\begin{array}{r}34.49 \\
(2005)\end{array}$ & $\begin{array}{l}84,517 \\
(1997)\end{array}$ & Pacific Power Association (2006) \\
\hline Fiji & $\begin{array}{l}194.00 \\
(2003)\end{array}$ & $\begin{array}{r}6,989,000 \\
(2003) \\
\end{array}$ & $\begin{array}{l}\text { Pacific Islands Renewable Energy Project Vol.4 } \\
\text { table } 3.2\end{array}$ \\
\hline French Polynesia & $\begin{array}{l}215.49 \\
(2005)\end{array}$ & $\begin{array}{r}514,900 \\
(2005)\end{array}$ & Electricité De Tahiti \\
\hline Guam & $\begin{array}{r}552.2 \\
(2004) \\
\end{array}$ & $\begin{array}{r}1,876,708 \\
(2004) \\
\end{array}$ & Guam Power Authority $^{11}$ \\
\hline Kiribati & $\begin{array}{r}7.75 \\
(2003) \\
\end{array}$ & $\begin{array}{l}15,900 \\
(2003) \\
\end{array}$ & $\begin{array}{l}\text { Pacific Islands Renewable Energy Project Vol.5 } \\
\text { Tables } 2.5 \text { and } 2.6\end{array}$ \\
\hline Marshall Islands & $\begin{array}{r}31.3 \\
(2005)\end{array}$ & $\begin{array}{r}101,166 \\
(2003)\end{array}$ & $\begin{array}{l}\text { Pacific Islands Renewable Energy Project Vol.6 } \\
\text { table 2.3, Pacific Power Association (2006) }\end{array}$ \\
\hline Northern Mariana Islands & $\begin{array}{r}126.5 \\
(2005) \\
\end{array}$ & $\begin{array}{r}432,000 \\
(2005) \\
\end{array}$ & Pacific Power Association (2006) \\
\hline Nauru & $\begin{array}{r}18.9 \\
(2004) \\
\end{array}$ & $\begin{array}{l}33,000 \\
(2000) \\
\end{array}$ & $\begin{array}{l}\text { Pacific Islands Renewable Energy Project } \\
\text { Vol.7, ADB Key Indicators } 2003\end{array}$ \\
\hline New Caledonia & $\begin{array}{r}348.4 \\
(2004)\end{array}$ & $\begin{array}{r}1,677,527 \\
(2004)\end{array}$ & $\begin{array}{l}\text { Institut de la Statistique et des Etudes } \\
\text { Economiques (2004) }\end{array}$ \\
\hline Niue & $\begin{array}{r}1.6 \\
(2002) \\
\end{array}$ & $\begin{array}{r}3,369 \\
(2002) \\
\end{array}$ & $\begin{array}{l}\text { Pacific Islands Renewable Energy Project Vol.8 } \\
\text { table } 2.2\end{array}$ \\
\hline Palau & $\begin{array}{r}28 \\
(2005) \\
\end{array}$ & $\begin{array}{l}81,866 \\
(2004) \\
\end{array}$ & Pacific Power Association (2006) \\
\hline Papua New Guinea & $\begin{array}{r}451 \\
(2001) \\
\end{array}$ & $\begin{array}{r}3,178,000 \\
(2003) \\
\end{array}$ & $\begin{array}{l}\text { Pacific Islands Renewable Energy Project } \\
\text { Vol.10, APEC energy overview } 2005\end{array}$ \\
\hline Samoa & $\begin{array}{r}36.02 \\
(2003) \\
\end{array}$ & $\begin{array}{r}93,070 \\
(2003) \\
\end{array}$ & $\begin{array}{l}\text { Pacific Islands Renewable Energy Project } \\
\text { Vol.11 table 2.3. }\end{array}$ \\
\hline Solomon Islands & $\begin{array}{r}22.4 \\
(2002) \\
\end{array}$ & $\begin{array}{l}86,887 \\
(2002) \\
\end{array}$ & $\begin{array}{l}\text { Pacific Islands Renewable Energy Project } \\
\text { Vol.12 table 2.8. }\end{array}$ \\
\hline Tonga & $\begin{array}{r}11.4 \\
(2003)\end{array}$ & $\begin{array}{l}34,000 \\
(2003)\end{array}$ & ADB Key Indicators 2003 \\
\hline Funafuti (Tuvalu) & $\begin{array}{r}2.4 \\
(2002) \\
\end{array}$ & $\begin{array}{r}4,658 \\
(2003) \\
\end{array}$ & $\begin{array}{l}\text { Pacific Islands Renewable Energy Project } \\
\text { Vol.15 table } 2.7\end{array}$ \\
\hline Vanuatu & $\begin{array}{r}21.6 \\
(2002) \\
\end{array}$ & $\begin{array}{l}47,148 \\
(2002) \\
\end{array}$ & $\begin{array}{l}\text { Pacific Islands Renewable Energy Project } \\
\text { Vol.16 table 2.4. }\end{array}$ \\
\hline TOTAL & 2207.86 & $15,472,449$ & \\
\hline
\end{tabular}

Figure 2.3, which displays electricity per capita in Pacific Islands, shows that the discrepancies in electricity generation between Pacific Islands cannot be explained solely by differences in population levels. Firstly, as previously stated, electricity may not be available to the entire population in each island. For instance, according to the Pacific Islands Renewable Energy Program team, less than 10 percent of the

\footnotetext{
${ }^{10} \mathrm{http}: / /$ www.aspower.com/ElectricLinks/SystemLoadGrowth.mht

11 www.guampowerauthority.com/operations/ (date: 31 may 2006)
} 
population of Papua New Guinea was electrified in 2004 ( Wade et al., 2005, Vol. 10, p. 24). Secondly, and more importantly, a large part of the electricity generated is consumed by industrial, commercial and government customers. Electricity generation is much higher in places where economic activity is focused towards energy-intensive activities such as industrial applications. For instance, the nickel industry accounts for more than half of the electricity consumption in New Caledonia (ISEE, 2004), and the developed tourism, commercial and U.S. military sectors use a large part of the electricity generated in Guam (Bureau of Statistics and Plans of Guam, 2004, p.290). Electricity per capita is also relatively large in Palau, which may be due to infrastructure development for tourism. In 2003, visitor and tourist arrivals numbered 68,000 for a population of about 20,000 meaning that tourism intensity is high, which suggests that the tourism sector is a major power consumer ${ }^{12}$. The widespread use of air conditioning in government offices and hotels may also account for a large part of electricity consumption.

Figure 2.3: Electricity per Capita in Pacific Islands ${ }^{13}$

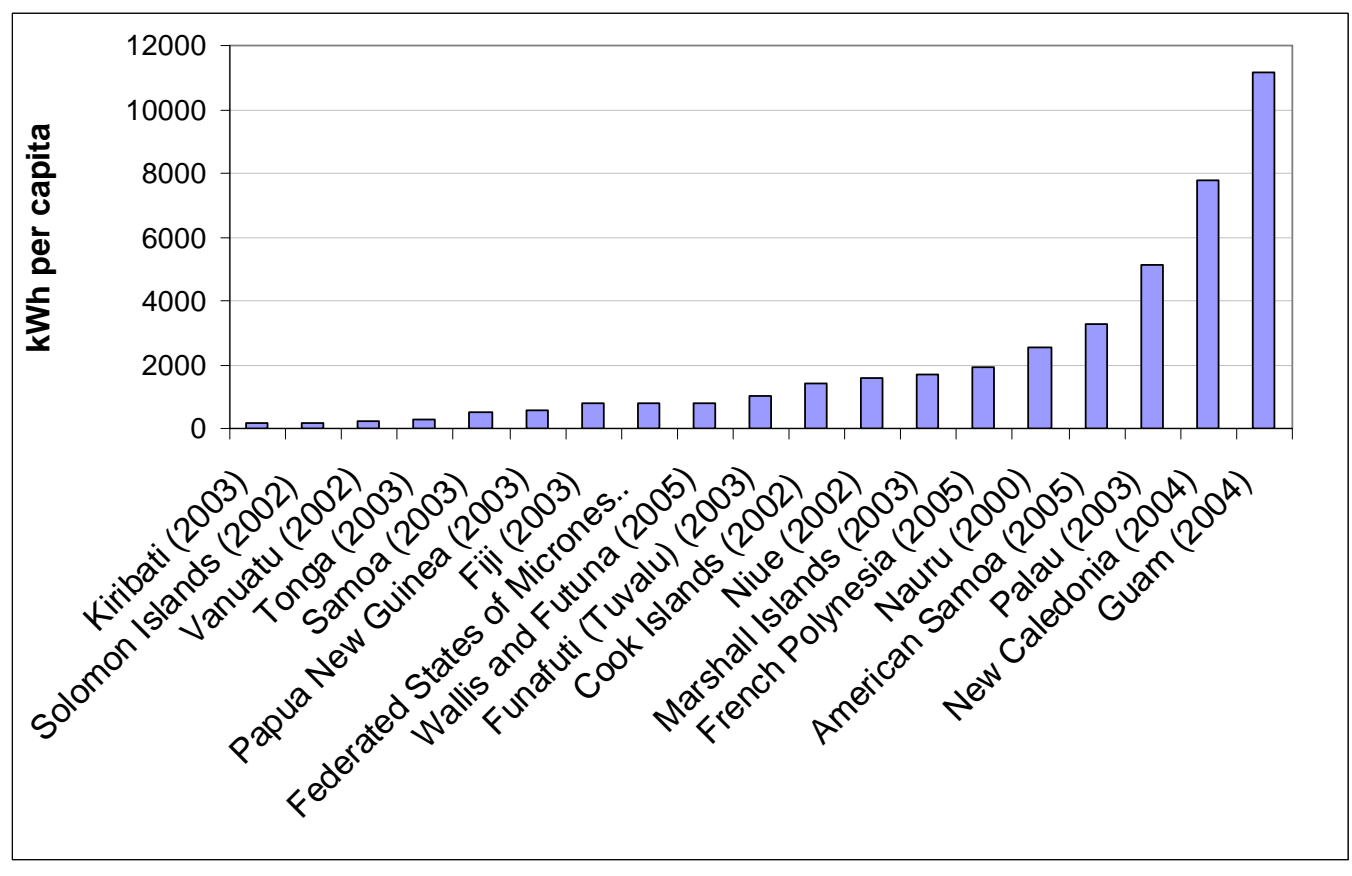

\footnotetext{
${ }^{12} \mathrm{http}: / / \mathrm{www} . \mathrm{spc}$. int/prism/country/pw/stats/PalauStats/Tourism/2003.htm, http://www.spc.int/prism/country/pw/stats/PalauStats/Social/Census/Census.htm

${ }^{13}$ Sources: American Samoa-www.aspower.com, Cook Islands-Cook Islands Statistics Office; Guam - www.guampowerauthority.com/operations/generationunpdate.html; Tuvalu-Government of Tuvalu (2005); Remainder-Wade et al. (2005) Vols. 3-6,8,9,11,12,16; Asia-Pacific Energy Research Centre (2005); ADB Key Indicators; www.elyo.com, , Central Intelligence Agency (2006).
} 


\section{3) Electricity Supply in Outer Islands and Remote Areas}

In most Pacific Island Countries, rural and outer island electricity supply is characterised by small diesel generators as well as individual solar home systems. Electricity in rural areas is generally provided by provincial utilities owned by island councils, public works departments or cooperatives ${ }^{14}$, but the management, maintenance and quality of service provided by such systems is generally poor. For example, many of the small rural supply systems (called C-centres) which have been installed in Papua New Guinea are no longer operating (Wade et al., 2005, Vol. 10, p.13). Consequently, in a large number of outer islands, local schools, health centres, resorts and households operate their own small diesel generators.

The cost of electricity supply in rural areas is much higher than in the main islands (Wade et al., 2005, Vol.1, Table2-7, p.24). Operation costs of the diesel generators are often exacerbated by low fuel efficiency due to poor maintenance, mostly because of a lack of skilled staff and spare parts. Government subsidies for rural electricity tend to be high, although subsidy arrangements are generally inconsistent and lack transparency (Wade et al., 2005, p.84). Despite large differences in supply costs, in some countries consumers in outer islands pay the same price as consumers in the main island and urban areas.

Electricity is available less than 18 hours per day in most outer islands. Households thus rely on a wide range of energy sources for cooking and lighting, particularly firewood and kerosene. Irregular fuel supply and poor fuel handling are typical. Fuels are often transported from the main islands to outer islands in 200 litre drums by ship and small boats. Sometimes, the drums are even floated from small boats to the shore (Wade et al., 2005). While problems such as leakages, rusting, corrosion and shortages of drums are not uncommon in outer islands, such inefficient fuel transportation and distribution processes are unlikely to change, because of the low levels of demand and consumption inherent to outer islands.

\footnotetext{
${ }^{14}$ except for Vanuatu, French Polynesia, Wallis and Futuna and New Caledonia, which have privatelyowned utilities supplying electricity to main and outer islands
} 
The development of reliable electricity supply systems in remote areas has often been claimed to be a government priority. Although all Pacific Islands have at least an implicit rural electrification policy, such policies are often unclear and particularly ambiguous with respect to responsibilities (Wade et al., 2005, Vol. 1, pp. 18-19). A large number of rural electrification projects have been funded by international aid and donor organisations from Australia, New Zealand, the United States, Japan and Europe (Wade et al., 2005, Vol. 1, p.18).

\section{4) International Aid for Electricity Supply in Pacific Islands}

International aid agencies and organisations have provided funds and technical assistance for a large number of energy projects in the Pacific Islands since the late seventies. Such projects mostly involved the installation of renewable energy technologies as a source of electricity supply, mostly solar photovoltaic systems, solar water heaters, and hydroelectricity. Most of these projects focused on rural areas and outer islands, for which, as stated previously, electricity supply is generally poor. Indeed, the objective of donors and organisations' programmes was often to boost development in rural areas by improving electricity supply using sustainable, environmentally-friendly energy sources.

The Asian Development Bank has provided assistance to a large number of Pacific Island Countries such as the Cook Islands, Fiji, Micronesia, Marshall Islands, Samoa, Solomon Islands, Tonga, and Vanuatu. Such assistance often came in the form of loans for improving or upgrading main electricity grids (Cook Islands, Kiribati, Tonga, Samoa), but also in the form of technical assistance for electrification in outer islands, power sector reforms (Tonga), case by case studies for outer island power development (Cook Islands), infrastructure development, and energy development plans (Vanuatu), which often recommended the use of renewable energy and the improvement of energy efficiency. In February 2006, ADB announced that it would help prepare a renewable power sector development project for Fiji Islands through a US\$650,000 technical assistance grant ${ }^{15}$.

\footnotetext{
${ }^{15}$ http://www.adb.org/media/Articles/2006/9393-Fiji-Islands-power/
} 
The European Community has provided a major contribution to outer island electrification, particularly with the installation of solar photovoltaic systems, through large funding programmes resulting from the 1975 Lomé Convention, the Lomé II Pacific Regional Energy Programme, and the Cotonou Agreement between the European Union member states and Africa, Caribbean and Pacific states. Solar energy has thus been promoted and developed in many Pacific Islands such as Fiji, the Marshall Islands, Nauru (grid-connected solar photovoltaic), Palau, the Solomon Islands (photovoltaic refrigeration for provincial health clinics), Tonga, and Tuvalu. Other projects involved the identification and promotion of new and renewable energy sources as part of outer island development programmes (in Micronesia), assistance for hydropower in Samoa, and electricity generation with a wood gasifier at a rural high school in Vanuatu (Wade et al., 2005, Vol. 16, p. 28). In addition, the European Development Fund (FED) recently started the TEP Vertes Project. This project was signed in October 2006 and aims at improving electricity supply in rural and isolated areas in French Polynesia, New Caledonia, and Wallis and Futuna.

The Japan International Cooperation Agency has helped many Pacific Countries with grants and funds for power upgrades, solar photovoltaic installations (Marshall Islands) and technical assistance, including the construction of a hydroelectricity plant in Vanuatu, and studies such as the Master Plan for Power Development for the Solomon Islands in 1999. Other donor organisations, such as AusAID, New Zealand Aid, Canada Aid, have been involved in training workshops, feasibility studies for electrification and hydroelectricity, and funding for solar photovoltaic projects.

Non-lending services have formed the core of World Bank assistance to Pacific Islands between 1992 and 2002 (World Bank Operations Evaluation Department, 2005, p.16), with studies for Samoa (Assessment for biomass energy use and prospects, a joint study with UNDP) and Papua New Guinea (Hydropower Resources Inventory Study, Rural Electrification Policy and Strategy to Improve Energy Access for Rural Services Delivery), and the 1992 Pacific Regional Energy Assessment studies carried out for twelve Pacific Islands.

Other large organisations such as the United Nations, UNESCO, ESCAP, have undertaken surveys, studies and investigations, legislation reviews, and provided 
funds for projects such as solar photovoltaic installations for rural health centres. In 1984, Save the Children and USAID funded 170 solar home systems for a project implemented by the Tuvalu Solar Electric Cooperative Society (TSECS). Other TSECS projects were funded by the European Union.

Regional organisations involved in Pacific Islands' electricity and energy projects and studies include the Energy Working Group (EWG) of the Council of Regional Organisations of the Pacific (CROP), the Secretariat of the Pacific Community (SPC), the South Pacific Regional Environment Programme (SPREP), the Pacific Islands Applied Geoscience Commission (SOPAC) and the Pacific Power Association (PPA). New Zealand's International Aid and Development Agency has been supporting SOPAC and SPREP for environmental projects including climate change and freshwater management. A Pacific Islands Energy Policy and Plan (PIEPP), was developed by EWG, which contains both energy policy and planning components. Regional cooperation has also resulted in various renewable energy projects. The SPC has put in place a programme called the Pacific Renewable Energy France Australia Common Endeavour programme which, with funds from France and Australia, has successfully implemented solar projects in the Marshall Islands, Tonga, and Vanuatu, as well as a wind project in the Cook Islands. From biomass to hydroelectricity and solar photovoltaic, SOPAC has been involved in a wide range of renewable energy projects, often providing technical assistance for donor projects, reviewing projects, or investigating renewable energy resource in Pacific Islands. SOPAC has also implemented the Pacific Islands Energy Policies and Strategic Action Planning (PIESPAP) to develop and review energy policies in Pacific Islands and provide supporting analysis on related matters such as tariff studies, rural electricity frameworks and wind energy development.

A striking feature from this brief overview of assistance from aid agencies is the recurring choice of solar photovoltaic as the technology used for electricity development programmes. Most projects seem to have concentrated on small solar systems in outer islands - there has not been any large-scale renewable energy project other than hydroelectricity in the main islands. This choice has been justified by the fact that solar energy is profuse in Pacific Islands, and that solar photovoltaic is a simple, commercially proven technology which can easily be implemented, and is 
suitable for low levels of demand. In general, renewable energy seems to be a sensitive choice for sustainable development: donors and organisations can provide investment funds for the technologies and install the systems; subsequently, the organisations only need to ensure system maintenance, without having to pay or lend money for consumers to import fuel inputs. Yet a large number of projects have failed due to insufficient maintenance.

Solar energy is understandably an attractive, feasible solution for providing electricity while aiming at reducing the islands' dependence on fuel products and promoting renewable energy (Lomé II Pacific Regional Energy Programme). However, a large number of projects have failed because of the institutional context chosen for their implementation ${ }^{16}$. The choice of institutional context for the implementation of solar projects is particularly important for the maintenance and duration of the solar systems. Indeed, not only do solar systems require regular maintenance, such as the replacement of batteries, but in most cases, a large number of solar systems are installed at the same time for a given project, which means that planning and organising the operation and maintenance of the systems is crucial. The sustainability of solar systems in outer islands and poor villages depends on the arrangements which determine who owns the systems, who maintains them, and who pays for them. Hence, although installing solar systems may be relatively easy and rapid, past experience has shown that agencies should not be lured by this simplicity, as solar photovoltaic systems require much more than installation to last more than a few years.

\section{5) Electricity Consumption in Pacific Islands}

Electricity consumption in Pacific Islands is relatively low, primarily because of the small size of Pacific Island Countries' economies, but also because consumers use a range of different energy sources to satisfy their energy needs.

Although the traditional use of biomass for household cooking has declined considerably in the past decades, it remains widespread in the rural areas of some Pacific Islands, notably in Chuuk (Micronesia), Vanuatu, Kiribati Solomon Islands,

\footnotetext{
${ }^{16}$ For a detailed example, see Wade et al. (2005) Vol. 14, pp. 32-40.
} 
Fiji and Papua New Guinea (Wade et al., 2005, Vol.1, p.36-37). A relatively low proportion of the population has access to electricity in these countries: as previously stated, around 10 percent of the population had access to electricity in Papua New Guinea in 2003, only 19 percent of households were electrified through the Chuuk power utility in 2000, and only 16 percent were electrified in the Solomon Islands in 1999 (Wade et al., 2005).

In most islands kerosene, and also more recently Liquified Petroleum Gas (LPG), have replaced firewood for household cooking. Electricity is mostly used for cooking in urban areas and on islands such as Nauru and Niue where most of the population is connected to the island grid (Wade et al., 2005, Vol. 7 p. 16, Vol. 8 p.13-14). Households often use a combination of different sources for cooking purposes (for example, they may use biomass and kerosene, or gas and electricity). Kerosene and electricity are mostly used for household lighting. The use of low efficiency incandescent lighting has also been reported to be widespread in Palau (Wade et al., 2005, Vol. 9 p. 17).

The energy needs of Pacific Island households are thus met by a variety of sources, primarily kerosene, gas, biomass and electricity. This pattern is portrayed in the following graph, which shows the small contribution of electricity to non-transport energy consumed in some Pacific Islands for $1988 / 1989^{17}$. It is likely that electricity represents a much larger part of energy consumed in these islands nowadays. For instance, in 1998, electricity accounted for more than thirty percent of the total energy consumed in Samoa, compared to less than five percent in 1988 (World Bank, 1992, Vol. 13). Unfortunately, recent energy balances are not available for any other islands.

\footnotetext{
${ }^{17}$ The transport sector typically constitutes the largest consumer of energy in Pacific Islands. Including transport energy consumption, which consists of petroleum products only, would have understated the share of electricity for sectors which can choose between different energy alternatives to satisfy their needs (e.g. household choice between kerosene and electricity for lighting).
} 
Figure 2.4: Electricity as a Percentage of Non-transport Energy Consumption in Pacific Islands (1988-1989 data) ${ }^{18}$

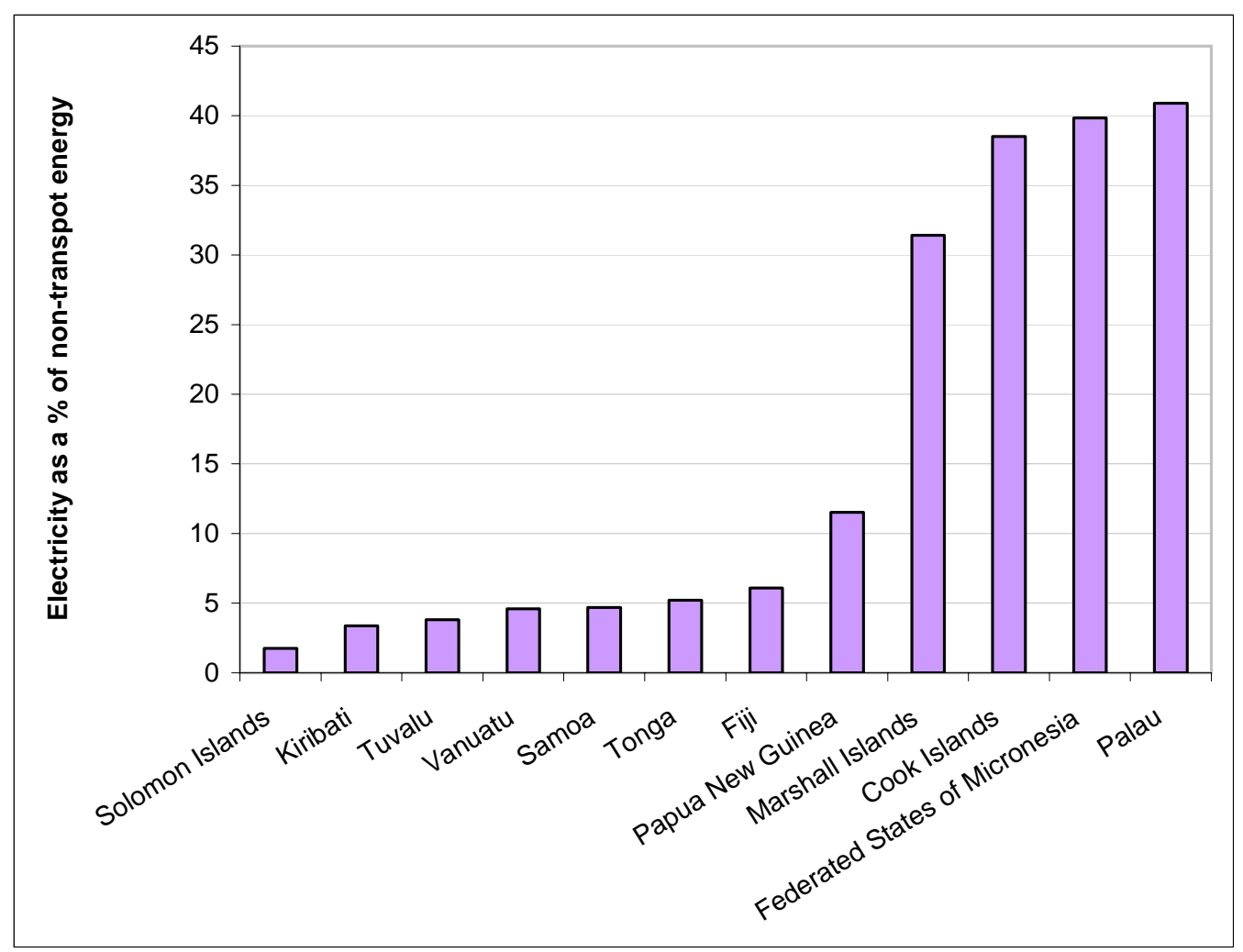

As explained in a previous section, electricity sales to industrial, commercial and government customers are typically much more significant than sales to residential customers, especially for islands with an important industrial sector. Government facilities, hotels and other tourism related businesses constitute the biggest electricity consumers in islands with little or no industrial activity such as Niue.

Electricity consumption in Pacific Islands is thus closely related to the level and structure of economic activity. In most countries, electricity generation could vary intensely with the construction of a new business or resort, which can make predictions of demand growth difficult. Demand for electricity can be expected to rise as the economy, tourism and population grow, or when the population becomes more affluent (through an increased use of appliances such as televisions). In addition, improvements in the availability of electricity in outer islands (such as increasing the power supply from 18 to 24 hours per day) are likely to be followed by increases in

\footnotetext{
${ }^{18}$ Source: World Bank (1992) Vol. 2-13.
} 
electricity use. For example, a shift in the power supply from 12 to 24 hours (with a similar appliance mix) has led to about a 75 percent increase in energy use in Rakahanga in the Cook Islands (Wade et al., 2005, Vol. 2). This suggests that the relationship between electricity reliability and electricity demand is positive, but that it is not a one-to-one relationship, so that reliability of electricity supply is a particularly important characteristic.

\section{6) Cost of power supply}

The cost of electricity supply is determined by a number of factors: cost of capital, inputs for generation (primarily fossil fuels), operation and maintenance costs, economies of scale, and administrative costs. In addition, a critical cost component arises from the efficiency of the generation, transmission and distribution systems, which condition the amount of system losses. In 1998, system losses were dramatically high in some islands: they accounted for 32.48 percent of gross electricity generation for the state utility of Chuuk in the Federated States of Micronesia (Meritec, 2001). System losses are still running above 15 percent in a number of islands including Tonga, Samoa, and the Solomon Islands, as shown in figure 2.5 . 
Figure 2.5: System Loss in Pacific Islands ${ }^{19}$

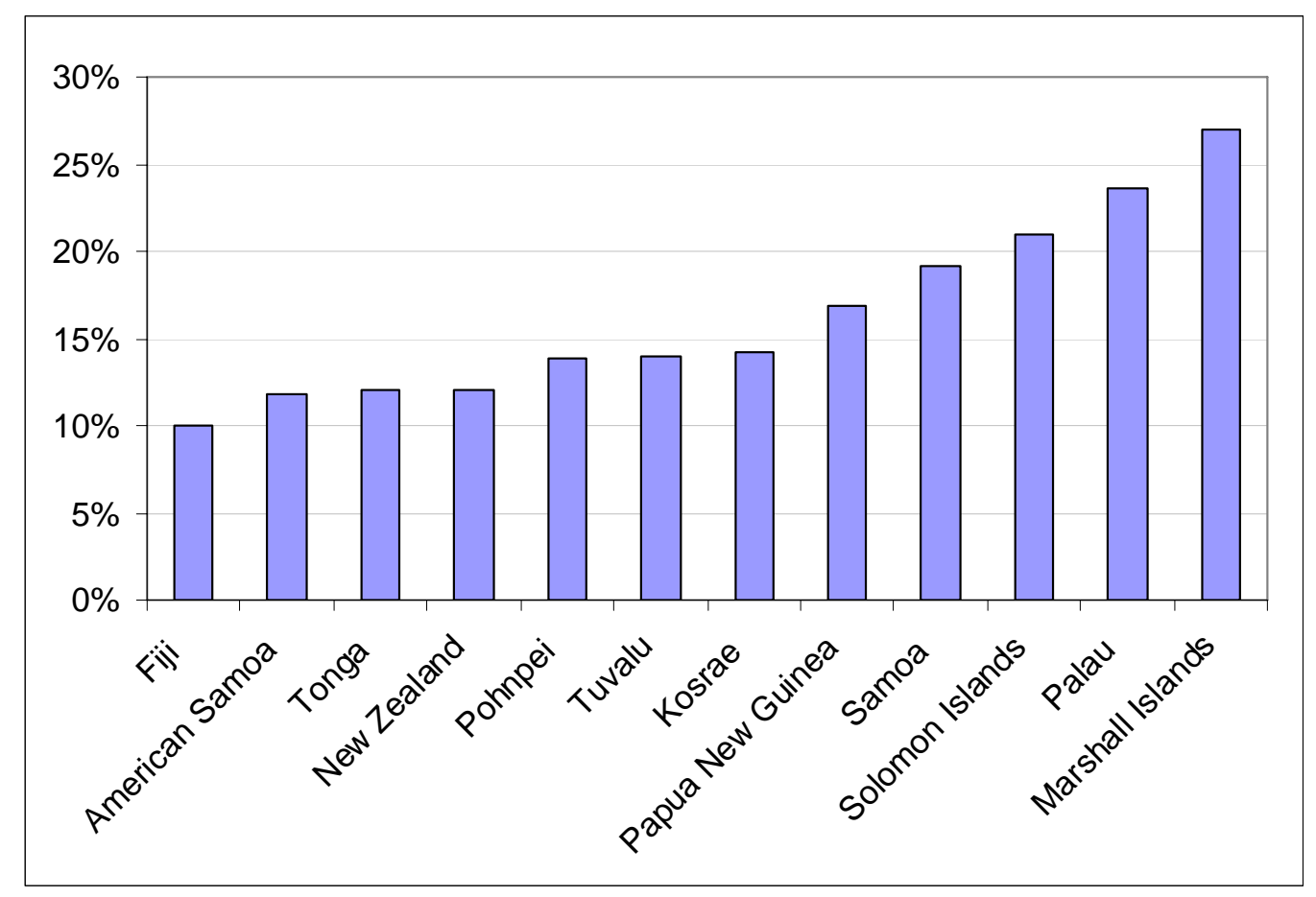

Wade et al. (2005) provide estimates of electricity supply costs in some Pacific Islands. These estimates, displayed in table 2.2 below, confirm that electricity supply is much more expensive in outer islands than in the main islands. The most striking figures are those of Fiji, where supply to rural areas of Ovalau was ten times more expensive than supply to urban consumers of Viti Levu (the main island) in 2001. (Note that the data displayed in table 2.2 were gathered from different sources and across different years; these figures should only be considered as indicative. All the

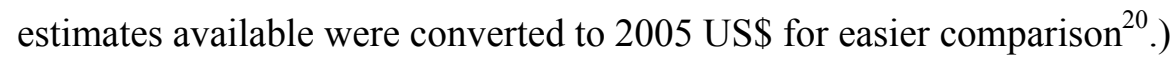

\footnotetext{
${ }^{19}$ Source: Fiji, Tonga, Tuvalu, Papua New Guinea, Samoa-Wade et al. (2005); American Samoa, Pohnpei, Kosrae, Palau, Marshall Islands-Pacific Power Association (2006); Remainder-Castalia (2005), p. 103.

${ }^{20}$ All figures were first converted to \$US using an average of the relevant year's conversion rates with the currency converter from http://www.oanda.com/convert/fxhistory. Then the inflation calculator from http://www.westegg.com/inflation/infl.cgi was used to convert \$US from different years to 2005 \$US.
} 
Table 2.2: Cost of Electricity Supply in some Pacific Islands

\begin{tabular}{|c|c|c|}
\hline $\begin{array}{l}\text { Country and year of } \\
\text { data }\end{array}$ & $\begin{array}{l}\text { Main Island cost of } \\
\text { electricity supply per kWh } \\
\text { (2005 US\$) }\end{array}$ & $\begin{array}{l}\text { Outer islands cost of } \\
\text { electricity supply per kWh } \\
\text { (2005 US\$) }\end{array}$ \\
\hline $\begin{array}{l}\text { Cook Islands } \\
\text { (1998 costs) }\end{array}$ & Rarotonga: $\$ 0.22$ & $\begin{array}{l}\text { Aitutaki: } \$ 0.27 \\
\text { Atiu: } \$ 0.36 \\
\text { Mangaia: } \$ 0.34 \\
\text { Mitiaro: } \$ 0.53 \\
\text { Mauke: } \$ 0.46 \\
\text { Penrhyn: } \$ 0.53 \\
\text { Manihiki: } \$ 0.46 \\
\text { Rakahanga: } \$ 0.55 \\
\text { Palmerston: } \$ 0.62 \\
\text { All outer islands: } \$ 0.36\end{array}$ \\
\hline $\begin{array}{l}\text { Fiji } \\
(2001 \text { costs })\end{array}$ & $\begin{array}{l}\text { Viti Levu Urban: } \$ 0.09 \\
\text { Viti Levu Rural: \$0.24 }\end{array}$ & $\begin{array}{l}\text { Vanua Levu Urban: } \$ 0.19 \\
\text { Vanua Levu Rural: } \$ 0.58 \\
\text { Ovalau Urban: } \$ 0.18 \\
\text { Ovalau Rural: } \$ 0.90\end{array}$ \\
\hline $\begin{array}{l}\text { Marshall Islands } \\
(2004 \text { costs) }\end{array}$ & Majuro: \$0.076 & $\begin{array}{l}\text { Ebeye: } \$ 0.14 \\
\text { Kili: } \$ 0.16 \\
\text { Bikini: } \$ 0.31\end{array}$ \\
\hline $\begin{array}{l}\text { Tonga } \\
\text { (1999 costs) }\end{array}$ & Tongatapu: $\$ 0.23$ & $\begin{array}{l}\text { Ha'apai Outer Islands: } \\
\text { Nomuka: } \$ 0.54 \\
\text { Ha'afeva: } \$ 0.64 \\
\text { 'Uiha: } \$ 0.55 \\
\text { Ha'ano: } \$ 0.53\end{array}$ \\
\hline $\begin{array}{l}\text { Tuvalu } \\
\text { (2000 generation cost) }\end{array}$ & Funafuti: $\$ 0.97$ & \\
\hline
\end{tabular}

Source: Wade et al. (2005)

Fuel costs constitute a major part of production costs: up to 80 percent of the supply costs of island electric utilities can be attributed to fuel costs (Castalia, 2005, p.99). Furthermore, a major component of fuel price in Pacific Islands is the transportation cost. Since fuels are usually imported through the main islands, the further an island is from the main island, the more expensive it is to transport fuel to this island, and the higher the price of fuel. Consequently, fuel costs of outer islands can be 200-400 percent higher than those of main islands (Castalia, 2005, p.99). Figure 2.6 illustrates this intuitive pattern, with the example of the Cook Islands. The fitted line represents a simple linear regression, and shows that the further an island is located from Rarotonga (the main island), the higher the cost of power supply. Note that the island 
of Aitutaki directly imports its own fuel, which explains why it has a cost of supply lower than that of Mangaia and Atiu, which are located almost as far from Rarotonga.

Figure 2.6: Cost of Electricity Supply in the Cook Islands

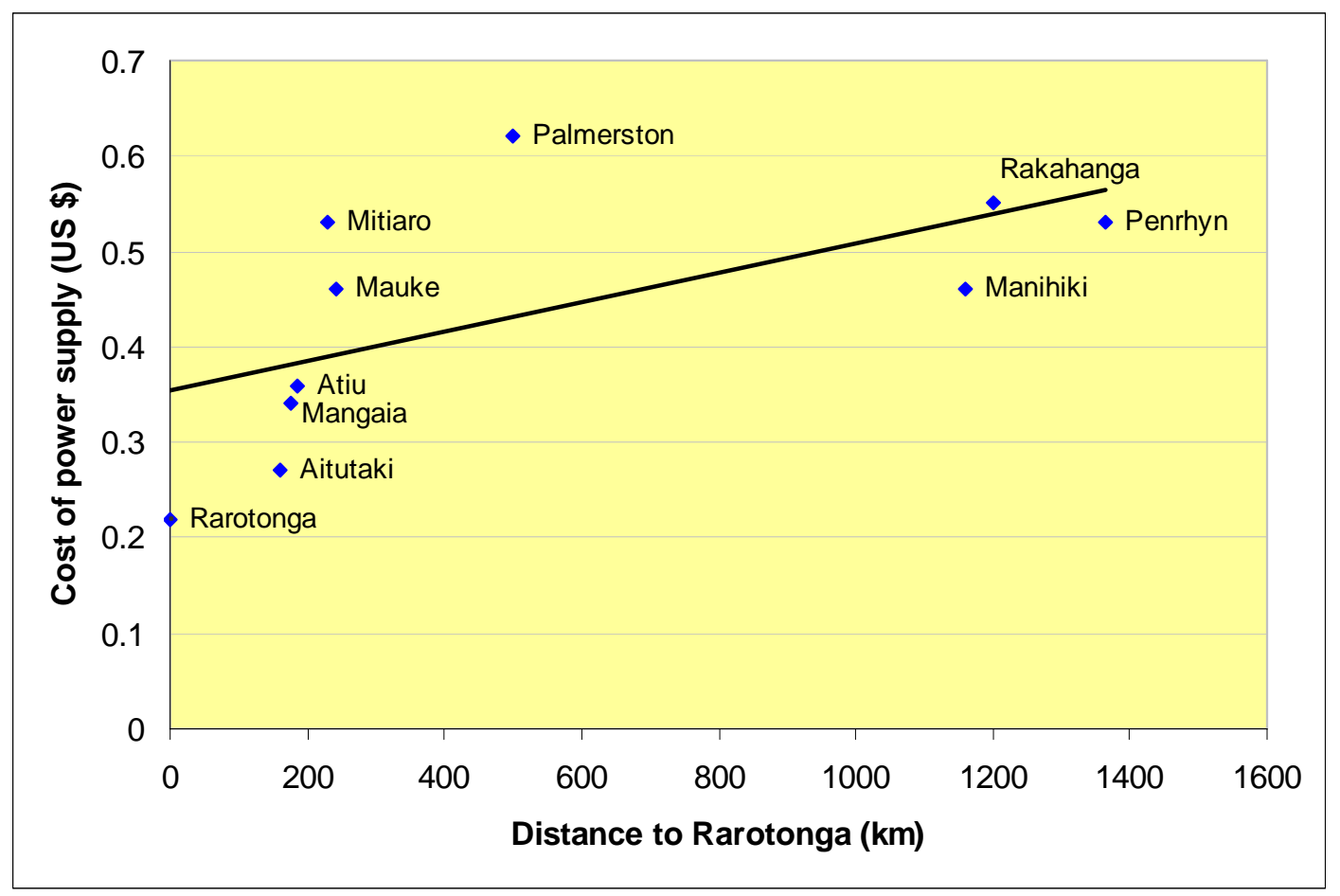

Sources: Table 2.2 above and Wade et al., 2005, Vol. 2, Table 2.8.

Fuel costs also depend on the national fuel procurement system in a given country. For instance, in some countries such as Vanuatu and Kiribati, the price of fuel has been found to be consistently higher than in Samoa and the Solomon Islands, which have an open market international tendering process for fuel supply (Castalia, 2005).

Another explanation for the substantial difference in cost of supply between main and outer islands is the existence of economies of scale, as displayed for the Cook Islands case in the graph below (using a logarithmic trendline). 
Figure 2.7: Economies of Scale in the Cook Islands

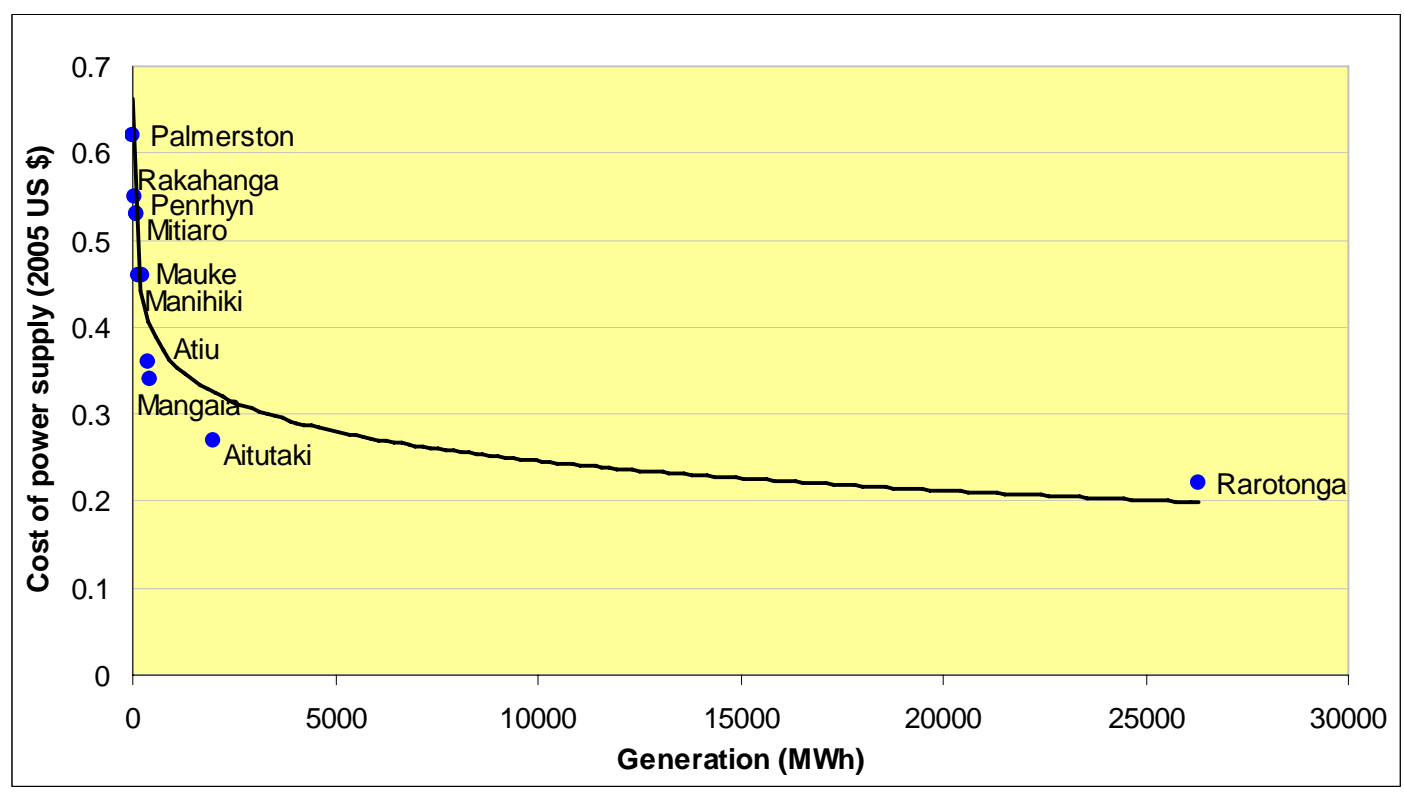

Source: Wade et al. (2005) Vol. 2, Table 2.8. Generation figures from the Cook Islands statistics office, table 7.2 (figures refer to generation in 2004).

Using the Cook islands data and running a simple Ordinary Least Squares regression of the cost of electricity supply on volume of electricity supply and distance to the main island, gives the following results:

Cost of electricity supply $=0.398-7.237$ Volume +0.000109 Distance

$$
\text { (7.332) (-1.6266) }
$$

Both the scale and distance variables are significant at the 90\% (though not the 95\%) significance level, with an $\mathrm{R}^{2}$ of 0.537 .

Supply costs in Pacific Island Countries, and specifically in outer islands, are thus exacerbated by remoteness, high transport costs for fossil fuel imports, limited demand for fossil fuels, limited ability to reap economies of scale, and high system losses. Another factor leading to high electricity supply costs is the topography of the islands: high mountainous terrain or small low lying atolls make it difficult and more costly to install and maintain infrastructure networks. Most Pacific Island countries are comprised of several small, dispersed islands or atolls, so that linking services between islands is more costly (Castalia, 2005, p.21). 
Despite the high running costs of thermal technologies due to high transportation costs, there is little use of renewable energy in Pacific Islands. At first sight, high fuel costs might be expected to enable renewable energy technologies to compete with traditional fossil-fuel technologies in Pacific Islands more readily than in most other parts of the world. However, reliability is very important in these countries, particularly in the main islands where most industrial and commercial activities are taking place. Hence, apart from some outer villages and islands, there is little willingness to incur the high level of intermittency associated with renewable energy in the absence of $100 \%$ thermal backup - and the cost of holding thermal capacity in reserve then has to be included in the cost comparison. . Other major obstacles to renewable energy in Pacific Islands are explored further in chapter 6.

\section{7) Electricity Tariffs}

Electricity tariffs are generally established by the utilities, and reviewed by the cabinet or the government department responsible for electricity, who must give their approval before a tariff increase. In Tuvalu, tariffs are set directly by the cabinet. In Palau, the utility can only change its tariff after public hearings (Wade et al., 2005, Vol. 9, p. 13). In fact, the utility can set whatever tariff it wants as it is not bound by the results of the hearings, but it has incentives to keep the prices down as the tariff is considered to be a major political matter in Palau. Except when a variable fuel rate is

included, tariffs are typically not altered very often or regularly-electricity prices can remain unchanged for years. 
Figure 2.8: Residential Electricity Tariffs in Pacific Islands and the United States, 2003-2004

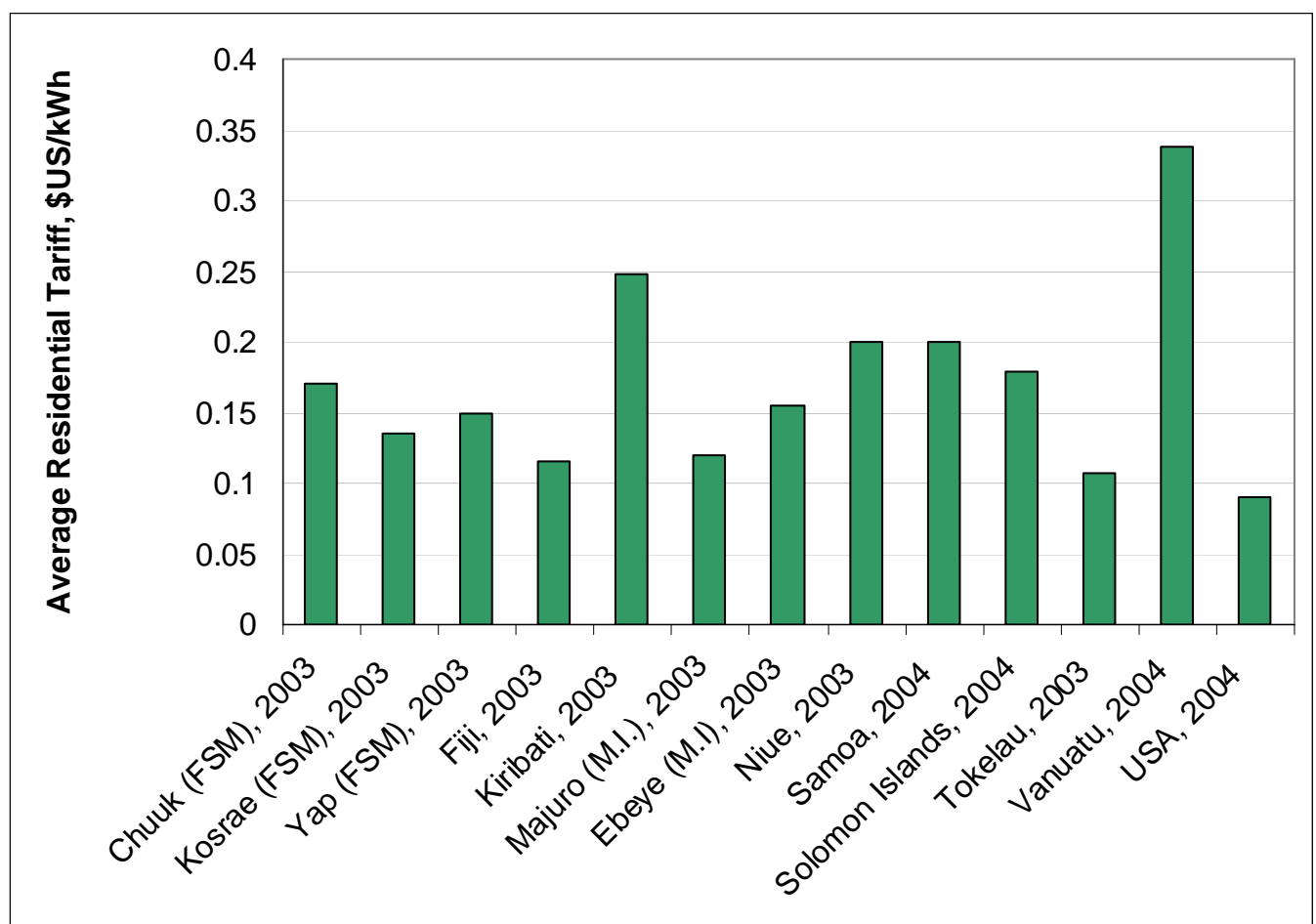

Source: Wade et al. (2005), Energy Information Administration (http://www.eia.doe.gov/cneaf/electricity/epa/epat7p4.html)

Note: FSM: Federated States of Micronesia, M.I: Marshall Islands

Average electricity tariffs are significantly high in some Pacific Islands, such as Vanuatu and Kiribati. In some countries, such as Tokelau and the Marshall Islands, the tariffs are only slightly higher than the tariffs charged in large countries such as the United States. These lower tariffs can be partly explained by government subsidies (Castalia, 2005, p. 98). In Fiji, the average electricity tariff is also lower mostly because more than 50 percent of electricity generation is hydro-based.

In some countries (Kiribati, Marshall Islands, Nauru, Tuvalu) the tariffs are very simple, involving a flat rate for different types of customers (residential, commercial and government customers) (Wade et al., 2005, Vols. 5-7 and 15). The most uniform tariffs can be found in Tokelau and Niue, where the government corporations charge a single tariff for all users, except for a premium tariff charged for the use of air conditioners in Niue. In Nauru, a simple tariff has been imposed since 1990 but there has been very little fee collection from residential customers since 2003 due to a financial crisis. 
In the Cook Islands, Fiji, French Polynesia, Micronesia, and Papua New Guinea, nonlinear pricing is used, with tariffs varying according to the type of customer as well as monthly consumption, typically charging higher rates for higher consumption levels (except in Fiji). Some utilities offer "lifeline tariffs" to low-income customers. Lifeline tariffs refer to the lower rates associated with low consumption levels. Such tariffs are charged to customers with a consumption of up to 30 kilowatt-hour (kWh) per month in Papua New Guinea, 50 kWh per month in Samoa, $60 \mathrm{kWh}$ per month in the Cook Islands, $100 \mathrm{kWh}$ per month in French Polynesia, Kosrae and Yap (Micronesia) and $500 \mathrm{kWh}$ per month in Palau ${ }^{21}$. In some countries, such as the Cook Islands, Fiji, Papua New Guinea, the Value Added Tax applies to electricity sales.

Electricity utilities in Tonga, Vanuatu, Guam, Chuuk, Palau and the Solomon Islands impose much more complex tariff structures with, for each type of customer, a rate which involves a minimum monthly charge, a fixed rate and a fuel surcharge which is adjusted monthly or every six months. In Vanuatu, adjustment is made quarterly and is based not only on fuel prices, but also on wage rates, an index of material costs, and exchange rates. EPC (Samoa) was also considering the adoption of a fuel surcharge in 2003; however it is unknown whether the tariff has been modified. Although it may be a sensible decision from the point of view of electricity utilities, adjusting electricity tariffs to fuel prices in Pacific Islands in the short run is likely to worsen the vulnerability of such economies to fuel prices by reinforcing price fluctuations.

As mentioned previously, a number of utilities (in Fiji, Kiribati, Palau, and Solomon Islands) impose a national tariff, meaning that they charge the same price in different islands or areas. In other countries, such as French Polynesia and Tuvalu, the price for electricity is lower in outer islands than in the main island. Such pricing practices may involve high cross-subsidies from customers in the main islands or urban areas to customers in outer islands, given the substantial difference between distribution costs to urban and rural areas. Cross-subsidization, defined in this instance as setting the price of electricity above its average cost in some places (typically in the main island) so as to set the price below its average cost in other places, can be interpreted as a

\footnotetext{
${ }^{21}$ Wade et al. (2005) Vol. 2,3,9,10 and 11; www.edt.pf
} 
means for redistributing resources (Viscusi, Vernon and Harrington, 2000, p. 327). The director of the electricity utility of Tahiti (EDT) has acknowledged that the company loses money in all the small outer islands it serves ${ }^{22}$, which implies a large cross-subsidy from customers in Tahiti to customers in outer islands such as Bora Bora and Moorea. In Tuvalu, customers in Funafuti (the main island) are charged a higher price than in outer islands, even though supply costs are higher in outer islands (Wade et al., 2005, Vol. 15, p. 14). However, the Tuvalu Electricity Corporation is required by the government to sell electricity below cost, which has significantly affected its performance. Wade et al. (2005) reported that the true cost of generation well exceeds the prices charged in both outer islands and Funafuti (the cost of supply was estimated to be more than four times the price of electricity in Funafuti in 2000) (Wade et al., 2005, Vol. 15, p. 13).

Overall, most public utilities fail to recover short run marginal costs and rely on government subsidies to operate. This is because the tariffs charged to consumers are generally much lower than the marginal cost of production; this condition is often required by governments (such as in Tuvalu). In most cases, such financial difficulties have hindered the maintenance and expansion of utilities, often resulting in high transmission losses or outages.

\section{8) Energy Policy and Legislation}

In most Pacific Island Countries, a small energy department is responsible for national energy policy planning and implementation, although responsibilities related to energy matters are often unclear and overlapping between different departments. In Nauru and Niue, there is no energy department; in Niue the electricity utility is in charge of energy planning while three other departments individually take care of issues related to fossil fuels, biomass and photovoltaic water pumps.

National energy policies have rarely been officially endorsed by governments in Pacific Islands: in 2004, only three countries had national energy policies with some form of official endorsement and two countries had prepared draft policies that were

\footnotetext{
${ }^{22}$ Conversation with Mr Joel Allain, director of EDT, on Tuesday the $18^{\text {th }}$ of July 2006 in Tahiti.
} 
under review (Wade et al., 2005, Vol. 1, pp. 16-17). Furthermore, national energy policies rarely provide specific guidelines and goals for implementation, such as priorities or budget preparation. According to Wade et al. (2005), such policies are often compelled or influenced by donors or regional organisations and provide a limited coverage of energy issues, with emphasis on power sector investment needs rather than policy.

Legislation and regulation regarding electricity supply is limited in Pacific Islands. The best known legislation relating to energy supply is the Renewable Energy Service Companies Legislation, which was prepared by United Nations Development Programme and Global Environment Facility in 2003 for Fiji (Wade et al., 2005, Vol. 1, Table 1-10). In most countries, the only legal document relating to energy supply is an Electricity Act which establishes the public electricity utility, its responsibilities and exclusive right to generate, distribute and sell electricity. In Samoa, the EPC act does not give exclusive rights to the utility (EPC), but allows for EPC to issue permits required to generated electricity as it is the owner of the electricity grid. Similarly, the Solomon Islands Electricity Authority (SIEA) and the Tonga Electric Power Board (TEPB) issue licenses for electricity generation in the Solomon Islands and Tonga respectively. In Nauru and Niue, there is no formal legislation or regulation with regards to electricity supply; the utilities are simply required to respond to government orders. Electricity supply in rural and remote areas is rarely regulated, particularly when the public utilities do not provide electricity to these areas. In the Cook Islands, for instance, electricity supply in only regulated on the main island, Rarotonga (Wade et al., 2005, Vol. 2, p. 23).

Given that the electricity sectors of most Pacific Islands are characterized by natural monopolies which operate in a poorly regulated environment, there is little room for competition in electricity supply. However, there has been considerable focus on regional cooperation in recent years. There are a number of institutions, agencies and organisations which are providing energy policy co-ordination and advice: the Pacific Forum Secretariat, the South Pacific Applied Geosciences Commission (SOPAC), the Committee of Regional Organizations of the Pacific (CROP), the South Pacific Regional Environmental Program (SPREP), the Pacific Islands Development Program (PIDP), the Pacific Power Association (PPA). The Council of the Regional 
Organizations of the Pacific (CROP) has prepared a regional Energy Policy and Plan which sets out a useful framework for energy policy planning in the Pacific (Wade et al., 2004, p.22). 


\section{Chapter Three: Renewable Energy and Electricity Supply: Integrating Wave Energy into an Electricity Network}

\section{1) Wave Energy}

Wave energy has been studied for decades, with the completion of hundreds of patents for wave energy capturing devices before 1950. Research for wave energy converters intensified with the 1973 oil crisis. At that time, several governments started to fund programmes for wave energy converters research and development, notably in the UK and Norway. Unfortunately, most of these programmes failed ${ }^{23}$ and by the mid-1980s most research had been abandoned, affecting confidence in the technology. Nevertheless, further increases in oil prices and rising climate change concerns contributed to a renewed interest in wave energy in the mid-1990s, reinforced by growing experience with the offshore gas and oil platforms industry, and the development of new offshore wind turbines. There are currently a large number of wave energy converters being developed around the world (Canada, USA, UK, Denmark, Australia, New Zealand). These devices may be classified according to their placement (onshore, near shore or offshore), fixing (floating devices, bottommounted devices), power take-off system (hydraulic, air turbine, water pump), and principle of operation (overtopping structures; Oscillating Water Columns which are partly submerged structures; point absorber devices, which are floating structures occupying a small area; wave power attenuators, which are oriented parallel to the direction of the waves; or wave power terminators, which extend perpendicular to the wave direction).

Wave energy is a large, clean and renewable energy source. Wave power, determined by the height, speed and length of the waves, is concentrated near the water surface. One of the most attractive characteristics of this resource is its high power density, compared to the diffuse wind and solar energy sources (it is often described as a concentrated form of solar energy). Although wave energy, like wind energy, is

\footnotetext{
${ }^{23}$ For more details, see http://www.wave-energy.net/Schools/History.htm
} 
variable, it is more continuous than wind power and can be predicted four to five days in advance. The extent of variability and predictability of renewable energy sources are important as they determine how new renewable technologies interact with the existing electricity system in any given country (see section 3 of this chapter). An advantage of wave energy is that the natural seasonal variability of wave energy follows electricity demand patterns. For example, wave power output in winter in the United Kingdom (from December to March) has been reported to be almost seven times higher than during summer (Environmental Energy Institute, 2005, p. 36), while average electricity demand levels are higher during winter. An assessment of wave energy resource in Hawaii also reports that wave power is higher between December and March, which corresponds to summer, when electricity demand is higher in Pacific Islands (Hagerman, Previsic, Bedard, 2004, p. 34).

High power density, relatively low variability, advantageous seasonal variability and the ability to forecast the availability of the resource (and therefore the possibility of dispatching wave generation) are the key characteristics that make wave energy an attractive renewable energy source. However, to date, uncertainty with respect to reliability and survivability of wave energy converters remains prevalent, and production costs are relatively high as wave energy technologies are still at an early stage. Nevertheless, uncertainty and perceived risk are likely to be reduced with further demonstration and production experience. Experience with solar energy, wind energy, and the gas platform industry suggest that capital and production costs of wave energy technologies are likely to decrease significantly with experience and government support. Many studies have shown how learning through production experience has reduced unit cost for renewable energy technologies, using learning curves which provide a quantitative (negative) relationship between cumulative production and unit cost (McDonald and Schrattenholzer, 2001; Ibenholt, 2002; Coulomb and Neuhoff, 2006). Learning curves have also been used to determine how much investment or support may be required from governments for a technology to become competitive. For instance, Goff (2006, p. 33) found that reductions in learning related costs associated with increases wind capacity and investment in public research and development justify the need to invest further in wind energy, even if it still involves high up-front costs. To date only two countries, United Kingdom and Portugal, have provided financial support for wave energy research and development, 
and the majority of wave energy technologies are still at an early stage. Hence risk, uncertainty (including regulatory uncertainty) and high costs are still associated with wave energy technologies, but are likely to be significantly reduced with production experience and government support.

Some important matters will need to be clarified to determine the viability and attractiveness of wave energy at a large scale. One is the environmental impact of wave power plants. This aspect is particularly important to Pacific Island Countries, as they derive a range of benefits from their marine environment. A study conducted by the Electric Power Research Institute's Electricity Innovation Institute (E2I EPRI) explored six different environmental issues for the island of Oahu, Hawaii, and concluded that wave energy is a harmless generation technology (Hagerman, Bedard, 2004, p. 28). Nevertheless, the authors recommended that each wave energy project include careful monitoring and evaluation, site selection, and consultation with interested parties. As environmental assessments will most likely be required before obtaining permits for the installation of a device, this may be the best way to approach the issue of environmental impact assessment. As stated above, there exist a wide range of wave energy converters, which may have different effects on the environment, depending on the distance to the shore of each device, its size and elevation, and whether it is noisy, floating or caisson-based.

There are several different wave energy converters currently being developed, and several will be commercialised within the next decade, leading to an eventual competition between different devices, not only in terms of least-cost generation but also in terms of characteristics such as maintenance, survivability and performance. Choices between different wave energy devices may be made according to the suitability of a device for a given site. However, only experience will show and determine the performance of each device in terms of efficiency, reliability and survivability. While most wave energy converters are still at the development stage, the deployment of the Pelamis in Portugal in 2007 will provide another step towards such experience. 


\section{2) The Pelamis}

The Pelamis is the world's first commercial floating wave energy converter. It was developed by Ocean Power Delivery, a company based in Edinburgh. In August 2004, a full-scale prototype of the Pelamis was installed at the European Marine

Energy Centre, which provides independent verification and testing of grid connected marine devices. In 2005, a Portuguese consortium ordered three $750 \mathrm{~kW}$ Pelamis machines, which were delivered in mid 2006 and are expected to start delivering electricity in late 2007, constituting the world's first wave farm.

The Pelamis is an offshore floating device which consists of a semi-submerged, articulated structure composed of four large cylindrical sections linked by three hinged joints. The wave-induced motion of these joints is resisted by hydraulic rams, which pump high-pressure oil through hydraulic motors via smoothing accumulators. The hydraulic motors drive electrical generators to produce electricity. Power is fed down a single cable to a junction on the sea bed (several devices can be connected together with a single cable ${ }^{24}$ ), and then transmitted to the shore through a subsea cable. Each power conversion module is rated at $250 \mathrm{~kW}$, so each device has a rated power output of $750 \mathrm{~kW}$, with a capacity factor of 25 percent to 40 percent. The Pelamis is about 120 metres long, with a diameter of 3.5 metres. Although it can be installed in a range of water depths and sea bed conditions, the Pelamis performs best in waters about 50-60 meters depth. It is tied to the seafloor by a mooring system which consists of floats and weights, designed to keep the Pelamis positioned while allowing it to swing head on to oncoming waves. The Pelamis can be connected straight into an electricity grid.

\footnotetext{
${ }^{24}$ www.oceanpd.com
} 
Figure 3.1:The Pelamis

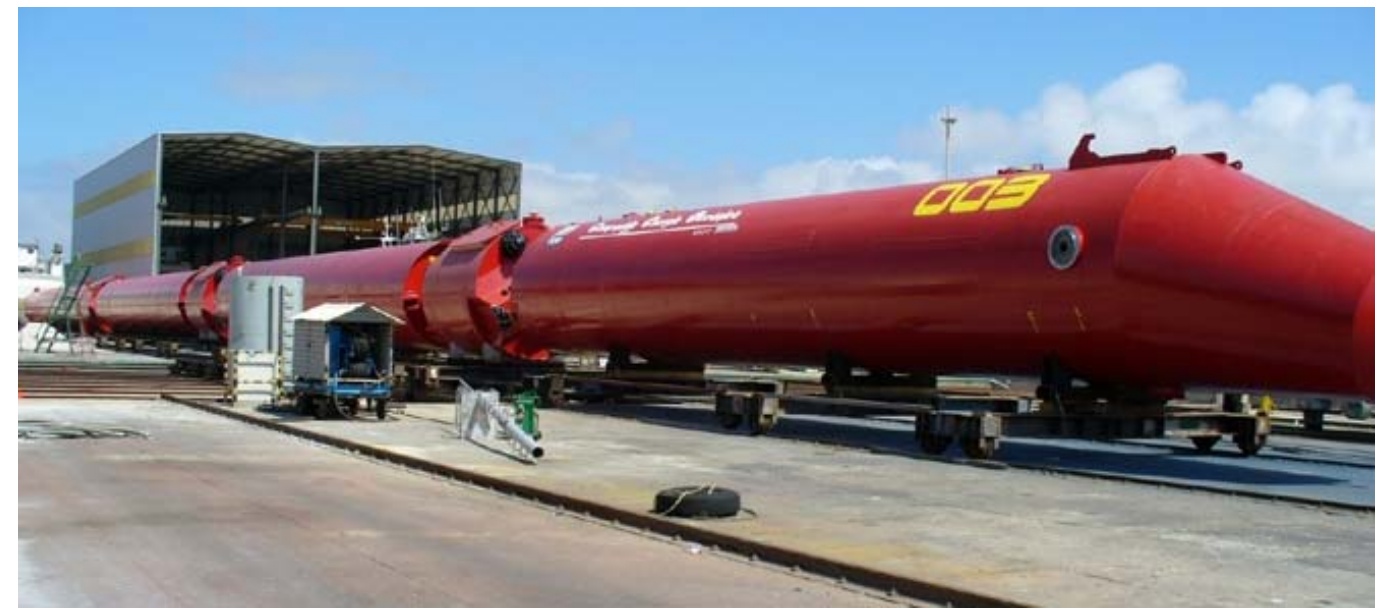

Pelamis machine sent to Portugal

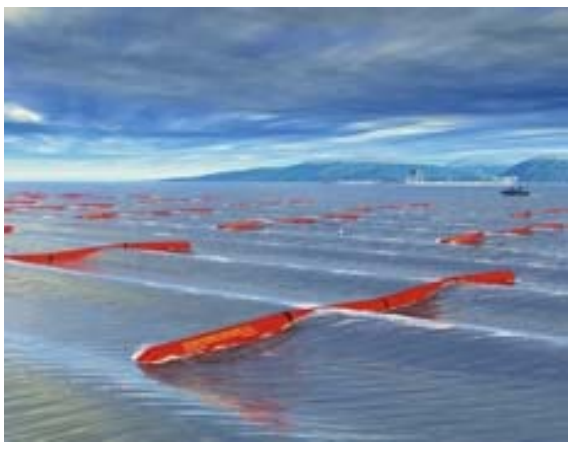

Impression of a wave farm

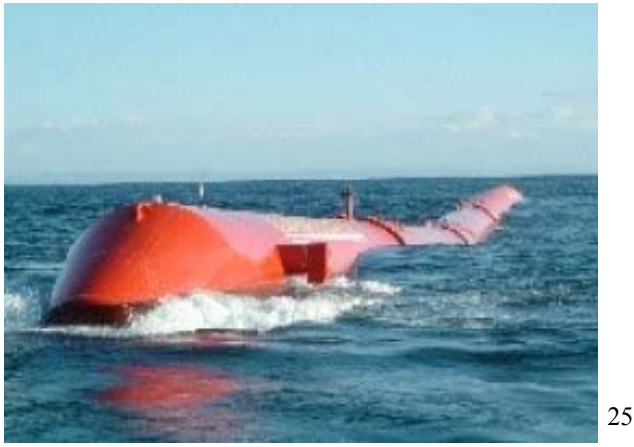

Pelamis under tow

In general terms, offshore wave energy devices do not entail any shoreline modification, and maximize the potential for mass production compared to onshore devices. However, offshore wave power plants operate in a very hostile environment, meaning that maintenance is likely to be more expensive than for onshore devices. The Pelamis was designed with survivability as a key criterion, in order to resist dangerous storm conditions. While it incorporates a degree of resonant response to improve power capture in small waves, the machine de-tunes in large waves to prevent excessive loads and motions ${ }^{26}$. Other important aspects of the Pelamis include easy maintenance, minimum on-site installation work, little noise, and little visual impact (as it is a low-profile, offshore device).

\footnotetext{
${ }^{25}$ Pictures from www.oceanpd.com

${ }^{26} \mathrm{http}$ ///www.oceanpd.com/Pelamis/keyConcepts.html
} 
Site selection for the Pelamis will rely on a number of criteria. The most obvious one will be an appropriate wave resource. Another important determinant is the bathymetry, notably what is the sea bed structure made of and whether there are any obstacles which may interfere with the mooring and subsea cables. This is potentially a major issue in the Pacific Islands, as a majority of these islands are surrounded by coral reefs which could potentially impede installation or damage cables, especially in rough conditions. Other important determinants include the proximity of an electrical grid connection, the existence of onshore facilities for maintenance, and other water users (boats, fishers, surfers...). The availability of facilities large enough to allow for local construction and/or assembly of the machines on site may reduce costs, since the structural elements are made of steel or concrete and can be built using standard construction techniques. In addition, a site with existing infrastructure such as a seawall, a pier or an ocean outfall would facilitate the integration of transmission cables on the land.

In 2004/2005, a series of studies on wave energy were released by the Electric Power Research Institute (EPRI) for five different states or cities in the United States (Oregon, Maine, Washington, Hawaii, and San Francisco). Among those reports was an assessment of the different available wave energy converters, which stated that the Pelamis was the only device evaluated which "was acceptable for selection by the State Advisors for application in a pilot plant for testing without addressing further issues" (Previsic et al., 2005, p. 9). At the time of the assessment, the Pelamis was the only device whose development was near completion and for which full-scale longterm testing in the ocean was underway. Another EPRI report which is particularly relevant is the report on Hawaii (Previsic et al., 2005b), which includes a detailed evaluation of a hypothetical pilot scale wave power plant on Oahu, as well as the evaluation of a commercial wave power plant consisting of 180 Pelamis Converters, with a capacity of $500 \mathrm{~kW}$ each (compared to the standard $750 \mathrm{~kW}$ capacity, which was overrated for the Hawaii wave climate). Appendices to the report contain detailed financial tables of the costs and revenues for the commercial plant scenario, with different estimates for the case of a regulated utility owning the wave plant, and a non-regulated utility owning the wave plant. Given that there are both federal and state production tax credits available in Hawaii, different tables were also given for both cases with and without such tax credits. 


\section{3) Accommodation of Renewable Energy by Electric Utilities}

Similarly to wave energy converters, a range of renewable energy technologies rely upon uncontrollable environmental conditions to generate output. For example, the amount of electricity generated by a solar panel depends on the amount of sun, and the amount of electricity yield by a wind turbine is determined by the speed of wind. The output generated by such forms of renewable energy is therefore characterised as intermittent, as it may fluctuate significantly, adding an element of uncertainty to the management of an electricity supply system. Consequently, the connection of renewable electricity generators into an electricity network is likely to have significant operational and financial impacts on the operation of the network. The extent of these impacts will depend on the amount of intermittency introduced into the electricity network, as well as the variability and predictability of the output of renewables connected into the grid. This section provides an identification and description of the impacts and related costs of the integration of renewable electricity generators into an electricity network.

The introduction of renewable energy into an electricity system heavily reliant on fossil fuels provides significant benefits in terms of fuel savings and reduction in carbon dioxide emissions. However, such benefits will be reduced to the extent that the addition of intermittent generators has impacts on reliability of supply, reserve requirements to manage unpredicted fluctuations, and the utilisation of other generators. The two major technical impacts of intermittency on electricity supply networks relate to system balancing and system reliability.

Electricity supply is continuously adjusted to match electricity demand, which changes constantly, and can fluctuate widely over a few hours. Operational margin refers to the amount of plant that must be operating to ensure that demand is met. Some generators can vary their output continuously and rapidly, whereas others must produce at a constant level. Fast responding plants are required as part of the operational margin as they can respond quickly to demand fluctuations. The addition of intermittent renewable electricity generators is likely to have an impact on system balancing as it can increase the extent of short-run fluctuations occurring in a supply 
system. In order to keep meeting electricity demand, it will be necessary to adjust for renewable generation fluctuation by ramping other plants up or down. Hence additional system reserves will be required when intermittent plants are added to a system, as uncertainty over the short-run supply and demand relationship will be increased. The amount of additional reserves required to maintain system balancing will depend on the extent of unpredicted variations in renewable energy output, whether intermittent output can be accurately forecasted, and the relationship between variation in electricity demand and intermittent output. Reserve requirements significantly increase if output generated by intermittent renewable generators decreases in periods of high demand. On the other hand, excess output from an intermittent generator may occur, which would require output curtailment or energy spilling. In addition, ramping existing thermal plants with frequent starting up and shutting down is likely to decrease their efficiency and cause more fuel to be burnt, which would partially offset fuel cost savings brought by the addition of renewable energy. One of the main advantages of wave energy is its predictability, meaning that changes in the utilisation of thermal plants could be planned in advance, reducing ramping duty and start up costs. However, the costs of intermittency to an electricity network depend not only on the nature and amount of intermittent generation, but also on the composition of existing conventional plants and their ability to manage or handle variability.

In addition to the reserves required to adjust electricity supply to demand in the shortterm, reliable electricity supply requires enough capacity (much larger than operational reserve) to meet expected peak demand. System margin refers to the total installed capacity available in excess of expected peak demand to ensure reliable electricity supply at peak periods; it is required in order to anticipate events such as generators breaking down, units taken out for maintenance, or peak demand being higher than projected. The relationship between system margin and reliability is often estimated using the concept of Loss of Load Probability (LOLP), which represents the probability that generation will be insufficient to meet demand, expressed as a percentage that is the maximum number of years per century in which load shedding will occur as a result of insufficient generation (Gross et al., 2006). Adding intermittent generators in an electricity system results in changes in the spread and shape of the frequency distribution of available plant margin (Gross et al., 2006), 
since intermittent output tends to vary significantly more than conventional plant output, and may not be available during periods of peak demand. In addition, renewable energy technologies typically have a smaller capacity factor than conventional thermal generators. This means that other things equal, a larger amount of capacity is required when replacing conventional generators with renewable technologies. Because there is uncertainty regarding the availability of intermittent output during peak demand periods, the addition of intermittent plants into an electricity network requires the installation or retention of some extra "backup" capacity in order to maintain system reliability, which will give rise to a cost.

The term "capacity credit" refers to the amount of conventional capacity that a given intermittent generator capacity can replace on an electricity system with no change in security based on Loss of Load Probability analysis (Anderson, 2006, p. 8). That is, the capacity credit of an intermittent generator is the amount of (actual or hypothetical) conventional capacity displaced by the intermittent source, minus the conventional actually-installed backup capacity required to maintain reliability. Once intermittent plants are introduced into an electricity network, the system margin is defined by both the conventional capacity and the capacity credit of the intermittent plants (Anderson, 2006). The total capacity credit of intermittent plants in an electricity system is determined by the correlation between demand peaks and intermittent output, as well as the range of intermittent outputs, the nature and variance of the geographical dispersion of the intermittent plants.

In summary, a range of costs may arise from the introduction of intermittent plants. In addition to the capital and operating costs of the plants themselves (and eventually supplemental investment in transmission), there will be incremental capital, maintenance and fuel costs arising from the additional reserves required to deal with a higher level of unpredicted short term fluctuations, and the additional fuel burnt because of the increased variation of the output of conventional plants, as well as costs related to the amount of extra capacity required to maintain system reliability. Whether such costs outweigh the benefits of adding renewables into the system depends on a range of factors, such as the type of generators used, system balancing and reliability requirements, the range, nature and predictability of intermittent plants, their geographical dispersion, and the correlation of their output with demand peaks. 
A large number of studies have sought to quantify the costs related to the introduction of intermittent renewables into electricity systems, particularly focusing on the integration of wind energy in European countries (e.g. Dale and Milborrow, 2003). However, such estimates cannot be directly transferred to Pacific Islands' conditions for a range of reasons. Firstly, Pacific Islands' electricity systems are not comparable to large systems given their small size and isolation, which entail important constraints in matters of capacity margin and reliability. Most islands manage their electric utilities under the N-2 criterion, which refers to an approach by which total system capacity exceeds expected peak load when the two largest units of the system are unavailable. The N-2 reliability criterion entails a relatively large amount of system margin, reflecting the fact that isolated systems must ensure a reliable supply system at all times given their inability to connect to continental grids. Mayer (2000) pointed out that such a management approach induces a trade off between economies of scale (via larger generators) and security of supply (larger generating units require a larger amount of backup to maintain reliability of supply). In addition, low levels of demand imply some rigidity with respect to the use and size of different technologies. Given such limited demand, the amount of intermittency should be carefully chosen as energy spilling may become an issue. Such characteristics are specific to isolated and small systems such as those of Pacific Islands.

Given the differences in system management, the impact and cost of increasing the amount of intermittency in Pacific Islands' electricity systems are likely to be substantially different from those of the European systems. While there may be less scope for geographical dispersion of renewable energy technologies on small islands, most Pacific Islands can potentially integrate a range of different types of renewables (solar, wind, wave), which may have positive implications for the total system capacity credit of intermittent plants. On a different note, the amount of fuel cost savings brought by increases in renewable energy for electricity generation is likely to be more significant in Pacific Islands since fuel cost can be up to 200 percent higher than in large European countries. 


\section{4) Application of Portfolio Theory to Electricity Generation}

As seen in the previous section, whether the introduction of intermittent renewables into electricity networks increases or reduces the total cost of electricity supply will depend on several counteracting factors, including whether or not externalities are included in the calculation. The benefits brought by renewables, notably environmental benefits such as emissions reductions, and economic benefits related to fuel savings, are likely to be particularly significant in the Pacific Islands where fossil fuel prices are dramatically high. In addition, given the uncertainties overhanging the world oil market, a country's security of energy supply would improve with the development of renewable energy for electricity generation as increasing the share of renewables for electricity generation would reduce vulnerability to international market price fluctuations. Many studies (Weisser, 2004; Domah, 2002; Awerbuch, 2004) have provided evidence that the risk related to fossil fuel price volatility and unpredictability has negative impacts on economic activity, terms of trade, employment and GDP growth. Awerbuch (2003) has argued that given such uncertainty, investment decisions in electricity generation should no longer be based solely on the costs of different technologies, but should also take into account the different risks related to each technology.

Increases in the price of oil can lead to severe macroeconomic consequences for low income, oil-importing countries (Weisser, 2004, p.134). A rise in the price of oil might be deflationary, reducing ability to import, worsening the terms of trade, and increasing debts. This is particularly the case for Pacific Island Countries, where fossil fuel is relatively expensive and where the proportion of petroleum imports compared to total exports is high. It has been reported that Pacific Islands Countries'energy imports account for 15-25 percent of total imports, and over 40 percent of gross domestic commodity exports (for some countries this figure can be as high as 500 percent - Grynberg, 2005, p. 9).

Despite abundance of natural resources and large potential benefits from renewable energy, however, there is little renewable energy capacity on Pacific Islands, indicating either that the benefits of renewables are not appropriable by the existing 
industry participants, or that other cost factors (such as the need to maintain reliability) outweigh the benefits of reduced oil dependence.

An increasing number of studies have applied to electricity planning the meanvariance analysis of portfolios, from the finance theory introduced by Harry Markowitz in 1952 (Awerbuch and Berger, 2003; Jansen et al, 2006; McLoughin and Bazilian, 2006). The mean-variance portfolio approach provides a quantitative framework to evaluate investment options in terms of both returns and risks (defined as the standard deviation of the returns), and shows that investors can reduce exposure to risk by holding a diversified portfolio of assets. While the goal of the analysis is to maximize return for a given level of risk, or minimize risk for a desired level of return (DeLaquil, Awerbuch, Stroup, 2005), the key characteristic for optimization is a less than perfect correlation between returns on each asset. In the case of electricity portfolios, different technologies are evaluated in terms of their generating costs (composed of fuel, operation and maintenance, and capital costs) and risk (in terms of the variability of those costs), in order to make decisions for energy planning.

The approach consists of calculating portfolio cost and risk combinations for varying asset allocations, where 'asset' may be defined as either the proportion of total electricity generated by a technology or the amount of generating capacity of a technology compared to total generating capacity. Portfolio optimization leads to the construction of an efficient frontier, which represents the portfolio generating mixes (asset allocations) which have the minimum cost for any given level of risk. Graphically, the efficient frontier shows all efficient portfolios in terms of risk and unit cost of electricity (in $\$ / M W h$ ). Portfolio efficiency implies that electricity cost can only be decreased by increasing risk. The analysis thus consists of depicting the trade-off between generating cost and risk, showing all combinations of technologies which are efficient. Hence there is no prescription of a single optimal portfolio, but a graphical representation which displays the range of efficient choices, enabling any actual or projected generating mix to be located compared to the efficient frontier.

The key variables for mean-variance portfolio analysis are the portfolio cost, risk, and the correlation coefficient or co-variance between the technologies' expected cost variances. Portfolio cost is typically defined as the weighted average life-cycle cost of 
the individual expected costs of the generating mix technologies. Portfolio risk is the sum of the weighted average of the individual technology cost variances, and their covariances. Overall, studies which have employed mean-variance portfolio theory have concluded that the inclusion of renewable energy technologies into generating portfolios is desirable from a societal point of view, as it can substantially reduce portfolio risk at little or no additional cost. Even though renewable technologies have high capital costs and induce higher generating portfolio costs, their inclusion into portfolios is desirable because the cost variance of renewables is not correlated with fossil fuel prices, which drive the bulk of cost variance for conventional generators. In addition, the cost structure of renewable technologies is relatively fixed over time, which allows for more certainty.

The following paragraphs provide a brief review of some of the main studies applying portfolio analysis to energy planning.

In one of the most detailed studies, Awerbuch and Berger (2003) apply portfolio theory to the European Union (EU) electricity planning. The model incorporates four different cost and risk components: fuel outlays, variable O\&M costs, fixed O\&M, and construction period costs (Awerbuch and Berger 2003, p. 20), where the risks and cross-correlations associated with fuel costs are based on historical time series and other risks are based on financial proxies. The efficient frontier, composed of the minimum risk portfolio for each level of cost, is found using Microsoft Excel Solver. The following graph represents the EU efficient frontier constructed in that study: 
Figure 3.2: EU Efficient Frontier (Awerbuch and Berger, 2003)

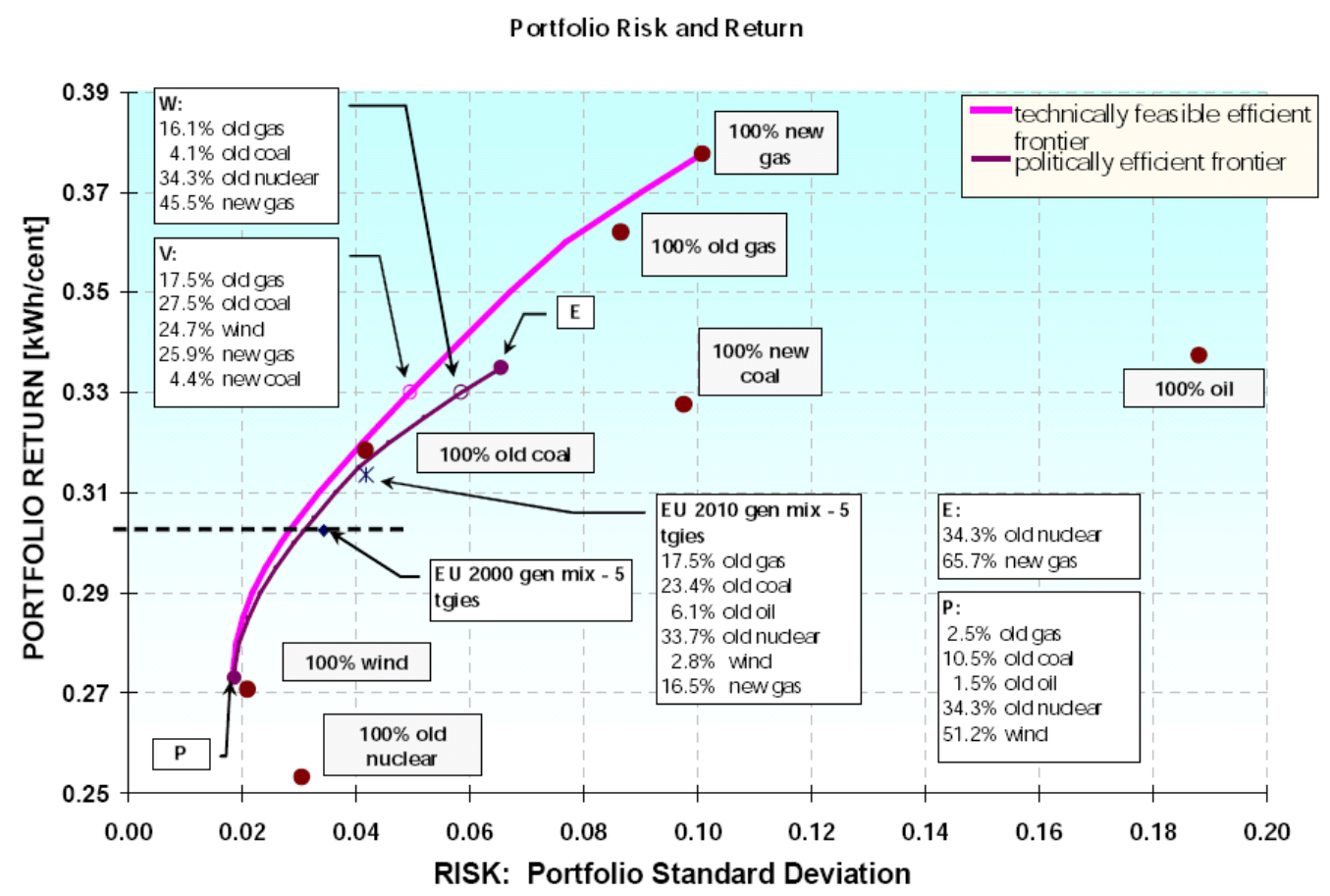

The 'politically efficient frontier' in the diagram accounts for practical efficiency; it constitutes an additional ad hoc constraint related to the inability to decommission and abandon the totality of existing nuclear capacity (however, it does not include decommissioning and salvage costs). This constraint was introduced in addition to a feasibility constraint, which implies that the shares of existing technologies cannot exceed their 2000 generation value. Existing capacity is thus considered separately to new capacity. Separating existing capacity from new capacity also matters in the sense that existing capacity has no construction period risk, whereas new capacity does. Awerbuch and Berger conclude that fixed cost renewable technologies must be included in a portfolio for efficiency, and that EU's planned 2010 generating mix is sub-optimal as it is not located on the efficient frontier. Results were found to be robust to sensitivity analysis.

Awerbuch (2005) considers Scotland's energy diversity, using the same framework. However, in order to reflect system integration costs, a fixed charge of $£ 16 / \mathrm{MWh}$ is added to the cost of wind generation, based on the estimates of Dale and Milborrow (2004). The graph below depicts the efficient frontier which includes integration costs, along with the reference-case efficient frontier which does not account for system 
integration costs. (Note that the vertical axis here shows cost, whereas the diagram from Awerbuch and Berger 2003 was drawn for the reciprocal of cost, namely return).

Figure 3.3: Scotland's Efficient Frontier (Awerbuch, 2005)

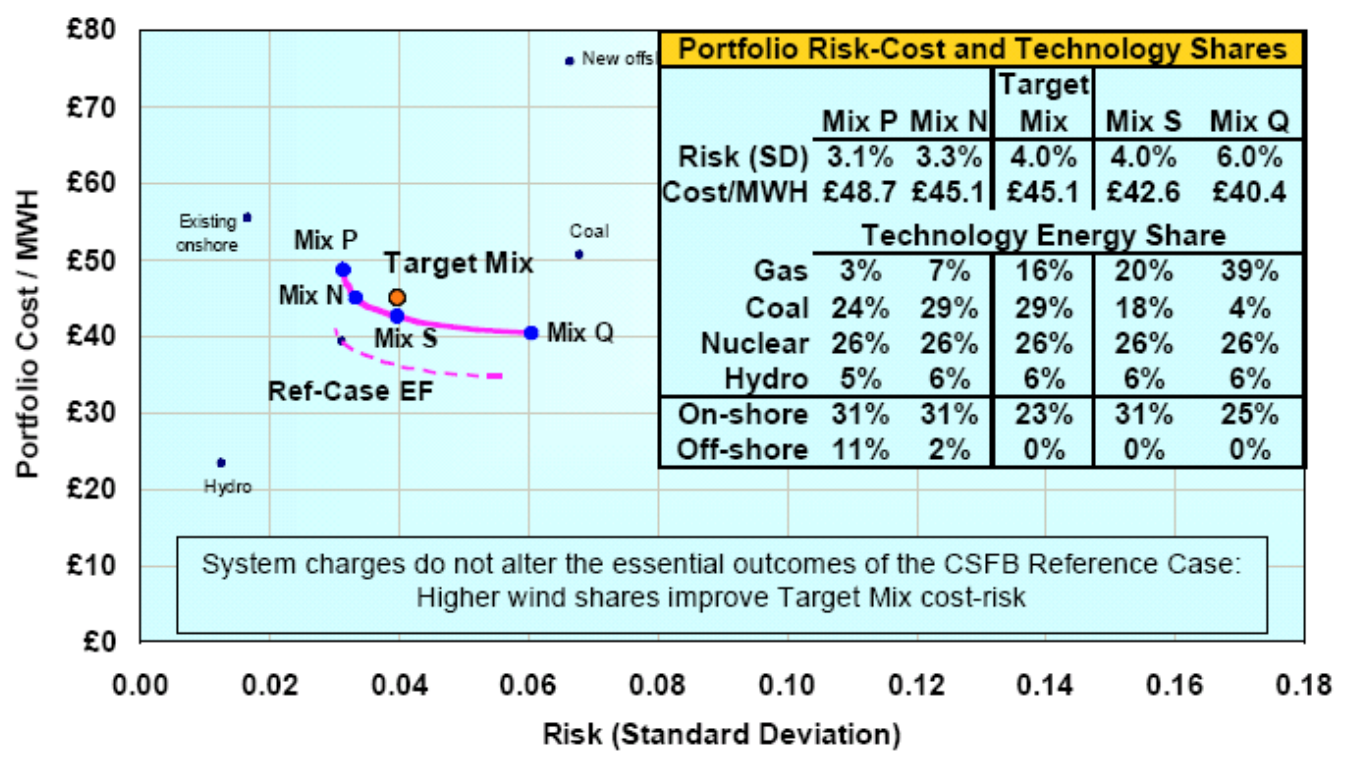

Awerbuch concluded that the portfolio results remain valid even with the inclusion of system integration costs.

Jansen, Beurskens and Tilburg (2006) look at the Dutch generating mix and propose some modifications to Awerbuch's theoretical framework. The most significant change is related to the calculation of portfolio risk-cost, notably the relationship between cost minimization and return maximization. Awerbuch had defined return as the inverse of the weighted average of portfolio cost, which Jansen et al show to be misleading when calculating returns of portfolios that consist of more than two assets. Another adjustment is to express portfolios in terms of energy generation instead of generating capacity, which allows for a more accurate comparison between technologies, given that renewable technologies typically have a lower capacity factor than conventional thermal technologies. Jansen et al also propose some refinements to the concept and calculation of risk found in the Awerbuch-Berger framework. Furthermore, the cost structure is different. It consists of an investment cost (which includes decommissioning costs), fuel cost, fixed operation and maintenance cost, 
variable operation and maintenance cost, and a cost for $\mathrm{CO} 2$ emissions per $\mathrm{MWh}$ of output, which provides a measure for environmental externalities. In addition, a fixed "intermittency cost" of $€ 6 / \mathrm{MWh}$ is added to intermittent technologies in order to account for the impacts of intermittency on the system. Jansen et al use the same type of graphical analysis and conclude that the 2030 pre-determined portfolio targets for the Netherlands are inefficient. This framework was replicated by McLoughlin, Bazilian (2006) for the Irish generating mix.

Boris Krey and Peter Zweifel (2006) apply portfolio theory to electricity generation in both Switzerland and the United States. Their study differs from the other portfolio analyses in a number of ways. Instead of determining the efficient frontier in a costrisk dimension, they use risk and expected decreases in costs, on the basis that investors are concerned with future returns rather than the current value of a share. More importantly, a Seemingly Unrelated Regression Estimation (SURE) is performed in order to control for the possible correlation of error terms across risk equations. The following graph shows the efficient frontier constructed for Switzerland.

Figure 3.4: Switzerland's Efficient Frontier (Krey and Zweifel, 2006)

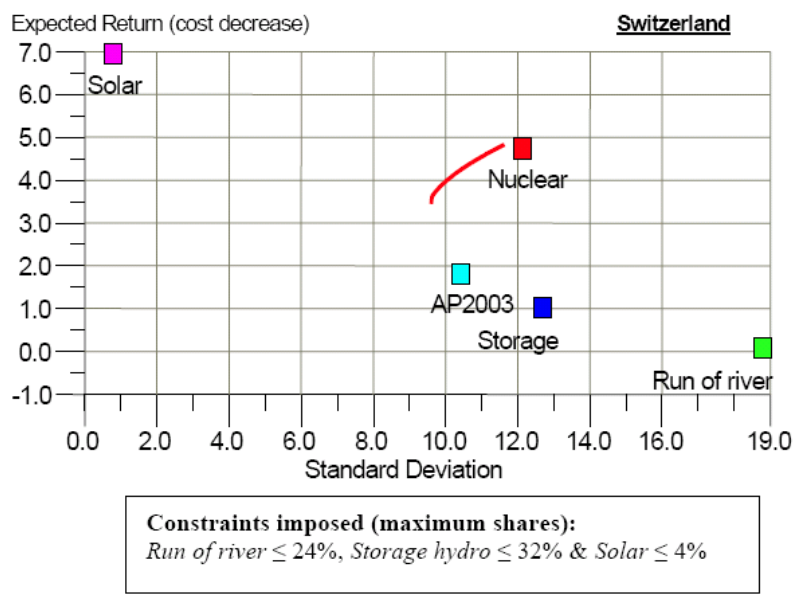

\begin{tabular}{|c|c|}
\hline \multirow{2}{*}{\multicolumn{2}{|c|}{$\begin{array}{l}\text { Maximum Expected Return Portfolio (MER) } \\
\text { Max. } E(R p)=4.83 \text {, St.D. }=11.63\end{array}$}} \\
\hline & \\
\hline $96 \%$ & Nuclear \\
\hline $4 \%$ & Solar \\
\hline \multicolumn{2}{|c|}{ Minimum Variance Portfolio (MV) } \\
\hline \multicolumn{2}{|c|}{$\mathrm{E}(\mathrm{Rp})=3.45$, Min St.D. $=9.60$} \\
\hline $60 \%$ & Nuclear \\
\hline $32 \%$ & Storage hydro \\
\hline $4 \%$ & Run of river \\
\hline $4 \%$ & Solar \\
\hline \multicolumn{2}{|c|}{ Actual Portfolio 2003 (AP2003) } \\
\hline \multicolumn{2}{|c|}{ Return $=1.82$, St.D. $=10.41$} \\
\hline $40 \%$ & Nuclear \\
\hline $24 \%$ & Run of river \\
\hline $32 \%$ & Storage hydro \\
\hline $4 \%$ & Solar \\
\hline
\end{tabular}

Figure 11 Swiss Efficient Electricity Portfolios (2003, SURE-based, with constraint, with high external costs)

Decreases in costs are used instead of cost on the vertical axis, which may be regarded as confusing as it represents the (negative) variation of cost, which is already picked 
up by the risk variable. Based on these estimates, the study concluded that for Switzerland, a move towards nuclear energy and away from run of river hydroelectricity was advisable, while an increase in production from coal and a decrease in gas production were advocated for the United States. Such results are different from those of previous studies, most likely because of the use of expected decrease in cost of a portfolio, rather than its cost.

The various studies which have applied mean-variance portfolio theory to electricity generation have shown that uncertainty and the variability of generating costs, in particular fossil fuel costs, can be and ought to be considered for energy decisions. By taking both cost and risk into account, this approach has provided an important framework for the evaluation of national electricity strategies and the diversification of electricity generating technologies for improving energy security. Nevertheless, a number of issues remain overlooked in this framework. In particular, the absence of assumptions relating to the maintenance of reliability of electricity networks constitutes a weakness of the analysis. Awerbuch and Berger (2003) assume that no backup capacity is necessary in addition to the existing capacity on the grounds that a number of studies have claimed that wind penetration levels of 5 percent to 10 percent cause little change to an electricity system operation strategy (Awerbuch, Berger, 2003, p. 57). Yet they recommend a portfolio containing 12.2 percent of wind generating capacity. While this figure may not be too far from the 10 percent threshold to be considered a threat to a system's reliability, another study (Awerbuch, 2005) concludes that "without increasing cost or risk, onshore wind can be increased to at least 31 percent of [Scotland's] electricity generation" (Awerbuch, 2005, p. 27). Nevertheless, by including an estimate of the cost of integrating wind in the UK, this study represents the first attempt to account for reliability maintenance in portfolio analysis. However, the Dale and Miborrow estimate used by Awerbuch refers to the costs associated with developing 20 percent wind in the UK electricity system (Dale, Milborrow, 2003, p. 24). Jansen et al (2006) and McLoughlin and Bazilian (2006) both include an additional cost of $€ 6 / \mathrm{MWh}$ for intermittent generation. However, these studies do not specify where this estimate comes from.

While depicting the maintenance of reliability may not be crucial for models which imply relatively low penetration levels of intermittent renewables in very large 
electricity networks, such as that of the UK with access to continental backup, it is likely to be far more significant once a similar analysis is applied to small island systems. The amount of backup capacity required to maintain reliability is relatively smaller for larger networks. Similarly, larger networks can sustain a wider range of types of generation (UKERC, 2006, p. 8). In contrast, small electricity networks require a large amount of reserve capacity. As already noted, most island systems operate with the N-2 reliability criterion (Mayer, 2000, p. 320), which means that a sufficient amount of capacity margin is maintained to cover peak demand in the event of the failure of the second largest generation unit when the largest is out for maintenance. In Oahu, Hawaii, for example, a system margin of 25 percent is maintained. Given that the system does not currently accommodate any significant amount of intermittent generation, any analysis involving the uptake of renewables must account for reliability. As pointed out by Jansen et al, ideally the cost of intermittency should be dependent on the penetration level (Jansen et al., 2006, p. 61) of intermittent technologies. In addition, the costs of integrating intermittency should be technology-specific; that is, they should vary with the extent of dispatchability of a technology. For example, it is likely that the costs arising from the integration of wave energy devices into an electricity system are substantially lower than those of the integration of wind turbines, as the wave energy resource is relatively continuous and can be forecast days in advance. As seen in chapter 2 , there is much potential for most Pacific Island Countries to generate electricity from a range of renewable resources. Hence, constructing electricity generation portfolios for Pacific Island would require the inclusion of a relatively larger number of renewable technologies (solar, wind, wave, hydro) than has been done for European countries. Incorporating a measure which determines the amount of back up required to maintain reliability for each technology would thus be appropriate for small island portfolios.

Another assumption at the core of the portfolio approach which does not necessarily fit to all electricity systems is that of a "flexible" generating mix; that is, that the generating mix can be "re-shuffled" relatively easily. Unfortunately, in Pacific Islands the ability to decommission plants and construct new ones is likely to be significantly constrained by financial resources, reliability requirements, and the utilities' market power. In addition, the efficient frontiers for small islands may not be as continuous and large as those of larger countries, since generating mix choices for Pacific Islands 
are likely to be constrained by low demand levels. Hence, the assumption for demand growth will be crucial when applying portfolio analysis to small systems such as those of Pacific Island Countries. Furthermore, an extended observation of the existing plants will be required in order to determine capacity replacement and the amount of backup required over the years. The separation of existing and new capacity, as in Awerbuch and Berger (2003), would thus be particularly useful for small island systems. In addition, the inclusion of construction period cost and risk and decommissioning costs would be useful. Although Jansen et al include decommissioning costs, they do not provide any specifications as to how such costs were determined. To replace such cost estimates, one may, for example, make assumptions regarding the durability of each plant. This would be a way to determine the maximum time a plant could be used before being abandoned.

Hence, while portfolio analysis has been applied successfully to large countries, a number of issues will need to be addressed before applying it to smaller systems such as those of Pacific Island countries. The modifications required to add constraints will be necessary not only for extending the analysis to small island systems, but will also be applicable to larger systems. Such refinements would enhance the accuracy and credibility of the analysis, while addressing issues which are of concern to energy planners.

So far, most studies which have applied portfolio theory to electricity generation have entailed the construction of an efficient frontier, providing graphical analysis for energy planning. Such studies have all led to the conclusion that the generating mix targets chosen by energy planners were not located on the efficient frontier, implying opportunities for Pareto improvements in the choice of electricity generating mix. While such analysis has typically shown that improvements could be obtained by increasing the amount of renewable energy for electricity generation, it has involved only limited discussion regarding the optimal or feasible amount of renewable energy in a given electricity system. The concept of portfolio analysis, however, can be used to investigate how much renewable energy can be integrated into an electricity system without compromising reliability of supply. Indeed, while it has already been applied to portfolios of electricity supply by minimizing the variance associated with their costs, the same concept of portfolio analysis could be applied to the integration of 
different types of renewables by minimizing the variance of output produced. This approach could be very useful to policy-makers who are striving to increase the share of renewable energy without jeopardizing reliability of electricity supply, as in Pacific Islands. When applying portfolio analysis to reliability of supply, the degree of correlation between the different renewable energy resources used would become the key variable. For instance, if the correlation between wind and waves was close to one, then having a large share of electricity supplied from wind and wave energy would be relatively risky: in the absence of both wind and waves at the same time, there would be a power shortage. If, however, the degree of correlation between the wind and wave resource was closer to zero, then wave energy could serve as a backup for wind energy in the absence of wind, and vice-versa. Intuitively, the larger the diversity of renewable energy sources used, the higher the reliability of supply. 


\section{Chapter Four: Entry of a Wave Energy Technology into the Electricity Market of a Pacific Island - Case Study of the Pelamis in Hawaii}

\section{1) Introduction}

Because of its status as part of the United States of America, Hawaii has a long-established electricity system with a well-developed regulatory regime and good sources of information. It faces essentially the same issues as other Pacific Islands with regard to isolation, remoteness, and limited opportunities to secure economies of scope and scale. It has also been one of the case-study locations selected by the Electric Power Research Institute (EPRI) for its evaluation of the Pelamis wavepower technology, which means that firm estimates of the economics of introduction of this renewable technology have been produced on a consistent basis. A ten-day field trip was undertaken in August 2006 to produce a Pacific Island case-study and to calibrate the mathematical model described in Chapter 5 below.

The field research was carried out on three islands in the Hawaii group: Maui, Big Island of Hawaii, and Oahu. The goal was to acquire information and insight on the operation and regulation of the islands' electricity systems, and to study the potential for the integration of the Pelamis wave energy technology into these networks. In order to understand the different perspectives and market forces evolving around the electricity and renewable energy markets, a broad range of market participants were interviewed: employees from the electric utilities, the Public Utilities Commission, the Government (Hawaii Department for Economic and Business Development), Independent Power Producers (IPPs), renewable energy research institutes, and political representatives. A list of the people interviewed is provided in Appendix B (table B1).

The case study of Hawaii is presented in the following sections, starting with a description of the electricity market and relevant regulation. Section 2 reviews some of the status quo barriers to renewable energy development in Hawaii (barriers to 
renewable energy development in Pacific Islands are discussed more thoroughly in chapter 6). Finally, the potential for integrating a wave energy technology in Hawaiian electricity networks is examined in section 3.

\section{2) Electric Utilities, Current Regulation and Requirements}

Hawaiian Electric Industries, Inc. (HEI) supplies power to 95 percent of the Hawaii electricity market through its subsidiaries Hawaiian Electric Company (HECO) on Oahu, Hawaii Electric Light Company (HELCO) on Big Island and Maui Electric Company (MECO) on Maui, which also supplies the islands of Lanai and Molokai ${ }^{27}$. The Kaua'i Island Utility Cooperative (KIUC) is responsible for power supply on the island of Kaua'i. All electric utilities operate and maintain not only the bulk of generation units, but also the transmission and distribution systems of the islands in which they operate: they are vertically integrated.

In this case study, the description of electricity suppliers is mainly focused on HEI subsidiaries, as very little information was collected on the KIUC compared to HEI subsidiaries (there was insufficient time to visit the island of Kaua'i). While this case study is concentrated on HEI subsidiaries, which are private companies, it is important to keep in mind that the KIUC is a cooperative and may be more open than HEI to integrating renewable energy technologies.

All utilities in Hawaii are regulated by the Public Utilities Commission (PUC), formed in 1913, and the Division of Consumer Advocate (DCA). The PUC is in charge of the supervision of public service companies, and the DCA represents utility consumer interests. The Department of Business, Economic Development and Tourism (DBEDT) is also involved in energy regulation and policy: the director of DBEDT is the Energy Resources Coordinator, and the administrator of the DBEDT division of Energy, Research and Technology is the Petroleum Commissioner (Freeman and Lazar, 2003, p. 20).

\footnotetext{
${ }^{27}$ www.hei.com
} 
Table 4.1 displays the total installed capacity in Hawaii (excluding Kaua'i Island). The HEI subsidiaries own and maintain the transmission and distribution systems on each island. All suppliers other than HECO, HELCO and MECO that are listed in the table below are independent power producers (IPPs) which are connected to the grid through Power Purchase Agreements (PPAs) signed with the electric utilities. PPAs are subject to the approval of the Public Utilities Commission. 
Table 4.1: Electricity Supply in Hawaii from Hawaiian Electric Industries

\begin{tabular}{|c|c|c|c|c|}
\hline Island & Company & Energy source / technology & Location & $\begin{array}{l}\text { Capacity } \\
\text { (MW) }\end{array}$ \\
\hline Oahu & HECO & Oil power plant & Honolulu & 113 \\
\hline Oahu & HECO & Oil power plant & Waiau & 499 \\
\hline Oahu & HECO & Oil power plant & Kahe & 651 \\
\hline Oahu & H-POWER & Waste to energy system & Kapolei & 46 \\
\hline Oahu & Kalaeloa Partners & Oil plant & Kalaeloa & 180 \\
\hline Oahu & AES-Hawaii & Coal-fired plant & Kapolei & 180 \\
\hline Oahu & $\begin{array}{l}\text { Kapaa } \\
\text { Generating } \\
\text { Partners }\end{array}$ & Landfill Gas (Methane) & Kailua & 3.5 \\
\hline Oahu & Tesoro Corp. & Diesel or oil plant & Kapolei & 18.5 \\
\hline Oahu & Chevron Corp. & Diesel or oil plant & & 9.6 \\
\hline Hawaii & HELCO & Oil power plant & Hill & 35.5 \\
\hline Hawaii & HELCO & Oil power plant & Puna & 36.3 \\
\hline Hawaii & HELCO & Oil power plant & Keahole & 29.5 \\
\hline Hawaii & HELCO & Oil power plant & Kanoelehua & 21.75 \\
\hline Hawaii & HELCO & Oil power plant & Shipman & 18.6 \\
\hline Hawaii & HELCO & Oil power plant & Waimea & 11.25 \\
\hline Hawaii & $\begin{array}{l}\text { Puna Geothermal } \\
\text { Venture }\end{array}$ & $\begin{array}{l}\text { Geothermal Hot Liquid (Steam } \\
\text { Turbine Generators) }\end{array}$ & Puna & 30 \\
\hline Hawaii & $\begin{array}{l}\text { Hamakua Energy } \\
\text { Partners }\end{array}$ & Combined Cycle plant & Honokaa & 60 \\
\hline Hawaii & HELCO & Wind Farm & Lalamilo & 2.3 \\
\hline Hawaii & HELCO & Hydropower (run-of-river) & $\begin{array}{l}\text { Puueo, } \\
\text { Waiau }\end{array}$ & 3.35 \\
\hline Hawaii & $\begin{array}{l}\text { Apollo Energy } \\
\text { Corp. }\end{array}$ & Wind Farm & South Point & 9.25 \\
\hline Hawaii & $\begin{array}{l}\text { Wailuku River } \\
\text { Hydroelectric }\end{array}$ & Hydropower (run-of-river) & Wailuku & 11 \\
\hline Maui & MECO & $\begin{array}{l}\text { Diesel units, plus two } \\
\text { Combined Cycle Gas Turbines }\end{array}$ & Maalaea & 196.5 \\
\hline Maui & MECO & $\begin{array}{l}\text { Steam Turbine (fired by bunker } \\
\text { fuel) }\end{array}$ & Kahului & 37.6 \\
\hline Maui & $\begin{array}{l}\text { HC\&S (Sugar } \\
\text { company) }\end{array}$ & $\begin{array}{l}\text { Bagasse (boiler, steam turbine } \\
\text { generators) / Coal / Oil }\end{array}$ & Puunene & 16 \\
\hline Maui & $\mathrm{HC} \& \mathrm{~S}$ & Hydropower run-of-river & $\begin{array}{l}\text { Kaheka, Paia, } \\
\text { Hamakua }\end{array}$ & 5.8 \\
\hline Maui & LLC, UPC & Wind Farm & Kaheawa & 30 \\
\hline Maui & MECO & Oil power plant & Hana & 2 \\
\hline Lanai & MECO & Oil power plant & Lanai & 10.4 \\
\hline Molokai & MECO & Oil power plant & Molokai & 12.05 \\
\hline
\end{tabular}

Source: www.heco.com

Table 4.2: Percentage of Total Installed Capacity held by Independent Producers

\begin{tabular}{|l|l|l|l|}
\hline & Oahu & Hawaii & Maui \\
\hline Total Capacity (MW) & 1700.6 & 290.8 & 287.9 \\
\hline \% Total Capacity from IPPs (MW) & 25.7 & 45.5 & 18.0 \\
\hline
\end{tabular}

Source: $\underline{w w w . h e c o . c o m}$ (figures from table 4.2 above) 
The tables above show that although Hawaiian Electric Industries subsidiaries are vertically-integrated structures and all have the status of monopolies (independent producers must sign a contract with the utilities in order to produce and sell electricity), there is some degree of competition in the market provided by a fringe of independent power producers exploiting renewable and fossil resources-mostly oil and diesel, with some hydropower and wind farms.

Independent supply is encouraged by a 1978 federal law of the United States called the Public Utility Regulatory Policies Act (PURPA). The aim of PURPA is to promote alternative energy sources and energy efficiency, and to diversify the electric power industry. PURPA obliges utility companies to purchase energy from independent companies at prices based on "avoided cost". The qualifying independent facilities include small-scale producers who generate energy for their own needs but may have surplus energy, and incidental producers who generate electricity as a byproduct of other activities ${ }^{28}$. The term "avoided cost" refers to the incremental cost which an electric utility avoids by purchasing from a qualifying facility.

The promotion of small-scale renewable energy in Hawaii was further enhanced in June 2001 with the enactment of a net-metering law. Net metering is available to residential and small commercial customers with solar, wind, biomass or hydroelectric systems with a capacity up to 10 kilowatts $(\mathrm{kW})$. This capacity limit was increased to $50 \mathrm{~kW}$ in 2004, and the Public Utilities Commission has discretion to increase it beyond $50 \mathrm{~kW}$ in particular cases ${ }^{29}$. Electricity utilities are required to offer net metering on a first-come, first-serve basis to eligible customers until the aggregated net-metered capacity equals 0.5 percent of each utility's system peak demand. This cap was provided by the law but may be increased by the PUC. The PUC is responsible for setting safety, performance, and reliability standards. Hawaii, like other U.S. states, has adopted national, standardized interconnection requirements as part of its net-metering law.

\footnotetext{
${ }^{28} \mathrm{http}: / /$ www.energyvortex.com/energydictionary

${ }^{29} \mathrm{http://www.heco.com/images/pdf/NEM} \mathrm{brochure8.pdf}$
} 
Net metering allows customers to offset their purchases of electricity from the utility with electricity produced by their renewable system, credited at the retail rate. When a customer produces more electricity than it consumes during a month, net excess generation credits in the form of kWh can be applied to the following month's bill. Net excess generation credits can be carried over for a maximum of 12 months. In the case of net excess generation, the customer still has to pay for a minimum charge which covers fixed costs such as meter readings and billing. Net-metered customers cannot be paid for excess generation (this can only occur under a power purchase agreement). A set of guidelines and a simple, short net metering agreement form are available from the HECO website ${ }^{30}$.

The net metering system is accompanied by state and federal renewable energy tax credits. State tax credits include a 35 percent tax credit on solar thermal systems and solar photovoltaic systems, and a 20 percent tax credit on wind systems, for both residents and businesses. These tax credits apply to the cost of the systems, including accessories and installation, and there is no maximum limit to the total amount of the credit. Tax credits that exceed the taxpayer's income tax liability may be used as a credit against income tax liability in subsequent years until exhausted. There is also a state capital goods excise tax credit for businesses, which reimburses businesses for the general excise tax or use tax that they pay on the purchase of a solar electric system (the credit is equal to four percent of the cost of the solar electric system). In addition, there is a federal business energy tax credit of 10 percent available to commercial businesses that purchase energy property in the US (including solar and geothermal energy). Finally, there is a Modified Accelerated Cost Recovery System (MACRS), under which businesses can recover investments in solar electric equipments through depreciation deductions.

An example of the outcomes from this combination of net metering services, state and federal taxes, is the company Big Island TOYOTA (on Big Island of Hawaii) which installed a $64.5 \mathrm{~kW}$ grid-connected net energy metered photovoltaic system in 2006, claimed to be the largest commercial solar electric system on East Hawaii. This installation was mostly planned and put in place by Mr Victor Trevino, chief

\footnotetext{
${ }^{30} \mathrm{http} / / / \mathrm{www} . h e c o . c o m / i m a g e s / \mathrm{pdf} /$ net_meter_appendix1.pdf
} 
operations officer at Big Island Toyota and manager of Hawaii Beef Producers, using an innovative financing approach based on a partnership between Big Island Toyota and the Bank of Hawaii ${ }^{31}$. Although Big Island Toyota hosts the solar panels and benefits from a net metering agreement with HELCO, the system is owned by the Bank, which bought the solar photovoltaic system, pays for its maintenance, and benefits from the tax credits enumerated in the previous paragraph. Eighty percent of what the bank spends on the solar panels is refunded by state and federal tax credits, yet the total amount spent on the panels, which reflects the real value of the system, appears as an asset on the bank's balance sheet. Meanwhile, Toyota gets to reduce its monthly electricity bill through its net metering agreement with the electric utility, without having had to spend any money on the panels' installation or maintenance.

Independent producers and net metering customers (such as Big Island Toyota) assist the electric utilities in meeting their Renewable Portfolio Standard (RPS) requirements. The RPS, enacted in 2001, is a law which "establishes goals for electric utility companies in implementing renewable portfolio standards by including a minimum percentage of renewable energy resources within an overall resource portfolio" 32 .

The 2001 renewable portfolio standard goals for each electric utility were 7 percent of net electricity sales by December 2003, 8 percent of net electricity sales by 2005, and 9 percent of net electricity sales by December 2010. The Act stated that "an electric utility company and its electric utility affiliates may aggregate their renewable portfolios in order to achieve the renewable portfolio standard" ${ }^{\prime 3}$. This means that HEI subsidiaries can aggregate their renewable portfolios, so that, for example, HELCO (on Big Island Hawaii) ends up with a larger percentage of net electricity sales coming from renewable sources than HECO on Oahu (which is currently the case).

In June 2004, Governor Linda Lingle signed a bill which replaced the RPS goal with an enforceable standard, under which 10 percent of each utility's electricity sales must

\footnotetext{
${ }^{31}$ Interview with V. Trevino, Hilo, August 2006.

${ }^{32}$ www.capitol.hawaii.gov/session2001/bills/HB173 cd1 .htm

33 www.capitol.hawaii.gov/session2001/bills/HB173 cd1 .htm
} 
be generated from renewable resources by 2010. The bill also added standards for 2015 (15 percent), and 2020 (20 percent). The intent is to expand the standards beyond 20 percent and beyond $2020^{34}$. The PUC is required to review and revise the RPS every five years.

Another requirement for electric utilities is the Integrated Resource Planning (IRP) Framework, which was established by the PUC around 1992. The goal of the IRP is "the identification of the resources or mix of resources for meeting near and long term consumer needs in an efficient and reliable manner at the lowest reasonable cost" (Public Utilities Commission, State of Hawaii, 1992, p. 3). Under the IRP, which is a public process, all electric utilities are responsible for submitting to the PUC an integrated resource plan which involves the identification and evaluation of available supply side and demand side options to meet expected demand over twenty years. Each plan must include a specification of the utility's objectives, the cost and implications of the objectives and alternatives to them, and a choice of resource options. After the PUC has approved a plan, the utility is required to carry it out by following its five-year implementation schedule, and to evaluate its implementation progress every year. A review of each utility's resource plan is also required every three years.

The PUC has the responsibility to review the utilities' integrated resource plan, including implementation schedule and evaluations, but also to monitor each utility's implementation of the plan (Public Utilities Commission, State of Hawaii, 1992, p. 5). The DCA, on the other hand, must make sure that each plan promotes the interest of utility consumers (Public Utilities Commission, State of Hawaii, 1992, p. 5).

To sum up, the electricity markets of Oahu, Maui, Lanai, Molokai and Big Island of Hawaii are all dominated by vertically integrated monopolies. At a first glance, the current situation looks not unpromising for independent renewable energy producers, given extended regulation on the electric utilities and for the promotion of independent power production and renewable energy generation. However, interviews with key industry participants revealed the existence of a number of flaws in the

\footnotetext{
${ }^{34}$ www.dsireusa.org/library
} 
regulatory framework. In practice, the regulated monopolies remain monopolies, and renewable energy producers face important obstacles.

\section{3) Barriers to Renewable Energy Development in Hawaii}

The regulatory context in which electric utilities operate provides a range of opportunities for independent power producers to enter and for the development of renewable energy. The existence of such a variety of laws and regulations can certainly justify the term "regulated monopoly" when referring to Hawaiian Electric Industries. Nevertheless, the utilities remain monopolies and the very low contribution of renewable energy to total electricity generation in Hawaii (excluding Kaua'i) indicates that there exist a number of barriers to renewable energy development by independent producers. In 2004, only 6.4 percent of the electricity supplied to consumers by the HECO companies came from renewable energy, as displayed in figure 4.1 .

Figure 4.1: Electricity Generation Sources in Hawaii (2005)

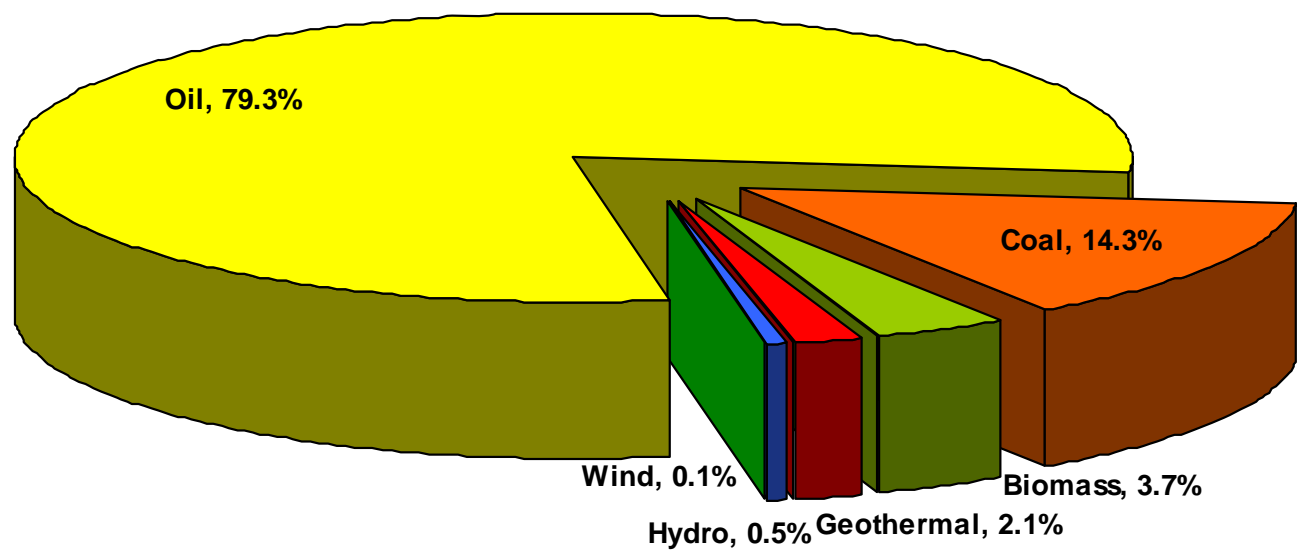

Source: www.heco.com

Note: The percentage of fuels used to produce electricity is based on the amount of electricity generated by the HECO family of companies and the amount purchased from independent power producers in 2004. 
The utilities argue that they have difficulty accommodating a large amount of capacity from intermittent renewable resources such as wind energy ${ }^{35}$ (see chapter 3 for a detailed discussion on the limitations to accommodating renewable energy into electricity systems). The biggest independent producers in Hawaii are coal fired and oil plants located on Oahu and Big Island Hawaii.

The Public Utilities Commission plays a critical role in the market for electricity supply: approval of independent power producers, determination of fees and tariffs, review of the Renewable Portfolio Standard (RPS) and the Energy Cost Adjustment Clause (ECAC), involvement in energy policy through the IRP process. Yet, as stated in a report on Hawaii energy utility regulation and taxation, the regulatory agencies have insufficient resources (in terms of both staff and funds) to focus on their public policy duties, as these agencies have been "consumed with substantial day to day workloads, processing applications, complaints and filings that are not explicitly policy matters" (Freeman and Lazar, 2003, p. 2). This was confirmed by an employee of the PUC interviewed in August $2006^{36}$, who pointed out that the PUC deals with all public utilities - not only electricity and water supply, but also telecommunications and transportation. Out of 44 existing positions at the PUC, only 30 are filled. The DCA seems to be experiencing the same problems.

The fact that the major utility regulatory agencies are understaffed does not constitute a barrier to renewable energy development in itself, but it may affect the integration of IPP's by delaying PPA's between the independent producers and the utilities. The 2003 report on Hawaii energy utility regulation and taxation states that: "The process for negotiation of a PPA and approval by the PUC can be protracted. The length of time for an IPP to complete a PPA with a utility is a major issue regarding the implementation of renewable resources. In part, the length of time to complete the negotiations is a function of the complexity of the issues. In some cases, where the utility is not motivated or is disinclined to execute a PPA, the process can be extremely arduous and frustrating for IPP's attempting to proceed with construction of resource projects" (Freemand and Lazar, 2003, p. 102). Hence, although utilities are obliged to integrate IPP's under PURPA, they have some degree of power over

\footnotetext{
${ }^{35}$ Conversation with Curtis Beck (Manager at HELCO) on the $4^{\text {th }}$ of August 2006.

${ }^{36}$ Interview with John Leite (PUC) and Curtis Beck (HELCO), $4{ }^{\text {th }}$ of August 2006.
} 
the PPA process and its length of time, which can negatively affect IPP's decision to enter the market; this effect can be significantly enhanced when the regulatory authority does not have enough resources to proceed quickly.

In addition to possible delays in PPA's, some independent renewable energy producers must allow a considerable amount of time and resources for permitting requirements. This is especially the case for Ocean Thermal Energy Conversion (OTEC), wave and tidal energy, and offshore wind projects. In 1991, a report on energy management and permitting analysis stated that over 100 permits and approvals may be required for a wave energy project, including environmental reviews, environmental impact assessments, construction, operation and land use permits at the federal, state and county levels (RGC/ Hagler, Bailly, Inc., 1991, p. 20). In addition, permit issues can be accompanied by cultural issues. Although Hawaiian indigenous beliefs and judgements differ across families, there has been much opposition to geothermal plants from cultural activists in the past ${ }^{37}$. Such cultural issues are not to be overlooked and may constitute a significant barrier; it is important that independent renewable energy producers keep the community informed before implementing a project.

Although the Renewable Portfolio Standard was enacted to increase the percentage of electricity generated from renewable energy, the electric utilities are able to at least temporarily delay the required increase in renewable energy generation. For example, the RPS law empowers the PUC to issue a temporary waiver for a utility if it is unable to meet the RPS "in a cost-effective manner, or as a result of circumstances beyond its control” ${ }^{\prime 3}$. The possibility of obtaining temporary RPS waivers gives an incentive for utilities to claim that renewable energy solutions are not cost-effective, rather than trying to accommodate renewable energy production (including letting independent renewable energy producers enter the market). This possibility is in fact reinforced by the IRP system. Indeed, although the IRP encourages the identification of renewable energy sources for meeting expected demand, the utilities may well state that renewable energy sources are not reliable or not efficient enough, and choose to

\footnotetext{
${ }^{37}$ Conversation with Andrea Gill (Hawaii Department of Business, Economic Development and Tourism), $3^{\text {rd }}$ of august 2006.

${ }^{38}$ www.capitol.hawaii.gov/session2001/bills/HB173_cd1_htm
} 
implement additional diesel plants or combustion turbines. A utility's IRP choice can then be used to justify its failure to meet the RPS, in order to be granted a temporary waiver. In addition, the IRP enables the utilities to install more capacity instead of accommodating entry of independent renewable energy producers.

In its latest IRP report (IRP-3), HECO states that "the IRP-3 Final Preferred Plan contains a strong commitment to increase the use of distillate fuels, and indigenous renewable resources, and in general to decrease the use of imported oil" (Hawaiian Electric Company, 2005, p. 1-1). This preferred plan involves the installation of a 100 MW simple combustion turbine in 2009. The IRP report contains a section of comments on the IRP draft from various associations and departments. Some of the criticisms of the IRP include: cost analyses biased against renewable energy (Hawaiian Electric Company, 2005, p. 12-22, 12-43, 12-44, and 12-51) (including the failure to account for high oil prices by relying on 2002 data for the oil price forecast analysis), a "lack of adequate transparency" for the direct comparison method (Hawaiian Electric Company, Inc, 2005, p. 12-23), failure to consider unconventional approaches to funding renewable energy projects, unclear objectives, and bias towards utility-ownership, utility implementation and self-build options.

Another problem with the RPS is that it allows utility affiliates to aggregate their renewable portfolios to achieve the RPS. This is mentioned in HECO's integrated resource plan, which justifies the low renewable energy production on Oahu by asserting that there is "greater potential for renewable energy on Maui and Big Island". Allowing Hawaiian Electric Utilities to aggregate their RPS across islands has led to a very asymmetric increase in renewable energy installation across islands, with the smallest integration of renewable energy independent production in Oahu. This is unlikely to change with the installation of new oil-fired powerplants on Oahu. Consequently, independent renewable energy producers can expect to have more difficulty in obtaining Power Purchase Agreements when dealing with HECO compared to HELCO and MECO. This could constitute a major barrier to wave energy development in Hawaii as Oahu has been recognised as the site with greatest immediate potential for wave power. 
Hawaiian Electric Industries utilities benefit from an Energy Cost Adjustment Clause (ECAC) policy. The ECAC is an automatic rate adjustment mechanism that passes changes in fuel costs to utility consumers, allowing electric utilities to avoid the risks associated with the costs of fuel and fuel price volatility (Department of Business, Economic Development and Tourism of Hawaii, 2006, p.1). The Hawaii Department of Business, Economic Development and Tourism has reported that ECAC accounts for over 30 percent of the total residential bill for an average household using 700 $\mathrm{kWh}$ per month in Oahu, and it accounts for almost 50 percent of the total residential bill for an average household with a consumption of $600 \mathrm{kWh}$ per month in Maui. The adverse impact on consumers is much bigger than in any other state with ECAC, due to the heavy (78 percent) dependency of Hawaii utilities on fuels. An important adverse effect of ECAC is that it removes a potential incentive for utilities to invest in renewable energy as they do not bear the risks of fuel price volatility.

A critical component of PURPA and PPA's is the avoided cost, which determines the price that independent producers receive from the utilities. It consists of the incremental costs to an electric utility which the utility would avoid by purchasing from a qualifying IPP facility. The avoided cost includes the avoided capacity costs (which consist of avoided capital costs and avoided fixed operation and maintenance costs), and avoided energy costs (including avoided fuel costs, avoided variable operation and maintenance costs, avoided working cash, avoided fuel inventory and avoided transmission and distribution energy losses). Hence, while the utilities do not bear the risks associated with fuel price volatility, the amount independent producers are paid is based on fuel costs. In addition, the avoided cost does not include the positive externalities brought by renewables (such as reduction on greenhouse gas emissions and greater energy security). The question of whether to include such externalities in the avoided cost has been raised, but it did not result in any change. It has previously been argued by the Public Utilities Commision that "the models used by the utilities to determine avoided costs could be improved to more accurately evaluate renewable energy systems" (Public Utilities Commission of Hawaii, 1995, p.1 c-1).

Net-metering, PURPA and Renewable Portfolio Standards form a regulatory context intended to facilitate the entry of independent renewable energy producers in Hawaii, 
more than in most other Pacific Islands. Nevertheless, there remain important barriers to independent renewable energy producers: aside from the general and universal issues of extensive permitting requirements and potential cultural opposition to new renewable energy technologies, there is a lengthy process for obtaining power purchase agreements (which can be slowed down by the utilities), and the utilities retain some degree of market power given their ability to invest in excess capacity, by building capacity ahead of independent producers. Despite extended regulation of the electric utilities and the promotion of independent power production and renewable energy generation, the HEI companies seem to retain a large degree of control over independent power producers and technology choice. This is well reflected in table 4.1, which shows that most IPPs operate oil or diesel plants. Facilitating the entry of independent renewable energy producers would require strengthening the regulating authorities and further control over the utilities' investment decisions.

\section{4) Feasibility and Potential for the Implementation of a Wave Energy Technology in Hawaii}

Financial benefits, permitting and wave energy in Hawaii

Wave energy producers are entitled to benefit from a number of tax incentives in Hawaii. For technology development and research, the qualified high technology business investment tax credit, for example, is a non-refundable credit of 100 percent of the investment available to investors, with a cap of US\$ 2 million per investor. This tax credit is available to businesses that conduct more than fifty percent of their activities in qualified research (including non-fossil fuel energy-related technology), and which conduct more than 75 percent of the qualified research in Hawaii, or companies that derive more than 75 percent of their gross income from qualified research and which receive their income from products or services sold from, manufactured in, or produced in Hawaii. Such companies can also benefit from a refundable research tax credit of 20 percent of the amount spent on certain qualified research expenses in Hawaii. Employees, officers, investors or directors of Qualified High Technology Businesses can also benefit from income tax exclusion for income from stock. Another income tax exclusion is available for income received by individuals or qualified high technology businesses as royalties and other income 
derived from any patents, copyrights, and trade secrets developed and arising out of a qualified high technology business. Finally, a non refundable income tax credit of 4 percent of the renovation costs (costs to plan, design, install, construct and purchase technology-enabled infrastructure) for each commercial building located in Hawaii is available. If a wave energy company qualifies as a high technology business, it will be able to benefit from these tax exemptions.

Permitting is likely to be a long and difficult process for wave energy project developers. A number of permits required for a wave energy project have already been identified by the DBEDT (DBEDT, 1992), including an energy permit, approval from the Public Utilities Commission, and a work permit from the Department of Transportation. The Federal Energy Regulatory Commission (FERC) has jurisdiction over wave energy projects beyond twelve miles offshore of Hawaii. If the wave energy converters are placed in state waters, between 0 and 12 miles offshore, the FERC will not be involved. If the converters are located in federal waters, the project developer will need to follow the FERC licence requirements under the Federal Power Act. Other requirements include: the Department of Interior Outer Continental Shelf Leasing Program, Coast Guard Regulations (hazards to navigation), an Environmental Assessment or an Environmental Impact Statement, consultation with Federal and State Fish and Wildlife agencies, consultation with the Secretary of Interior to determine if endangered species may be present, lease for use of state lands under waters (up to three miles offshore), and other state environmental statutes such as coastal erosion. In addition, coastal states with an approved Coastal Zone Management plan must issue a consistency finding that the proposed project is consistent with the state's coastal zone management plan. The choice of where to implant the wave energy converters will be crucial given the amount of recreational activities (surf, diving...) and commercial shipping occurring around the islands. Moreover, the various whale exclusion zones and military hazard zones around Oahu are likely to be a problem for finding an appropriate location for a wave energy project. Note that the indigenous community does not seem to have a problem with wave energy or ocean thermal energy, but as suggested above it is likely that other members of the community, such as the tourism industry, surfers or fishers, may be opposed to a wave energy project depending on where it is located. 
What are the utilities' views on a potential firm wishing to implement a wave energy project in Hawaii? During an interview with Curtis Beck, manager at HELCO on Big Island, a number of criteria were identified for the utility to consider integrating a wave energy project: size, dispatchability, reliability, and price. Firstly, Mr. Beck stated that HELCO could accommodate up to $30 \mathrm{MW}$ of wave energy; anything bigger would threaten the capacity margin of the utility. HELCO, HECO and MECO all maintain a 25 percent margin of generating capacity at peak load, sufficient to be able to supply electricity in the event of the failure of the second largest generation unit when the largest unit is out for maintenance. Secondly, the utilities do not consider wave energy as a firm power resource: wave conditions are identical at all points on a given seashore, meaning that all wave energy converters would stop producing electricity if the waves stopped. HELCO is interested in renewable energy which could supply power on demand at anytime. To be considered as dispatchable, a wave energy plant would need to be backed up by another system such as pumped storage $^{39}$, or a diesel plant. HELCO is also concerned about the reliability of wave energy systems. The utilities require further proof and demonstration in order to be convinced that wave energy converters can resist the tough ocean environment, and that the plants are reliable in the long term. Finally, the avoided cost is the price at which any independent power producer is paid under the PURPA ${ }^{40}$, however HELCO claims it would be interested in being offered a fixed price contract with a price below the avoided cost, and decoupling of the contract price from the oil price.

The potential requirements of the utilities regarding the implementation of a wave energy project, as understandable as they may be, are highly demanding: high reliability, dispatchability, and a low, fixed price. At this stage, such requirements would be difficult to meet, given the novelty of wave energy technologies. In addition, there is confusion with regards to the provision of backup for renewables. To our

\footnotetext{
${ }^{39}$ However, storage reservoirs are difficult to maintain due to the geology of the islands, as they consist of porous volcanic rock. In addition, there are a number of environmental and permitting issues associated with pumped storage in Hawaii, mostly because of the recent failure of a dam in Big Island in which people were killed.

${ }^{40}$ The avoided cost changes monthly. In august 2006, Curtis Beck reported that the avoided cost was between 15 and 16 cents per kWh in Big Island, and that the lowest avoided cost in the last five years was around 8 cents per $\mathrm{kWh}$.
} 
knowledge, there is no statement in PURPA or the RPS which clearly assigns responsibility for backing up renewable energy: should it be ensured by independent producers or the utilities?

Enabling "wheeling" would allow wave energy companies to sell electricity directly to businesses or other facilities. Under a wheeling arrangement, electricity would be transmitted from a wave power plant to a facility via the utility's transmission grid. The utility would be compensated for its transmission costs, such as operation and maintenance of the transmission system. However, wheeling is not currently legal in Hawaii, and local utilities are opposed to it, regarding wheeling as a "competition issue". Unless the PUC mandates wheeling, wave energy producers will have to sell their power directly to the utilities.

Two major studies have been undertaken on wave energy resource in Hawaii. A 1992 study concluded that the annual wave energy resource off the northern shores of Hawaiian Islands far exceeds the electricity demand in the islands of Kauai, Maui, and Hawaii (Hagerman, 1992, p.5-1). In 2004, another report concluded that "the available annual wave energy resource off the northern shores of the Hawaii Islands far exceeds the electricity demand of each of the islands, with the exception of Oahu that has a large population and electricity demand and an available wave resource that is approximately equal to the electricity demand" (Previsic et al., 2005b).

There has already been a demonstration project with wave energy in Hawaii. This project, initiated by the US Navy, enabled Ocean Power Technologies to deploy its PowerBuoy wave generation system at the Marine Corps Base on Oahu in June 2004 and October 2005. The $20 \mathrm{~kW}$ project is still at a demonstration phase, and locals have reported that the buoy was redesigned a few times due to technical problems. No delivery of power from this unit has yet taken place. Nevertheless, the military base location of this project has provided a unique opportunity for a rapid permitting process and positive state cooperation.

In 2005, a report was produced for the Electric Power Research Institute, describing the results of a system level design, performance and cost study for a feasibility demonstration pilot Pelamis wave power plant and a commercial size Pelamis plant 
installed in Hawaii (Previsic et al., 2005b). The study reported that the Makai Research Pier on the eastern coastline of Oahu offers an opportunity for wave power due to existing physical infrastructure and scientific resources. It provides a cost analysis of installing 180 Pelamis converters of $500 \mathrm{~kW}$ each on Oahu, with a total rated capacity of 90MW, which would provide 300,000 MWh per year. For this plant, Previsic et al estimate a total investment of about US\$243 million (in 2004 US\$). The study provides a cost analysis to determine the levelized cost of electricity for the installation and operation of the wave farm under four different scenarios. These scenarios and corresponding estimates of the study are displayed in table 4.3 below:

Table 4.3: Cost of Electricity Generated by a Wave Farm ${ }^{41}$

\begin{tabular}{|l|l|l|}
\hline & $\begin{array}{l}\text { Installation and } \\
\text { operation by a regulated } \\
\text { utility }\end{array}$ & $\begin{array}{l}\text { Installation and } \\
\text { operation by an } \\
\text { Independent Power } \\
\text { Producer (IPP) }\end{array}$ \\
\hline $\begin{array}{l}\text { With Federal Production } \\
\text { Tax Credit }\end{array}$ & 10.37 cents per kWh & $\begin{array}{l}\text { Internal rate of return (post } \\
\text { tax) of 9.6\% }\end{array}$ \\
\hline $\begin{array}{l}\text { Without Federal } \\
\text { Production Tax Credit }\end{array}$ & 11.33 cents per kWh & No internal rate of return \\
\hline
\end{tabular}

The federal production tax credit used in this study equals 18 cents per $\mathrm{kWh}$ for the first ten years of the operation of the wave farm. Note that all scenarios assume a federal investment tax credit of 10 percent for the first year of investments. The estimates for the IPP assume an avoided cost of electricity of about 8 cents per $\mathrm{kWh}$. However, the avoided cost of electricity rose up to 13 cents per kWh in 2006. This suggests that the internal rate of return for such a project may now be positive for IPPs even in the absence of the federal production tax credit.

\section{5) Using Insights from the Case-Study of Hawaii to Develop a Mathematical} Model for the Integration of Renewables into Pacific Islands Electricity Systems

The case study outlined in the previous section shows that even in the presence of regulation to promote renewable energy generation and independent power production, there remain issues related to market power in Hawaii. However,

\footnotetext{
${ }^{41}$ Source: Previsic, M. et al. (2005). "System level design, Performance and Costs - Hawaii State Offshore Wave Power Plant".
} 
electricity market structures are not the same in all Pacific Islands: as seen in chapter 2 , electricity is supplied by the governments themselves in the majority of Pacific Islands.

The underlying aim of developing the model which is presented in chapter 5 is not to explain competition issues in Pacific Islands' electricity markets, nor to recommend solutions to such issues. The goal is to develop a model for the integration of renewables into electricity systems, using concepts and ideas which are relevant to energy policy-making in Pacific Islands. The competition issues and barriers to renewable energy development lie outside the structure of the model, yet they are not to be overlooked when studying the integration of renewable energy technologies into existing electricity systems. Chapter 6 provides further discussion of the obstacles to renewable energy development in Pacific Island Countries, as well as policies to overcome these barriers.

Compiling data and information from chapter 2 with the more specific case study presented in the previous section, has led to the identification of three key issues which are of particular significance to electricity supply in Pacific Island Countries, and which are central to the model presented in chapter 5:

- Increasing the share of renewable energy: all Pacific Islands are highly dependent on imported fossil fuels and have all at least expressed interest in augmenting the share of renewable energy for electricity generation. At least some of the benefits of renewables are external to current market prices and accounted for by means of a shadow price in the model.

- Price of electricity supply: all Pacific Island Countries incur high costs of electricity supply. While the costs of importing fossil fuels are high, the great majority of electric utilities are using fuel-based technologies, implying that the capacity cost of plants is of great importance to suppliers. The model will need to account for both types of costs.

- Reliability: Reliability of supply is one of the biggest concerns to electric utilities worldwide, particularly in Pacific Islands (as confirmed during 
interviews at HECO and HELCO in Hawaii). This is because isolation and remoteness imply that the countries cannot rely on interconnection with other electric grids. In addition, small electric systems have less ability to deal with intermittency than large systems do, so that increasing the share of renewable electricity generation would require extra backup capacity. The model will need to account for reliability, and provide a measure of backup for renewables.

The next chapter provides a detailed description of the model for integrating renewables into Pacific Islands' electricity systems, and presents the key results obtained from the model. 


\section{Chapter Five: A Model for the Integration of Renewable Energy into an Existing Electricity Network}

\section{1) Context and Objective}

Electricity supply involves choices about numerous characteristics. These characteristics or features may be thought of as entering into a social welfare function. In the model presented in this chapter, this social welfare function is represented by a "social planner".

The characteristics of electricity supply may be divided in three broad groups. The first set of features relates to the physical characteristics of the product that reaches consumers. These physical characteristics include voltage, frequency and the compliance of these with quality and frequency standards; and also reliability: what is the probability, and frequency of occurrence, of unplanned outages or failures? All else equal, the social welfare function is maximised when consumers are supplied with a continuous, uninterrupted supply of perfectly-calibrated electricity. In reality, a minimum number of system outages and voltage fluctuations are unavoidable. However, an important physical feature of electricity supply relates to the extent to which supply outages can be planned or foreseen.

The second set of electricity supply features relates to the market characteristics of the product reaching consumers, such as the price, the tariff structure (is the tariff fixed or variable? What is the range of options available? Is there net-metering to credit customer-premises generation? Is there any option and special rate for "green electricity"?), and the availability and quality of supporting services (appliances repair, faults service, information services).

The third set of features relates to the techniques or set of techniques available and chosen to produce and distribute electricity: what are the relative costs of the different technologies available? What are the shares of different technologies, and what are 
the complementarities between these technologies? In particular, what is the share of renewable energy technologies compared to non-renewable energy technologies? How do variations in input prices affect the share of each technology in electricity generation? What are the emission profiles of the different technologies, relative to policy objectives regarding pollution and carbon emissions? How much exposure to uncertainty and volatility is incurred (with respect to oil price fluctuations, and intermittency of renewable energy)? Is there a possibility for interconnection to electricity supply networks in other jurisdictions?

Electricity supply is a multi-dimensional problem, involving multiple tradeoffs and complementarities. As for most products, there exists a trade-off between the price and quality of electricity. The demand for high-quality supply is higher in affluent communities with greater dependence on electricity usage and higher expectations of quality of life. In poor communities with lower aspirations and less equipment, cost considerations may outweigh quality: in poor rural communities, the intermittency of wind and solar supply may be more than compensated for by their low operating costs, especially if the capital costs are picked up by some outside aid agency (as discussed in chapter 2, this has been the case in several outer islands in the Pacific). This particular trade-off is illustrated in Figure 5.1, which displays hypothetical indifference curves and budget constraints between electricity quality (in terms of intermittency) and other goods in New Zealand and rural Papua New Guinea. Figure 5.2 displays hypothetical willingness-to-pay frontiers relating acceptable price to intermittency in New Zealand and rural Papua New Guinea. In this diagram, 100 percent intermittency means non-supply, and zero intermittency is absolutely continuous supply. Each frontier represents the maximum price each market can bear, and the corresponding quality of electricity supplied. 
Figure 5.1: Indifference Curves and Budget Constraints for Electricity Quality New Zealand and Rural Papua New Guinea (PNG)

Other goods

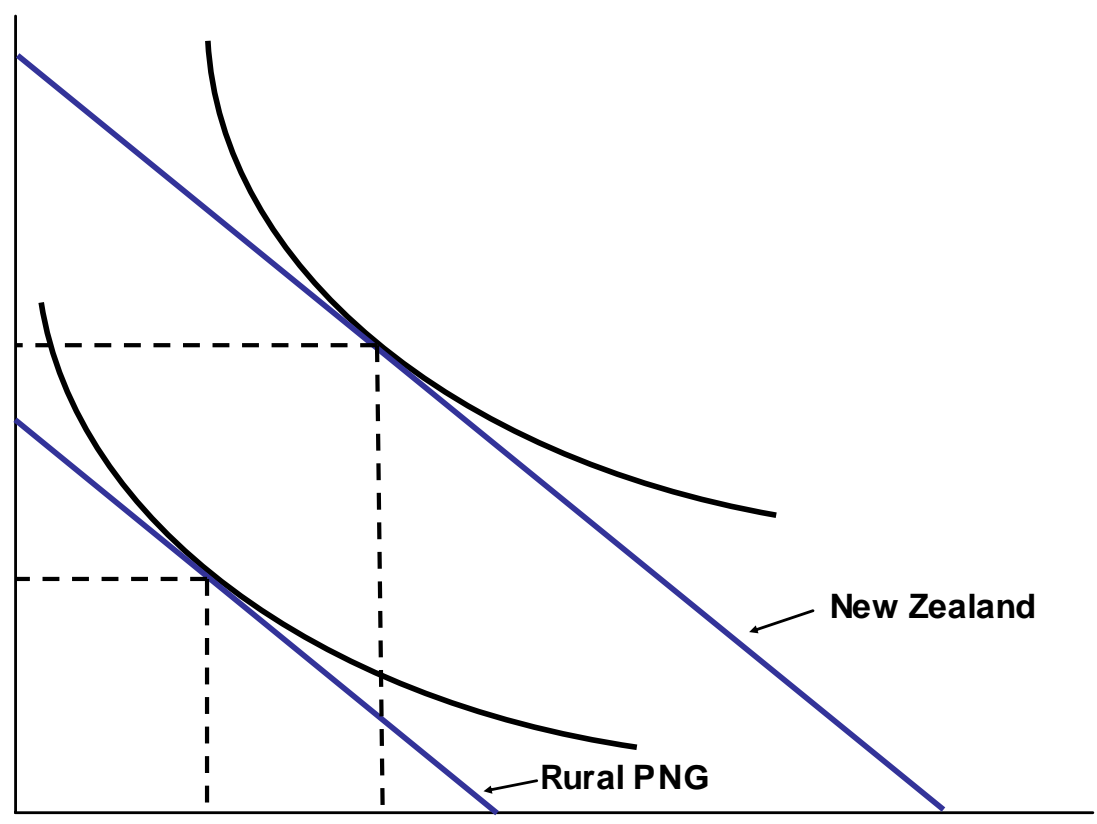

Electricity quality

Figure 5.2: Trade-off between Price and Intermittency of Electricity

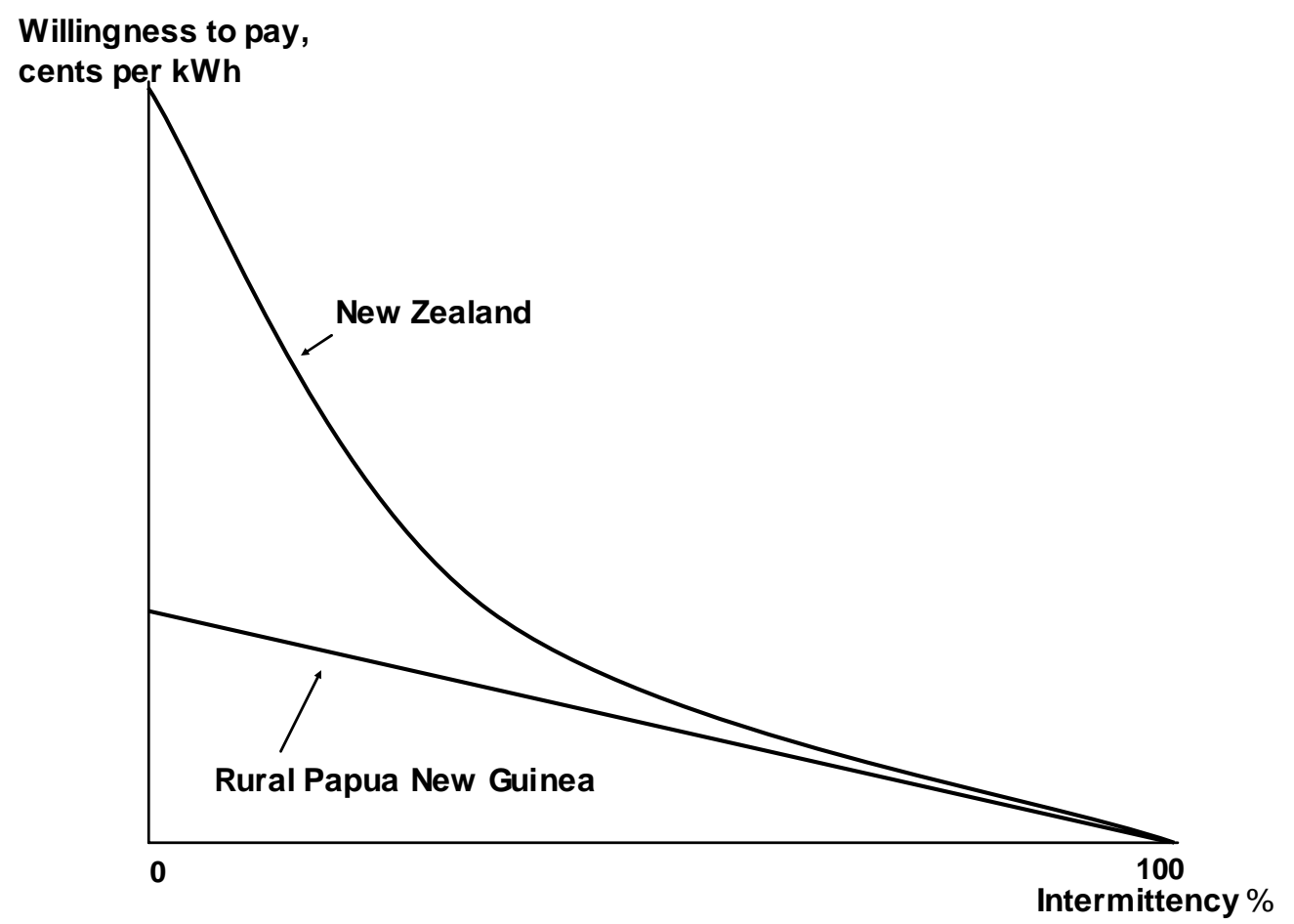


Another trade-off in electricity supply exists between the cost and price volatility of a portfolio of electricity generation. As discussed in chapter 3, a diverse portfolio of resources used for electricity generation can make more sense than complete specialisation, even if one technology currently dominates the others in terms of cost. Portfolio diversification spreads risks, and hedges against future price changes that might lead to a re-ranking of the merit order of technologies. This is especially important in the electricity industry, where there is substantial investment inertia (it takes years to build a generation plant, and once built, a generation plant lasts for decades).

In standard simple theory, multiple competing technologies exist separate from each other and each has its own supply chain that reaches through to the customer. Thus competition is head-to head on final price and quality, and any technology that cannot pay its way does not enter the markets. In electricity, however, the prevalence of transmission and distribution networks means that the quality and price dimensions of the product reaching the final consumer are often dictated by intermediaries, so that generators are able to offer a range of quality/price pairs into a common pool, from which the standardised final product is withdrawn.

Consider, therefore, the situation for a renewable energy generator which has "high quality" in terms of its emission profile (little or no emissions) but low quality in terms of reliability or intermittency. For the social planner, this package of low reliability/high renewability will be at a point such as A on an indifference curve, with a fossil-fuel, high-reliability plant at point B: 


\section{Figure 5.3: Trade-off between 'Renewability' and Reliability of Electricity}

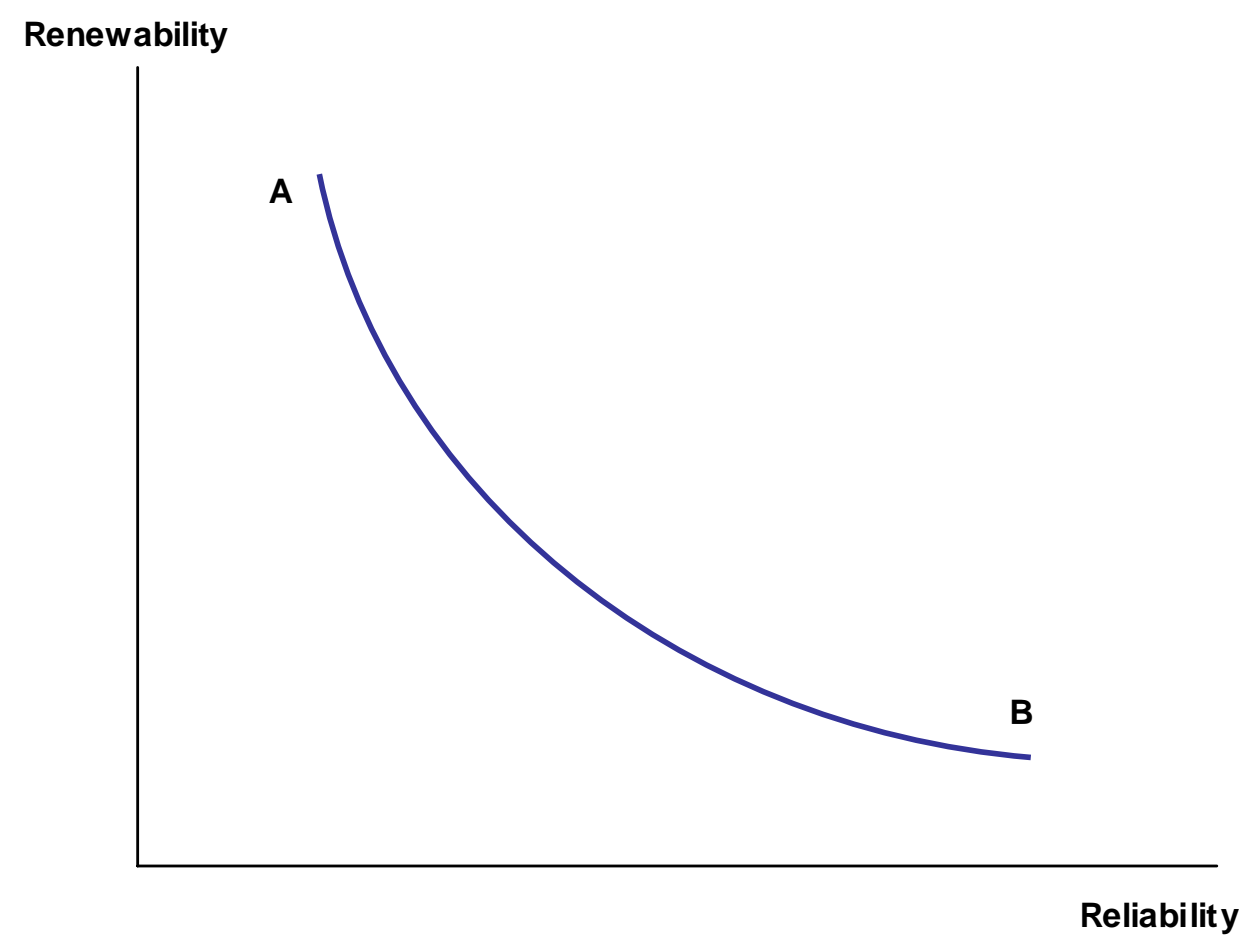

The tradeoffs depicted in figures 5.2 and 5.3 represent four of the dimensions or characteristics of electricity supply that a social planner would consider carefully: the overall cost of electricity supply, diversity of the portfolio of electricity generation, the share of non-polluting or renewable technologies, and the reliability of supply (in terms of continuity and quality).

Now consider the traditional choices made by private operators, with respect to the third set of characteristics (the techniques). In the private sector, renewable energy technologies are chosen if and only if the prices are advantageous. For example, high oil prices and low capital cost of renewable equipment would drive private investment towards renewables. Figure 5.4 below represents the classic choice-of-technique setup with two technologies: 
Figure 5.4: Choice of Technique with Two Technologies

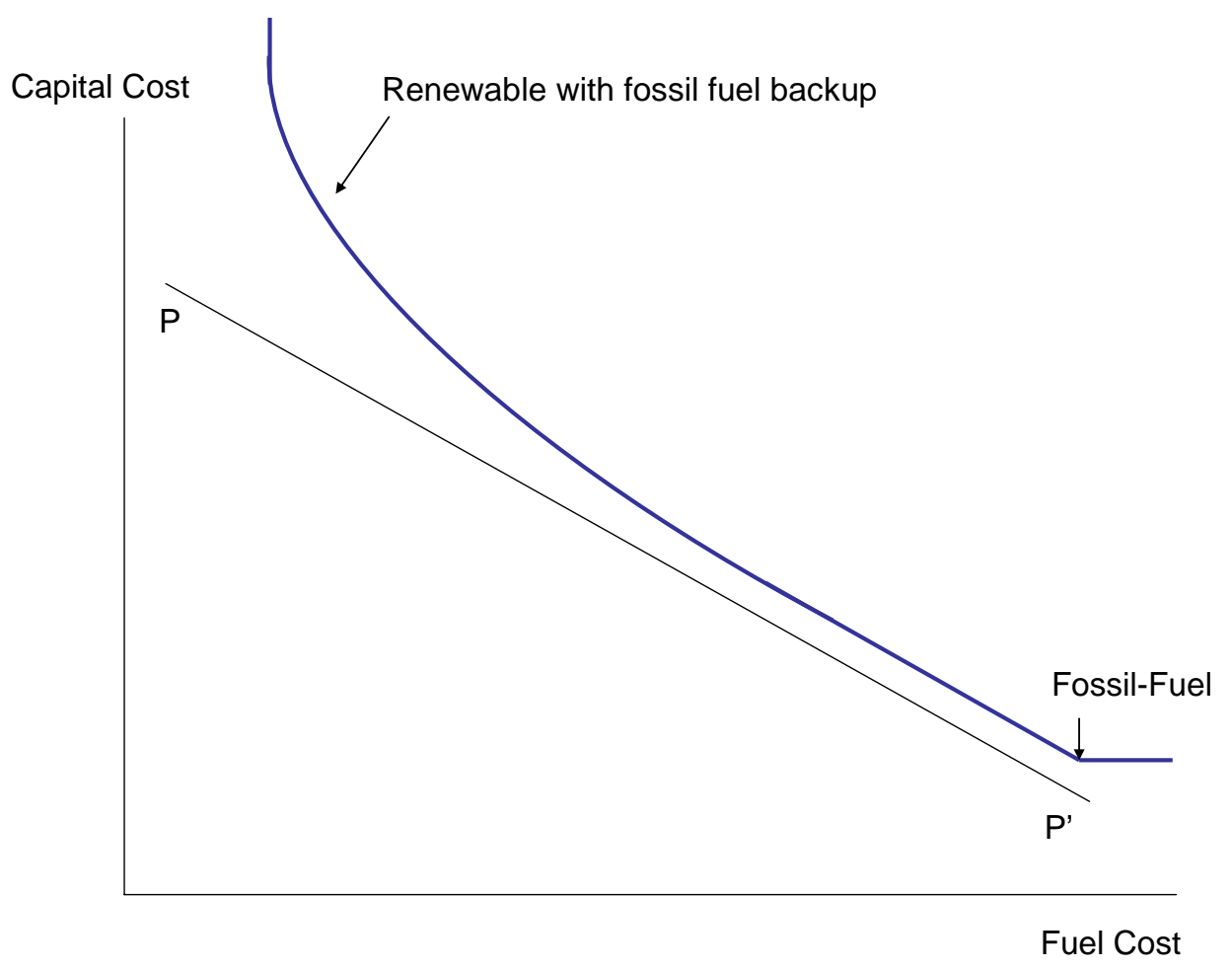

In the diagram above, the slope of PP' is the price ratio at which private investors would change their choice of technology, other things being equal. The top line represents the isoquant for the technologies. Technology-switching occurs as technology prices change. Thus, a flattening of the exogenously-set price ratio PP' would induce a complete switch to the fossil fuel technology. However, a steepening of the price ratio would only lead to a partial switch towards the renewable technology, because of the need to retain backup capacity in order to maintain reliability (at the current technology cost, fossil fuel technologies would likely be used to backup renewables, which means that some fuel costs are still involved).

The historic lack of private investment in renewables reflects their high capital cost to date, combined with the need to have backup capacity in hand. In addition, inertia and path dependence have contributed to the lack of private investment in renewable technologies. If the capital for both the renewable and fossil fuel technologies was already installed, price changes would only affect the decision of which plant to operate, and price-responsiveness would be straightforward. If there was no capital installed for either technology, then a fully-specialised investment decision would be 
optimal only in the absence of uncertainty about price trends. With uncertainty, the familiar risk-spreading benefits of a diversified portfolio would be relevant. However, in reality there is already a somewhat specialised capital stock installed from past decisions. While the installed capital is reflective of past history, and technical progress is changing the set of options available, the two key issues in investment decisions are relative prices, and the utilisation of existing assets (including human capital, control technology, management systems, and installed transmission and distribution network infrastructure).

Private electric utilities have traditionally based their investment decisions primarily on technology capital costs and path dependence, leading to a predominance of fuelbased technologies for electricity production. However, there is likely to be a divergence between these private decisions and the decisions made by a social planner, meaning that there might be a social case for more renewables than the market is delivering.

The application of mean-variance portfolio analysis to electricity generation provides an analytical methodology to highlight areas of possible market failure, as well as the direction in which market-led investment is likely to move in the future, to the extent that the benefits of portfolio diversification may be captured by private-sector operators. Yet, as noted above, planning electricity supply is a process involving multiple dimensions, not all of which are captured by portfolio analysis. The cost and risk of a portfolio of electricity generation represent only two of these dimensions. From a social planner's perspective, reliability of supply and the share of polluting technologies are also important. In addition, even for a social planner, path dependence is almost unavoidable and needs to be accounted for-decommissioning existing plants is very costly ${ }^{42}$.

This chapter introduces a model for the integration of renewable energy technologies into existing electricity systems of the Pacific Islands, built using concepts from portfolio analysis and integrated resource planning. This model includes different technologies (renewable and non-renewable), a measure of financial risk for a given

\footnotetext{
${ }^{42}$ Note that path dependence has been accounted for in some portfolio analysis studies (see chapter 3 ).
} 
electricity generating mix, and it provides an optimization process leading to a choice of optimal electricity generating mix. Set as an intertemporal optimization problem, the model presented in this chapter builds on concepts from integrated resource planning by looking at different options to meet future electricity demand. In order to be applicable to Pacific Island Countries, the model ought to emphasize the aspect of maintaining reliability of electricity supply. Accounting for reliability of supply is important in Pacific Island Countries as their isolation prevents any connection to continental grids. With no grid backup available, reliability comes at a high price for these countries compared to large integrated continental systems or mainlandconnected islands such as Prince Edward Island (Stuart 2006). The potential tradeoff between reliability and other characteristics such as lower cost is thus more important in Pacific Islands.

Investment planning for electricity generation has been studied for decades, and numerous optimization models have been developed for resource and equipment planning, fuel planning, demand-side management, fuel, maintenance and production scheduling, and dispatching ${ }^{43}$. Integrated models can also be used to perform and analyse a large number of functions together (e.g. demand-side management as well as reliability and production costing...), although such models have been criticised for simplifying some of the representative functions (c.f. Hobbs, 1995). However, the model presented in the following sections has not been built using any of these existing models; it has been built using insights and objectives which arose from the observation of electric utility issues in Pacific Island Countries. The following diagram (Figure 5.5) frames the conceptual issue which we are seeking to capture. The smooth upward-sloping curves, which we here call "iso-reliability curves", each represent a trade-off between the share of renewables and the cost of electricity supply for a fixed level of reliability. For a given level of reliability, an increase in the share of renewables output to total output leads to an increase in the cost of electricity supply, both because of the higher cost of renewable energy technologies themselves and because of rising costs of securing backup to maintain the target level of reliability. For any given technology mix, an increase in the level of reliability induces a higher cost of supply. At the current technology costs, achievement of 100

\footnotetext{
${ }^{43}$ See Hobbs (1995) for a detailed review of optimization models for electricity resource planning, and Anderson (1972).
} 
percent reliability (that is, no power cut or blackout at all during the year) requires more generators to be added to the system as backup as the proportion of renewables increases, which will be costly. However, up to some point it will be possible to use existing fossil-fired capacity for backup purposes - hence the relatively flat left-hand end of the iso-reliability curves..

Figure 5.5: Framework for the Integration of Renewables into an Existing Electricity System

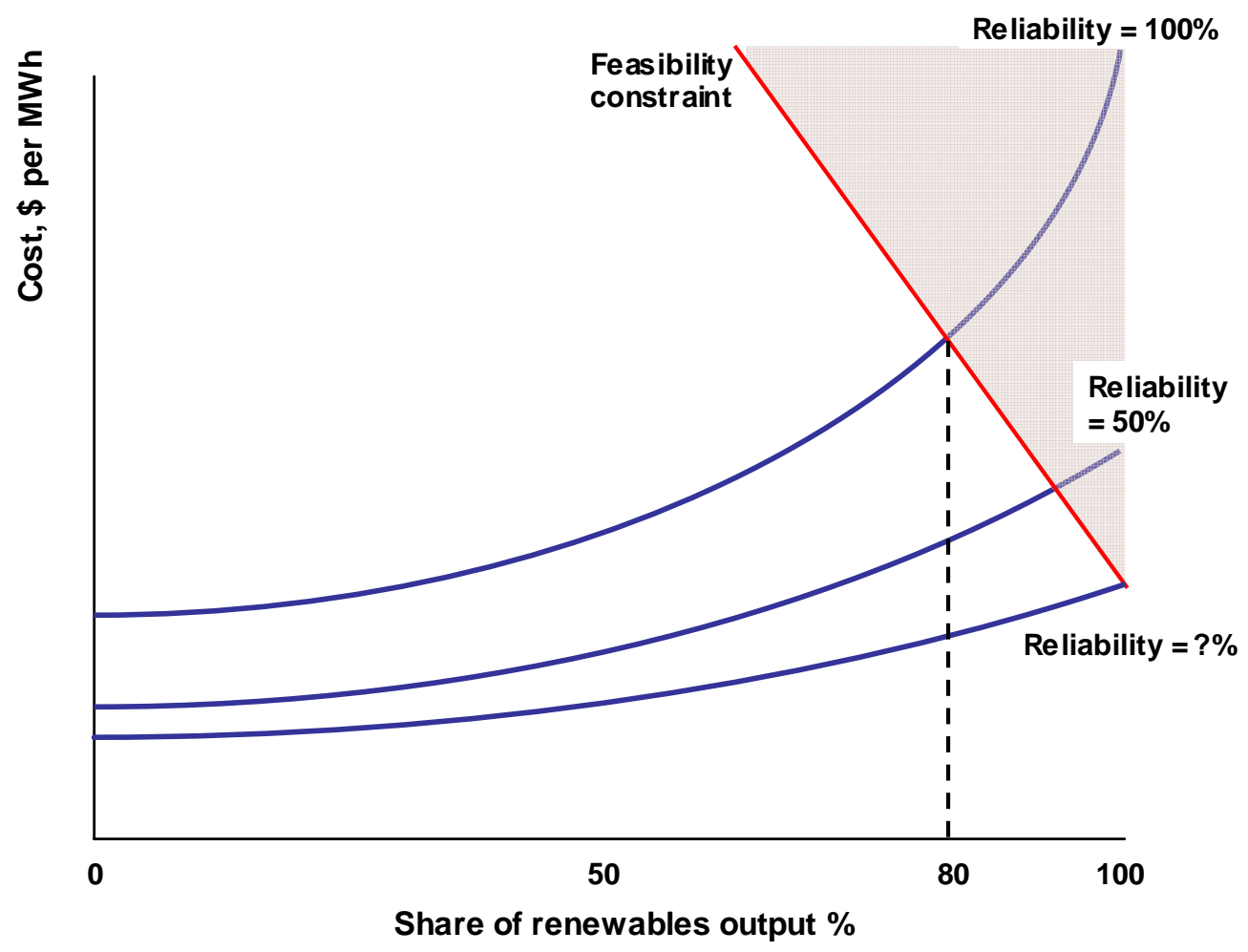

The downward-sloping line on the right-hand corner represents the country's feasibility constraint in terms of availability of resources; points above the feasibility constraint (in the shaded area) are unfeasible. In this hypothetical case, for example, the country does not have sufficient resources to sustain 100 percent reliability with more than 80 percent of renewables. That is, there are not enough resources to allow backing up renewables exclusively with other renewables; there needs to be at least 20 percent of non-renewables in order to maintain full reliability. There are enough resources to supply all electricity from renewables, but the lights would be off more than 50 percent of the time. 
Intuitively, if we were to draw the same diagram for a European country and compare it to that of a small Pacific Island Country, the iso-reliability curves would be flatter and lower for the European country (a lower cost of electricity supply than in the Pacific Island Country for any given level of reliability), given the larger size of the system (enabling substantial economies of scale) and the ability to connect to a continental grid. The price of fuel in Pacific Islands being much higher than in European countries, the left-hand end of the iso-reliability curves will be higher for the Pacific Island country than for the European country. On the other hand, the feasibility constraint for the Pacific Island Country would likely be above for the constraint of the European Country. Indeed, the Pacific Island country is likely to have plenty of renewable resources available (waves, wind, sun, hydro, bagasse) and could easily sustain, say, an 80 percent share of renewables. The large European country, however, does not necessarily benefit from enough resources to provide as much as 80 percent renewable energy for its 70 million consumers. While nonrenewable technologies can be turned on and off depending on the level of demand, a renewable backstop consisting entirely of renewables would require a diverse range of resources to maintain reliability, so that if there is no wind at peak demand times another resource such as wave or solar power is used to ensure electricity supply. Hence there is likely to be a strong relationship between the availability and variety of renewable energy resources, the level of electricity consumption, and the potential level of integration of renewable energy capacity into the electric system. The feasibility constraint is located further left in countries which have few renewable energy resources, and a large population size and electricity consumption. At the outer extreme, an island with a population size below 200 people may have no constraints on the amount of renewable energy which can be installed to provide electricity to the whole population, in which case the integration of renewable energy will solely depend on the cost and willingness to pay to maintain reliability.

On the other hand, European countries may be able to sustain a large amount of renewable energy generation given their access to the relatively cheap and almost unlimited backup resources of neighbour countries. Figure 5.6 illustrates the hypothetical case of a country which can connect to another country's grid. 


\section{Figure 5.6: Integrating Renewables with Unlimited Backup Resources}

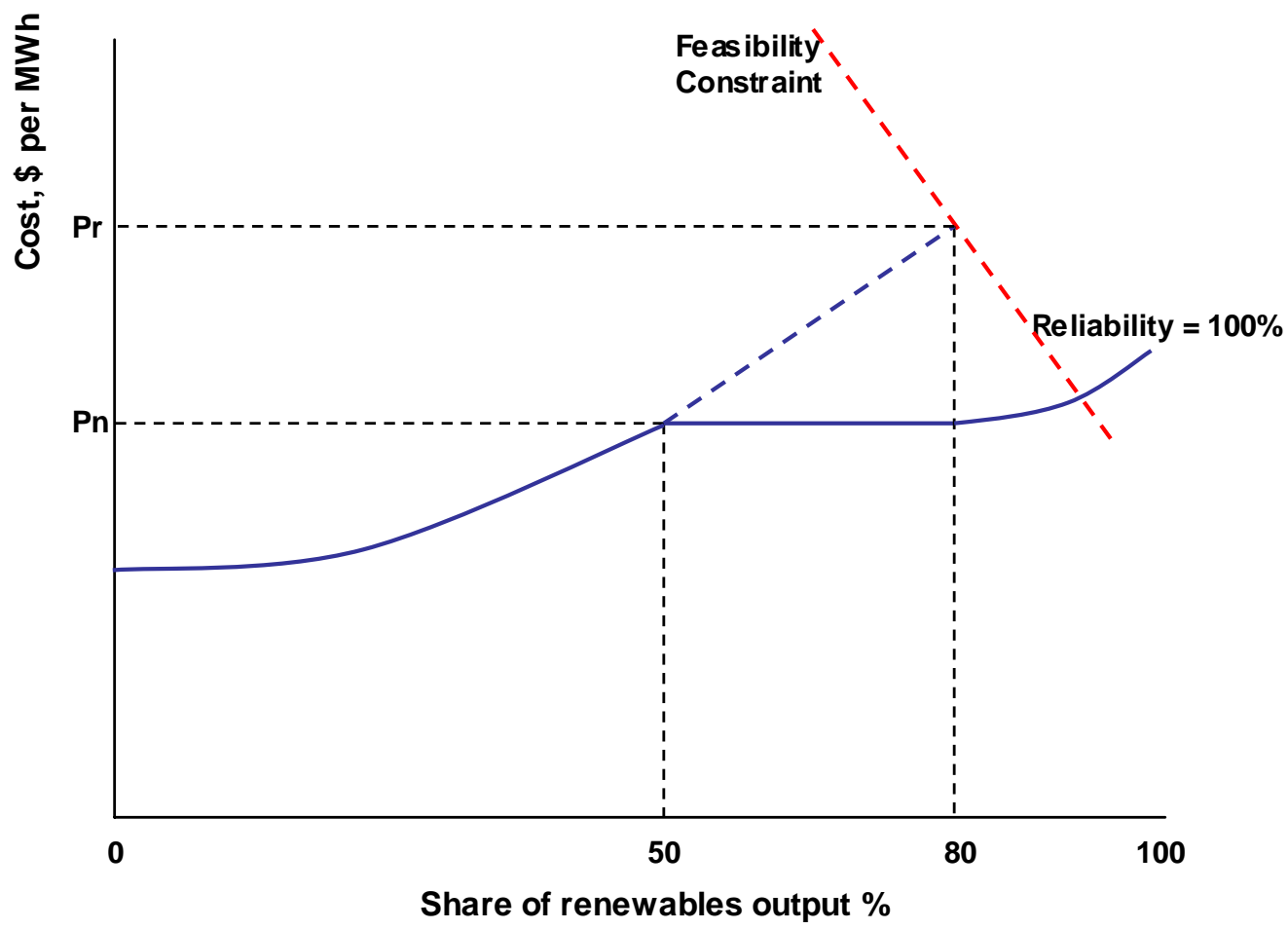

In the diagram above, in this hypothetical case, the country can benefit from a connection to the grid of its neighbouring countries because the connection enables more and cheaper options for backing up renewable electricity generation. The isoreliability curve is drawn so that increasing the share of renewable output leads to a higher cost of producing electricity for a given level of reliability. The diagram shows that this country has enough renewable resources to generate up to 80 percent of its power supply using only renewable resources, at price Pr. However, in this case the country can increase the share of renewable output beyond 50 percent without incurring increases in the cost of supply by importing cheap backup supply from its neighbouring countries, at price $\mathrm{Pn}$. In addition, if the neighbouring countries also generate renewable output using different resources, it may be possible to import renewable electricity as a backup for the country's renewable output, meaning that the country could use solely (100 percent) renewable energy for its power supply. The price associated with generating power using 80 percent to 100 percent of neighbouring countries' resources is higher than $\mathrm{Pn}$, as maintaining 100 percent reliability requires extremely abundant and varied renewable resources. 
In figure 5.5, the iso-reliability curves were given a positive slope to reflect the current situation with existing technologies and their costs. However, in the future these curves may eventually become downward-sloping as in figure 5.7 below, as the price of fuel rises and renewable energy technology costs decrease. If technological progress were made on renewable energy storage or other means of backing up renewable energy generation, the iso-reliability curves would also become flatter, as illustrated in the diagram below (backing up renewables using renewables would become cheaper and easier).

Figure 5.7: Possible Future Shape of Iso-Reliability Curves

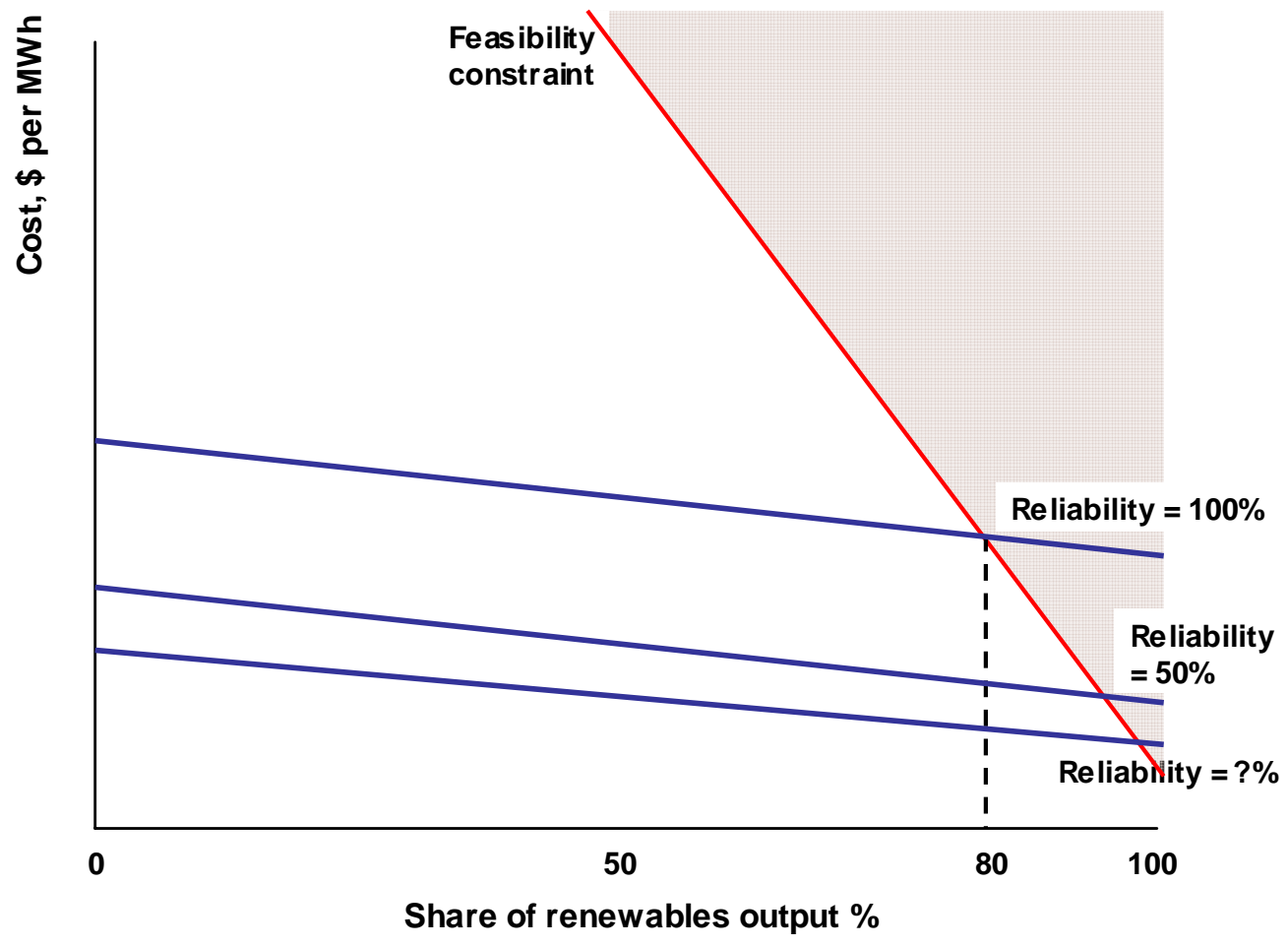




\section{2) The Model}

This section presents the intertemporal optimization problem of an energy planner in discrete time. The model focuses on selecting an optimal amount of investment in renewable $(r)$ and non-renewable $(n)$ generating capacity in each period over a fixed horizon $\mathrm{T}$, given a specified demand growth rate and a renewable portfolio standard. We assume that there are two types of large-scale renewable energy technologies, subscripted $a$ and $b$.

\section{Social Surplus}

The energy planner seeks to maximize present-valued social surplus J:

$$
J=\sum_{t=0}^{T-1} \frac{1}{(1-\rho)^{t}}\left[\frac{-\bar{\pi}_{t}}{2}\left(1-\frac{q_{t}}{\bar{q}_{t}}\right)^{2}+\bar{\omega}_{t} \frac{c_{t}}{\bar{y}_{t}}-\bar{\phi}_{t} \frac{q_{n t}}{\bar{q}_{t}}\right]
$$

defined as the sum of three components:

1) The cost of deviating from projected electricity demand $\left[\frac{-\bar{\pi}_{t}}{2}\left(1-\frac{q_{t}}{\bar{q}_{t}}\right)^{2}\right]$, captured by a penalty weight $\bar{\pi}_{t}$ for not supplying enough electricity to meet the projected quantity demanded $\bar{q}_{t}$ in period $t$. If the quantity of electricity actually supplied corresponds to quantity demanded at time $t, q_{t}=\bar{q}_{t}$ and no penalty is incurred. This ensures that the policymaker has an incentive to minimize deviation from quantity demanded by ensuring adequate electricity supply in each period, insofar as it is costeffective to do so. The quadratic specification of the deviation from projected electricity demand means that the penalty rises exponentially as the deviation increases.

2) The second part of social surplus $\left(\bar{\omega}_{t} \frac{c_{t}}{\bar{y}_{t}}\right)$ places a positive value on "consumption" $\left(c_{t}\right)$, defined as all expenditure on non-electricity goods and services. The positive sign implies that the policymaker wants to maximise the amount of resources available for purposes other than electricity production, which implies minimizing the cost of producing electricity. 
3) Finally, an environmental cost $\left(\bar{\phi}_{t} \frac{q_{n t}}{\bar{q}_{t}}\right)$ is associated with non-renewable electricity production. This represents the shadow price, or penalty on non-renewables, of the energy planner.

The planner faces a macroeconomic budget constraint:

$\bar{y}_{t}=c_{t}+p_{u} u_{t}+p_{n} i_{n t}+p_{a} i_{a t}+p_{b} i_{b t}$

in which expenses for electricity production (fuel $u_{t}$ and capital investment for renewable and non-renewable energy plants $i_{a t}, i_{b t}$, and $i_{n t}$ ) are treated as diverting scarce resources from other uses $\left(c_{t}\right)$.The variables $u_{t}, i_{a t}, i_{b t}$ and $i_{n t}$ represent fuel input for the non renewable plants, capacity investment in the two renewable technologies " $a$ " and " $b$ ", and non renewable capacity investment, respectively. The parameters $p_{u}, p_{n}, p_{a}$ and $p_{b}$ represent the coefficients associated with the cost of fuel input for the non renewable plant, the cost of capacity investment for the nonrenewable plant, and the cost of capacity investment for the renewable plants respectively. The budget constraint implies that every dollar which is used for electricity production or capacity investment is withdrawn from other purposes $\left(c_{t}\right)$.

The problem can thus be written as:

Max. $J=\sum_{t=0}^{T-1} \frac{1}{(1-\rho)^{t}}\left[\frac{-\bar{\pi}_{t}}{2}\left(1-\frac{q_{t}}{\bar{q}_{t}}\right)^{2}+\bar{\omega}_{t} \frac{c_{t}}{\bar{y}_{t}}-\bar{\phi}_{t} \frac{q_{n t}}{\bar{q}_{t}}\right]$

(Objective function)

s.t. $\bar{y}_{t}=c_{t}+p_{u} u_{t}+p_{n} i_{n t}+p_{a} i_{a t}+p_{b} i_{b t}$

(Budget constraint)

$$
q_{t}=q_{n t}+q_{a t}+q_{b t}
$$

Total energy output $q_{t}$ is the sum of renewable output $\left(q_{a t}+q_{b t}\right)$, and non-renewable output $q_{n t} . \rho$ is the social discount rate. 


\section{Electricity Production}

The electricity production process is designed as follows: renewable electricity generation using renewable energy technology $a$ depends on the amount of available capacity $k_{a t}$ and the factor productivity parameter $A_{a}$ for the type of renewable energy resource used. The capacity factor of a plant $z$ is defined as the amount of electricity produced over a period of time divided by the amount of electricity it could have produced if it had run at full capacity over that time period. Assume a Leontief process for renewable energy production, with $\alpha$ being the fixed coefficient on labour input $l$ :

$q_{a t}=A_{a} \min \cdot\left\{z_{a} k_{a t}, \frac{l_{t}}{\alpha}\right\} \quad q_{b t}=A_{b} \min \cdot\left\{z_{b} k_{b t}, \frac{l_{t}}{\alpha}\right\}$

Efficiency in production requires

$$
z_{a} k_{a t}=\frac{l_{t}}{\alpha} \Rightarrow l_{t}=\alpha z_{a} k_{a t} \quad z_{b} k_{b t}=\frac{l_{t}}{\alpha} \Rightarrow l_{t}=\alpha z_{b} k_{b t}
$$

so that

$q_{a t}=A_{a} z_{a} k_{a t} \quad q_{b t}=A_{b} z_{b} k_{b t}$

Non-renewable electricity production depends on fuel input $u$, in addition to the amount of installed capacity available. This available capacity is made up of two categories: capacity which is earmarked to back-up renewable generating capacity, which is operated only when renewable generators are down; and capacity entirely dedicated to stand-alone non-renewable generation, which can be operated without restriction at any time. The amount of non renewable capacity set aside as a backup to the intermittent, renewable plant is determined by fixed coefficients $\theta_{a}, \theta_{b}$, proportional to the amount of capacity installed in each of the renewable technologies. The $\theta$ parameters are set to maintain a fixed level of reliability of supply for the system. As explained in the previous section, the electricity systems of Pacific Island Countries are typically very small and have important requirements with regards to reliability. On the other hand, maintaining reliability may not be such a significant issue for an island in which power is only supplied less than twelve hours a day, such 
as in Tokelau. The model is flexible in the sense that it allows us to specify the amount of backup required for each unit of renewable capacity. As the range of renewables used for electricity production increases, the model can easily be modified to include an additional parameter to account for renewable backup using other renewables (e.g. backing up wind power using wave power or hydro).

The non-renewable capacity which serves as a backup for renewable resources is used solely when the renewable plants are not working $\left(1-z_{a}, 1-z_{b}\right)$; that is, backup capacity is turned on whenever there are not enough renewable resources to produce renewable electricity. Once again, we assume a Leontief process for non-renewable energy production, with $\beta$ being the fixed coefficient on fuel input $u_{t}$. Fuel input is used for non-renewable energy production $\left(u_{n t}\right)$ and also for backing up renewable plants using non-renewable capacity $\left(u_{r t}\right)$.

Non-renewable electricity production is thus specified as follows:

$$
\begin{aligned}
& q_{n t}=A_{n} \min .\left\{k_{n t}-\theta_{a} k_{a t}-\theta_{b} k_{b t}, \frac{u_{n t}}{\beta}\right\}+A_{n}\left[\left(1-z_{a}\right) \theta_{a} k_{a t}+\left(1-z_{b}\right) \theta_{b} k_{b t}, \frac{u_{r t}}{\beta}\right] \\
& k_{n t}-\theta_{a} k_{a t}-\theta_{b} k_{b t}+\left(1-z_{a}\right) \theta_{a} k_{a t}+\left(1-z_{b}\right) \theta_{b} k_{b t}=\frac{u_{t}}{\beta} \\
& u_{t}=u_{n t}+u_{r t} \\
& \Rightarrow u_{t}=\beta\left[k_{n t}-\theta_{a} k_{a t}-\theta_{b} k_{b t}+\left(1-z_{a}\right) \theta_{a} k_{a t}+\left(1-z_{b}\right) \theta_{b} k_{b t}\right] \\
& q_{n t}=A_{n}\left(k_{n t}-\theta_{a} k_{a t}-\theta_{b} k_{b t}\right)+A_{n}\left[\left(1-z_{a}\right) \theta_{a} k_{a t}+\left(1-z_{b}\right) \theta_{b} k_{b t}\right] \\
& =A_{n}\left(k_{n t}-z_{a} \theta_{a} k_{a t}-z_{b} \theta_{b} k_{b t}\right)
\end{aligned}
$$

\section{Capacity Accumulation}

Capacity accumulation for both renewable and non-renewable plants depends on the amount of investment in renewable and non renewable capacity, $i_{a t}, i_{b t}$ and $i_{n t}$, and the rate of capacity depreciation for each type of plant, $\delta_{a}, \delta_{b}$ and $\delta_{n}$. 


$$
\begin{aligned}
& k_{n t+1}=i_{n t}+\left(1-\delta_{n}\right) k_{n t} \\
& k_{a t+1}=i_{a t}+\left(1-\delta_{a}\right) k_{a t} \\
& k_{b t+1}=i_{b t}+\left(1-\delta_{b}\right) k_{b t}
\end{aligned}
$$

Hence the amount of capacity in period $t+1$ is equal to the amount of net investment in period $t$ plus the existing capacity in period $t$. This implies a rather simplistic assumption of rapid construction and installation of generation plants by means of investment. Realistically, the model should account for investment-installation delays according to each type of plant, which currently constitute a significant barrier to renewable energy implementation. This would involve imposing an upper bound on $i_{a t}, i_{b t}$ and $i_{n t}$. (Such a bound was not imposed for this study.)

Insofar as the government is implementing policies to "level the playing field" between renewables and non-renewables, part of $c_{t}$ in the model would be taken up by the cost of these policies.

\section{The Optimal Control Problem}

The optimal control problem can be summarised as follows:

Max. $J=\sum_{t=0}^{T-1} \frac{1}{(1-\rho)^{t}}\left[\frac{-\bar{\pi}_{t}}{2}\left(1-\frac{q_{t}}{\bar{q}_{t}}\right)^{2}+\bar{\omega}_{t} \frac{c_{t}}{\bar{y}_{t}}-\bar{\phi}_{t} \frac{q_{n t}}{\bar{q}_{t}}\right]$

s.t.

$\bar{y}_{t}=c_{t}+p_{u} u_{t}+p_{n} i_{n t}+p_{a} i_{a t}+p_{b} i_{b t}$

$q_{t}=q_{n t}+q_{a t}+q_{b t}$

$q_{a t}=A_{a} z_{a} k_{a t}$

$q_{b t}=A_{b} z_{b} k_{b t}$

$q_{n t}=A_{n}\left(k_{n t}-z_{a} \theta_{a} k_{a t}-z_{b} \theta_{b} k_{b t}\right)$

$u_{t}=\beta\left(k_{n t}-\theta_{a} k_{a t}-\theta_{b} k_{b t}+\left(1-z_{a}\right) \theta_{a} k_{a t}+\left(1-z_{b}\right) \theta_{b} k_{b t}\right)$

$k_{a t+1}=i_{a t}+\left(1-\delta_{a}\right) k_{a t}$

$k_{b t+1}=i_{b t}+\left(1-\delta_{b}\right) k_{b t}$

$k_{n t+1}=i_{n t}+\left(1-\delta_{n}\right) k_{n t}$

Given $k_{n 0}, k_{a 0}, k_{b 0}, k_{n T}, k_{a T}$ and $k_{b T}$ 
The initial capacities $k_{a 0}, k_{b 0}$ and $k_{n 0}$, are already known and taken as given. The terminal conditions, or final state capacities, $k_{a T}, k_{b T}$ and $k_{n T}$, must be specified. The terminal conditions can easily be computed using the pre-specified electricity demand path and target level of output at time $\mathrm{T}\left(\bar{q}_{T}\right)$, and the planner's two choice parameters $\bar{x}$ and $\bar{v}$, which determine the share of renewables to total output and the share of renewable $a$ to total renewable output in the terminal state respectively:

$$
\begin{aligned}
& \bar{v} \equiv \frac{A_{a} z_{a} k_{a T}}{A_{a} z_{a} k_{a T}+A_{b} z_{b} k_{b T}} \Rightarrow \bar{v}\left(A_{a} z_{a} k_{a T}+A_{b} z_{b} k_{b T}\right)=A_{a} z_{a} k_{a T} \\
& \bar{x} \equiv \frac{q_{r T}}{q_{T}} \Rightarrow \bar{x} \bar{q}_{T}=A_{a} z_{a} k_{a T}+A_{b} z_{b} k_{b T} \\
& \overline{v x} \bar{q}_{T}=A_{a} z_{a} k_{a T} \\
& \therefore k_{a T}=\frac{\bar{v} \bar{x} \bar{q}_{T}}{A_{a} z_{a}}, k_{b T}=\left(\frac{1-\bar{v}}{\bar{v}}\right)\left(\frac{A_{a} z_{a} k_{a T}}{A_{b} z_{b}}\right) \\
& \bar{q}_{T}=q_{r T}+q_{n T} \\
& \overline{\bar{q}_{T}}=A_{a} z_{a} k_{a T}+A_{b} z_{b} k_{b T}+A_{n}\left[k_{n T}-z_{a} \theta_{a} k_{a T}-z_{b} \theta_{b} k_{b T}\right] \\
& \therefore k_{n T}=\frac{\bar{q}_{T}-A_{a} z_{a} k_{a T}-A_{b} z_{b} k_{b T}}{A_{n}}-z_{a} \theta_{a} k_{a T}-z_{b} \theta_{b} k_{b T}
\end{aligned}
$$

Hence the final state capacities can be specified to match a renewable portfolio standard (which corresponds to $\bar{x}$ here), which constitutes a requirement to provide a certain amount of total generation from renewable energy plants (see chapter 6). The model can thus be applied to Hawaii, where a renewable portfolio standard has been enacted and requires 20 percent of renewable electricity generation by year 2020 (see chapter 5). The renewable portfolio composition parameter $\bar{v}$ is typically not specified by renewable energy policies, whether they are portfolio standards or feed- 
in tariffs, probably because it is difficult to do so and because future technological trends are hard to predict. A simulation can be done (with the initial arbitrary values) to determine the optimal $\bar{v}$, which can then be re-entered into the model to find optimal investment paths.

The set of equations displayed above, notably (15) and (16), constitute a Two-Point Boundary Value Problem, which can be solved using two different methods. Since the model is deterministic, it can be solved using the method of shooting, by choosing initial investment values. The other way to solve it, which is used here, is to use nonlinear programming. This method makes it computationally easier when introducing stochastics into the model, such as fuel price variability and variability of renewable energy resources.

The goal of the optimizing formulation is to maximize $J$ subject to investment in all plants being $\geq 0$ in every period, so that final capacity is sufficient to meet electricity demand and meets the renewable portfolio standard, and operating non-renewable capacity is $\geq 0$ in every period. The first-order conditions and Lagrangian for the optimization can be found in appendix $\mathrm{C}$.

The specification of this model closely resembles the Ramsey model of household optimization, in which households optimize their period-by period consumption and saving behaviour, subject to a budget constraint over some time horizon. 


\section{3) Results}

a) Scenario 1: Base Case Scenario for Oahu, Hawaii

The base case scenario values for Hawaii are summarised in the following table:

Table 5.1: Base Case Scenario Parameters and Values

\begin{tabular}{|c|c|c|c|}
\hline Parameter & Description of the Parameter & Value & Unit \\
\hline \multicolumn{4}{|c|}{ General Parameters } \\
\hline$\rho$ & Social discount rate & 5 & $\%$ per period \\
\hline $\bar{\pi}_{0}$ & $\begin{array}{l}\text { Initial penalty weight on energy } \\
\text { tracking }\end{array}$ & 1.00 & \\
\hline $\bar{\pi} g r$ & $\begin{array}{l}\text { Growth rate of the penalty } \\
\text { weight on energy tracking }\end{array}$ & 50 & $\%$ per period \\
\hline$\overline{\phi_{0}}$ & $\begin{array}{l}\text { Initial environmental penalty on } \\
\text { non-renewable output }\end{array}$ & 1.00 & \\
\hline $\bar{\phi} g r$ & $\begin{array}{l}\text { Growth rate of the } \\
\text { environmental penalty }\end{array}$ & 10 & $\%$ per period \\
\hline$\overline{\bar{\omega}_{0}}$ & $\begin{array}{l}\text { Initial priority weight on the } \\
\text { consumption to GDP ratio }\end{array}$ & 1.00 & \\
\hline $\bar{\omega} g r$ & $\begin{array}{l}\text { Growth rate of the priority } \\
\text { weight on consumption to GDP } \\
\text { ratio }\end{array}$ & 10 & $\%$ per period \\
\hline $\bar{q}_{0}$ & Initial production tracking target & $10,090,000$ & MWh \\
\hline $\bar{q} g r$ & $\begin{array}{l}\text { Growth rate of the production } \\
\text { tracking target }\end{array}$ & 1.124 & $\%$ per period \\
\hline $\bar{y}_{0}$ & $\begin{array}{l}\text { Initial macroeconomic } \\
\text { resources }\end{array}$ & $32,008,500,000$ & US\$ (2000\$) \\
\hline $\bar{y} g r$ & $\begin{array}{l}\text { Growth rate of macroeconomic } \\
\text { resources }\end{array}$ & 2.167523 & $\%$ per period \\
\hline \multicolumn{4}{|c|}{ Non-Renewable Parameters } \\
\hline$A_{n}$ & Coefficient of fabrication & $6,858.81$ & $\begin{array}{l}\text { Assumed } \\
\text { load factor } \\
79 \%, \text { times } \\
\text { the number } \\
\text { of hours in a } \\
\text { year }\end{array}$ \\
\hline$\beta$ & Fuel Leontief coefficient & 1.307651066 & $\begin{array}{l}\text { Barrels of } \\
\text { fuel/MWh }\end{array}$ \\
\hline$\theta_{a}$ & $\begin{array}{l}\text { Backup coefficient for } \\
\text { renewable A (wind) }\end{array}$ & 100 & $\%$ \\
\hline$\theta_{b}$ & $\begin{array}{l}\text { Backup coefficient for } \\
\text { renewable B (wave) }\end{array}$ & 100 & $\%$ \\
\hline$p_{u 0}$ & Initial price of fuel & 56.61 & $\begin{array}{l}\text { US\$ per } \\
\text { barrel }\end{array}$ \\
\hline$p_{u} g r$ & Growth rate of the price of fuel & 1 & $\%$ per period \\
\hline
\end{tabular}




\begin{tabular}{|c|c|c|c|}
\hline$p_{n 0}$ & Initial price of investment & $1,500,000$ & US\$ per MW \\
\hline$p_{n} g r$ & $\begin{array}{l}\text { Growth rate of the price of } \\
\text { investment }\end{array}$ & 0.00 & $\%$ per period \\
\hline$\delta_{n}$ & Capacity depreciation rate & 0.033 & $\%$ per period \\
\hline \multicolumn{4}{|c|}{ Parameters for Renewable A (Wind Energy Technology) } \\
\hline$A_{a}$ & Coefficient of fabrication & $8,760.00$ & $\begin{array}{l}\text { Number of } \\
\text { hours per } \\
\text { year }\end{array}$ \\
\hline$z_{a}$ & Utilization loading factor & 35 & $\%$ \\
\hline$p_{a 0}$ & Initial price of investment & $1,966,559$ & US\$ per MW \\
\hline$p_{a} g r$ & $\begin{array}{l}\text { Growth rate of the price of } \\
\text { investment }\end{array}$ & -0.05 & $\%$ per period \\
\hline$\delta_{a}$ & Capacity depreciation rate & 0.04 & $\%$ per period \\
\hline \multicolumn{4}{|c|}{ Parameters for Renewable B (Wave Energy Technology) } \\
\hline$A_{b}$ & Coefficient of fabrication & $8,760.00$ & $\begin{array}{l}\text { Number of } \\
\text { hours per } \\
\text { year }\end{array}$ \\
\hline$z_{b}$ & Utilization loading factor & 38 & $\%$ \\
\hline$p_{b 0}$ & Initial price of investment & $2,465,632$ & US\$/MW \\
\hline$p_{b} g r$ & $\begin{array}{l}\text { Growth rate of the price of } \\
\text { investment }\end{array}$ & -0.1 & $\%$ per period \\
\hline$\delta_{b}$ & Capacity depreciation rate & 0.05 & $\%$ per period \\
\hline \multicolumn{4}{|c|}{ Initial and Terminal Conditions } \\
\hline$k n_{0}$ & Initial non-renewable capacity & $1,471.1$ & MW \\
\hline$k a_{0}$ & Initial capacity of technology A & 0.00 & MW \\
\hline$k b_{o}$ & Initial capacity of technology B & 0.00 & MW \\
\hline$\overline{\bar{x}}$ & $\begin{array}{l}\text { Renewable to total output ratio } \\
\text { requirement }\end{array}$ & 20 & $\begin{array}{l}\% \text { in the last } \\
\text { period }\end{array}$ \\
\hline $\bar{v}$ & $\begin{array}{l}\text { Ratio of renewable A to total } \\
\text { renewable output }\end{array}$ & 95 & $\begin{array}{l}\% \text { in the last } \\
\text { period }\end{array}$ \\
\hline$k n T$ & $\begin{array}{l}\text { Terminal non-renewable } \\
\text { capacity }\end{array}$ & 1759.76 & MW \\
\hline$k a T$ & $\begin{array}{l}\text { Terminal capacity for renewable } \\
\text { A }\end{array}$ & 781.91 & MW \\
\hline$k b T$ & $\begin{array}{l}\text { Terminal capacity for renewable } \\
\text { B }\end{array}$ & 37.90 & MW \\
\hline
\end{tabular}

The initial electricity production target and its growth rate were taken from an annual report of Hawaii Electric Industries, and the Integrated Resource Planning report of HECO, the electric utility in Oahu. The Gross State Product (GSP) of the county of Honolulu for 2000 is used as a proxy for initial macroeconomic resources. The values of the GSP and its growth rate displayed in the table were both found in databooks of 
the Hawaii Department of Business and Economic Development ${ }^{44}$. The databooks provide estimates of the GDP per year, and the GSP growth rate for every five years between 2000 and 2030. These estimates were used to calculate a single growth rate for the GSP between 2000 and 2030.

Information on the initial and terminal conditions was found on the HECO website and in legislative documents on the Hawaii Renewable Portfolio Standard (RPS). For simplicity, a few assumptions were made on the existing generating capacity and the RPS. Firstly, all non-renewable generating capacity — which includes mostly oil-fired plants, but also coal-fired plants, diesel units and combined cycle gas turbines-was brought together in a single group. This implies that all non-renewable generating plants have the same costs, coefficients of fabrication, and fuel parameters.

Secondly, we assume that there is no renewable energy capacity installed or used in period 0 . In addition, the existence and possibility of electricity generation from renewable resources other than wind and wave power is ignored. This assumption may not be so unrealistic since apart from solar energy, as there is little use of renewables on the island of Oahu (other renewable resources such as geothermal, hydro and biomass are used in Hawaii on Maui and Big Island but not Oahu). Finally, the terminal conditions listed in table 5.1 imply that renewable energy should account for 20 percent of Oahu's electricity generation in period 20. In reality, however, the RPS requires 20 percent of renewable electricity generation in the whole state of Hawaii: electric utilities may have different shares of renewable electricity generation and it is the average across the whole state which matters. Indeed, to date the electric utility on Oahu has accommodated much less renewable energy than the utility on Big Island. The renewable energy requirements entered into the model can readily be adjusted to represent a lower target for Oahu.

The terminal capacity of each type of plant was calculated using the renewable energy requirements, $\bar{x}$ and $\bar{v}$, with $\bar{x}$ set to 20 percent and $\bar{v}$ set arbitrarily to 95 percent, reflecting the prevailing view that wind is the dominant renewable energy technology. The renewable plant backup requirements, growth rate in the price of investment of

\footnotetext{
${ }^{44}$ http://www.hawaii.gov/dbedt/info/economic/databook/db2005/
} 
each plant, and growth rate of the price of fuel were all set on an ad hoc basis as exogenous parameters which can be changed for various scenarios as required. In order to ensure as much reliability as possible, we impose a one-to-one backup requirement for renewable energy plants (every MW of wind and wave power is thus backed up by a MW of non-renewable capacity). The price of investment in wave energy is assumed to decline faster than that of wind energy because the novelty of the wave energy technology implies that learning by doing should enable large cost reductions. The price of investment in the non-renewable technology is assumed to remain constant over time.

The coefficients of fabrication for wind and wave energy were set by multiplying 365 by 24 in order to find the number of MWh per year produced by each plant operating continuously; they were then multiplied by the capacity factors $z$ to determine output from each technology. The coefficient of fabrication for non-renewables was derived from the electricity production and non-renewable capacity in year 1 . The capacity depreciation rates and utilisation loading factors of renewables were found in studies relating to wind (Dale and Milborrow, 2006) and wave (Previsic et al., 2005b) energy. The investment price for non-renewables, wind and wave energy were found in Wikipedia, www.offshore.co.uk, and in Previsic et al. (2005b) respectively.

Ad hoc feasibility constraints for the production of renewable energy can also be included in the model, although it has not been done in this instance. If the model incorporated production functions for all the available types of plants as well as a feasibility constraint for each type of renewable energy, the optimal feasible share of generation of each type of renewable $(\bar{x}$ and $\bar{v})$ could be easily determined. Limited time and data resources have precluded such an extension of the model in this study.

The values displayed in table 5.1 are all exogenous. Using these parameter values, the model defines the welfare-maximising capacity accumulation process for all types of plants over the specified time horizon (20 years in this case), and the resulting electricity output. The following figures display the results associated with the exogenous values shown in Table 5.1: 
Figure 5.8: Model Output for Scenario 1
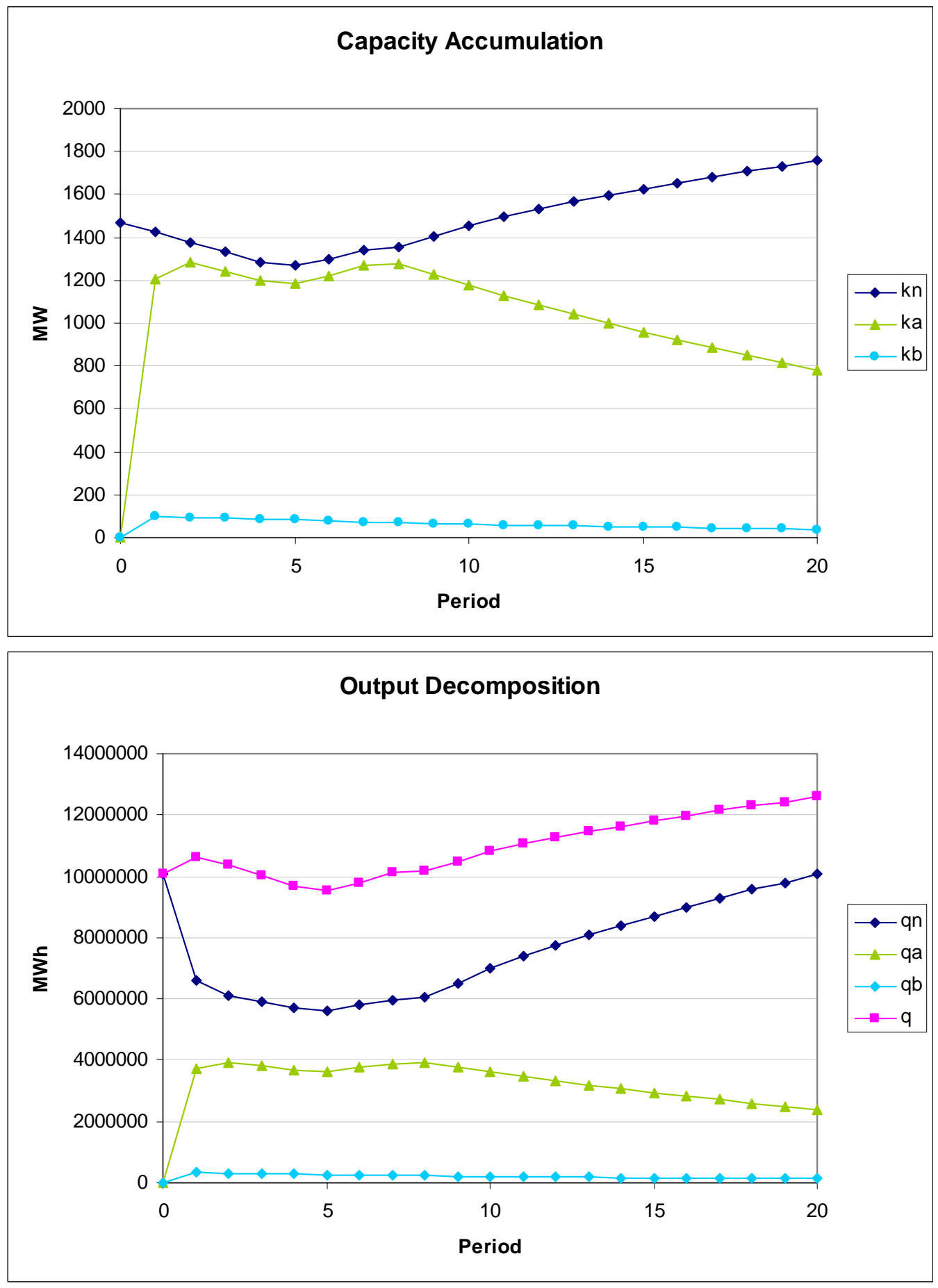


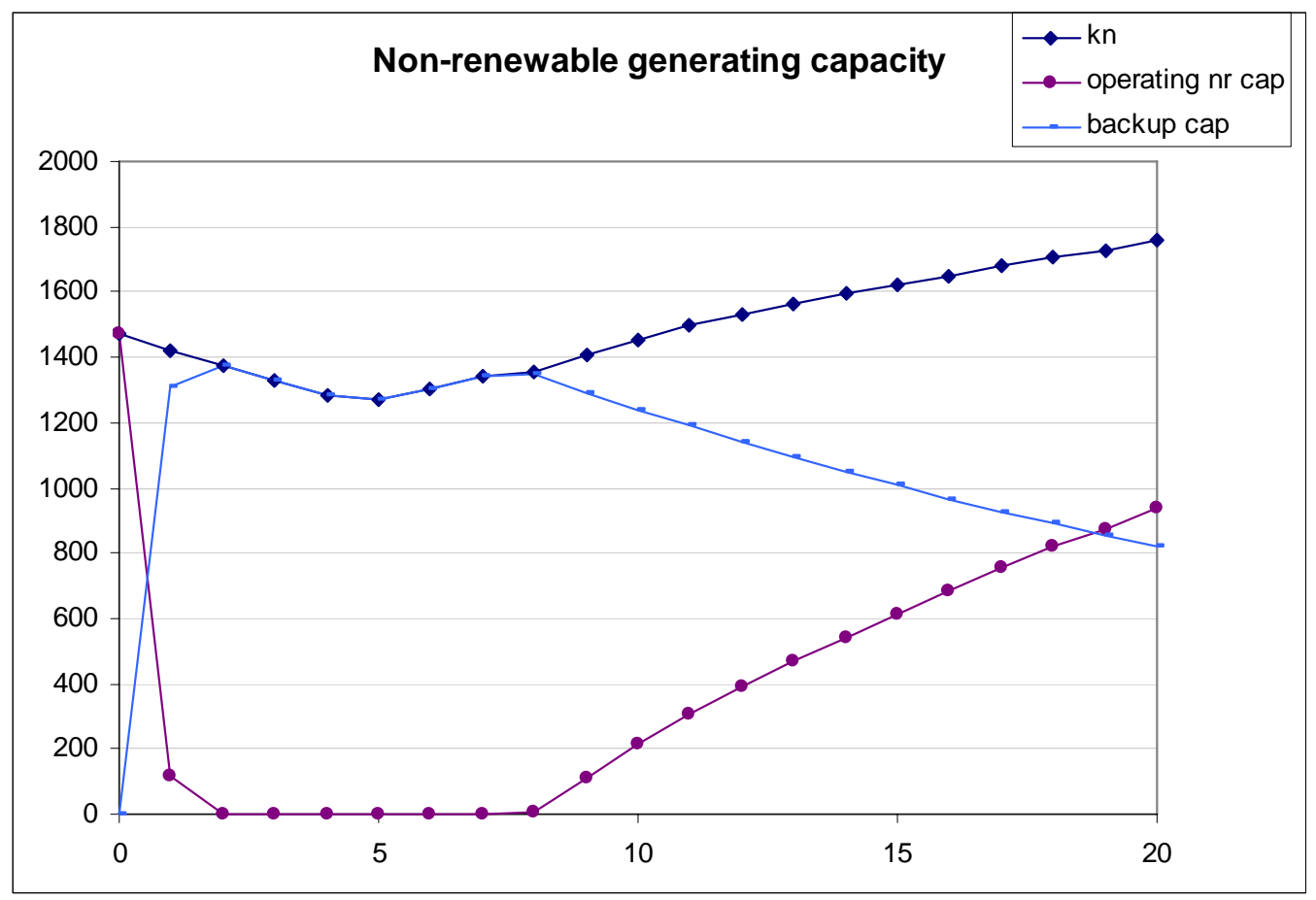

Welfare $=9.97$

As seen in the second graph above, the capacity accumulation process follows the terminal condition requirements: in year 20, renewable energy output constitutes 20 percent of total electricity output (as required by $\bar{x}=0.2$ ); most renewable energy output is produced by technology " $a$ ", or wind turbines (as required by $\bar{v}=0.95$ ), hence little investment is made in wave energy.

How does the energy planner choose to meet these requirements? Despite a decreasing price of investment for renewable energy, the energy planner in this scenario chooses to make the largest investment in renewable energy capacity in the first period. Investments in renewable energy, particularly wind energy, are still made in subsequent periods (until period 7 for wind energy; and also very small amounts until period 7 for wave energy). However, as shown in table 5.8 below, the magnitude of these investments is hardly comparable to that of period 1 : 
Table 5.2: Investment in Renewable and Non-Renewable Energy Plants (Scenario 1)

\begin{tabular}{|l|l|l|l|}
\hline Period & $\begin{array}{l}\text { Investment in } \\
\text { renewable A } \\
\text { (wind energy) }\end{array}$ & $\begin{array}{l}\text { Investment in } \\
\text { renewable } \\
\text { (wave energy) }\end{array}$ & $\begin{array}{l}\text { Investment in } \\
\text { non- } \\
\text { renewables }\end{array}$ \\
\hline $\mathbf{0}$ & 1207.2 & 100.4 & 0.0 \\
\hline $\mathbf{1}$ & 121.2 & 0.00004 & 0.0 \\
$\mathbf{2}$ & 10.6 & 0.00068 & 0.0 \\
\hline $\mathbf{3}$ & 10.2 & 0.00062 & 0.0 \\
\hline $\mathbf{4}$ & 33.6 & 0.00000 & 23.7 \\
\hline $\mathbf{5}$ & 84.8 & 0.00009 & 75.1 \\
\hline $\mathbf{6}$ & 94.9 & 0.00000 & 85.0 \\
\hline $\mathbf{7}$ & 57.7 & 0.000011 & 56.2 \\
\hline $\mathbf{8}$ & 0.0 & 0.0 & 96.8 \\
\hline $\mathbf{9}$ & 0.0 & 0.0 & 96.2 \\
\hline $\mathbf{1 0}$ & 0.0 & 0.0 & 89.9 \\
\hline $\mathbf{1 1}$ & 0.0 & 0.0 & 85.3 \\
\hline $\mathbf{1 2}$ & 0.0 & 0.0 & 82.2 \\
\hline $\mathbf{1 3}$ & 0.0 & 0.0 & 80.4 \\
\hline $\mathbf{1 4}$ & 0.0 & 0.0 & 80.5 \\
\hline $\mathbf{1 5}$ & 0.0 & 0.0 & 82.6 \\
\hline $\mathbf{1 6}$ & 0.0 & 0.0 & 85.7 \\
\hline $\mathbf{1 7}$ & 0.0 & 0.0 & 83.3 \\
\hline $\mathbf{1 8}$ & 0.0 & 0.0 & 75.8 \\
\hline $\mathbf{1 9}$ & 0.0 & 0.0 & 88.1 \\
\hline
\end{tabular}

Therefore, the energy planner finds it optimal to invest in wind energy mostly in the first period, and subsequently invest just enough to 'maintain' capacity so that 20 percent of output is delivered by wind turbines in the last period. On the other hand, there is no investment in non-renewable capacity until period 4, and an increasing investment thereafter. As shown in the above figure representing non-renewable generating capacity, actual non-renewable output other than backup supply drops to zero between periods 2 and 8 (as all non-renewable capacity is used to backup renewables), so that all electricity is produced using solely wind turbines and wave plants plus non-renewable backup supply. There is relatively little investment in wave energy, mainly because although setting $\bar{v}$ to 0.95 means that 95 percent of renewable electricity generation should come from wind energy in period 20 only, not in other periods, the twenty-year period of the simulation is equal to the economic life of a wave plant, so that substantial investment in wave plant during the intervening period would leave undepreciated wave capacity stranded and idle at the terminal date. In addition, building a wave power plant is more costly than building a wind power 
plant; as shown in table 5.1, which displays the parameter values used in this scenario, the initial price of investment for a wave plant is US\$2,465,632 per MW, compared to US\$ $1,966,559$ per MW for a wind plant.

A major question follows from observing the capacity accumulation process: why does the energy planner start by making such large investments in wind energy? The following paragraph provides a first intuitive answer; however, this question is examined more carefully in section 4 .

It is possible to think that the electricity supplier would meet a renewable portfolio standard $(\bar{x})$ by investing and installing renewable capacity later in the planning period: intuitively, an increasing price of fuel, a decreasing price of investment for renewables, and a increasing environmental penalty on non-renewable output should make investments in renewable energy capacity more and more advantageous over time. Yet in this scenario the energy planner meets the portfolio requirement by investing mostly in the first period, then letting the capacity depreciate down to 20 percent of total generation in year 20. This suggests that renewables are already competitive with fossil fuel technologies, and that $\bar{x}=20 \%$ represents a downward constraint on the planner's desired renewable energy investment and development. Hence, when the renewable portfolio standard is represented by an absolute number, it can constitute a constraint to renewable energy development in either direction, upward or downwards.

Another reason for such a large, sudden investment in wind energy may be the existence of a growing penalty weight on electricity output tracking. The following graph displays the evolution of electricity supply (q) verses the pre-determined electricity demand path $(\bar{q})$ : 
Figure 5.9: Desired Vs. Actual Output for Scenario 1

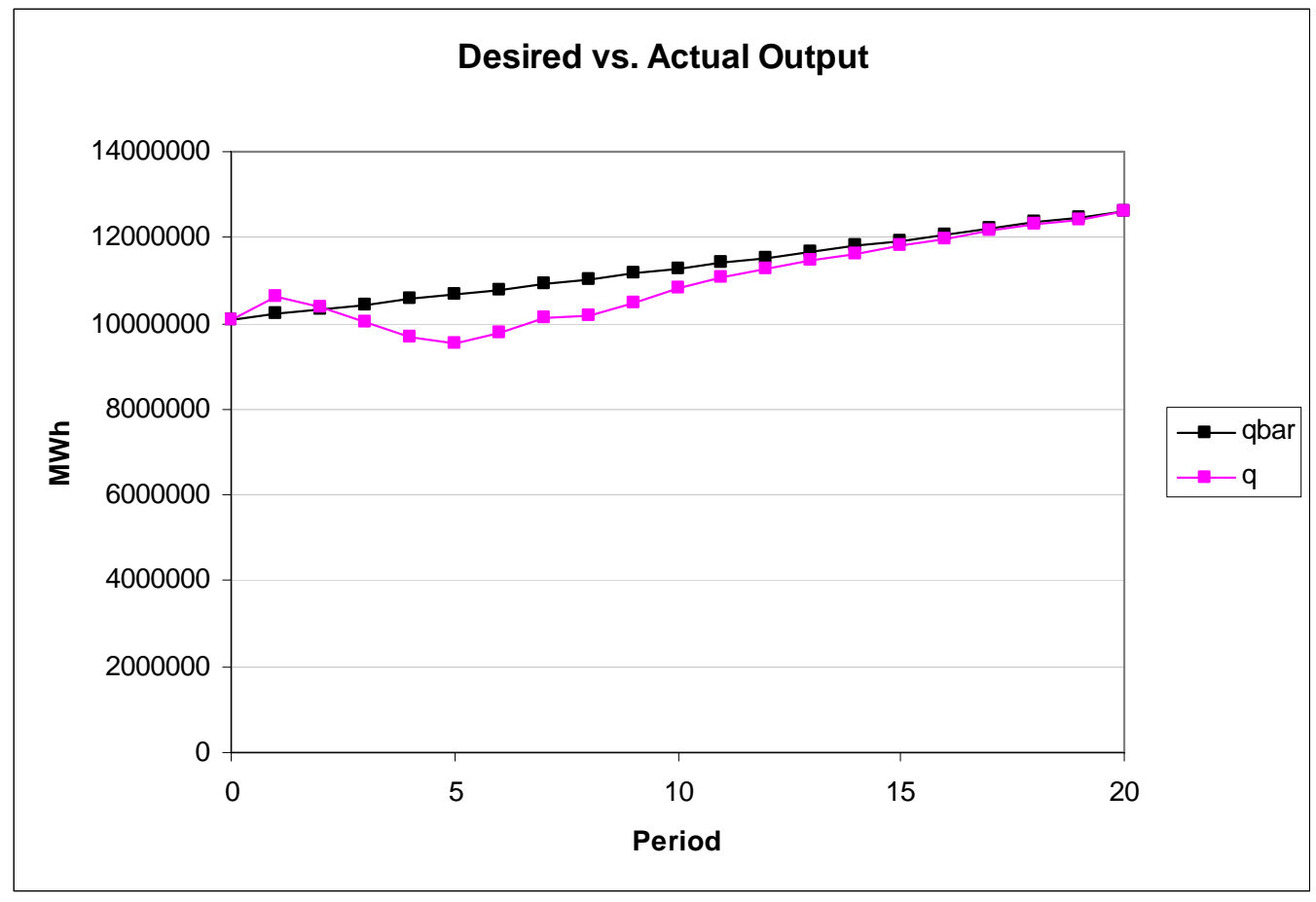

In this particular scenario it is optimal for the energy planner/supplier to deviate from the pre-determined electricity demand path by not supplying enough electricity, except in period1. This deviation can be "corrected" by increasing the penalty weight on output tracking (see scenario 4), but it is possible that there will always remain some deviation. Note, however, that in this case the deviation from $\bar{q}$ decreases with time, with the electricity output finally reaching the target value in the last period. This is likely due to the positive growth rate on the penalty weight for energy tracking ( $\bar{\pi} g r$ ), so that it becomes less and less optimal to deviate from the output target. Hence, the largest deviation is made rather early (when it is still relatively "cheap" to deviate from the output target) by supplying all the electricity with an intermittent source of energy and living with some under-supply.

In period 1, there is excess supply due to the large increase in wind energy supply and available backup capacity, coupled with the inability to decommission the existing non-renewable energy capacity. The planner is temporarily letting existing nonrenewable capacity depreciate, with no investment until period 4, as well as turning this capacity into backup for renewables. The non-renewable capacity depreciation 
rate is more than offset initially by the large new wind energy capacity, so that there is temporary excess supply; subsequently the pattern is reversed for a number of years.

\section{b) Second Scenario for Oahu: Optimal Value of $\bar{v}$}

After modelling the base-case scenario described in the previous section, a simulation was made by varying the parameter $\bar{v}$ (the ratio of wind output to total renewable output) and observing the resulting welfare surplus, in order to find the optimal, welfare-maximising value of $\bar{v}$. The simulation revealed that the optimal ratio is actually close to zero, meaning that given the exogenous specifications employed, our energy planner would prefer to generate electricity using the wave energy technology rather than wind turbines. This "technology preference" may come from four different parameters: utilization loading factor or capacity factor of the plants, initial price of investment for each technology, expected growth in the price of investments and for capacity depreciation rate ${ }^{45}$. The initial price of investment and capacity depreciation rate associated with the wave energy technology are higher than those associated with the wind energy technology. However, the capacity factor of the wave energy converter is slightly higher than that of the wind turbine (by 3 percent), and its price is arbitrarily set to decrease faster (given the novelty of the wave energy technology, there is assumed to be more scope for the price to fall due to effects such as learning by doing). This implies that the model favours the renewable energy technology which has the highest capacity factor and largest expected decrease in price.

After running the simulations to find the optimal value for $\bar{v}$, the model was applied to a second scenario, similar to the base case scenario except for the value of $\bar{v}$, which was set to 0.01 . The resulting capacity accumulation and output trajectory are displayed in the following figures:

\footnotetext{
${ }^{45}$ The "preference" for wave energy revealed by the simulation was cross-checked by running a simulation with the same parameter values for both technologies. The simulation revealed a constant welfare for all values of $\bar{v}$ (except for 0.01 and 0.02 , which were associated with a lower welfare).
} 
Figure 5.10: Model Output for Scenario 2
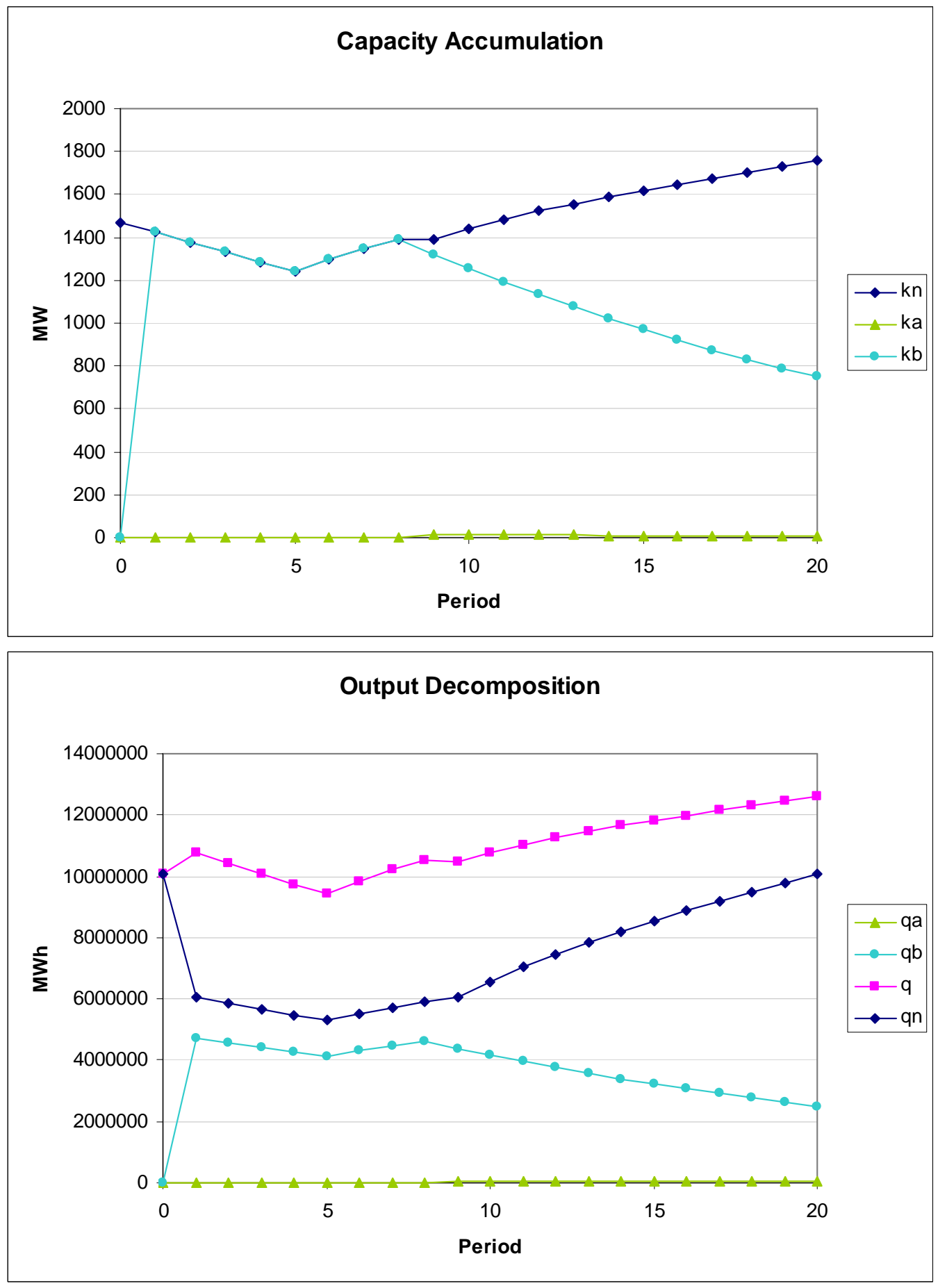

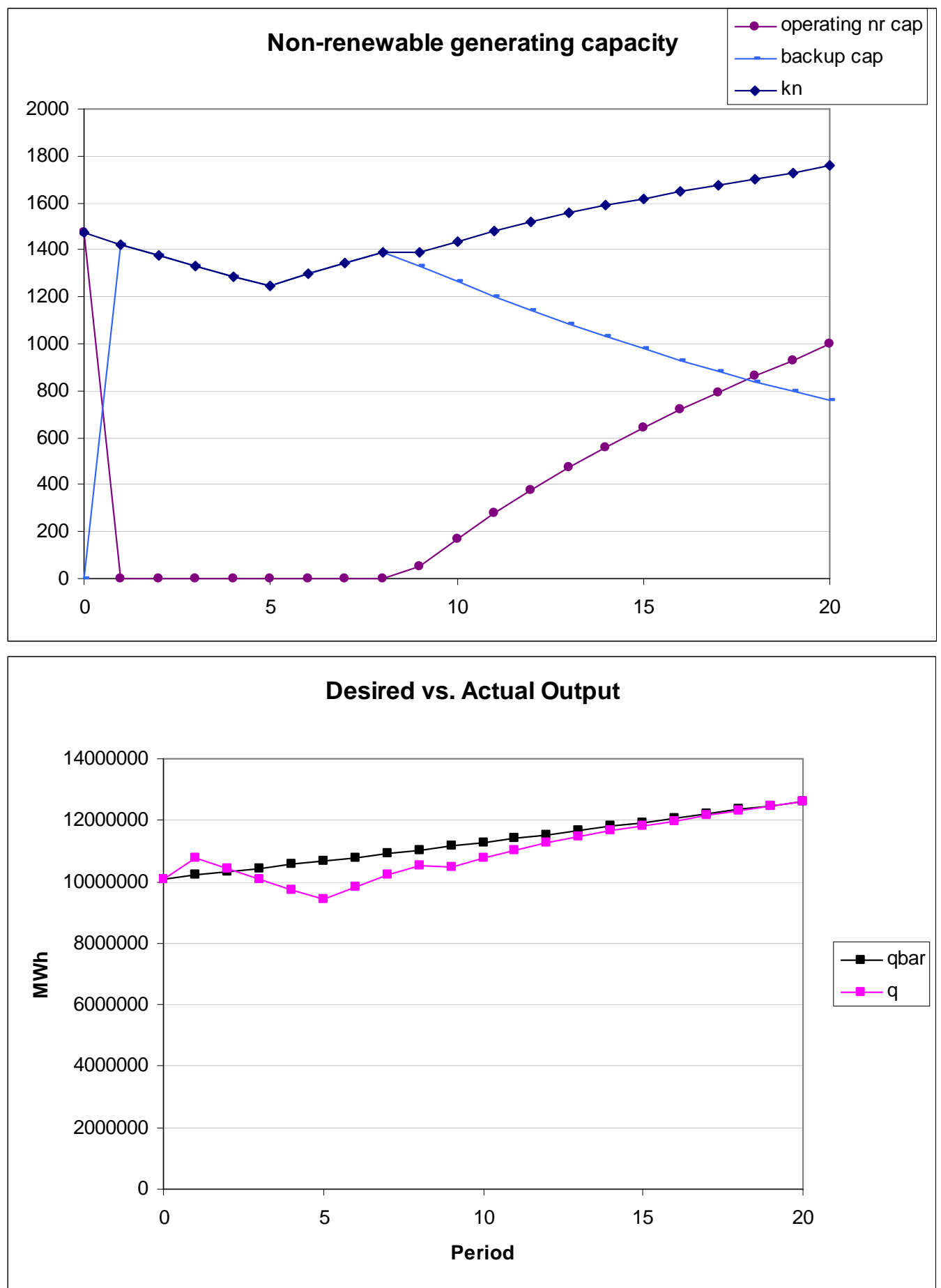

Welfare $=10.61$

Unsurprisingly, the capacity accumulation and output decomposition figures are quite similar to those of the base case scenario (including a large investment in renewables in the first period), except that the majority of renewable output comes from wave energy, as required by the low value of $\bar{v}$. The value of welfare associated with this 
scenario is larger than in the base case scenario; this confirms that a lower value of $\bar{v}$ is preferred to a higher value. There is also more renewable output being produced than in the previous scenario, for two reasons. Firstly, due to the higher capacity depreciation associated with the wave energy technology, the energy planner starts by installing more capacity in the first period than under the base case scenario in order to end up with 20 percent of renewable energy in period 20. Secondly, the capacity factor of the wave technology is higher than that of the wind technology, which means that every MW of wave capacity installed produces more than a MW of wind capacity.

Thus in this case, the energy planner uses mostly wave energy (and very little wind energy) and non-renewable capacity as a backup to produce electricity for 8 periods, using more non-renewable energy from period 9. All non-renewable capacity serves as a backup for renewables from periods 1-9, after which the ratio of backup capacity to total non-renewable capacity decreases as the energy planner lets the renewable plants capacities depreciate (from periods 9 to 20). A sudden increase in deviation from the output target occurs in period 9: as the energy planner lets the wind and wave energy plants depreciate, the corresponding backup capacity is also let to depreciate. Instead of maintaining the total amount of non-renewable capacity and increasing the share of non-renewable electricity production, the energy planner keeps using the totality of non-renewable capacity as a backup for renewables, and lets it depreciate with the renewable plants. From period 10, however, stand-alone nonrenewable supply reappears and its share of total supply rises thereafter.

\section{c) Third Scenario: A Higher Renewable Portfolio Standard}

This section provides an overview and explanation of the modelling results for the case of Oahu with a Renewable Portfolio Standard of 40 percent in year $20(\bar{x}=0.4)$. This scenario thus consists of the same parameter values outlined in the previous scenario $(\bar{v}=0.01)$, except for $\bar{x}$, which is set at 0.4 . The resulting output for this scenario is displayed in the following diagrams: 
Figure 5.11: Model Output for Scenario 3
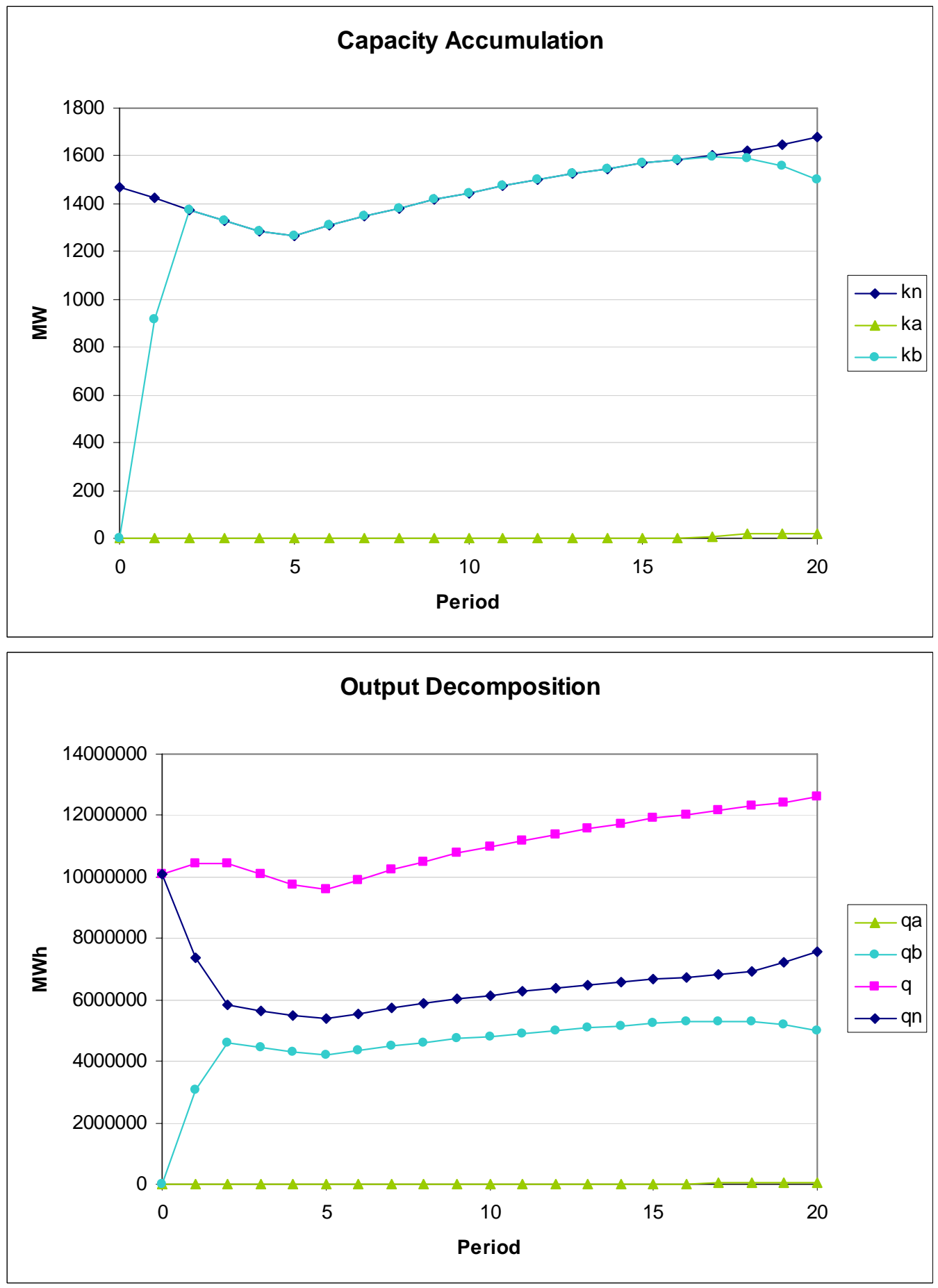

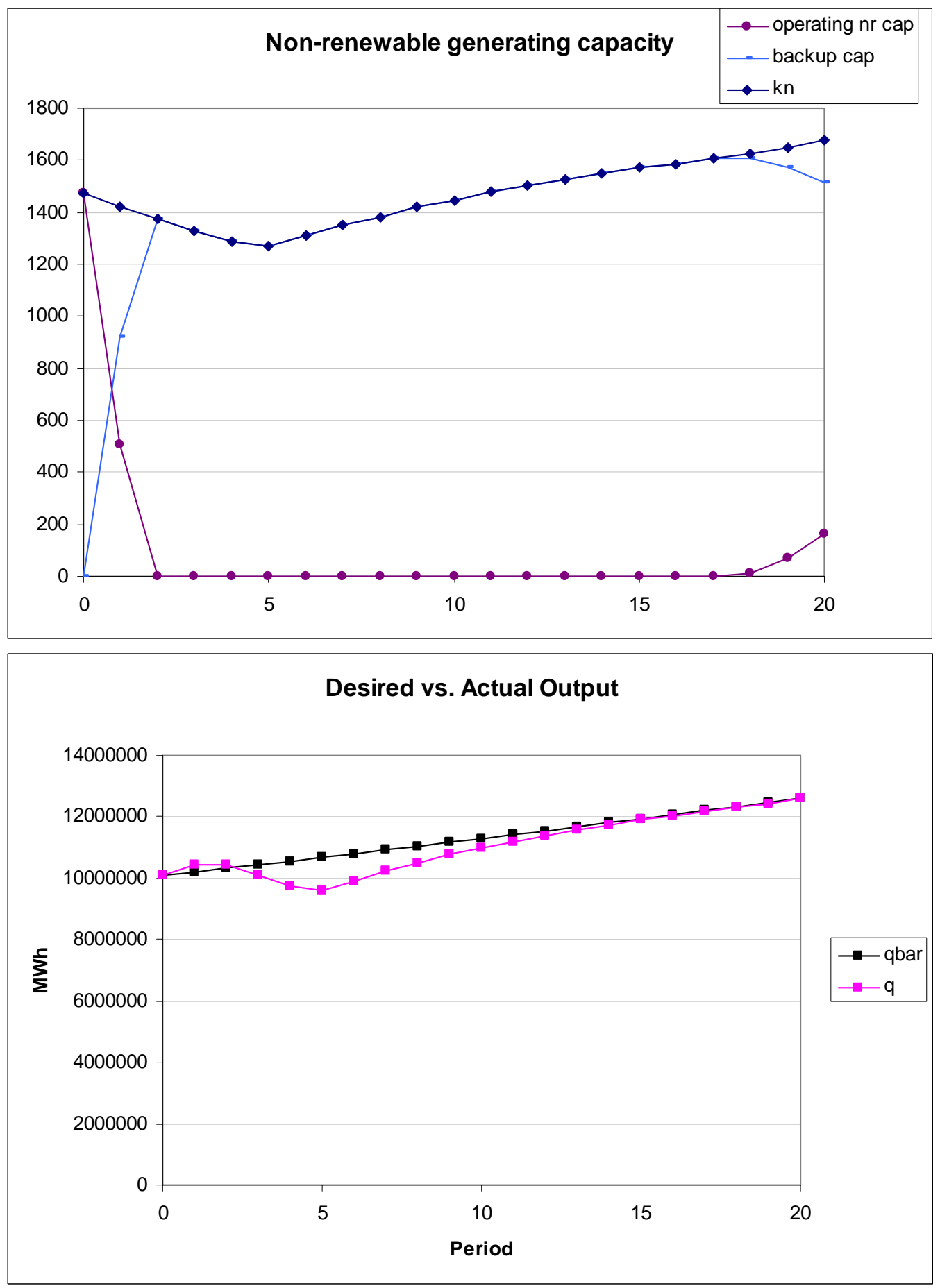

Welfare $=13.49$

Once again, our energy planner starts investing in wave energy capacity straight away in order to meet the renewable energy requirements in year 20. Renewable energy capacity (mostly wave energy) and corresponding non-renewable backup is used to produce the totality of electricity output for 15 consecutive periods. Since the 
portfolio standard is set higher, however, capacity accumulation follows a slightly different path. Instead of installing the largest amount of wave energy capacity early and letting it depreciate, the energy planner accumulates renewable capacity gradually, with a capacity peak in period 17 , in order to meet the portfolio standard. Welfare has increased as the renewable portfolio standard $\bar{x}$ has increased to 40 percent.

Non-renewable capacity is entirely used as a backup for renewables, except in periods 1, 18, 19 and 20 where some stand-alone non-renewable generation occurs. Some non-renewable capacity is installed in periods 18 and 19 in order to ensure that the output target is met in period 20 as wave energy capacity declines slightly. In period 20 , however, the majority of non-renewable capacity is still used for backing up renewables.

\section{d) Fourth Scenario: Behaviour of the Model Output as $\bar{x}$ increases}

This section provides a brief description of the model output behaviour as $\bar{x}$ is increased gradually by 10 percent from 20 percent to 100 percent. Apart from the value of $\bar{x}$, all parameter values used for this scenario are the same as in scenario $b$ $(\bar{v}=0.01)$.

A number of observations can be made on the amount of renewable energy installed as $\bar{x}$ increases:

- Whatever the value of $\bar{x}$, the largest investment is made in wave energy in the initial period, increasing the amount of wave energy capacity from $0 \mathrm{MW}$ in period 0 to $1422 \mathrm{MW}$ in period 1 in each case. This is always accompanied by a drop in operating non-renewable capacity in period 1, with all nonrenewable capacity used as a backup for renewable energy. In each case, the capacity of wave energy decreases to $1375 \mathrm{MW}$ in period 2, then $1330 \mathrm{MW}$ in period 3, and $1286 \mathrm{MW}$ in period 4. These figures remain the same regardless of the value of $\bar{x}$. In each case, wave energy capacity drops again between 1242 and $1245 \mathrm{MW}$ in period 5. Hence, whatever the value of $\bar{x}$, a large investment is made in wave energy capacity in period 0 , leading to a jump in wave energy capacity and production in period 1 . Small investments are also made between period 1 and 4; nevertheless, the magnitude of these 
investments is smaller than the capacity depreciation rate, which leads to a decrease in capacity from period 2 to 5 .

- From period 5, larger investments are made in wave energy, leading to a gradual increase in wave energy capacity.

- After period 5, the investment and capacity accumulation paths differ from case to case, depending on the value of $\bar{x}$. When $\bar{x}$ is set at 20 percent, wave energy capacity starts decreasing again from period 8 , in order to meet the portfolio standard requirement of 20 percent, which corresponds to $750 \mathrm{MW}$. As $\bar{x}$ increases, this decrease in capacity occurs more and more late: for example, when $\bar{x}$ is set to 30 percent, wave energy capacity starts decreasing again from period 14 from $1530 \mathrm{MW}$ down to $1126 \mathrm{MW}$ - the capacity required by the 30 percent standard. This is shown in the figures below, which display capacity accumulation for $\bar{x}=0.2, \bar{x}=0.3$ and $\bar{x}=0.4$. 
Figure 5.12: Model Output for Scenario 4-Increasing the Renewable Portfolio Standard from $20 \%$ to $30 \%$ and $40 \%$
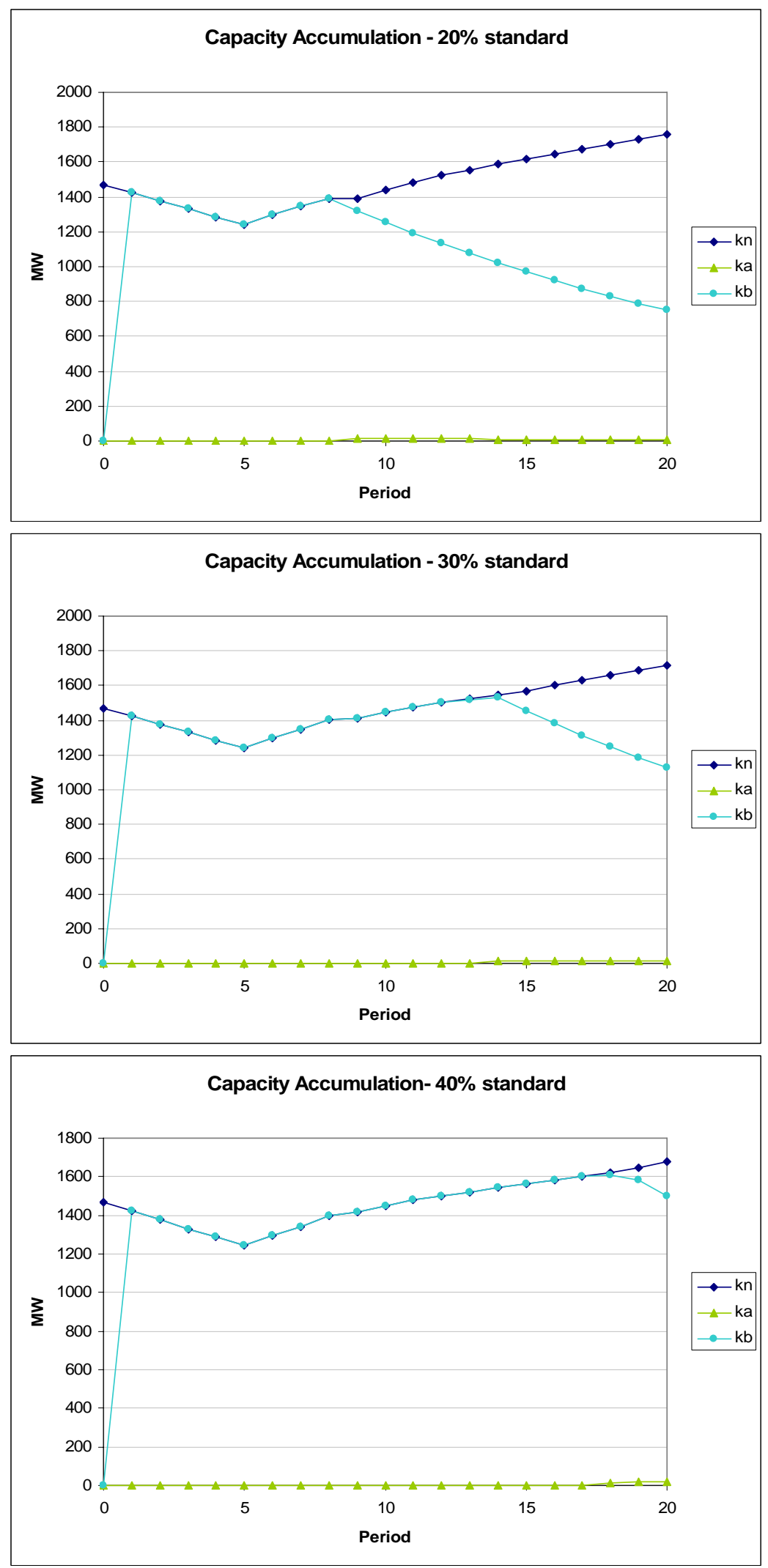
- When $\bar{x}$ is set between 20 and 40 percent, the model seems to be reaching for an optimal amount of renewable energy capacity. The similarities observed in the investment path and capacity accumulation process when $\bar{x}$ is set below 40 percent imply that all else equal, there is an optimal value of $\bar{x}$, which defines an optimal amount of capacity for every type of generating technology, and which simultaneously determines an optimal capacity accumulation path. Hence, all else equal, the model is reaching for the optimal value of $\bar{x}$ by remaining as close as possible to the corresponding optimal accumulation path.

- However, once $\bar{x}$ is set beyond 40 percent, the model does not solve. In other words, there is no solution that satisfies the constraints given the value of parameters and requirements. There are 3 constraints applied to this model: the first constraint is that investment remains non-negative from period 0 to 19 . The second constraint is that non-renewable operating capacity remains nonnegative in all periods. This constraint is applied to non-renewable operating capacity, which refers to the capacity used for stand-alone non-renewable energy production - it does not include the capacity that is used as a backup for renewables. The third constraint is placed on final state capacities for all three technologies, so that the renewable energy requirements set by $\bar{x}$ and $\bar{v}$ are met in the final period. Any combination of $\bar{x}$ and $\bar{v}$ implies a very specific set of $\mathrm{knT}$, kaT, and $\mathrm{kbT}$ values, which further, and endogenously, affects the values that the non-renewable operating capacity can take on during the last period. For example, setting $\bar{x}$ to 100 percent with $\bar{v}$ set at 0.01 would require 100 percent of the capacity in the final period to consist of renewable energy capacity, including 99 percent of wave energy capacity and 1 percent of wind energy. However, this is not compatible with the second constraint, which states that non-renewable operating capacity must be nonnegative at all times. Indeed, with 100 percent of renewable energy feeding the system, there should be no fossil fuel technology operating, except for backing up renewable energy whenever it is necessary. Hence, all else equal, when $\bar{x}$ is set above 40 percent, the second and the third constraints are not compatible with each other, and the model cannot solve. When the second constraint is not applied, renewable energy capacity accumulation follows the same process as when $\bar{x}$ is set between 20 percent and 40 percent, except for an additional 
"jump" in wave energy capacity in the final period in order to meet the portfolio standards. This jump is accompanied by a jump in non-renewable backup capacity, which is enabled by imposing a negative value on the operating non-renewable capacity. Similarly to the 20 percent RPS scenario observed above, the last-minute increase in renewable energy capacity implies that the energy planner seeks to remain as close as possible to the optimal capacity accumulation path, and deviates from this path only in the last period in order to meet the requirements. This behaviour implies that all else equal, the optimal value of $\bar{x}$ is lower than 100 percent. When running the model without imposing the second constraint, the optimal value of $\bar{x}$ was found at 42 percent.

\section{e) Fifth Scenario: Increasing the Penalty on Output Tracking}

In this scenario we aim to increase the output tracking penalty, $\bar{\pi}$, in order to have the output stay as close as possible to the target output. The results presented in this section are based on the same input values as in scenario b, except for the value of $\bar{\pi}$ which is arbitrarily set to 30 . The resulting model output is displayed in the figure below: 
Figure 5.13: Model Output for Scenario 5
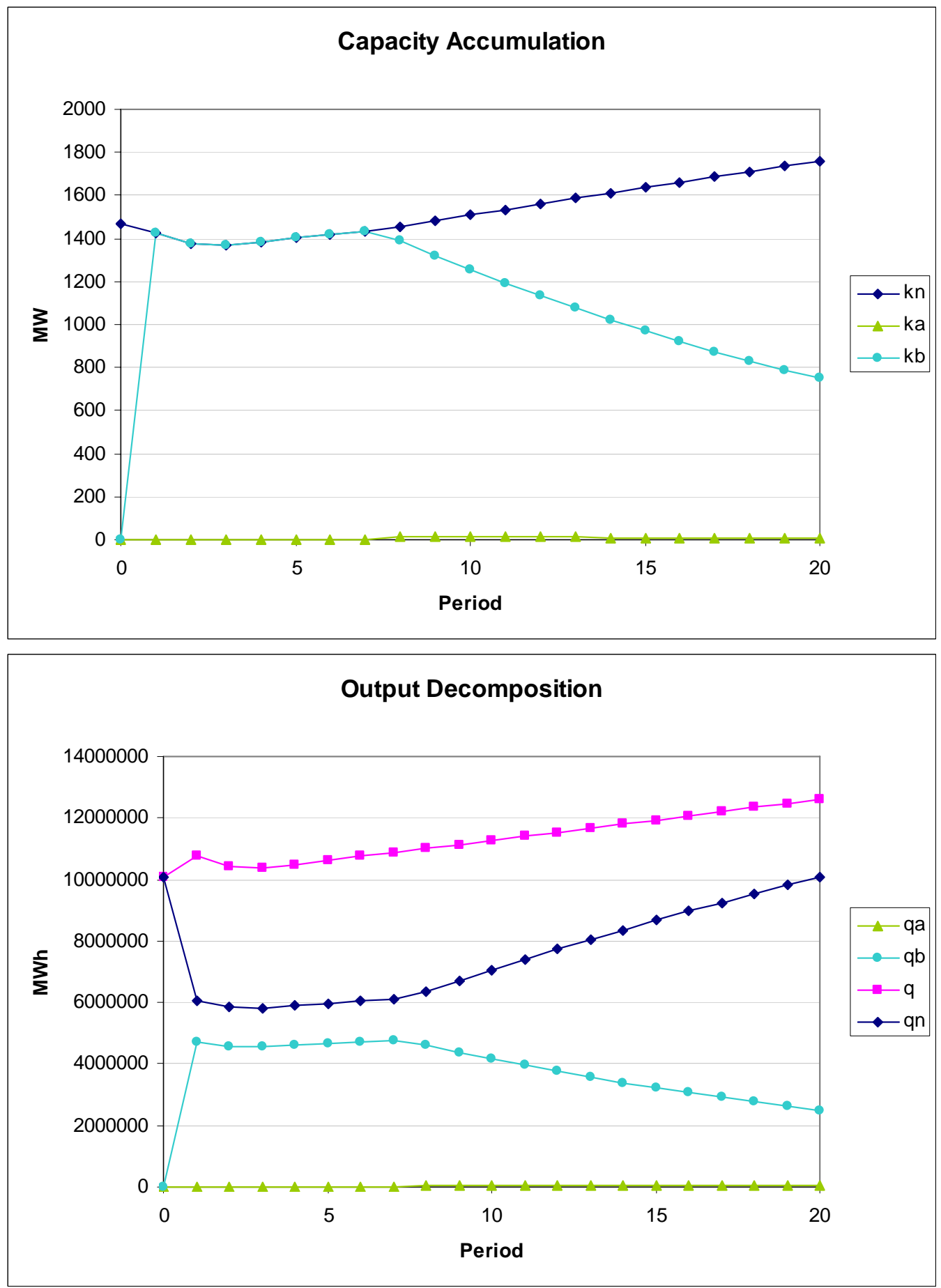

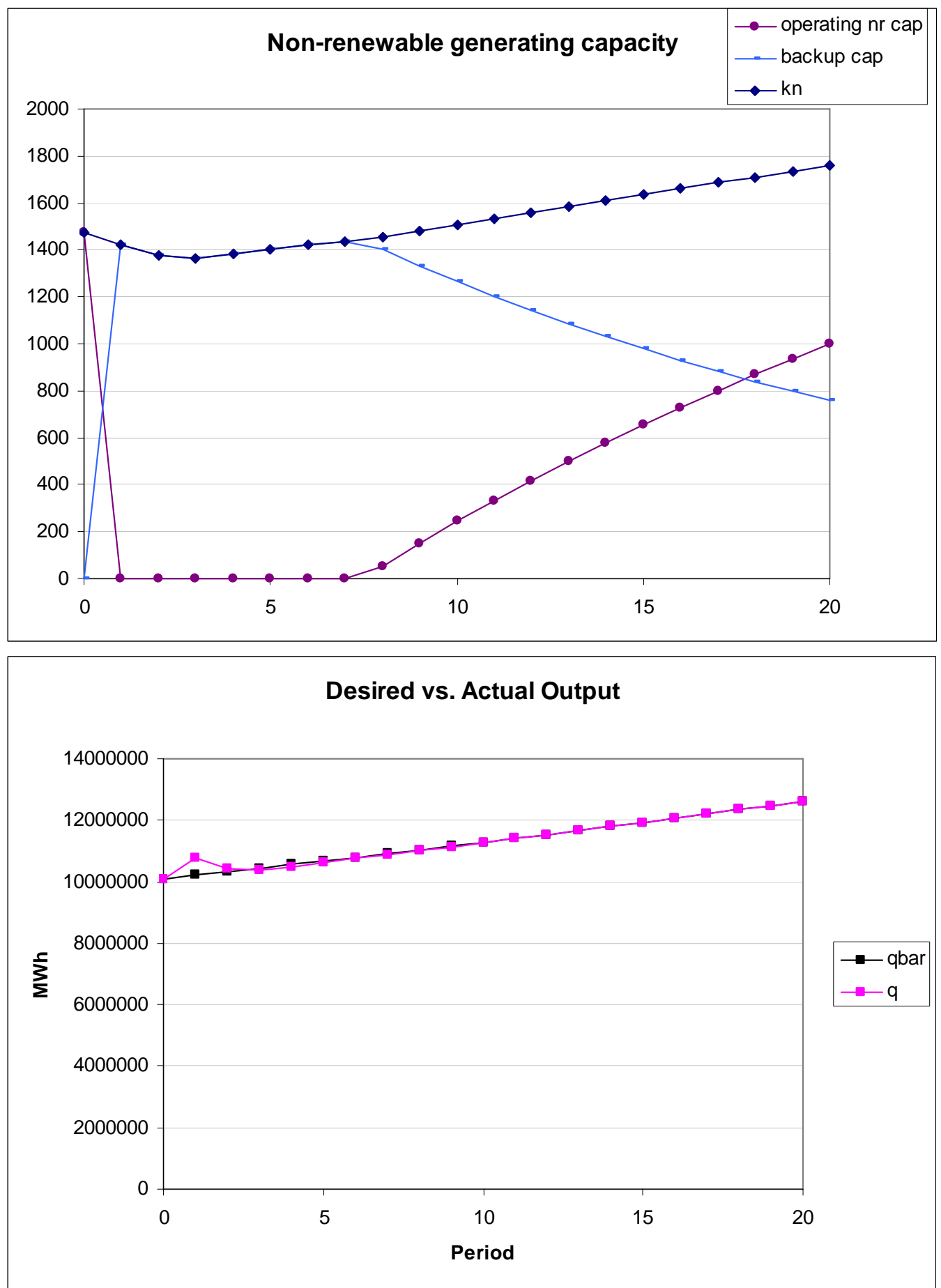

Welfare $=10.16$

The capacity accumulation and generation paths are very similar to those in scenario 2 (outlined in section b). In order to meet the output target, however, the energy planner accumulates more wave energy capacity during the first periods, and lets it depreciate slightly earlier than in scenario 2 , leading to a continuous increase in non-renewable 
generation from period 7. In addition, investments in wind energy are deferred until non-renewable generation kicks off.

f) Sixth Scenario: Lower Backup Requirements on Renewables

This section presents the model output when imposing a fossil fuel backup requirement of 50 percent on wave and wind energy capacity $\left(\theta_{a}=0.5, \theta_{b}=0.5\right)$. The parameter values are all set as in scenario 2 , except for $\theta_{a}$ and $\theta_{b}$. The model output is displayed below: 
Figure 5.14: Model Output for Scenario 6
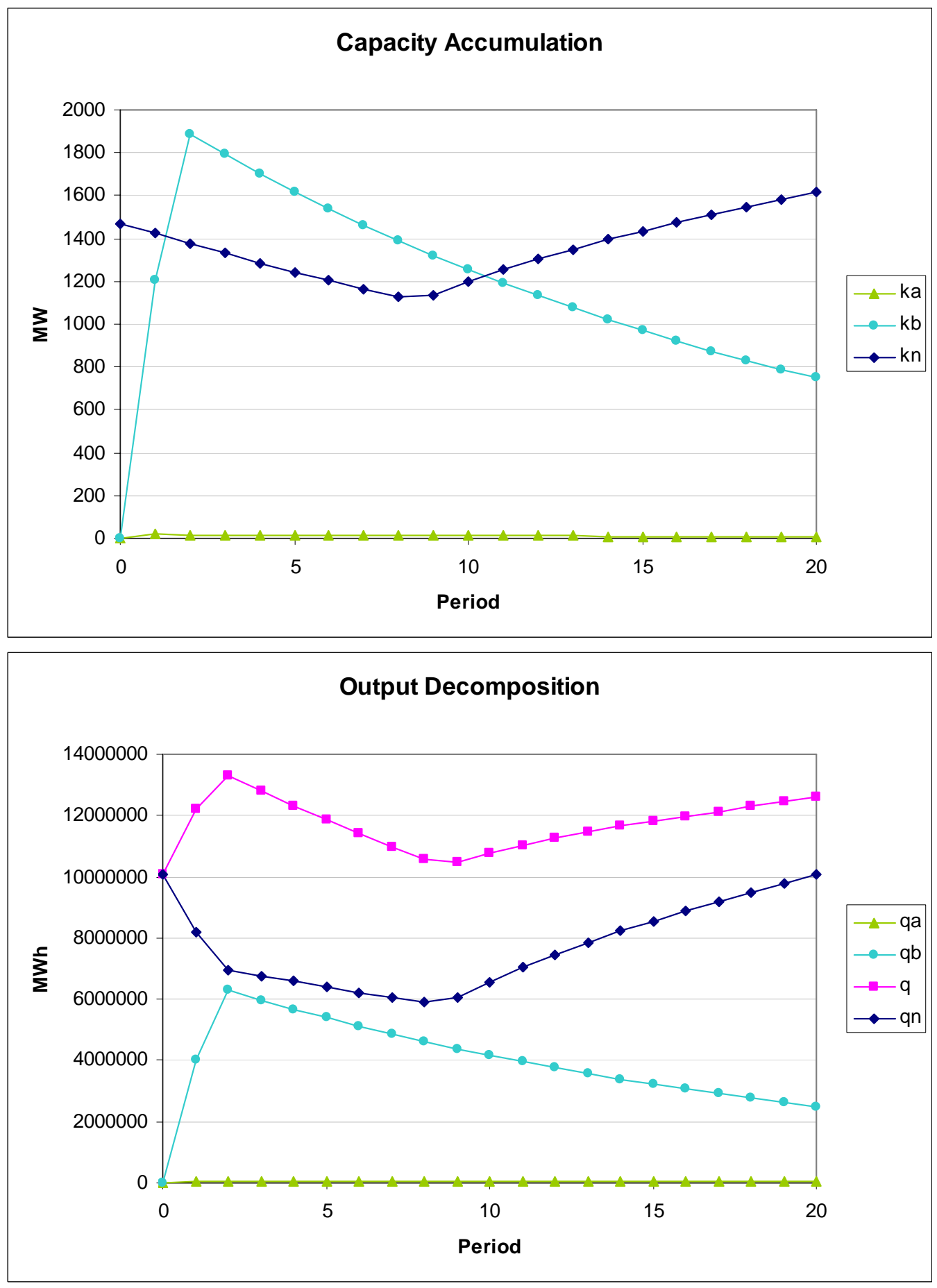

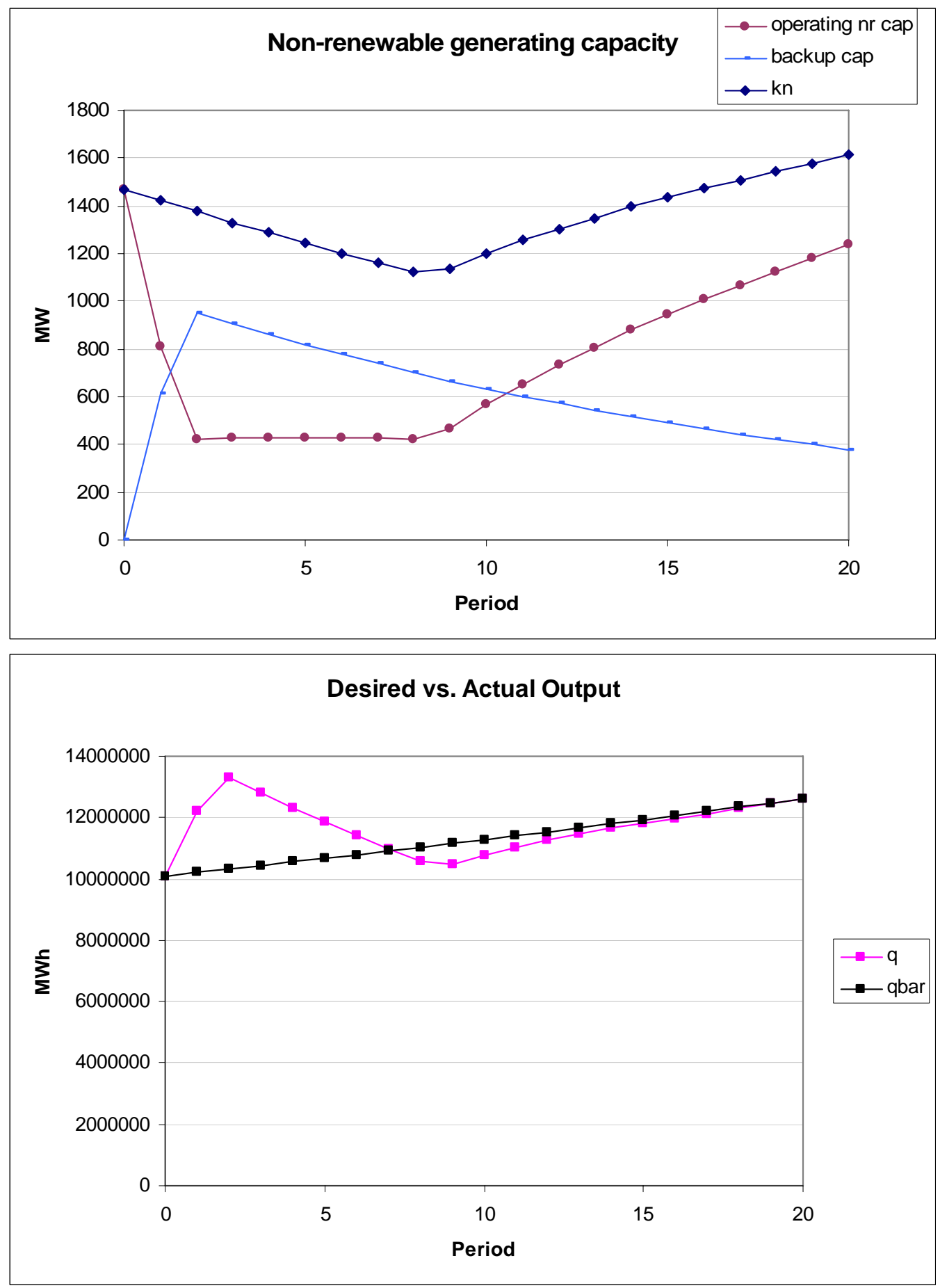

Welfare $=9.58$

The accumulation process observed above is fundamentally different to that observed in scenario 2 . Here, the energy planner invests largely in wave energy during the first two periods (period 0 and 1), and in wind energy capacity in the first period. No other investments are made in renewable energy in subsequent periods. Hence, the energy planner installs enough renewable capacity within the first periods so as to let it 
depreciate until the final period while meeting the renewable energy requirements. In period 2, the amount of wave energy capacity installed reaches almost $1890 \mathrm{MW}$, which is more than $400 \mathrm{MW}$ larger than in scenario 2, and the amount of energy produced is significantly higher than the production target. This is because the renewable backup requirements are smaller, so there is relatively more of the existing non-renewable operating capacity available for use. All renewable energy capacity installed is thus backed up by non-renewable capacity, however not all non-renewable capacity is used for backing up renewables, and this "remainder" capacity is used in all periods, with a load factor of 79 percent. This is likely due to the linear specification of backup capacity with respect to renewable energy capacity factors. At the same time, all renewable energy and non-renewable backup capacity is also used. In period 8 the quantity of energy produced is below the production target, as renewable capacity and the corresponding backup capacity are depreciating. The energy planner then invests in non-renewable capacity from period 8 until period 19, so that the production target is met in the final period.

The welfare value associated with this scenario is lower than in scenario 2 , where the renewable backup capacity requirement was higher. Intuitively, lowering the renewable backup requirements could lead to lower investments in non-renewable capacity, and hence more welfare. The cost of investments in non-renewable capacity is indeed lower than in scenario 2. However, these savings are outweighed by two types of expenses. Firstly, because the totality of renewable energy investments was made within the first two periods, the energy planner did not benefit from the decreasing price of renewable energy capacity. Hence, even if the amount of renewable energy capacity is the same as in scenario 2, the cost of renewable investments made by the planner is higher. Secondly, because a large part of nonrenewable energy capacity was generating energy from periods 1 to 20, the amount of non-renewable energy production was higher, which incurred additional spending due to the environmental penalty. It is also likely that the large upward deviation from the output target may have incurred more costs (due to the penalty on output tracking) than in scenario 2 . 


\section{4) Discussion}

The results outlined in the previous section reveal some interesting characteristics about the behaviour of the model. In each case with a portfolio standard of 20 percent, the energy planner satisfies the terminal conditions (renewable portfolio standards) by investing in renewable energy surprisingly early. We observe a declining path for renewable electricity, rather than a sudden growth in renewable electricity in the last periods. What are the explanations for such behaviour?

Firstly, because of the quadratic term associated with output tracking in equation (1), the model can be regarded as a quadratic-linear programming framework, with linear optimality conditions. Hence in each scenario, the trajectory of choice represents the unique solution which satisfies the linear conditions. Secondly, there is an implicit assumption of perfect foresight on investment prices and fuel prices, so that the model is forward-looking. The model takes these values and the terminal conditions into account, and solves the problem backwards for the entire period. In other words, given the terminal conditions, the model solves backwards to identify the "ideal" initial conditions. We suspect that these ideal initial conditions involve a relatively high (and definitely non-zero) share of renewable electricity generation. Because the actual initial capacity and generation in renewables are much lower than those identified as "ideal", the model undertakes a large investment in renewables within the first periods, in order to jump onto the optimal path as soon as possible and subsequently follow this path.

\section{5) Future Research}

The model presented in the previous sections still contains a number of flaws that could not be solved within the bounds of this Master's Thesis. The first noticeable weakness inherent to this model is the simplistic assumption on the lag between capacity investment and plant construction and installation. Although the lag between investment and actual plant installation currently constitutes a significant barrier to renewable energy development (in particular for new technologies such as wave energy, which entail a significant lag), the capacity accumulation process underlying this model implies that all types of generation plants are operational one period after 
investment is made. Setting a longer delay between investment and construction for renewable energy technologies would ensure that current, relevant challenges such as installing the plants and obtaining permits are accounted for. Ideally, the model should be specified so that each technology would have a specific investment/installation delay, depending on variables such as the amount of permits required and construction experience. Such delays may become smaller over time, as the process of obtaining environmental permits becomes easier and industries gain from experience and learning-by-doing. The specification of capacity accumulation equations for each technology could be done on an ad-hoc basis, and updated with the accumulation of data and experience. Unfortunately, there is little experience in wave energy to fine-tune our equations. However, it seems unlikely that that correcting for this simplistic assumption would change the core of the model output. As previously explained, the model sets out an optimal capacity accumulation process, given a number of exogenous parameters such as fuel price, investment price, and output target. The assumption that installation can occur one period after investment for all types of plants has resulted in model outputs involving the installation of a large amount of renewable energy capacity in little time (see, for instance, scenario 1, where the energy planner installs almost $2000 \mathrm{MW}$ of wind energy capacity in period 1). If the period between investment and installation for renewables was set to be longer, say 5 years, the core of the model output would remain similar: the optimal capacity accumulation path would remain the same, the energy planner would simply not be able to meet this optimal path as early as period 1, but from period 5. In other words, this simplistic assumption only impacts on the speed at which the energy planner can "jump" onto the optimal capacity accumulation path.

Another weakness of the model's capacity accumulation process is the failure to account for both lumpiness and economies of scale in investments for electricity generating capacity. While installing small amounts of wind energy capacity at a time may be feasible, it is not the case for non-renewable plants. Ideally, the capacity investment equations should contain a limit which specifies the minimum amount of generating capacity to be installed at a time. In addition, an assumption inherent to the model specifications is that the price of each plant does not vary with size, meaning that there are no economies of scale for investment in generating capacity. While this assumption does not change anything with regards to feasibility, economies of scale 
are very important to investment decisions in electricity generation, and the subsequent price of electricity.

Finally, a major weakness inherent to the specification of this model is the linearity of the renewable electricity production functions, which entails the "domination" of one renewable energy technology over the other. This technology domination (or preference) became particularly obvious in scenario $b$, where the optimal value of $\bar{v}$ was found to be zero, leading to a high wave-energy share of renewable generation. Looking back at equation 6 , both renewable technologies have the same linear production function. However, wave energy has a higher capacity factor than wind energy, which makes the production of electricity more efficient with wave energy than with wind energy. It is suspected that this preference for wave energy is also partly due to the faster decrease in the wave energy investment price, given that the growth of investment price appears directly in the investment co-state variable. In any case, linear production functions of renewable electricity lead to a corner solution: the optimal $\bar{v}$ is always going to be either zero or one, because the production function of one technology will dominate the other.

One way of dealing with this problem would be to set non-linear production functions for renewable energy technologies. Non-linearity would entail an interior solution with respect to the ideal combination of renewable energy resources, $\bar{v}$. Having an interior solution would then be useful to find the combination of renewable energy resources which maximises reliability, or minimizes the amount of non-renewable backup required to maintain reliability. This would enable a proper integration of portfolio analysis into the model. While the modelling work above had no mutual backup of renewables " $a$ " by renewables " $b$ ", a more sophisticated version would definitely need to incorporate this. The following diagram provides an intuitive framework for this concept. 


\section{Figure 5.15: Framework for Reliability with a Portfolio of Renewable Energy}

\section{Reliability, \%}

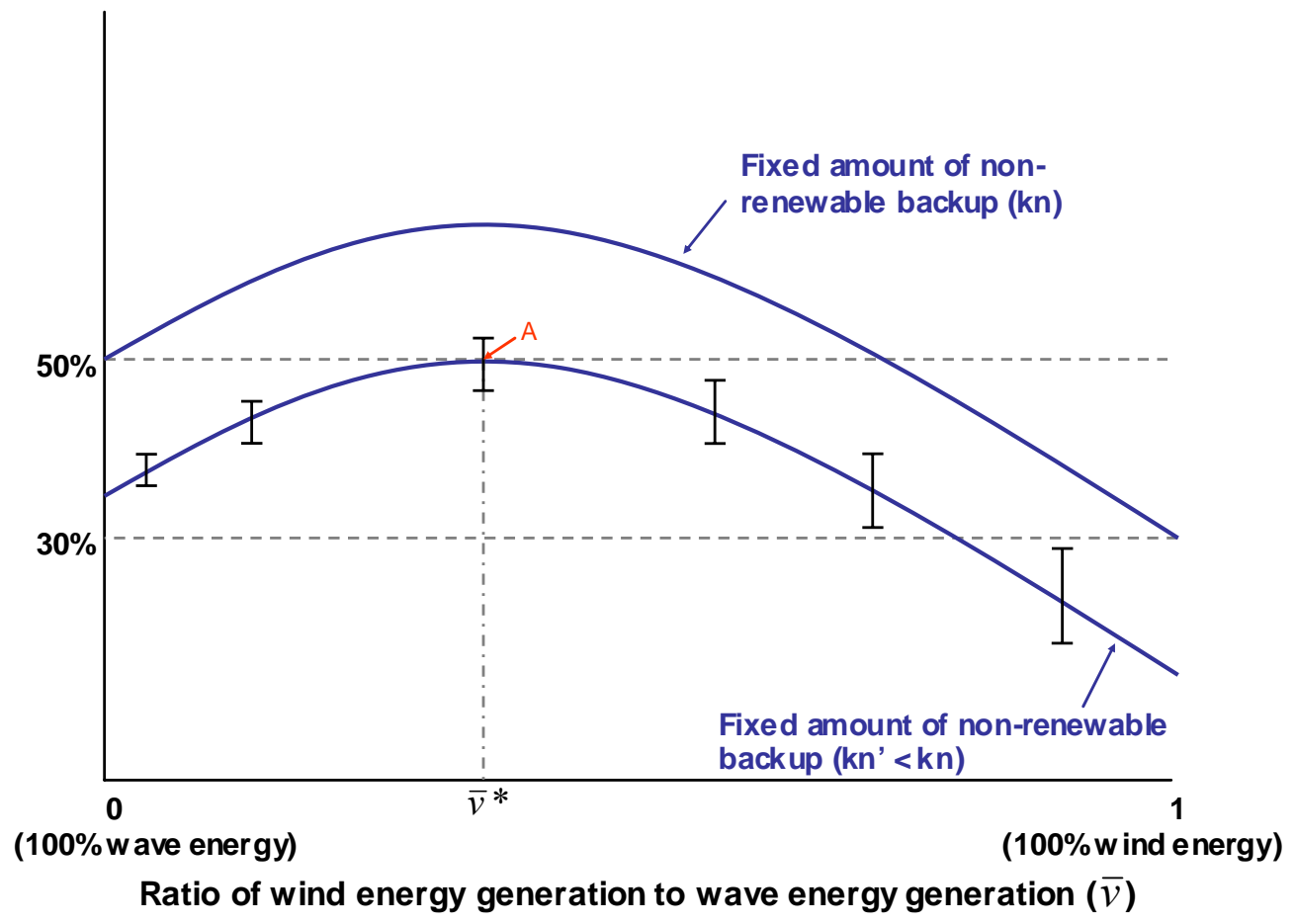

The concave functions display the relation between reliability of electricity supply, expressed as a percentage, and the ratio of wind energy to wave energy generation, $\bar{v}$, for a fixed amount of non-renewable back-up capacity. For simplicity and consistency, we assume that there are only two large-scale renewable energy technologies available: wind and wave energy. As was the case in section 3, when $\bar{v}$ equals zero, all renewable electricity generation comes from wave energy; when it is equal to one, all renewable electricity generation comes from wind energy.

The curves displayed in figure 5.8 are concave; there is diminishing substitutability between wind and wave energy in terms of reliability. As explained in chapter 3, the more diverse the resources, the higher the reliability of supply: adding some wave energy capacity to a system where all renewable energy is generated from wind power will increase the reliability of supply. Similarly, adding wind energy to a system which consists of solely wave energy for renewable generation will lead to an increase in reliability of supply. However, there is a point after which adding wind energy will no longer increase reliability (e.g. point A on the lower curve): as $\bar{v}$ 
approaches 1, there is less diversity. Hence, when looking at the relationship between reliability of renewable energy supply and the combination of renewable resources used, it makes more sense to have an interior solution than a corner solution. Intuitively, one might expect to find this interior solution close to $\bar{v}=0.5$. In the figure, however, the local maximum is drawn to occur below $\bar{v}=0.5$, reflecting the likelihood that wave energy is inherently more reliable than wind energy (hence, reliability is higher when $\bar{v}=0$ than when $\bar{v}=1)$. This assumption reflects the fact that wave energy is characterised as more continuous, more predictable, and with a higher power density than wind energy (Power Projects Limited, 2005).

The error bars displayed on the lower curve provide a measure of uncertainty with respect to the level of reliability for different values of $\bar{v}$. The error bars become wider as $\bar{v}$ increases because wave energy is considered more predictable than wind energy.

The diagram displayed in figure 5.8 presents an innovative way of thinking about portfolio analysis, which was mentioned in chapter 3: increasing the diversity of renewable electricity generating resources leads to an increase in reliability of supply. Observing and calibrating the correlation between outputs of different renewable energy resources will likely lead to significant improvements in reliability of renewable energy supply at any given cost, with better investments in backup capacity. For instance, the hypothetical diagram above shows that the level of reliability (50 percent) achieved by using solely wave energy generation on the higher curve can also be achieved with an ideal combination $\bar{v}^{*}$ of wind and wave energy (point A on the lower curve), which is cheaper as it requires less backup $\left(k_{n}{ }^{\prime}<k_{n}\right)$. If a minimum of 50 percent reliability was required at all times, one may consider investing in more non-renewable backup capacity, shifting the lower curve up so that the lower part of the error bar at point A corresponds to 50 percent reliability. This option would remain cheaper than using solely one resource for renewable electricity generation.

Rewriting the renewable production functions as non-linear and introducing interdependency amongst renewables would thus enable a deeper analysis of reliability using renewable energy resources, which is particularly important to Pacific 
Islands. Future research in this area may also require a redefinition of the concept of reliability. In reality, the duration and frequency of power interruptions are important, as well as the time at which these interruptions occur. However, rewriting the renewable production functions and reliability functions would entail complications for the model, which are beyond the scope of this thesis. 


\section{Chapter Six: Policies and Market Instruments to Promote Renewable Energy in Pacific Islands}

\section{1) Barriers to the Development of Renewable Energy in Pacific Islands}

The potential for Pacific Island Countries to generate electricity using renewable energy is significant, given their endowments in various renewable energy sources and the availability of an increasing range of renewable energy technologies. Yet these countries are even more heavily reliant on imported fossil fuels for electricity supply than the typical country in the world economy. Part of the explanation for limited market penetration by renewables is the economic issues analysed in Chapter 4. However, it is also true that renewable energy technologies face strong institutional and market barriers - which may be specific to a technology, a country or region (Painuly, 2001) - in addition to a variety of market failures. This section provides an identification of the structural and institutional barriers to renewable energy development, with particular reference to the context of Pacific Island Countries.

Pacific Islands are remote, isolated, and fragmented countries. These geographic characteristics, coupled with small and dispersed populations, place important constraints on the production of electricity. In most islands, there is little opportunity to benefit from economies of scale because of the small size of markets, their geographical fragmentation, and the inability to connect to a bigger continental grid (Mayer, 2000; Stuart, 2006). Due to low absolute demand, Pacific Islands do not have bulk electricity markets so that there is little room for competition and consequent price reductions (Weisser, 2004). In most islands, electricity supply is in the hands of vertically integrated monopolies which have control over all stages of power generation, transmission and distribution (see chapter 2). The lack of incentive for existing electric utilities to buy or produce renewable energy has been identified as a significant market barrier for the development of renewables worldwide (Neuhoff, 2004), and monopolistic market structures hinder the deployment of renewables further. For example, utilities may set burdensome and expensive interconnection 
requirements for independent power producers. Hence, renewable energy producers have no or limited access to electricity grids in Pacific Islands. In addition, if access to the grid is granted, the intermittency of renewable energy can become an issue because utilities often pay independent producers solely for the energy value of their production, not the capacity value of the generation.

There is typically little opportunity for profit in small, remote islands, even though renewable energy projects may be less expensive than non-renewable energy in such areas (Weisser, 2004). As explained in chapter 2, due to the small size of the markets electricity demand is lumpy and can vary sharply with the construction of a new business or resort, which can make predictions of demand growth difficult (especially since large new enterprises can choose to self-supply in preference to relying on local grid supply). This may have limited the ability of electricity suppliers and potential investors to plan capacity expansion on an integrated basis, resulting in little commitment to renewable energy.

With little or no competition for electricity production, there is little opportunity to create markets for green electricity; but such market structures could ease the implementation and monitoring of policies aimed at increasing the share of renewables in a generating mix. Clear legal and regulatory frameworks for independent producers, especially with respect to power purchase agreements with the utilities, would also encourage and support the deployment of renewables. More independence for regulatory bodies could potentially ensure better frameworks to reduce the influence of incumbent suppliers, and enhance new private sector participation in the industry.

The presence of direct and indirect subsidies for fuel-based generating technologies clearly distorts incentives for electric utilities to invest in renewables. This is especially the case since the cost structure of renewable energy technologies is different to that of conventional technologies. Renewable energy technologies involve high initial capital costs, and little input costs thereafter. While some utilities benefit from import tax exemptions for fuel inputs, the high investment costs of renewable energy technologies are often exacerbated by high taxes and import duties (Wade, $\mathrm{H}$. et al., 2005, Volume 1 p.84). Electricity generating technologies typically last for 
decades, which makes it difficult to radically change the electricity generating mix once an investment decision has been made. Partly for this reason, Neuhoff (2004) argues that the energy industry is characterised by a strong technology lock-out which impedes renewable energy development.

Another market distortion which affects the competitiveness of renewables related to fossil fuel technologies is the absence of recognition of the costs related to fossil fuel price volatility. Price volatility is believed to have significant, negative impacts on macroeconomic activity as measured by GDP growth, employment and inflation (Awerbuch, 2004b, p.8). Increasing the amount of renewable energy leads to a more diversified electricity generating mix and reduces the costs related to fuel price volatility (see the section on portfolio theory in chapter 3 ). Nevertheless, such costs are typically not accounted for in utilities' pricing or investment decisions ${ }^{46}$. This is especially the case for Pacific Islands: in some countries, such as Guam and Hawaii, the distortion is exacerbated by the fact that fuel costs are passed on to consumers. Similarly, in Palau, Vanuatu and the Solomon Islands, electricity tariffs contain a fuel price adjustment component (Wade et al., 2005, Vol. 9, p.13, Vol. 16 p.14, Vol. 12 p.18). In Kiribati, Tokelau and the Marshall Islands, all fuels used by the electric utilities (PUB, Taupulegas and MEC respectively) are exempt from taxes and import duties (Wade et al., 2005). Other market distortions in Pacific Islands include government subsidies for conventional electricity supply and fossil fuels and pricing electricity below its average cost of production (Wade et al., 2005, Vol.1 p.29), which undermine the economic viability of renewable energy technologies. Furthermore, it is particularly difficult to evaluate the amount and impact of these subsidies as they are rarely transparent, and information on electricity and energy costs is difficult to obtain (Wade et al., 2005).

In addition to existing distortions in electricity markets themselves, a number of characteristics inherent to the financial, institutional and regulatory environments hinder renewable energy development in Pacific Islands. Perhaps the most noticeable institutional obstacle to the development of renewables in most Pacific Islands is the

\footnotetext{
${ }^{46}$ On the other hand, the high capital cost and uncertainty associated with renewable energy technologies (such as survivability, potential licensing and construction delays) constitute risks which are of primary concern to (reluctant) investors.
} 
lack of clear, recent national energy policies (see chapter 2). Most governments of the Pacific Islands have at least expressed the desire to enhance the implementation of renewables (Domah, 2002; World Bank, 1992; Wade et al., 2005). Some island countries have recently developed national energy policies, and others are currently reviewing their policies with regards to renewable energy (e.g. New Caledonia). However, in a majority of islands, energy policies, if available, do not prioritize renewable energy, and lack specific objectives and implementation procedures for renewable energy development (Weisser, 2004, Wade et al., 2005).

Another issue which impedes renewable energy development, and helps to explain the lack of accurate energy planning, is the lack of financial and human resources for energy departments in Pacific Islands. This is reflected in table 6.1 below (from Wade et al., 2005), which displays information on the size of Pacific Islands' energy offices and their authority. Yu and Taplin (1997) note that "experience in the region suggests that promoting the capabilities of energy institutions related to planning, implementation, management and technical training will be an important approach for developing renewable energy" (Yu and Taplin, 1997, p.116). Such capabilities depend directly on the availability of qualified personnel. The lack of energy policymakers, energy economists, technicians and managers in Pacific Islands has hampered energy planning for decades ( $\mathrm{Yu}$ and Taplin, 1997). Furthermore, inadequate funding allocated to energy offices makes the monitoring, following up and rehabilitation of renewable energy projects difficult (Wade et al., 2005, Volume 1, p.84). 
Table 6.1: Overview of PIC National Energy Office Staffing and Authority

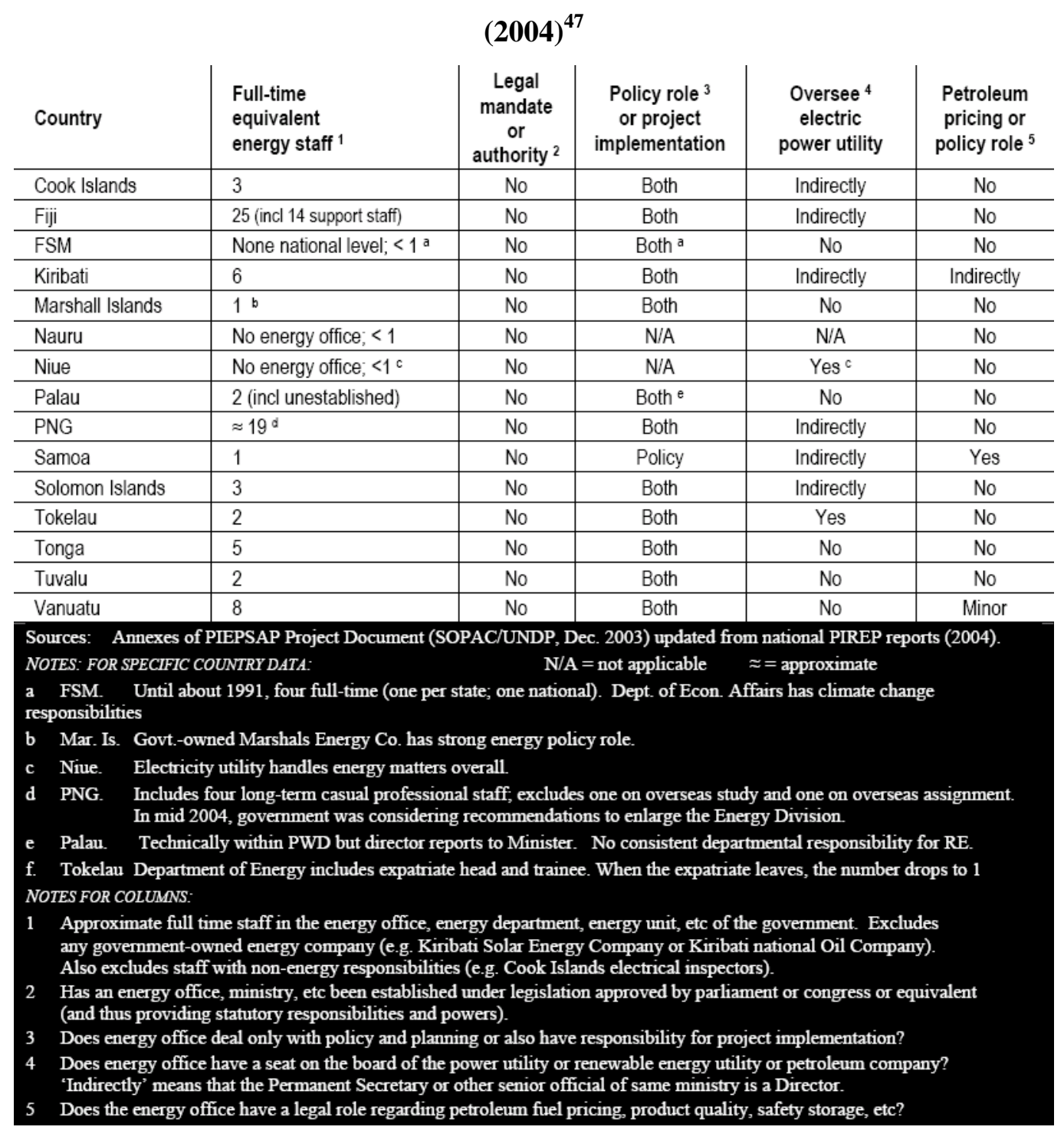

Finally, limited access to credit and financial resources in Pacific Islands impedes the large upfront capital investments required for deploying renewable energy technologies. Aside from aid from international donor organisations, there are few financing mechanisms for renewable energy in the Pacific Islands. Renewable plants involve particular costs and benefits, which should be accounted for by financing authorities. For example, the implementation of renewable energy technologies involves high upfront capital costs compared to traditional electricity generating technologies. Providing low-interest loans for renewable energy investments would therefore encourage investments at the local level.

\footnotetext{
${ }^{47}$ Source: Wade et al. (2005) Vol. 1, p.16
} 
In addition to the regional characteristics and market barriers which hinder the deployment of renewable energy technologies in Pacific Islands, there exist five types of market failures which are fundamental: unpriced costs and benefits due to the existence of environmental and knowledge externalities, high transaction costs, adoption externalities, and the absence of thick markets.

\section{Environmental Externalities}

The challenge to developing renewable energy technology markets and increasing their contribution to electricity generating mixes first relates to their competition against conventional, fossil fuel technologies which have been long established in a world where energy supply is considered critical to a country's economic development ${ }^{48}$. Conventional technologies benefit from a first-mover advantage in the sense that electricity supply decisions and tariff structures have been shaped by the long predominance of fossil fuel generation in electricity markets (Neuhoff, 2004). The production costs of conventional technologies have been significantly reduced with long experience, mass production, and large government subsidies.

While renewable energy technologies still have much to gain from learning by doing (by "improving efficiency, reducing their costs and develop mature, self-sustaining industries to manufacture, install and maintain those systems" - Sawin, 2004) they are forced to compete with these established traditional technologies on the basis of price. Neuhoff (Neuhoff, 2004, p.6) refers to an "uneven playing-field" between traditional and emerging renewable technologies. A major reason for this is that traditional energy pricing does not reflect accurately the social and economic risks of different energy options, starting with the failure to internalise the costs of environmental externalities in electricity production and consumption. The implementation of an environmental tax for the production of non-renewable electricity, for example, would give electric utilities an incentive to use renewables (Menanteau et al., 2003). Without such taxes, the environmental benefits of renewable energy technologies as opposed to conventional technologies are not accounted for in investment decision-making, while the costs of intermittency are explicitly considered, leading to under-investment

\footnotetext{
${ }^{48}$ For instance, Newbery (2005) states the importance of energy to a country's macroeconomic development.
} 
in renewables relative to the social optimum. This effect is exacerbated by a lack of information on emissions from the utilities in Pacific Islands.

The absence of a market or cost for environmental externalities from electricity production in Pacific Islands creates an incentive problem, in which electric utilities do not bear the consequences of their investment decisions, meaning that they have no incentive to invest in "clean" generating capacity such as renewable energy technologies. Yet, implementing an optimal environmental tax is practically difficult, and may not be sufficient to support renewables until their costs are driven down by the learning process (Menanteau et al., 2003) ${ }^{49}$.

\section{Knowledge Externalities}

Jaffe et al. (2005, p.166) argue that market failures associated with pollution externalities interact with market failures associated with knowledge externalities. Contrary to the pollution externality, innovation and knowledge are in essence positive externalities, yet the failure to account for this externality also leads to a suboptimal level of investment. Because knowledge is a non-rival and more or less non-excludable good, it retains the characteristics of a public good, with which the problem of free riding is traditionally associated. As explained by Jaffe, "innovative firms cannot keep other firms from also benefiting from their new knowledge and therefore cannot capture for themselves all the benefits to the innovation"(Jaffe, 2000), leading to a reduced incentive to invest in technology development. Hence, while the failure to internalise the costs of environmental externalities leads to little incentive to buy and use renewables, the failure to internalise the costs of knowledge externalities creates little incentive to innovate and develop renewables on the supply side. The uptake of renewables is thus hindered by market failures which create a double-sided incentive problem: failures to account for environmental and knowledge externalities.

\footnotetext{
${ }^{49}$ Most renewable energy technologies are relatively new technologies, so that their costs are likely to be driven down with the accumulation of production and experience (learning by doing, economies of scale, reduction of input prices...).
} 


\section{High transaction costs}

Renewable energy projects typically involve a smaller installed capacity than traditional energy projects; however, implementing a renewable energy project may require additional costs related to resource assessments, utility connection and transmission, construction permits, and environmental impact assessments. For instance, in most Pacific Islands there is a significant lack of accurate data with respect to the availability of renewable energy resources, which can create uncertainty and increase the costs to renewable energy projects, as the cost of resource assessment would need to be borne by project developers ${ }^{50}$. In addition, renewable energy projects involve high information costs, due to the novelty of the technologies and because there is little information on the technologies available. Having little or no experience with renewables, local project developers need to allocate extra resources to acquire information on the quality and cost of each technology, to compare this information, and to determine which technology is the most appropriate for the Pacific Islands environment. While information costs are likely to decrease with experience, the perceived rate of risk of investing in an unfamiliar technology can initially be extremely high, affecting both investment and the ability to borrow from financial institutions, so that government intervention is required in order to foster experience, information and expectations.

These additional information and implementation costs make transaction costs higher for renewable energy projects than for conventional energy projects. High transaction costs can substantially deter market formation even when the exchange of a good is beneficial and desirable; the exchange is unlikely to occur if it is prohibitively expensive to set up (Jaffe et al., 2005).

\section{Adoption Externalities}

High transaction costs induce little effort in implementing renewable energy technologies in markets such as Pacific Islands. This problem is exacerbated because of "adoption externalities", which Jaffe et al. characterise as "dynamic increasing

\footnotetext{
${ }^{50}$ Nevertheless, this seems to have improved in the last few years, thanks to regional institutions such as SOPAC (which has released specific assessment reports on wind, solar, geothermal resources in different islands) and SPREP, as well as local corporations such as SRP, which has been studying the potential for wave energy in some Pacific Islands since early 2006.
} 
returns due to learning-by-using" (Jaffe et al., 2005, p.167): even if environmental externalities were accounted for, investors and electric utilities would rather wait for others to invest and install renewable capacity, as transaction costs are likely to decrease once a number of renewable energy projects have been implemented. Moreover, once a project developer has installed a new technology successfully, other firms become more confident about the technology and benefit from additional information on its characteristics. In addition to learning-by-using effects, adoption externalities include learning-by-doing, an effect associated with the learning curve. A learning curve shows the empirical relationship between costs and accumulated production or capacity (Ibenholt, 2002, p.1181). This relationship is typically negative, revealing a cost reduction for a technology over time due to learning by doing and production experience (e.g. finding the minimum efficient scale, finding cheaper inputs and assembling the technologies in different countries). Hence, given that most renewable energy technologies are still at a relatively early development stage or production process, investors have an incentive to defer investments in renewables until the production costs have decreased further.

\section{Thin Markets}

While this may be considered a result of inherent, geographical characteristics rather than a market failure, the size and nature of electricity markets in Pacific Islands constitute constraints on the amount of renewable energy which can be handled by these systems while maintaining reliability of supply. The ability to deal with intermittency in electricity supply involves constraints on both quantity and diversity of supply. Thick markets, which involve large volume of supply and activity, imply a greater ability to maintain a reliable supply of electricity, even when dealing with large amounts of intermittency. To illustrate this point, imagine a large country with a large and competitive market for electricity, a wide range of energy resources, and a renewable portfolio standard under which renewable energy is required to supply 20 percent of total annual electricity supply. Supposing that wind energy constitutes the most exploited renewable energy resource; under such market conditions (with a large number of different types of electricity producers), in the absence of wind the system operator would be able to contract a different type of supplier (selling hydroelectricity, or power from an oil or diesel plant) immediately in order to ensure that electricity 
supply matches electricity consumption. That is, intermittency is less of a problem in thick markets. Although Pacific Island Countries benefit from a diverse range of renewable energy resources (hence the possibility to ensure diversity of electricity supply and to use a renewable resource to back up another one), the size of these countries does not necessarily allow for a large number of electricity producers, given that producers have little opportunity to reap economies of scale. In other words, competition for electricity supply is constrained by the size of the markets, hence the presence of thin markets; which results, ceteris paribus, in a smaller ability to deal with intermittency.

Environmental and knowledge externalities, high transaction costs, adoption externalities, and thin markets constitute market failures which impede renewable energy development. Market failures mean that the existing markets fail to achieve the efficient allocation that perfectly competitive markets would foster (Newbery, 1989). Under such circumstances, renewable energy projects in Pacific Islands will probably remain funded by aid and donor agencies for a long time. In order to foster a commercial, competitive deployment of renewables, there are a variety of policies which could be implemented to address the market failures. In particular, policies may target high transaction costs, which constitute one of the most substantial market failures for renewable energy in Pacific Islands. The traditional technology choice for electricity supply is unlikely to change if it remains expensive to implement a new technology - even if the capital cost of the renewable technology is the same as that of the traditional technology. On the other hand, some of the market failures listed above may not necessarily need to be addressed. For example, knowledge externalities are not particularly relevant to Pacific Islands: it can be assumed that most Pacific Island Countries would have insufficient resources to develop and export a technology of their own. In addition, the market failure caused by adoption externalities may be addressed by decreasing the transaction costs to renewable energy projects. The following section provides a description of the different policy instruments available, as well as an evaluation of these policies for addressing the market failures in the Pacific Islands context. 


\section{2) Policies and Instruments to Facilitate Renewable Energy Development}

Since the late 90 s a range of policies aimed at accelerating the development of renewables have been introduced worldwide, notably in Europe and the United States. These policies were motivated by a number of factors and could almost be qualified as multipurpose policies, aiming not only at reducing carbon emissions to meet Kyoto Protocol targets, but also at developing the renewable energy industry with the prospects of subsequently exporting high quality renewable energy technologies to the world by being first-movers in the production of such technologies. This increasing support also comes from an acknowledgement both of the benefits brought by the use of renewables, and of the existence of market failures which impede renewable energy development. Pacific Islands Countries could potentially benefit greatly from an increased use of renewables, enabling them to pursue sustainable socio-economic development and to reduce reliance on expensive fossil fuel imports. Furthermore, while the prospects for Pacific Island Countries to develop a technology of their own are still low, Pacific Island Countries could benefit economically by developing local industries around the installation and servicing of renewables (including assembling and maintaining imported technologies).

The variety of instruments which provide incentives for the development of renewable energy technologies have been evaluated in numerous studies (Sawin, 2004; Butler and Neuhoff, 2004...). Beck and Martinot (2004) classify such policies into four main categories: mandated market policies (price-setting and quantity-forcing policies), cost reduction policies (or financial incentives), public investment and market facilitation activities, and power grid access policies.

\section{a). Mandated market policies: a renewed debate on prices vs. quantities}

Price and quantity instruments have long been the subject of debates on environmental policy. While Coase $(1960$, p.44) argued that "the right to do something which has a harmful effect is also a factor of production" and that taxing pollution leads to inefficiency when polluting agents can bargain with "harmed" agents, the issue of global warming has become significant enough to lead to the general consent that pollution ought to be dealt with by penalizing polluting agents (in 
line with the OECD's adoption of the polluter-pays principle in 1972). The debate on prices and quantities was traditionally focused on how to regulate environmental externalities such as pollution (using either a pollution quota or a pollution tax). While such instruments are still in use (carbon tax and carbon credits), the discussion seems to have recently drifted to a new set of instruments which aim at promoting renewable energy technologies.

\section{i) Price-setting policies: feed-in laws}

Price-setting policies establish stable, favourable pricing regimes for renewables (Beck and Martinot, 2004) and are often coupled with regulations which ease the connection of independent producers to electricity grids (Wiser et al., 2002). Under a price setting policy, electric utilities are obliged to purchase electricity produced from renewable energy resources at a guaranteed, predetermined price for a specific amount of time (typically between 15 and 20 years). The price is typically set higher than the market price, acting as a subsidy towards renewable energy producers, and is adjusted regularly in order to account for changes in the technologies costs and efficiency. It has been noted that the countries which have experienced the greatest deployment of renewables and created the strongest domestic industries are those which have enacted feed-in laws (International Conference for Renewable Energy, 2004, p.14; World Bank Renewable Energy Toolkit, 2006).

A number of pricing policies used to offer a price expressed as a fixed percentage of the retail electric price (e.g. 85 percent of the retail rate in Denmark, 90 percent in Germany $^{51}$ ), but these policies were revised in the late 1990s and today most pricing laws provide a fixed payment for renewable electricity (Sawin, 2004; World Bank Renewable Energy Toolkit, 2006). The feed-in tariff may vary according to the technology used and/or location of the plant. Differentiating prices according to each type of technology allows for the deployment of different technologies which are at a different development stages (e.g. wind, solar, wave, tidal). Offering higher payments for projects located on sites which comprise lower renewable resources constitutes a way of dealing with competition for project sites. By providing a compensation for

\footnotetext{
${ }^{51}$ Wiser et al. (2002). p.3.
} 
lower production, the German feed-in tariff has led to a more "uniform" development of wind projects with respect to location. In addition, this type of scheme prevents the creation of scarcity rents by land owners or project developers associated with high wind sites (Butler and Neuhoff, 2004).

As argued by Menanteau et al. (2003), the feed-in tariff system works similarly to a pollution tax for polluting firms. In the case of a feed-in tariff, the price for renewable energy is fixed and the quantity of renewable energy produced depends on the marginal cost curve of the producers, which is typically unknown. The total amount of subsidy (if any) given to renewable energy producers is thus initially unknown. Just as the main criticism of a pollution tax relates to an uncertain amount of pollution reduction, feed-in tariffs are often criticised for creating large and uncertain government expenditures ${ }^{52}$. In addition, because the quantity of renewable electricity supplied is initially unknown, a feed-in tariff policy which induces more renewable energy supply than expected can result in "excess" intermittency. Unpredicted excess intermittency could lead to a decrease in reliability of electricity supply, depending on the type of renewables used and the size of the system and existing "firm" supplygiven the size of electric systems and the importance of reliability in most Pacific Islands, this could become a significant issue in these countries. While striving to increase the amount of renewables, such countries may not be able or willing to accommodate a large amount of renewables at first. Hence, if implemented in Pacific Islands, pricing policies should include requirements with respect to renewable energy backup and intermittency. Alternatively, a pricing policy may be combined with a Renewable Portfolio Standard or a maximum target share of renewable energy in electricity supply.

A feed-in tariff is generally funded either by levying an additional charge per $\mathrm{kWh}$ on all electricity customers (such as in Spain, Italy, and the USA), or by a combination of additional charges for all customers and reimbursement of a carbon tax - such as in Denmark (World Bank Renewable Energy Toolkit, 2006). Until 2000, the German feed-in law required the customers of only some utilities to purchase green electricity,

\footnotetext{
52 Butler and Neuhoff (2004), p.9; Wohlgemuth and Madlener (2000) p.2 ("potentially exponential public expenditure"); Menanteau et al. (2003) p.804.
} 
however this mechanism was modified as it was considered inequitable, 'placing a disproportionate burden on utility customers in regions where wind power development was heaviest'(Beck and Martinot, 2004, p.8).

The first feed-in tariff measure, the Public Utilities Regulatory Act (PURPA), was enacted in the United States in 1978. PURPA requires utilities to purchase electricity from qualifying facilities, including renewable energy plants, at avoided costs of production (see the Hawaii case study in chapter 4). Since then, feed-in laws have been implemented in a large number of European countries as well as South Korea, Israel, Brazil, and China ${ }^{53}$. Pricing policies may also be implemented with mandated targets for renewable energy (as in China, Brazil and the United States), which creates more certainty with regards to the quantity of renewable energy produced.

By providing guaranteed, profitable prices and long-term grid access to renewable energy producers, feed-in laws can lead to a significant reduction in uncertainty and risk and thus create a stable environment for investment in renewables (Goldstein et al 1999). Nevertheless, it is important to remember that such policies have not always been successful. The success of a pricing policy depends on a number of critical factors, such as the level of the feed-in tariff, its duration, charges for access to the electric grid, and permitting process. Goldstein et al. (1999) consider that feed-in laws have been less effective in countries which chose lower tariffs (e.g. \$US 0.032/kWh in Sweden, compared to \$US $0.07 / \mathrm{kWh}$ in Portugal). Prices must be sufficiently high to stimulate the development of renewables, and they should be guaranteed for long enough to provide investors with an acceptable return on investment (Goldstein et al., 1999, p.7). Ideally, a pricing policy should have a simple design that allows for low administrative costs, and be flexible in order to adjust for the evolvement of cost efficiency. Enacting other policies such as financial incentive policies, as well as standardizing interconnection requirements, would also improve the effectiveness of a pricing policy.

Criticisms of feed-in tariffs mostly relate to excess profits and cost reduction. It has been argued that such policies do not encourage renewable energy cost reduction

\footnotetext{
${ }^{53}$ IEA Global Renewable Energy Policies and Measures Database,
} www.iea.org/textbase/pmsdb/grresult.aspx? $\operatorname{mode}=$ gr 
(Sawin, 2004, p.12). While feed-in tariffs do not directly create price competition among renewable energy project developers, firms still have an incentive to lower their costs in order to benefit more from the subsidy. Another argument against feedin tariffs is that "setting the price too high may result in excess profits to renewable energy producers at the expense of electricity consumers" (Van der Linden, 2005). This possibility arises from the lack of information on the costs of production of the technologies, which also leads to uncertainty with respect to the amount of renewables which will be deployed. It may be possible to restrain excessive profits by implementing a feed-in tariff which decreases over time according to technological advances or market changes.

\section{ii) Quantity-based policies}

\section{Tendering Policies}

Under a tendering policy, the government schedules several competitive bidding rounds to achieve a renewable energy generation or capacity target. The government may also specify a maximum price per $\mathrm{kWh}$ for the bids. The bidding process typically involves price-based competition among renewable energy project developers over long-term contracts in the form of power purchase agreements with electric utilities and/or access to government financial support (Van der Linden, 2005). Successful bidders may be guaranteed their bid price for the period of the contract. Tendering policies are sometimes argued to be more compatible with open electricity markets (World Bank Renewable Energy Toolkit, 2006). In some countries, competitive bidding has also been used to implement concession programs (China, Norway). Note that there may be different tenders for different technologies, so that companies within a given technology band compete with each other.

While feed-in laws involve setting a price for renewables, tendering policies involve the specification of a desired quantity of renewables. Unlike a feed-in tariff, not all renewable energy companies can benefit from a tendering policy. Only those who submit proposals at the lowest price are selected for a guaranteed purchase. This process thus aims at fostering competition by giving incentives for renewable project developers to reduce their price. Unfortunately, such policies have not always worked as expected. 
Tendering policies have been used in the UK, Ireland (AER program), France (EOLE program), China, Norway and the United States. The most cited example is that of the UK's Non-Fossil-Fuel Obligation (NFFO) policy, which was implemented from 1990 to 1997 . The NFFO involved four bidding rounds, with an overall capacity target of $1500 \mathrm{MW}$ for renewables. It required lower prices at each round. The government placed a national levy on fossil fuels to pay for any difference between the market price and the successful bid, on the assumption that bids reflected incremental cost. Although the NFFO led to a rapid decrease in prices of renewable electricity, notably for onshore wind energy, this program has been criticized for encouraging renewable project developers to bid below cost in order to capture contracts (World Bank Renewable Energy Toolkit, 2006). This distorted incentive resulted in a number of projects which were never carried out due to the inability of successful bidders to meet the terms of their contract. The World Bank reports that only 25 percent of the capacity of awarded contracts has been installed. The NFFO scheme was finally replaced by a Renewables Obligation system. The three rounds of bidding for the Chinese Wind Concession program have had similar results: although eight developers have been selected since 2002, no project has been developed yet (World Bank Renewable Energy Toolkit, 2006). Similar policies in Ireland and California, however, were more successful and resulted in significant price decreases as stringent criteria for pre-qualifying bidders was applied, setting competition between bidders of similar quality levels (World Bank Renewable Energy Toolkit, 2006).

While quantity-setting policies have not always led to satisfying results after awarding contracts, these policies could be complemented by additional mechanisms or incentives in order to ensure credible enforcement and performance post-tender. For example, the California Renewable Energy Incentive Program successfully set incentives for early project implementation and penalties for project delays (projects that come on line before their target date are eligible for up to a ten percent bonus on top of original incentive bid, and project delays can result in a ten percent reduction in the bidder's incentive payment, or a fifty percent reduction if the project is delayed by a year after the target date, and no payment beyond a year $)^{54}$.

\footnotetext{
${ }^{54}$ World Bank Renewable Energy Toolkit, 2006.
} 


\section{Renewable Portfolio Standards and Tradable Certificates}

A renewable portfolio standard establishes a target quantity of renewable energy to be integrated into the energy mix by a specific date (Wiser et al, 2002). The target quantity, typically increasing over time, may be expressed in terms of output (as a minimum percentage of the total generation, or a fixed $\mathrm{MWh}$ requirement) or installed capacity (fixed MW requirement). It has been argued that energy-based requirements are preferable to capacity-based requirements as the latter entail a number of challenges with regards to performance incentives, allocation and calculating the value of renewable energy (Centre for Resource Solutions, 2001; Wiser et al., 2002). For example, under a capacity-based requirement, utilities may install renewable capacity, but they have less incentive to use this capacity or maintain it properly than would be the case under an energy-based requirement. To avoid this problem, capacity-based renewable portfolio standards can be complemented by a set of established technical performance standards. Alternatively, the capacity goal may be translated into an energy-based requirement, as in Texas (Center for Resource Solutions, 2001, p.3-4).

Market share mandates typically do not provide any specification with regards to the price of renewables introduced; however there must be penalties for utilities which do not comply with the standards. The additional costs of payments to renewable energy producers are generally covered by charging higher rates to all consumers as with feed-in laws (World Bank Renewable Energy Toolkit, 2006).

Renewable energy obligations can easily be implemented along with other policies such as tendering policies (as in the UK with the NFFO) and feed-in tariffs (as in Hawaii with PURPA). A number of countries have also used obligation systems in combination with Tradable Renewable Energy Certificates, or Green Certificates (the Netherlands, Belgium, Denmark, United Kingdom, and Australia). This sort of scheme involves the creation of a "paper" market for renewables that is independent of electricity sales (Beck and Martinot, 2004), where renewable energy producers obtain green certificates or renewable energy credits (RECs) for the electricity they generate. Renewable energy producers can thus sell these certificates on the green certificates market, in addition to selling their electricity to utilities at the market price 
(Menanteau et al., 2003). Tradable certificates serve both as a subsidy for renewable electricity producers and a means for checking whether the targets have been met by each participant. The certificates can be bought by utilities which are unable to meet their renewable energy obligations. Given that operators have different costs and opportunities for developing renewable energy, a tradable certificate scheme constitutes a flexible instrument for allocating renewable quotas efficiently and/or implementing quantitative aggregate emission limits (Menanteau et al, 2003; Bertram and Pauls, 2000; Van der Linden et al., 2005). Tradeable certificates represent an efficient way of creating a market for pollution and at the same time for renewable energy, by internalising the pollution externality which constitutes a market failure impeding the development of renewables. Importantly, this type of scheme also creates competition among renewable energy generators and project developers, providing incentives for cost reduction and increased efficiency of renewable energy technologies. In addition, by operating ex post and not ex ante, such schemes do not lead to the creation of perverse incentives such as understating costs and slow project completion, which have been major issues with tendering policies (Bertram and Pauls, 2000).

\section{iii) Discussion}

It has been widely recognised that policy instruments for renewable energy should above all create long-term, stable and consistent market environments in order to increase certainty for investors and project developers. Overall, there seems to be general consensus in the existing literature that feed-in systems are more effective than quantity-based instruments at promoting renewable energy by creating predictable and consistent markets (Sawin, 2004; German Federal Ministry for Economic Cooperation and Development, 2004; World Bank Renewable Energy Toolkit, 2006). Feed-in laws have generally been very successful in terms of renewable energy deployment, while a number of tendering policies have failed to meet their target renewable capacity. Tendering policies are known to be less expensive than price-setting policies, leading to a rapid decrease in price. However, Butler and Neuhoff (2004) compared the German feed-in tariff and UK's NFFO and ROC programs for onshore wind energy projects and found that when the difference in wind resource between the two countries is accounted for, the difference in price 
for wind energy projects in the two countries is much smaller than generally suggested (Butler and Neuhoff, 2004, p. 31). In addition, although tendering policies are meant to stimulate strong competition, Butler and Neuhoff found that the German feed-in tariff resulted in stronger competition among wind turbine producers and constructors, leading to significant developments in the industry. They also note that it is easier to differentiate prices according to the resources under a feed-in tariff, which prevents owner of projects in high wind sites from capturing large scarcity rents. Feed-in tariffs allow for more flexibility to account for different sites and resources, and for different development stages of renewable energy technologies, assuring more diversity.

By promoting least-cost projects, tendering policies may not provide sufficient investment to take new, more expensive technologies down the learning curve. Indeed, new renewable energy technologies will require a minimum of support before attaining a minimum cost of production: due to learning-by-doing and learning-by using effects, the costs of renewable electricity supply will considerably decrease as the industry grows (through adoption externalities, improved efficiency, finding the minimum efficient scale of the technologies). Additionally, given the use of competitive bidding, tendering policies base technology choice solely on a price criterion, which may not be appropriate in all cases. Some technologies may be designed more appropriately for certain environments, or for a certain amount of electricity demand. For example, for a solar photovoltaic system to function properly, the overall capability of the system should match the electrical needs of the users, as installing undersized panels can create problems (World Bank, 1992). Installing undersized panels has been recognised as one of the factors for unsuccessful solar energy programs in the Pacific Islands in the past (World Bank, 1994, Liebenthal et al., 1994). When installing a solar panel in a remote place such as an outer island in the Pacific where there is a low population density and low skill levels, it is important to choose high quality, low-maintenance systems in order to have the systems working for as long as possible, and to reduce the costs related to repair and maintenance. Selection of least-cost technology without allowance for quality differences may not lead to the most appropriate choices; the environmental, economical, and social characteristics of the countries should be accounted for, as well as the context in which the technologies are implemented. 
Tradable certificates have been criticised for the limited support they provide to less mature renewable energy technologies (Espey, 2001; Carbon Trust, 2006). For example, the United Kingdom's Renewables Obligation has lead to little development in offshore wind energy (Carbon Trust, 2006). It has also been argued that both types of quantity-based policies create instability and involve high administrative costs. With tendering policies, bidding rounds create a "stop and go" situation, altering periods of activity with periods of inactivity, which leads to instability (Butler and Neuhoff, 2004). Price volatility of tradable certificates can lead to significant uncertainty and have negative impacts on the behaviour of investors (Carbon Trust; Menanteau et al., 2003; Van der Linden, 2005). Quantity-based policies have been found to generate more risky, less rewarding environments for renewable energy developers (Espey, 2001; Sawin, 2004).

On the basis of the above arguments, a price-setting policy is likely to be more appropriate for the development of renewable energy technologies in Pacific Islands. Pricing laws tend to favour smaller companies (Sawin, 2004 p.4), whereas small developers have more difficulty financing their projects under tradable certificate systems and tendering policies (Sawin, 2004; Van der Linden, 2005). Wiser et al (2002) argue that tendering policies are unlikely to result in price decreases if implemented in a country which has not developed its own independent power producer industry. The success of tendering policies is likely to depend on the size of the market - enforcing a tendering policy in small Pacific Islands could result in a handful of companies developing the projects, leading to strong market power and little diversity. In order to ensure more competition in small markets, it might be sensible to enforce tenders in which all renewable energy technologies compete with each other. However, if this type of tender were implemented and involved a small quantity of supply, it would be likely to rule out large-scale technologies such as wave farms. For example, a Pelamis wave farm may not be modular enough to participate in a tender for $400 \mathrm{~kW}$. Even if each Pelamis device was rated at $400 \mathrm{~kW}$, this technology may still be ruled out because the installation of one single device would entail high costs compared to the installation of a farm of 10 Pelamis devices (the installation of such technology involves significant economies of scale). 
Implementation of a tradable certificates system in a country where there is a high degree of market concentration can result in the formation of cartels and abuse of market power. At the other end of the spectrum, a large number of small market participants can result in large administration and transaction costs (Espey, 2001, p.561). A tradable certificates scheme constitutes a very suitable approach for large countries which intend to fulfil multiple goals (reduction of carbon emissions, development of a domestic renewable energy industry) such as Australia and European countries. However, implementing a tradable certificates market in a country which operates only one utility would be effectively the same as implementing a feed-in tariff, but with higher administration costs, higher uncertainty, and less flexibility. Feed-in tariffs involve lower administration and transaction costs than tendering policies and tradable certificates, which are important characteristics in countries such as Pacific Islands, where policy and administration resources can be scarce, and where transaction costs are already a major barrier to renewable energy development.

Furthermore, feed-in tariffs provide enough flexibility to encourage the development of a range of different technologies which may be at different development stages, which would be useful as Pacific Island Countries benefit from a variety of renewable energy resources. In addition, the ability to differentiate prices according to the site or resource availability would make the implementation of renewable energy projects easier in such countries, particularly in places where native people own the land and may refuse the development of such projects.

Hence, a feed-in tariff is likely to be the most suitable policy for Pacific Islands. However, it is important to keep in mind that whatever instrument is chosen, it should be complemented with other policies or incentives, such as financial incentives and public investment, in order to target market failures such as knowledge externalities and asymmetric information. The following sections provide a description of financial incentives and public investment possibilities. 


\section{b). Cost-reduction policies: financial incentives}

Financial incentives help to reduce the initial capital costs of renewable technologies, and to address the issues related to high perceived risks of investing in renewables. Furthermore, providing incentives for increasing investment in renewable energy technologies is likely to help overcome issues such as adoption externalities and asymmetric information. There exist various types of financial incentives for accelerating renewable energy development. Although such incentives cannot be considered as substitutes for mandated market policies, they constitute flexible complements to these policies and can easily be targeted to specific technologies and groups of investors (Clement et al., 2005), and increase predictability and stability for investors and financing institutions. Financial incentives can apply to both investors and customers and may also be used to promote local manufacturing of renewable energy technologies (Clement et al., 2005; Wiser and Lewis, 2005). Similarly to mandated market policies, financial incentives may be gradually phased out as the renewable energy industry matures.

Tax incentives offer a reduction in the amount of taxes owed by a renewable energy company, investor, or consumer (Clement et al., 2005). An advantage of such incentives is that an institution administering taxes already exists in every country, making the organisation and administration of a tax incentive program relatively simple (Gutermuth, 1998, Gouchoe et al., 2002). There are various types of tax incentives: investment tax incentives (for investment in renewable energy projects), production tax incentives (for renewable energy production), property tax reduction to the owner of the land where renewable energy projects are installed, reduced income tax, reduction in value-added tax, and excise tax reductions (for the purchase of renewable energy equipment). Production tax incentives are generally preferred to investment tax incentives as they encourage performance, efficient use and good maintenance of renewable energy technologies rather than large amounts of investment in these technologies (Sawin, 2004). Other tax incentives include tax holidays, accelerated depreciation, and tax credits on research and development, demonstration or manufacturing (Clement et al., 2005). On the other hand, a government may also decide to implement taxes on conventional fuels, or carbon taxes. The most important is to create a stable market for renewable energy investors 
and to target aspects or needs which are not covered by mainstream renewable energy policies such as renewable portfolio standards and feed-in tariffs. Tax incentives, however, can only be useful if investors or customers owe sufficient tax to the government. Consequently, they cannot provide benefits to some organizations such as government agencies and schools (Gutermuth, 1998; Gouchoe et al., 2002).

Other financial incentives include long-term and low-interest loans, import duty reduction and favourable custom duties for renewable energy technologies. As noted by Lewis and Wiser (2005), import duty reductions and favourable custom duties may be applied to components of the technologies, in order to create favourable conditions for domestic manufacturing and assembling of renewable energy technologies.

\section{c). Public investment and market facilitation activities}

Market facilitation activities include support to market institutions and participants, and rules to encourage renewable energy technology deployment (Beck and Martinot, 2004. p.13). Similarly to financial incentives, these types of policies are unlikely to be sufficient to foster large-scale renewable energy development on their own; however their implementation are likely to be crucial for the success of any market-based policy in Pacific Islands. There exist various policies that help overcome market failures and barriers such as high transaction costs and high perceived risk, including design standards, accelerated siting and permiting, education and information.

Firstly, governments can encourage the use of renewable energy by purchasing and using renewables in public places and buildings. Public investment in renewables would both increase public awareness and reduce uncertainty with regards to the technologies (Sawin, 2004; Beck and Martinot, 2004). Direct participation in renewable energy projects may also help government officials to identify some market distortion or barriers and accordingly encourage the development relevant market facilitation policies.

Industry standards, such as equipment certification and design standards, as well as contractor certifications, ensure a uniform quality of equipment and installations

(Beck and Martinot, 2004), hence providing information on the quality of 
technologies for potential customers and buyers. Ideally, such standards may be adjusted to the geographical and environmental conditions of a given country. On the other hand, providing resource assessments, siting requirements and restrictions, and permitting standards can significantly lower transaction costs for renewable energy suppliers.

Additionally, the implementation of market-based policies in Pacific Islands would require setting consistent grid-connection and transmission standards, in order to facilitate the connection of independent power producers to the electric grids which are typically owned by a single electric utility. The goal is to create a stable and transparent framework for independent power producers, which is critical to renewable energy development in the context of market-based policies.

Another important type of public investment involves providing information to the general public on the benefits and characteristics of renewable energy technologies, resource availability, and the programs and policies implemented to support renewable energy (Sawin, 2004). Providing consumer education would enable consumers and investors to make informed decisions, while ensuring that all agents are aware of the incentives in place.

\section{d). Power grid access policies}

Power grid access policies, such as interconnection requirements, standard Power Purchase Agreements, Wheeling, and Net Metering, provide a framework for renewable energy independent producers to access power grids and transmission systems. The choice of power grid access policy may depend on the structure of the existing electricity market and, if implemented, the type of renewable energy mandated market policies in place. Power grid access policies are likely to be particularly important in countries where electricity is generated, transmitted and distributed by a single, vertically-integrated utility, as vertically-integrated monopoly utilities may be able to deter competition by restricting transmission access to independent renewable energy producers, or by charging high prices for transmission access. 
Standard Power Purchase Agreements are contracts which define the legal terms and conditions for the sale of power, the roles and responsibilities of the parties to the Power Purchase Agreement, interconnection and transmission provisions, tariff and price adjustments, operating requirements and restrictions, and dispute resolution mechanisms (World Bank Renewable Energy Toolkit, 2006). Such agreements typically accompany mandated market policies such as feed-in tariffs.

Interconnection requirements allow independent renewable energy producers to connect to power grids, and specify the conditions with which interconnection can occur (e.g. determine access charges and technical requirements). Interconnection regulation may be determined on its own, or as part of a Standard Power Purchase Agreement. Regardless of the policies implemented for renewable energy development, interconnection regulation is particularly important for renewable energy producers, since some renewable energy resources may be located far from the population centres (Beck and Martinot, 2004).

Alternatively, access to the transmission system may be opened by allowing power wheeling. Wheeling can be defined as the transmission of electricity by an entity that does not own or use the power it is transmitting (www.srpnet.com/competition/terms). Power wheeling would thus enable renewable energy producers to sell electricity directly to customers, without necessarily signing an agreement with the electric utilities. As noted by Schweppe, "wheeling is a mongrel concept resulting from mating two inherently different economic concepts: an ideal world of regulated utilities, and an ideal deregulated competitive market place. Wheeling would not exist at either extreme." (Schweppe, 1988).

Finally, net-metering policies allow electric utility customers to offset their purchase of electricity from the utility with excess electricity produced by their renewable system at a specified rate (see chapter four). Net-metering constitutes a type of feed-in tariff or power purchase agreement for small-scale renewable energy (often small wind turbines or solar panels). When a customer provides excess power with his own small-scale plant, this power is fed back into the grid, and the customer gets credit on his electricity bill. Essentially, excess power is thus "stored" on the grid until needed (Martinot et al., 2005). 


\section{3) Discussion}

Renewable energy technologies are facing significant market barriers and failures in Pacific Island Countries: insufficient information, unpriced environmental and adoption externalities creating incentive problems, high transaction costs, subsidies for fuel-based technologies, and thin electricity markets which are typically served by vertically integrated monopolies. The existence of such market failures provides an explanation to the lack of commercial, grid-connected production of renewable energy in Pacific Islands: there are incomplete or missing markets for renewable energy in Pacific Islands. Despite large endowments in renewable resources, a particularly high cost of running conventional plants, and little possibility to use nuclear energy, most renewable energy projects in the Pacific Islands consist of rural, small-scale projects which have been undertaken by governments, donors, international and regional organisations (apart from hydroelectricity plants). The existing market failures can be addressed by various government interventions in order to create favourable market conditions for the development of commercial renewable energy projects.

A large number of countries have already enacted policies to correct for existing market failures and accelerate renewable energy development. Although most of these policies have only been implemented in the last decade, there is already much to learn from the diversity of available instruments, whether they are market-based policies, financial incentives, or public investments. According to the majority of the literature on renewable energy policies, the creation of consistent, stable and reliable market conditions is crucial to renewable energy development and cost reduction (Sawin, 2004; World Bank Renewable Energy Toolkit, 2006, Martinot et al., 2005). Such market conditions can be created by enacting long-term, credible, consistent and transparent policies, in order to increase certainty, particularly for investors (Sawin, 2004). Furthermore, such policies should be flexible enough to account for market changes such as cost reductions in the technologies.

The characteristics of Pacific Island Countries (small scale, dispersed, thin markets) require policies which create conditions that enable a variety of small and medium- 
scaled renewable energy independent producers to connect to the electrical grids. As discussed previously, feed-in tariffs seem to be more suited to such characteristics than tendering policies and renewable trading certificates. To date, most feed-in tariff policies have shown to be effective at developing renewable energy markets for different types of technologies and allowing the entry of small and medium scale independent power producers. Nevertheless, given the monopolistic nature of Pacific Islands' electricity markets, the implementation of feed-in tariffs would require extensive work and consideration for the creation of a stable and transparent framework for independent power producers (including the removal of subsidies for electricity generating petroleum products, standards and power purchasing agreements, and possibly open access to transmission systems, or wheeling). Furthermore, any attempt to accelerate renewable energy development would require the implementation of activities that address the high transaction costs of renewable energy projects, which constitute a major market failure in Pacific Islands. Additionally, there remains an unconditional need for education and public information on renewable energy in the Pacific Islands, particularly in outer islands and rural areas, which has already been undertaken by regional institutions such as the Pacific Islands Applied Geoscience Commission (SOPAC) and the Pacific Regional Environment Programme (SPREP). On a different note, Sawin (2004) has highlighted the importance of stakeholder involvement and public participation in the decisionmaking process for project development and viability, particularly in developing countries. This is likely to be the case for projects in outer islands and rural areas, where a number of solar electrification projects have failed due to little information and education, and consequent poor maintenance.

Eventually, the implementation of such programs and policies may lead to competitive markets for renewable energy production: in addition to learning by doing effects, transaction costs will be driven down as the number of renewable energy independent power producers increases and as the domestic industries become experienced ("there is a national learning curve for each individual country as the domestic industry matures, eventually manufacturing, installing and maintaining renewable energy systems using local equipment and labour" Sawin, 2004). In other words, once market failures and externalities have been corrected for, and once the appropriate market conditions have been reconstituted, the renewable energy industry 
is likely to grow, and the costs are likely to decrease significantly, so that the policies and incentives implemented can gradually be phased out, and eventually be removed.

Aside from green certificates and the removal of subsidies for fuel-based technologies, in the previous sections there has been no mention of any policy which purposely target the market failure related to environmental externality. Feed-in tariffs provide subsidies to renewable energy technologies in order to address the "learning by doing” externalities. Renewable Portfolio Standards may be considered as a means of reducing emissions from electricity generation, yet these policies do not provide direct subsidies or targets for a reduction in the level of emissions. The relevance of policies targeting pollution and environmental externalities to Pacific Island Countries is questionable: Pacific Islands are small countries which emit small levels of pollution. In addition, while some Pacific Island Countries have ratified the Kyoto Protocol, they do not have any obligation to reduce their emission levels. Nevertheless, environmental externalities are becoming more and more important at the global level. The establishment of cap-and-trade systems, such as the European Union Emissions Trading Scheme, has shown that countries which have obligations of emission reductions are willing to pay to 'trade' carbon emissions. This type of trading scheme could provide a potentially significant source of subsidies to Pacific Islands, given their large endowments in renewable energy resources. This can be demonstrated using a quick "back of the envelope" calculation with the installation of a wave energy device in a country trading CO2. The installation of a 750kW Pelamis, which has a capacity factor of 35 percent, would provide 2,299,500 kWh of "carbon-free" electricity per year. Assuming a price of $\$ \mathrm{US} 13$ per ton of $\mathrm{CO} 2$ and assuming that a fossil fuel technology produces 625 tons of $\mathrm{CO} 2$ per year, the installation of a Pelamis would save 1,437 tons of $\mathrm{CO} 2$ and provide a total subsidy of $\$ \mathrm{US} 18,683$ per year. Hence, it is possible that participating in carbon trading schemes can address environmental externalities and encourage both local and foreign investment in commercial renewable energy projects in Pacific Island Countries. 


\section{Chapter Seven: Conclusion}

There is a large potential for electricity production using a variety of renewable energy sources in Pacific Islands. However, renewable resources remain largely untapped in these countries. Policies aimed at increasing the share of renewable energy will need to be tailored to account for the characteristics of these countries and their electricity markets. In particular, electricity production in Pacific Island is often ensured by a small number of companies which have significant market power. In some countries, such as New Caledonia, these electricity companies have historically dominated not only electricity markets, but also most decisions with regards to energy policy, until recently. This implies that institutional and political changes may need to be implemented in order to open Pacific Islands' electricity markets to independent power producers.

The technical feasibility for increasing the share of renewables is a particularly important matter in Pacific Islands. Pacific Islands are isolated countries and cannot be interconnected to larger, continental electric systems, which means that reliability of supply can be critical, particularly in the main islands with industrial or commercial activities. The mathematical model developed in Chapter 4 accounts for this significant aspect by including a measure for backing up renewable energy production using non-renewable capacity. One of the main conclusions of this analysis, however, is that the amount of backup capacity for renewable energy could be optimally minimized by diversifying the mix of renewable energy resources in each island. This would require studying the complementarities and loading curves of the various renewable resources available, and comparing their total potential production, and the variability of this production, to electricity demand. Looking at the seasonability, variability and complementarities of available renewable resources would allow planners to model the inclusion of a maximum amount of renewable energy using a minimum of backup capacity to maintain system reliability. This would enable a more efficient implementation and formulation of policies aimed at developing renewable energy generation. 


\section{Appendix A: Electricity Generation in Pacific Island Countries}

Table A1: Sources of electricity generation in Pacific Island Countries

\begin{tabular}{|c|c|}
\hline Country & Main sources of electricity generation \\
\hline & $\begin{array}{l}\text { Diesel generators. } \\
\text { Source: Pacific Power Association (2006) United States of America Insular Areas Energy } \\
\text { Assessment Report }\end{array}$ \\
\hline & $\begin{array}{l}\text { Mostly diesel generators. Solar photovoltaic, solar water heating and wind } \\
\text { energy are also used. A wind generator was installed in Mangaia in } 2003 \text { and } \\
\text { consists of two } 20 \mathrm{~kW} \text { turbines. In early 2004, } 10.9 \% \text { of homes were using } \\
\text { biomass for cooking. } \\
\text { Source: Pacific Islands Renewable Energy Program (2003). Pacific Regional Energy } \\
\text { Assessment Vol. 2. }\end{array}$ \\
\hline $\begin{array}{l}\text { Federated } \\
\text { States of } \\
\text { Micronesia }\end{array}$ & $\begin{array}{l}\text { Diesel generators are used by the state utilities. There is one run-of-river } \\
\text { hydroelectric plant in Pohnpei; however, it was not operating in early } 2004 \\
\text { due to penstock problems which were costly to repair (it is unknown whether } \\
\text { the plant has been repaired). In Kosrae, the construction of a } 35 \mathrm{~kW} \text { micro- } \\
\text { hydro plant was started and abandoned in the late } 1980 \text { s (PREA). Solar water } \\
\text { heating and solar photovoltaics are also used. According to the } 2000 \text { census, } \\
51.4 \% \text { of households were using biomass for cooking in } 2000 \text {. } \\
\text { Source: Pacific Islands Renewable Energy Program (2003). Pacific Regional Energy } \\
\text { Assessment Vol. 3. }\end{array}$ \\
\hline Fiji & $\begin{array}{l}\text { Hydroelectricity and thermal electricity are the main sources. The } \\
\text { contribution of hydroelectricity to the total production of electricity has } \\
\text { declined from } 92 \% \text { in } 1995 \text { to } 55 \% \text { in } 2003 \text {, but several mini and micro } \\
\text { hydropower projects were under consideration in } 2004 \text {. In 2003, Fiji } \\
\text { Electricity Authority was operating a } 83.2 \mathrm{MW} \text { hydropower plant in Viti } \\
\text { Levu, and a } 0.8 \mathrm{MW} \text { hydropower plant in Vanua Levu. Solar photovoltaic } \\
\text { and solar water heating are also used. } \\
\text { In } 1997 \text {, PV and wind energy were integrated with an existing diesel } \\
\text { generator at Nabouwalu government station in Vanua Levu. There are eight } \\
6.7 \mathrm{~kW} \text { wind turbines, } 37.4 \mathrm{~kW} \text { of PV and } 200 \mathrm{kVA} \text { of diesel. Initially, wind } \\
\text { and solar did contribute over } 60 \% \text { but this fell steadily to less than } 15 \% \text {. } \\
\text { Because fees only cover } 30 \% \text { of operating costs, the operator has no incentive } \\
\text { to maintain the wind and solar components as diesel operation is easier and } \\
\text { better understood than the wind and solar components. } \\
\text { Source: Pacific Islands Renewable Energy Program (2003). Pacific Regional Energy } \\
\text { Assessment Vol. 4. }\end{array}$ \\
\hline $\begin{array}{l}\text { French } \\
\text { Polynesia }\end{array}$ & $\begin{array}{l}\text { Electricite De Tahiti, the main electricity provider in French Polynesia, } \\
\text { reports that } 2 / 3 \text { of its production comes from thermal power plants with diesel } \\
\text { motors, and } 1 / 3 \text { comes from hydropower. Another small hydropower plant is } \\
\text { operated by CHPP, a private company (production of about } 1 \mathrm{GWh} \text { per year). }\end{array}$ \\
\hline
\end{tabular}




\begin{tabular}{|c|c|}
\hline & $\begin{array}{l}\text { In addition, there are } 2 \text { wind turbines of } 50 \mathrm{~kW} \text { in Rurutu, and also a hybrid } \\
\text { power plant combining solar and diesel generation in Makatea, with } 300 \text { solar } \\
\text { panels of } 45 \mathrm{kWc} \text { and a production of about } 50000 \mathrm{kWh} / \text { year. } \\
\text { Programme PHOTOM (solar photovoltaic electrification of remote } \\
\text { Areas): has led to about } 1200 \text { installations and a production of about } \\
1 \mathrm{GWh} / \text { year. There is also a photovoltaic installation at the University of } \\
\text { Tahiti, which produces about } 80000 \mathrm{kWh} / \text { year. } \\
\text { Source: http://www.edt.pf/edt/web/webedt.nsf/pages/rp tech prot index.html; interview at } \\
\text { EDT }\end{array}$ \\
\hline Guam & $\begin{array}{l}\text { Thermal power plants. Some solar panels and solar thermal units, and a few } \\
\text { wind generators. } \\
\text { Source: www.guampowerauthority.com; Lienbenthal et al. (1994). Solar Energy: Lessons } \\
\text { from the Pacific Island Experience; Pacific Power Association (2006) United States of } \\
\text { America Insular Areas Energy Assessment Report }\end{array}$ \\
\hline Hawaii & $\begin{array}{l}\text { The electricity utilities of Oahu, Maui, and Big Island use oil power plants, } \\
\text { there are also some combustion cycle gas turbines. On Big Island, HELCO } \\
\text { (the utility) owns two small hydro plants (total of } 3.35 \mathrm{MW} \text { ) and a wind farm } \\
\text { of } 2.3 \mathrm{MW} \text {. Independent power producers run biomass, geothermal, coal } \\
\text { plants, waste-to-energy systems, as well as a wind farm, and small } \\
\text { hydropower plants. } \\
\text { Source: http://www.heco.com/images/pdf/PowerFacts.pdf }\end{array}$ \\
\hline Kiribati & $\begin{array}{l}\text { Thermal electricity is mostly used; solar pumping and solar photovoltaic are } \\
\text { also used and provide most of the electricity in outer islands. Note that } \\
\text { biomass is the primary fuel for cooking on all islands except Tarawa and } \\
\text { Kiritimati. Wind power has been used for water pumping but those systems } \\
\text { were no longer used in } 2004 \text {. } \\
\text { Source: Pacific Islands Renewable Energy Program (2003). Pacific Regional Energy } \\
\text { Assessment Vol. 5. }\end{array}$ \\
\hline & $\begin{array}{l}\text { Diesel generators are used for the main grid power. Solar PV is also used, } \\
\text { particularly in outer islands. There are biomass resources and the use of } \\
\text { biomass remains important for cooking and copra drying. } \\
\text { Source: Pacific Islands Renewable Energy Program (2003). Pacific Regional Energy } \\
\text { Assessment Vol. 6.; Pacific Power Association (2006) United States of America Insular } \\
\text { Areas Energy Assessment Report }\end{array}$ \\
\hline Nauru & $\begin{array}{l}\text { All electricity generation is by diesel. } \\
\text { Source: Pacific Islands Renewable Energy Program (2003). Pacific Regional Energy } \\
\text { Assessment Vol. } 7 \text {. }\end{array}$ \\
\hline $\begin{array}{l}\text { New } \\
\text { Caledonia }\end{array}$ & $\begin{array}{l}\text { Electricity is produced from thermal plants, hydropower, wind energy, and } \\
\text { solar photovoltaic. } \\
\text { In } 1997 \text {, about } 76 \% \text { of the total electricity production was generated from } \\
\text { thermal plants, } 23.5 \% \text { was hydroelectric, and about } 3 \% \text { came from wind } \\
\text { turbines. In } 2004,80 \% \text { of the electricity came from thermal plants, } 19 \% \text { was } \\
\text { hydroelectricity, and the share of total production from wind turbines } \\
\text { increased to } 0.7 \% \text { ( } 10 \text { new wind turbines were installed in } 2003 \text {, and } 21 \text { other } \\
\text { new turbines were installed in 2004). Thermal electricity generation may } \\
\text { have increased further with the construction of two new plants to satisfy the }\end{array}$ \\
\hline
\end{tabular}




\begin{tabular}{|c|c|}
\hline & $\begin{array}{l}\text { needs of the growing nickel industry (Source: Bilan Energie } 2003 \text { and 2004). } \\
\text { Source: Institut de la Statistique des Etudes Economiques de Nouvelle-Calédonie (2004) } \\
\text { Bilan Energie } 2004\end{array}$ \\
\hline Niue & $\begin{array}{l}\text { Diesel engines generate most of the electricity; there are some solar water } \\
\text { heaters and solar PV installations. } \\
\text { Source: Pacific Islands Renewable Energy Program (2003). Pacific Regional Energy } \\
\text { Assessment Vol. 8. }\end{array}$ \\
\hline $\begin{array}{l}\text { Northern } \\
\text { Mariana } \\
\text { Islands }\end{array}$ & $\begin{array}{l}\text { There are five diesel engine electric power plants on Saipan, Tinian and Rota, } \\
\text { and some small installations on some of the outer islands. } \\
\text { Source: Pacific Power Association (2006) United States of America Insular Areas Energy } \\
\text { Assessment Report }\end{array}$ \\
\hline Palau & $\begin{array}{l}\text { All power generation is with diesel engines. Solar water heating and solar } \\
\text { photovoltaic are used in some islands. } \\
\text { Source: Pacific Islands Renewable Energy Program (2003). Pacific Regional Energy } \\
\text { Assessment Vol.9. }\end{array}$ \\
\hline $\begin{array}{l}\text { Papua } \\
\text { New } \\
\text { Guinea }\end{array}$ & $\begin{array}{l}\text { Hydroelectricity provides } 32 \% \text { of electricity generated; geothermal provides } \\
1 \% \text { and thermal (gas and fuel oil) } 67 \% \text {. (Source: APEC Energy Overview } \\
2005 \text { ). A few wind turbines were installed in farms in the Morobe Province } \\
\text { after independence but it is not known whether any are still functioning. } \\
\text { Commercial companies market and sell small wind generators. } \\
\text { Source: Pacific Islands Renewable Energy Program (2003). Pacific Regional Energy } \\
\text { Assessment Vol. 10. }\end{array}$ \\
\hline Samoa & $\begin{array}{l}\text { About half of Upolu's electricity generation is from hydropower; the rest is } \\
\text { diesel generation. The percentage provided by hydro varies depending on } \\
\text { rainfall but there has been a downward trend as demand for power has } \\
\text { increased whereas hydro capacity has not. } \\
\text { Source: Pacific Islands Renewable Energy Program (2003). Pacific Regional Energy } \\
\text { Assessment Vol. 11. }\end{array}$ \\
\hline $\begin{array}{l}\text { Solomon } \\
\text { Islands }\end{array}$ & $\begin{array}{l}\text { Mostly diesel generators; some hydro and solar energy is also used, although } \\
\text { hydroelectricity only accounted for about } 1 \% \text { of generation in } 2003 \text {. } \\
\text { In 2004, Solomon Islands Electricity Authority was operating two } \\
\text { government-funded small hydroelectric plants on Malaita and Santa Isabel } \\
\text { islands, with a capacity of about } 30 \mathrm{~kW} \text { and } 150 \mathrm{~kW} \text { respectively. Three other } \\
\text { hydroelectricity projects were also under consideration by the government in } \\
2004 \text {. Seven other small and micro hydroelectric systems have been } \\
\text { developed by APACE, an Australian organization, and other systems have } \\
\text { been operated by religious missions. } \\
\text { Source: Pacific Islands Renewable Energy Program (2003). Pacific Regional Energy } \\
\text { Assessment Vol. 12. }\end{array}$ \\
\hline Tokelau & $\begin{array}{l}\text { Diesel generators and solar photovoltaic. Biomass is used for some cooking. } \\
\text { Source: Pacific Islands Renewable Energy Program (2003). Pacific Regional Energy } \\
\text { Assessment Vol. 13. }\end{array}$ \\
\hline Tonga & $\begin{array}{l}\text { Diesel generators, there are also some solar photovoltaic and solar water } \\
\text { heaters installations, especially in outer islands. }\end{array}$ \\
\hline
\end{tabular}




\begin{tabular}{|c|c|}
\hline & $\begin{array}{l}\text { Source: Pacific Islands Renewable Energy Program (2003). Pacific Regional Energy } \\
\text { Assessment Vol. } 14 .\end{array}$ \\
\hline Tuvalu & $\begin{array}{l}\text { Diesel generators. Except for cooking with fuel wood, very small scale } \\
\text { coconut oil production (at a small Vaitupu oil expeller facility intended for } \\
\text { soap production, not for energy) and attempts to provide outer island } \\
\text { households with high efficiency wood stoves for cooking with biomass, solar } \\
\text { photovoltaic and solar water heaters are the only renewable technologies used } \\
\text { in Tuvalu. } \\
\text { Source: Pacific Islands Renewable Energy Program (2003). Pacific Regional Energy } \\
\text { Assessment Vol. 15. }\end{array}$ \\
\hline Vanuatu & $\begin{array}{l}\text { Diesel generators (provide more than 90\% of generation), small } \\
\text { hydroelectricity systems and solar installations. } \\
\text { The government-owned Sarakata hydroelectric system is located at Santo. } \\
\text { This two turbine } 600 \mathrm{~kW} \text { system was built by JICA and is operated by } \\
\text { UNELCO, the main electricity provider. An expansion of the plant to } 1200 \\
\mathrm{~kW} \text { was reportedly planned but it is unknown whether it has been carried out. } \\
\text { One private company in Port Vila imports Vietnamese-made pico-hydro } \\
\text { systems which cater for individual households or small communities. } \\
\text { Source: Pacific Islands Renewable Energy Program (2003). Pacific Regional Energy } \\
\text { Assessment Vol. } 16 \text {. }\end{array}$ \\
\hline $\begin{array}{l}\text { Wallis and } \\
\text { Futuna }\end{array}$ & $\begin{array}{l}\text { Little information was found on electricity generation. It is likely to come } \\
\text { mostly from diesel generators, but there may be other sources of electricity } \\
\text { such as solar photovoltaic. }\end{array}$ \\
\hline
\end{tabular}

Source: PIREP Reports, www.heco.com. 
Table A2: Main electricity utilities in the Pacific Islands

\begin{tabular}{|c|c|c|}
\hline Group of Islands & $\begin{array}{l}\text { Main electricity utilities } \\
\text { responsible for electricity supply }\end{array}$ & $\begin{array}{l}\text { Status of the main electricity } \\
\text { utility }\end{array}$ \\
\hline $\begin{array}{l}\text { American } \\
\text { Samoa }\end{array}$ & American Samoa Power Authority & Government-owned \\
\hline Cook Islands & $\begin{array}{l}\text { Te Aponga Uira O Tumu te } \\
\text { Varovaro (TAU) }\end{array}$ & Government-owned \\
\hline $\begin{array}{l}\text { Federated States } \\
\text { of Micronesia }\end{array}$ & $\begin{array}{l}\text { Chuuk Public Utilities Corporation, } \\
\text { Kosrae Utility Authority, } \\
\text { Pohnpei Utilities Corporation, } \\
\text { Yap State Public Service } \\
\text { Corporation }\end{array}$ & State-owned \\
\hline Fiji & Fiji Electricity Authority & Government-owned \\
\hline $\begin{array}{l}\text { French } \\
\text { Polynesia }\end{array}$ & Electricité de Tahiti & Public service concession \\
\hline Guam & Guam Power Authority & $\begin{array}{l}\text { Government-owned } \\
\text { (public corporation) }\end{array}$ \\
\hline Hawaii & $\begin{array}{l}\text { Hawaiian Electric Company } \\
\text { (HECO), Hawaii Electric Light } \\
\text { Company (HECLO), Maui Electric } \\
\text { Company (MECO), Kaua'I Island } \\
\text { Utility Cooperative (KUC) }\end{array}$ & $\begin{array}{l}\text { HECO, HELCO and MECO: } \\
\text { regulated monopoly. } \\
\text { KUC: corporation }\end{array}$ \\
\hline Kiribati & Public Utilities Board & Statutory authority \\
\hline Marshall Islands & $\begin{array}{l}\text { Majuro Electric Company, } \\
\text { Kwajalein Atoll Joint Utility } \\
\text { Resources }\end{array}$ & Government-owned \\
\hline Nauru & Nauru Phosphate Corporation & Government-owned \\
\hline New Caledonia & $\begin{array}{l}\text { Electricité et Eau de Calédonie, } \\
\text { Enercal }\end{array}$ & Public Service Concession \\
\hline Niue & Niue Power Corporation & Government-owned \\
\hline $\begin{array}{l}\text { Northern } \\
\text { Mariana Islands }\end{array}$ & $\begin{array}{l}\text { Commonwealth Utilities } \\
\text { Corporation }\end{array}$ & Government-owned \\
\hline Palau & Palau Public Utilities Commission & Government-owned \\
\hline $\begin{array}{l}\text { Papua New } \\
\text { Guinea }\end{array}$ & PNGPower & Government-owned \\
\hline Samoa & Electric Power Corporation & $\begin{array}{l}\text { Government-owned (operates } \\
\text { commercially) }\end{array}$ \\
\hline Solomon Islands & $\begin{array}{l}\text { Solomon Islands Electricity } \\
\text { Authority }\end{array}$ & $\begin{array}{l}\text { Government-owned statutory } \\
\text { body (operates commercially) }\end{array}$ \\
\hline Tokelau & Individual Taupulegas & $\begin{array}{l}\text { Owned by island Taupulegas } \\
\text { (Council of Elders) }\end{array}$ \\
\hline Tonga & Shoreline & Regulated monopoly \\
\hline Tuvalu & Tuvalu Electric Corporation & Government-owned \\
\hline Vanuatu & UNELCO & Public service concession \\
\hline $\begin{array}{l}\text { Wallis and } \\
\text { Futuna }\end{array}$ & $\begin{array}{l}\text { Electricité et Eau de Wallis et } \\
\text { Futuna }\end{array}$ & Public Service Concession \\
\hline
\end{tabular}




\section{Appendix B: Hawaii Case-Study}

Table B1: List of Interviews in Hawaii (August 2006)

\begin{tabular}{|c|c|c|c|c|}
\hline Date & Name & Position & Company / Institution & Island \\
\hline $\begin{array}{l}\text { Tuesday } 1 \text { August } \\
2006\end{array}$ & $\begin{array}{l}\text { Neal } \\
\text { Shinayaka }\end{array}$ & Manager & $\begin{array}{l}\text { Maui Electric Company } \\
(\mathrm{MECO})\end{array}$ & Maui \\
\hline $\begin{array}{l}\text { Wednesday } 2 \text { August } \\
2006\end{array}$ & Lee Jakeway & $\begin{array}{l}\text { Director of } \\
\text { Energy } \\
\text { Development } \\
\text { and Planning } \\
\end{array}$ & $\begin{array}{l}\text { Hawaiian Commercial and } \\
\text { Sugar Company (HC\&S), } \\
\text { Independent Power Producer }\end{array}$ & Maui \\
\hline $\begin{array}{l}\text { Thursday } 3 \text { August } \\
2006\end{array}$ & Andrea Gill & $\begin{array}{l}\text { Program } \\
\text { Manager for } \\
\text { Wave Power } \\
\text { for the State } \\
\text { Energy Office }\end{array}$ & $\begin{array}{l}\text { Department of Business and } \\
\text { Economic Development } \\
\text { (DBEDT) }\end{array}$ & $\begin{array}{l}\text { Big } \\
\text { Island }\end{array}$ \\
\hline Friday 4 August 2006 & Curtis Beck & $\begin{array}{l}\text { Manager at } \\
\text { the Customer } \\
\text { Services } \\
\text { Department }\end{array}$ & $\begin{array}{l}\text { Hawaii Electric Light } \\
\text { Company (HELCO) }\end{array}$ & $\begin{array}{l}\text { Big } \\
\text { Island }\end{array}$ \\
\hline Friday 4 August 2006 & John Leite & $\begin{array}{l}\text { Representative } \\
\text { of the Public } \\
\text { Utilities } \\
\text { Commission } \\
\text { on Big Island }\end{array}$ & $\begin{array}{l}\text { Public Utilities Commission } \\
\text { (PUC) }\end{array}$ & $\begin{array}{l}\text { Big } \\
\text { Island }\end{array}$ \\
\hline Friday 4 August 2006 & $\begin{array}{l}\text { Victor } \\
\text { Trevino }\end{array}$ & $\begin{array}{l}\text { Chief } \\
\text { Operations } \\
\text { Officer }\end{array}$ & Big Island Toyota & $\begin{array}{l}\text { Big } \\
\text { Island }\end{array}$ \\
\hline $\begin{array}{l}\text { Monday } 7 \text { August } \\
2006\end{array}$ & Arthur Seki & $\begin{array}{l}\text { Director of } \\
\text { Technology }\end{array}$ & $\begin{array}{l}\text { Hawaiian Electric Company } \\
\text { (HECO) }\end{array}$ & Oahu \\
\hline $\begin{array}{l}\text { Monday } 7 \text { August } \\
2006\end{array}$ & Maria Tome & $\begin{array}{l}\text { Alternate } \\
\text { Energy } \\
\text { Engineer }\end{array}$ & $\begin{array}{l}\text { Department of Business and } \\
\text { Economic Development } \\
\text { (DBEDT) }\end{array}$ & Oahu \\
\hline $\begin{array}{l}\text { Monday } 7 \text { August } \\
2006\end{array}$ & Steve Alber & $\begin{array}{l}\text { Energy } \\
\text { Analyst }\end{array}$ & $\begin{array}{l}\text { Department of Business and } \\
\text { Economic Development } \\
\text { (DBEDT) }\end{array}$ & Oahu \\
\hline $\begin{array}{l}\text { Tuesday } 8 \text { August } \\
2006\end{array}$ & $\begin{array}{l}\text { Cynthia } \\
\text { Thielen }\end{array}$ & Representative & & Oahu \\
\hline $\begin{array}{l}\text { Tuesday } 8 \text { August } \\
2006\end{array}$ & Henry Curtis & $\begin{array}{l}\text { Executive } \\
\text { Director }\end{array}$ & Life of the Land & Oahu \\
\hline $\begin{array}{l}\text { Tuesday } 8 \text { August } \\
2006\end{array}$ & $\begin{array}{l}\text { Catherine } \\
\text { Awakuni }\end{array}$ & $\begin{array}{l}\text { Legal Councel } \\
\text { (now } \\
\text { executive } \\
\text { director of the } \\
\text { Department of } \\
\text { Commerce } \\
\text { and Consumer } \\
\text { Affairs) }\end{array}$ & $\begin{array}{l}\text { Public Utilities Commission } \\
\text { (PUC) }\end{array}$ & Oahu \\
\hline
\end{tabular}




\section{Appendix C: Model for the Integration of Renewables into Pacific Islands'Electricity Systems - First Order Conditions}

Substituting the renewable and non-renewable production functions (6) and (11) into the generating portfolio (3):

$$
q_{t}=A_{n}\left(k_{n t}-z_{a} \theta_{a} k_{a t}-z_{b} \theta_{b} k_{b t}\right)+A_{a} z_{a} k_{a t}+A_{b} z_{b} k_{b t}
$$

Similarly, substituting fuel use from non-renewable electricity production and backup (10) into the budget constraint (2):

$$
\begin{aligned}
& c_{t}=\overline{y_{t}}-p_{u} u_{t}-p_{n} i_{n t}-p_{a} i_{a t}-p_{b} i_{b t} \\
& c_{t}=\overline{y_{t}}-p_{u}\left(\beta\left(k_{n t}-\theta_{a} k_{a t}-\theta_{b} k_{b t}+\left(1-z_{a}\right) \theta_{a} k_{a t}+\left(1-z_{b}\right) \theta_{b} k_{b t}\right)\right)-p_{n} i_{n t}-p_{a} i_{a t}-p_{b} i_{b t}
\end{aligned}
$$

Let $\Lambda_{n t}, \Lambda_{a t}$ and $\Lambda_{b t}$ be the multipliers associated with capacity accumulation for renewable and non-renewable plants (12), (13) and (14), the Lagrangian for this problem is:

$$
\begin{aligned}
& L=\cdots+\frac{1}{\left(1-\rho^{t}\right)}\left[\begin{array}{l}
-\frac{\bar{\pi}_{t}}{2}\left(1-\frac{A_{n}\left(k_{n t}-\theta_{a} k_{a t}-\theta_{b} k_{b t}+\left(1-z_{a}\right) \theta_{a} k_{a t}+\left(1-z_{b}\right) \theta_{b} k_{b t}\right)+A_{a} z_{a} k_{a t}+A_{b} z_{b} k_{b t}}{\bar{q}_{t}}\right)^{2} \\
+\bar{\omega}_{t} \frac{\bar{y}_{t}-p_{u}\left(\beta\left(k_{n t}-\theta_{a} k_{a t}-\theta_{b} k_{b t}+\left(1-z_{a}\right) \theta_{a} k_{a t}+\left(1-z_{b}\right) \theta_{b} k_{b t}\right)\right)-p_{n} i_{n t}-p_{a} i_{a t}-p_{b} i_{b t}}{\bar{y}_{t}} \\
-\bar{\phi}_{t} \frac{A_{n}\left(k_{n t}-\theta_{a} k_{a t}-\theta_{b} k_{b t}+\left(1-z_{a}\right) \theta_{a} k_{a t}+\left(1-z_{b}\right) \theta_{b} k_{b t}\right)}{\bar{q}_{t}}
\end{array}\right] \\
& +\frac{1}{\left(1-\rho^{t+1}\right)}\left[\begin{array}{l}
-\frac{\bar{\pi}_{t+1}}{2}\left(1-\frac{A_{n}\left(k_{n t+1}-\theta_{a} k_{a t+1}-\theta_{b} k_{b t+1}+\left(1-z_{a}\right) \theta_{a} k_{a t+1}+\left(1-z_{b}\right) \theta_{b} k_{b t+1}\right)+A_{a} z_{a} k_{a t+1}+A_{b} z_{b} k_{b t+1}}{\bar{q}_{t+1}}\right)^{2} \\
+\bar{\omega}_{t+1} \frac{\bar{y}_{t+1}-p_{u}\left(\beta\left(k_{n t+1}-\theta_{a} k_{a t+1}-\theta_{b} k_{b t+1}+\left(1-z_{a}\right) \theta_{a} k_{a t+1}+\left(1-z_{b}\right) \theta_{b} k_{b t+1}\right)\right)-p_{n} i_{n t+1}-p_{a} i_{a t+1}-p_{b} i_{b t+1}}{\bar{y}_{t+1}} \\
-\bar{\phi}_{t+1} \frac{A_{n}\left(k_{n t+1}-\theta_{a} k_{a t+1}-\theta_{b} k_{b t+1}+\left(1-z_{a}\right) \theta_{a} k_{a t+1}+\left(1-z_{b}\right) \theta_{b} k_{b t+1}\right)}{\bar{q}_{t+1}}
\end{array}\right] \\
& +\Lambda_{a t}\left[i_{a t}+\left(1-\delta_{a}\right) k_{a t}-k_{a t+1}\right]+\Lambda_{b t}\left[i_{b t}+\left(1-\delta_{b}\right) k_{b t}-k_{b t+1}\right]+\Lambda_{a t+1}\left[i_{a t+1}+\left(1-\delta_{a}\right) k_{a t+1}-k_{a t+2}\right] \\
& +\Lambda_{b t+1}\left[i_{b t}+\left(1-\delta_{b}\right) k_{b t+1}-k_{b t+2}\right]+\Lambda_{n t}\left[i_{n t}+\left(1-\delta_{n}\right) k_{n t}-k_{n t+1}\right]+\Lambda_{n t+1}\left[i_{n t+1}+\left(1-\delta_{n}\right) k_{n t+1}-k_{n t+2}\right]+\cdots
\end{aligned}
$$


We impose non-negativity constraints on capital investment for electricity generating plants, and on the capacity of the plants. The first-order conditions are:

$$
\begin{aligned}
& \frac{\partial L}{\partial i_{a t}} \leq 0, i_{a t} \geq 0 \Rightarrow \frac{-\bar{\omega}_{t} p_{a}}{\bar{y}_{t}}=\frac{\Lambda_{a t}}{\rho^{t}} \equiv \lambda_{a t} \Rightarrow i_{a t}=\frac{\lambda_{a t}}{\frac{-\bar{\omega}_{t} p_{a}}{\bar{y}_{t}}} \\
& \frac{\partial L}{\partial i_{b t}} \leq 0, i_{b t} \geq 0 \Rightarrow \frac{-\bar{\omega}_{t} p_{b}}{\bar{y}_{t}}=\frac{\Lambda_{b t}}{\rho^{t}} \equiv \lambda_{b t} \Rightarrow i_{b t}=\frac{\lambda_{b t}}{\frac{-\bar{\omega}_{t} p_{b}}{\bar{y}_{t}}} \\
& \frac{\partial L}{\partial i_{n t}} \leq 0, i_{n t} \geq 0 \Rightarrow \frac{-\bar{\omega}_{t} p_{n}}{\bar{y}_{t}}=\frac{\Lambda_{n t}}{\rho^{t}} \equiv \lambda_{n t} \Rightarrow i_{n t}=\frac{\lambda_{n t}}{\frac{-\bar{\omega}_{t} p_{n}}{\bar{y}_{t}}} \\
& \frac{\partial L}{\partial \Lambda_{a t}} \geq 0, \Lambda_{a t} \leq 0 \Rightarrow k_{a t+1}=i_{a t}+\left(1-\delta_{a}\right) k_{a t} \\
& \frac{\partial L}{\partial \Lambda_{b t}} \geq 0, \Lambda_{b t} \leq 0 \Rightarrow k_{b t+1}=i_{b t}+\left(1-\delta_{b}\right) k_{b t} \\
& \frac{\partial L}{\partial \Lambda_{n t}} \geq 0, \Lambda_{n t} \leq 0 \Rightarrow k_{n t+1}=i_{n t}+\left(1-\delta_{n}\right) k_{n t} \\
& \lambda_{n t+1}=\frac{\Lambda_{n t+1}}{\rho_{t+1}}
\end{aligned}
$$

$$
\begin{aligned}
& \frac{\partial L}{\partial k_{n t+1}} \leq 0, k_{n t+1} \geq 0 \\
& \Rightarrow \frac{1}{\left(1-\rho^{t+1}\right)}\left[\begin{array}{l}
\frac{-A_{n} \bar{\pi}_{t+1}}{\bar{q}_{t+1}}\left(1-\frac{A_{n}\left(k_{n t+1}-\theta_{a} k_{a t+1}-\theta_{b} k_{b t+1}+\left(1-z_{a}\right) \theta_{a} k_{a t+1}+\left(1-z_{b}\right) \theta_{b} k_{b t+1}\right)+A_{a} z_{a} k_{a t+1}+A_{b} z_{b} k_{b t+1}}{\bar{q}_{t+1}}\right) \\
-\frac{p_{u} \beta \bar{\omega}_{t+1}}{\bar{y}_{t+1}}-\bar{\phi}_{t+1}\left(\frac{A_{n}}{\bar{q}_{t+1}}\right)
\end{array}\right] \\
& -\Lambda_{n t}+\Lambda_{n t+1}\left(1-\delta_{n}\right)=0
\end{aligned}
$$




\section{Bibliography}

AEA Technology, ETSU (1999). Evaluation of the PREP Component: PV Systems for Rural Electrification in Kiribati and Tuvalu. Final Report for the European Commission DGVIII Development.

AEA Technology (2006). Review and Analysis of Ocean Energy Systems Development and Supporting Policies. Report prepared for Sustainable Energy Ireland for the IEA's Implementing Agreement on Ocean Energy Systems.

Alves, L.M.M., Costa, A.L., Carvalho, M.D. (2000). “Analysis of Potential for Market Penetration of Renewable Energy Technologies in Peripheral Islands". Renewable Energy Vol. 19 (2000), pp. 311-317.

http://www.sciencedirect.com/science? ob=MImg\&_imagekey=B6V4S-3XCFPG1$\underline{1 \mathrm{C}-}$

$1 \&$ cdi $=5766 \&$ user $=1495406 \&$ orig $=$ search $\&$ coverDate $=01 \% 2 \mathrm{~F} 02 \% 2 \mathrm{~F} 2000 \&$ qd $=1 \&$ sk $=999809998 \&$ view $=\mathrm{c} \&$ alid $=456511969 \&$ rdoc $=1 \& \mathrm{wchp}=\mathrm{dGLbVtz}-$

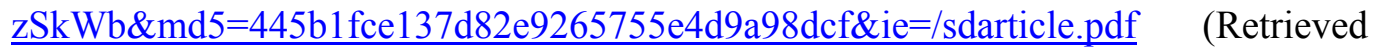
3rd of October 2006)

Anderson, D. (1972). "Models for Determining Least-Cost Investments in Electricity Supply”. The Bell Journal of Economics and Management Science, Vol. 3, No.1, pp. 267-299.

Anderson, D. (February 2006). "Power System Reserves and Costs with Intermittent Generation”. UKERC Working Paper 16.

http://www.ukerc.ac.uk/component/option,com_docman/task,doc_download/gid,548/ (Retrieved $4^{\text {th }}$ of October 2006)

Asian Development Bank (2006). Country Strategy and program Update - Kiribati 2006-2007. 
Asian Development Bank (2006). "Technical Assistance for the Republic of Fiji Islands: Preparing the Renewable Power Sector Development Project". Technical Assistance Report for project No. 39521.

Asian Development Bank (2005). Country Economic Report: The Republic of Palau.

Asian Development Bank (2005). Country Strategy and Program Update 2005-2006: Papua New Guinea.

Asian Development Bank (2005). Key Indicators 2005: Labor Markets in Asia: Promoting Full, Productive, and Decent Employment.

Asian Development Bank (2004). Country Strategy and Program Update (20052006): Samoa.

Asian Development Bank (2004). Country Strategy and Program Update 2005-2006: Solomon Islands.

Asian Development Bank (2003). Country Strategy and Program Update 2004-2006: Tuvalu.

Asian Development Bank (2002). Country Strategy and Program Update 2003-2005, Federated States of Micronesia.

Asian Development Bank (2002). Country Strategy and Program Update 2003-2005: Tonga.

Asian Development Bank (2002). Country Strategy and Program Update 2003-2005: Tuvalu.

Asian Development Bank (2002). Technical Assistance to the Independent State of Samoa for Preparing the Savai'I Renewable Energy Project. 
Asian Development Bank (2001). Country Strategy and Program Update (20022004): Samoa.

Asian Development Bank (2000). Country Assistance Plan 2001- 2003: Samoa.

Asia Pacific Energy Research Centre (2005). APEC Energy Overview 2005.

Asia-Pacific Economic Cooperation (2005). New Energy Technologies: Measuring Potential Impacts in APEC.

Asia Pacific Energy Research Centre (2005). Renewable Electricity in the APERC Region: Internalising Externalities in the Cost of Power Generation.

Asia-Pacific Economic Cooperation (2004). APEC Energy Statistics 2002.

Asia Pacific Energy Research Centre (2004). APEC Energy Overview 2004.

Asia Pacific Energy Research Centre (2004). New and Renewable Energy in the APEC Region.

Asia-Pacific Economic Cooperation (2003). APEC Energy Handbook 2003.

Asia Pacific Energy Research Centre (2003). APEC Energy Overview 2003.

Asia-Pacific Economic Cooperation (2001). APEC Energy Handbook 2001.

Awerbuch, S. (2004a). "Energy Security and Diversity: Portfolio Perspectives". IREC Interconnection Newsletter, July 2004.

Awerbuch, S. (2004b). "Portfolio-Based Electricity Generation Planning: Implications for Renewables and Energy Security”. SPRU, University of Sussex. http://www.sussex.ac.uk/spru/documents/portfolio-based_planning-dec-26-04-mitifinal-for_distribution.doc (Retrieved 4th of October 2006) 
Awerbuch, S. (2005). "A Brief Overiew of Wind Economics in the $21^{\text {st }}$ Century". SPRU, University of Sussex.

Awerbuch, S. (2006). “The Role of Wind Generation in Enhancing Scotland's Energy Diversity and Security: A Mean-Variance Portfolio Optimization of Scotland's Generating Mix". Report for Airtricity.

Awerbuch, S., and Berger, M. (2003). "Applying Portfolio Theory to EU Electricity Planning and Policy-Making”. IEA Report EET/2003/03, Paris.

http://www.iea.org/textbase/papers/2003/port.pdf (Retrieved 4th of October 2006)

Baddour, E. (2004). Energy From Waves and Tidal Currents - Towards 20yy? Institute for Ocean Technology National Research Council.

Barstow S.F., Falnes, J. (1996). "Ocean Energy in the South Pacific: The Resource and its Utilization”. SOPAC miscellaneous Report 234.

Beck, F., Martinot, E. (2004). "Renewable Energy Policies and Barriers". Forthcoming in Encyclopedia of Energy, Cutler J. Cleveland, ed. (Academic Press/Elsevier Science, 2004).

Berry, D. (2005). "Renewable Energy as a Natural Gas Price Hedge: The Case of Wind”. Energy Policy Vol. 33 (6), pp. 799-807.

Bertram, G., Pauls, R. (2000). Economic Implications of a Mandatory NewRenewables Quota in New Zealand. Prepared for the New Zealand Wind Energy Association by Simon Terry Associates Ltd.

BP (2005). BP Statistical Review of World Energy.

Bureau of Budget and Planning of the Republic of Palau (2004). Republic of Palau: 2002-2003 Statistical Yearbook. 
Bureau of Statistics and Plans of Guam (2005). 2004 Guam Statistical Yearbook. http://www.pacificweb.org/DOCS/guam/2004\%20Guam\%20Yearbook/2004_Guam Yearbook_FinalR2_Full\%20Version.pdf (Retrieved in March 2006).

Butler and Neuhoff (2004). "Comparison of Feed in Tariff, Quota and Auction Mechanisms to Support Wind Power Development".

Carbon Trust (2006). Future Marine Energy. Results of the Marine Energy Challenge: Cost Competitiveness and Growth of Wave and Tidal Stream Energy. London: Carbon Trust.

Carbon Trust (2006). Policy frameworks for Renewables. London: Carbon Trust.

Castalia (2005). "Infrastructure in the Pacific: Obstacles and Opportunities to Improve Performance". Report for the World Bank.

Center for Resource Solutions (2001). Capacity and Energy Based RPS Policies.

Central Intelligence Agency (2001). The World Factbook 2001.

Central Intelligence Agency (2006). The World Factbook 2006.

Clement, D. et al. (2005). "International Tax Incentives for Renewable Energy: Lessons for Public Policy”. Draft Report prepared for the Energy Foundation and China Sustainable Energy Program. Center for Resource Solutions.

Coase, R.H. (1960). "The Problem of Social Cost". Journal of Law and Economics, Vol. 3, p. 44.

Coulomb, L., Neuhoff, K. (2006). "Learning Curves and Changing Product Attributes: The Case of Wind Turbines". Cambridge Working Papers in Economics CWPE 0618.

Dale, L., Milborrow, D., Slark, R., and Strbac, G. (2003). “A Shift to Wind is Not Unfeasible". Power UK Vol. 108, 17-25. 
www.bwea.com/pdf/PowerUK-March2003-page17-25.pdf (Retrieved 4th of October 2006)

Dale, L., Milborrow, D., Slark, R., Strbac, G. (2004). "Total Cost Estimates for Large-Scale Wind Scenarios in UK”. Energy Policy Vol. 32, pp. 1949-1956.

DeLaquil, P., Awerbuch, S., Stroup, K. (2005). "A portfolio-Risk Analysis of Electricity Supply Options in the Commonwealth of Virginia”. Prepared for the Chesapeake Climate Action Network.

http://www.chesapeakeclimate.org/doc/VA_Renewables_Study.pdf (Retrieved 4th of October 2006)

Department of Business, Economic Development and Tourism of Hawaii, Energy Division (1992). "Hawaii Integrated Energy Policy (HEP) Technical Report”.

Department of Business, Economic Development and Tourism of Hawaii (2006). "Summary report on Energy Cost Adjustment Clause (ECAC)".

Domah, P. (2002). "Technical Efficiency in Electricity Generation - The Impact of Smallness and Isolation of Island Economies". University of Cambridge, Department of Applied Economics, Working Paper WP 0232.

http://www.econ.cam.ac.uk/electricity/publications/wp/ep14.pdf (Retrieved 4th of October 2006).

Economic and Social Commission for Asia and the Pacific (2004). Asia-Pacific in Figures 2004. http://www.unescap.org/stat/data/apif/index.asp (Retrieved in March 2006).

Economic, Planning, Development and Statistics Unit of Niue - Premiers Department (2001). "Chapter V: Household and Housing Characteristics". Niue - 2001 Census of Population and Housing Report., pp.34-42.

http://www.spc.int/prism/country/nu/stats/NU_Publications/Others/E_ch5 hhld.pdf (Retrieved 16th of March 2006). 
Economic Policy, Planning and Statistics Office of the Marshall Islands (2004). Republic of the Marshall Islands Statistical Yearbook 2002.

Economic Policy, Planning and Statistics Office of the Marshall Islands (2004). Republic of the Marshall Islands Statistical Yearbook 2004.

Economic Policy, Planning and Statistics Office of the Marshall Islands (2001). "Chapter 10: Water and Energy". Republic of the Marshall Islands Statistical Abstract 2001.

Energy Information Administration (2003). International Energy Annual 2003.

Environmental Energy Institute (2005). Variability of UK Marine Resources: An Assessment of the Variability Characteristics of the UK's Wave and Tidal Current power Resources and Their Implications for Large Scale Development Scenarios. Report commissioned by the Carbon Trust.

Espey, S. (2001). "Renewables Portfolio Standard: A Means for Trade with Electricity from Renewable Energy Sources?” Energy Policy, Vol. 29, p. 557-566.

Federated States of Micronesia, European Community (2002). Country Strategy Paper and National Indicative Programme for the Period 2002-2007.

Fiji Islands Bureau of Statistics (2005). Fiji Facts and Figures as at 1st July 2005.

Freeman, C., Lazar, J. (2003). "Hawaii Energy Utility Regulation and Taxation: practice, policy and incentives for energy efficiency, renewable and distributed energy resources". A report for the Hawaii Energy Policy Project.

German Federal Ministry for Economic Development and Federal Ministry for the Environment, Nature Conservation and Nuclear Safety (2004). "International Conference for Renewable Energies: Conference Issue Paper”. Renewables 2004, 1-4 June 2004. Bonn, Germany. 
Gillet, B., Wilkins, G. Solar so Good - An EC-Funded Solar Utility Succeeds in Kiribati. ACP-EC Courier No. 177 (October-November), pp. 5-7.

Goff, C. (2006). "Wind Energy Cost Reductions: A Learning Curve Analysis with Evidence from the United States, Denmark, Germany, Spain and the united Kingdom”. A thesis submitted to the Faculty of the Graduate School of Arts and Sciences of Georgetown Univesrity in partial fulfillment of the requirements for the degree of Master of Public Policy.

Government of Tuvalu (2005). "Quarterly Statistical Report: December Quarter 2004". Quarterly Statistical Report. Central Statistics Division, Ministry of Finance, Economic Planning and Industries, Government of Tuvalu.

Government of American Samoa (2004). Statistical Yearbook 2003 \& 2004.

Government of the Cook Islands (2003). National Assessment Report for Barbados Programme of Action +10 .

Goldstein et al. (May 1999). "Grid-Connected Renewable-Electric Policies in the European Union". National Renewable Energy Laboratory Topical Issues Brief NREL/TP.620.2627.

Gouchoe, S., Everette, V., Haynes, R. (September 2002). "Case Studies on the Effectiveness of State Financial Incentives for Renewable Energy". National Renewable Energy Laboratory.

Gross, R., Heptonstall, P., Anderson, D., Green T., Leach, M., and Skea, J. (2006). "The Costs and Impacts of Intermittency: An Assessment of the Evidence on the Costs and Impacts of Intermittent Generation on the British Electricity Network". UKERC/Imperial College London.

http://www.ukerc.ac.uk/component/option,com_docman/task,doc_download/gid,550/ (Retrieved $20^{\text {th }}$ of September 2006) 
Grynberg, R. (2005). “Toward a New Pacific Regionalism”. An Asian Development Bank and Commonwealth Secretariat Joint Report to the Pacific Islands Forum Secretariat. Pacific Study Series, Volume 3: Working Papers, Working paper no.13.

Gutermuth, P.G. (1998). "Financial measures for the enhanced deployment of renewable energies". Solar energy Vol. 64, No.1-3, pp. 67-78.

Hagerman, G. - SEASUN Power Systems (1992). "Wave Energy Resource and Economic Assessment for the State of Hawaii”. Report prepared for the Energy Division of the Department of Business, Economic Development, and Tourism (State of Hawaii).

Hagerman, G. Previsic, M., Bedard, R. (2004). "E2I Epri Survey and Chacterization of Potential Offshore Wave Energy Sites in Hawaii”. E2I EPRI Global WP-003-HI Rev 1

http://www.epri.com/oceanenergy/attachments/wave/reports/003 Hawaii_Site_Report Rev 1.pdf (Retrieved 20th of September 2006)

Hagerman, G., Bedard, R. (2004). "Offshore Wave Power in the US: Environmental issues". E2I Global EPRI Global-007-US

http://www.epri.com/oceanenergy/attachments/wave/reports/003_Hawaii_Site_Report Rev 1.pdf (Retrieved 20th of September 2006)

Hawaiian Electric Company, Inc (October 2005). Integrated Resource Plan 20062025.

Hay E., Sablan-Zebedy, E. (2005). "Republic of the Marshall Islands - Country Environmental Analysis". Final report prepared for the Asian Development Bank and its Technical Assistance on Regional Mainstreaming Environmental Considerations in Economic and Development Planning Processes in Selected Developing Member Countries.

Hobbs, B.F. (1995). "Optimization Methods for Electric Utility Resource Planning”. European Journal of Operational Research Vol. 83, pp. 1-20. 
Ibenholt, K. (2002). "Explaining Learning Curves for Wind Power". Energy Policy Vol. 30, pp. 1181-1189.

Institut de la Statistique de la Polynésie Française, Banque de Données Statistiques http://www.ispf.pf/(eo0y1x45xtrfas45sx0mxyz3)/stat/bds/rubriques.aspx?nChap=14 (Retrieved in March 2006 and April 2007).

Institut de la Statistique de la Polynésie Française (2005). Polynésie en Bref (French Polynesia at a Glance).

Institut de la Statistique des Etudes Economiques de Nouvelle-Calédonie (2001). Bilan Energie 2001.

Institut de la Statistique et des Etudes Economiques de la Nouvelle-Calédonie (2003a). Bilan Economique et Social 2003.

Institut de la Statistique des Etudes Economiques de Nouvelle-Calédonie (2003b). Bilan Energie de Nouvelle-Calédonie 2003.

Institut de la Statistique des Etudes Economiques de Nouvelle-Calédonie (2004). Bilan Energie de Nouvelle-Calédonie 2004.

International Bank for Reconstruction and Development, International Development Association (2005). "Regional Engagement Framework 2006-2009 for Pacific Islands". World Bank Report No. 32261-EAP.

International Conference for Renewable Energies: Renewables 2004 (2004). “Conference Issue Paper”. International Conference for Renewable Energies, Bonn.

International Energy Agency (2004). Renewable Energy: Market and Policy Trends in IEA Countries. OECD/IEA 2004. 
International Energy Agency (2006). Global Renewable Energy Policies and Measures Database, www.iea.org/textbase/pmsdb (Retrieved 17th of November 2006).

International Monetary Fund (1998). IMF Staff Country Report No. 98/121.

Jafar, M. (2000). "Renewable Energy in the South Pacific- Options and Constraints". Renewable Energy Vol. 19, pp. 305-309.

Jaffe, A., Newell, R.G. and Stavins, R.N. (2005). "A Tale of Two Market Failures: Technology and Environmental Policy". Ecological Economics Vol. 54(2-3), pp. 167174.

Jansen, J.C., Beurskens, L.W.M., Van Tilburg, X. (February 2006). "Application of Portfolio Analysis to the Dutch Generating Mix. Reference case and two renewable cases: year 2030 - SE and GE Scenario". Energy Research Centre of the Netherlands. ECN-C-05-100.

Jensen, T. L. (1998). "Renewable Energy on Small Islands". Forum for Energy and Development (FED).

Kingdom of Tonga (2003). National Assessment Report for Barbados Programme of Action +10 .

Kiribati, European Community (2002). Country Strategy Paper and National Indicative Programme 2002-2007.

Krey, B., Zweifel, P. (2006). "Efficient Electricity Portfolios for Switzerland and the United States". University of Zurich Socioeconomic Institute, Working Paper No. 0602.

Kubler, F. and Schmedders, K. (2001). "Incomplete Markets, Transitory Shocks, and Welfare". Review of Economic Dynamics Vol.4, pp. 747-766. 
Lancaster, K.J. (1966). “A New Approach to Consumer Theory”. The Journal of Political Economy, Vol. 74 (2), pp. 132-157.

Lewis, J., Wiser, R. (March 2005). “A Review of International Experience with Policies to Promote Wind Power Industry Development". Prepared for the Energy Foundation and China Sustainable Energy Program. Center for Resource Solutions.

Liebenthal, A., Mathur, S., Wade, H. (1994). "Solar Energy: Lessons from the Pacific Islands Experience”. World Bank Technical Paper \#244, Energy Series. Washington, DC: World Bank.

http://www-

wds.worldbank.org/external/default/WDSContentServer/IW3P/IB/1994/05/01/000009 265 3970311122736/Rendered/PDF/multi_page.pdf (Retrieved 3rd of October 2006)

Martinot, E., Wiser, R., Hamrin, J. (2005). "Renewable Energy Policies and Markets in the United States".

Mayer, P.C. (2000). "Reliability Economies of Scale for Tropical Island Electric Power”. Energy Economics Vol. 22, pp. 319-330.

McDonald, A., Schrattenholzer, L. (2001). "Learning Rates for Energy Technologies". Energy Policy Vol. 29, pp. 255-261.

McLoughlin, E., Bazilian, M. (2006). "Application of Portfolio Analysis to the Irish Electricity Generating Mix in 2020”. Working paper for Sustainable Energy Ireland. www.sei.ie/getFile.asp?FC ID $=1631 \&$ docID $=59$ (Retrieved $20^{\text {th }}$ of September 2006)

Menanteau, P., Finon, D., Lamy, M-L. (2003). "Prices versus Quantities: Choosing Policies for Promoting the Development of Renewable Energy". Energy Policy Vol. 31, pp. 799-812.

Meritec (2001). "Private Participation in Infrastructure in Pacific Island Countries". 
Ministry of Resources and Development of the Marshall Islands, Marshalls Energy Company, Economic Policy, Planning and Statistics Office of the Marshall Islands (2004). Acting for the Development of Marshall Islands Renewable Energy.

Ministry of Resources and Development of the Republic of Palau (2004). Republic of Palau National Assessment Report: Barbados Programme of Action +10 Review.

Nauru, European Community (2002). Country Strategy Paper and National Indicative Programme for the Period 2002-2007.

Neuhoff, K. (2004). "Large Scale Deployment of Renewables for Electricity Generation". Cambridge Working Papers in Economics No. 0460. Faculty of Economics, University of Cambridge.

Newbery, D.M. (1989). Missing Markets. In The Economics of Missing Markets, Information, and Games. Edited by Franck Hahn, Oxford: Clarendon Press.

Newbery, D. (2005). "Power Sector Reform, Private Investment and Regional Cooperation".

Niue, European Community (2002). Country Strategy Paper and National Indicative Programme for the period 2002-2007.

Pacific Power Association (2006). United States of America Insular Areas Energy Assessment Report: An Update of the 1982 Territorial Energy Assessment. Prepared for the U.S. Department of Interior, Washington, D.C.

Painuly, J.P. (2001). "Barriers to Renewable Energy Penetration: A Framework for Analysis". Renewable Energy Vol. 24, pp. 73-89.

http://www.sciencedirect.com/science? ob=MImg\& imagekey=B6V4S-42R0S25-6-

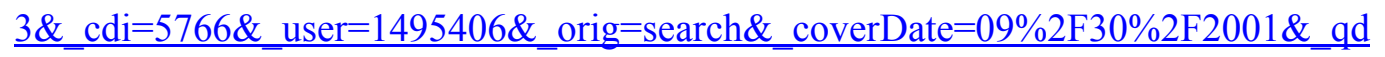
$=1 \&$ sk $=999759998 \&$ view $=\mathrm{c} \&$ alid $=465694867 \&$ rdoc $=1 \& \mathrm{wchp}=\mathrm{dGLbVzZ}-$ zSkWW\&md5=ea2a17745a14831f3062b683bb879336\&ie=/sdarticle.pdf $\quad$ Retrieved 10th October 2006). 
Papua New Guinea, European Community (2002). Country Strategy Paper and National Indicative Programme for the Period 2002-2007.

Petrocini, S., Yemm. R.W. (2000) "Introducing Wave Energy Into the Renewable Energy Marketplace". Presented at the 4th European Wave Energy Conference, Alborg, Denmark, 2000.

Power Projects Limited (2005). "Marine Energy: Summary of Current Developments and Outlook for New Zealand”. Prepared for the Energy Efficiency and Conservation Authority.

Previsic, M., Siddiqui, O., Bedard, R. (2004a). "Economic Assessment Methodology for Offshore Wave Power Plants". E2I EPRI WP-US-002 Rev 4 http://www.epri.com/oceanenergy/attachments/wave/reports/002_Rev_4_Econ_Meth odology_RB 12-18-04.pdf (Retrieved 20th of September 2006)

Previsic, M., Siddiqui, O., Bedard, R. (2004b). "System Level Design, Performance and Costs for San Francisco California Pelamis Offshore Wave Power Plant". E2I EPRI Global -006A-SF.

http://www.epri.com/oceanenergy/attachments/wave/reports/006_San_Francisco_Pela mis_Conceptual_Design 12-11-04.pdf (Retrieved 20th of September 2006)

Previsic, M. et al. (2005a). "Offshore Wave Energy Conversion Devices”. E2I EPRI WP-004-US-Rev 1.

http://www.epri.com/oceanenergy/attachments/wave/reports/004_WEC Device_Asse ss_Report_Rev1_MP_6-16-04.pdf (Retrieved 20th of September 2006)

Previsic, M. et al. (2005b). "System level design, Performance and Costs - Hawaii State Offshore Wave Power Plant”. E2I EPRI Global WP-006-HI.

http://www.epri.com/oceanenergy/attachments/wave/reports/006_Hawaii_System_Le vel_Conceptual_Design_RB 01-12-05.pdf (Retrieved $20^{\text {th }}$ of September 2006) 
Public Utilities Commission, State of Hawaii (1992). “A Framework for Integrated Resource Planning”.

Public Utilities Commission of Hawaii (1995). "Current avoided cost price offered to renewable developer/producers may be insufficient".

Ram, B. et al. (2004). "Wave Power in the US: Permitting and Jurisdictional Issues". E2I Global EPRI DOE NREL-008-US.

http://www.epri.com/oceanenergy/attachments/wave/reports/008 Wave Permitting_I ssues_Final.pdf (Retrieved 20th of September 2006).

Republic of Nauru (2004). National Assessment Report - Ten Year Review of the Barbados Programme of Action.

Republic of the Marshall Islands, European Community (2002). Country Strategy and National Indicative Programme for the Period 2002-2007.

RCG/ Hagler, Bailly, Inc. (October 1991). Energy management and permitting analysis. Hawaii integrated energy policy development (HEP) - Briefing document.

Samoa, European Community (2001). Country Strategy Paper for the Period 20012007.

Sawin, J.L. (2004). "National Policy Instruments: Policy Lessons for the Advancement and Diffusion of Renewable Energy Technologies Around the World". Thematic Background Paper. Secretariat of the International Conference for Renewable Energies, Bonn 2004.

Schweppe, F.C. (1988). "Mandatory Wheeling: A Framework for Discussion”. Paper 88 SM 690-0, presented at the IEEE/PES Summer Meeting, Portland, Oregon, July 24-29, 1988. 
Sinden, G. (2006). "Renewable Electricity Generation”. Supporting Documentation for the Renewables Advisory Board Submission to the 2006 UK Energy Review. http://www.dti.gov.uk/files/file30091.pdf (Retrieved 15th of September 2006)

Solomon Islands, European Community (2001). Country Strategy Paper and National Indicative Programme for the Period 2002-2007.

SOPAC (2004). "SOPAC Miscellaneous Report 596: Record of Meeting- REM 2004". Joint Regional Energy Meeting and PIESPAP Regional Planning and Consultative Meeting: "Linking Policy and Strategy with human Resource Development, Access to Finance and Budgets", 29 November - 3 December 2004. Madang, Papua New Guinea.

Stassen, H.E. (1995). "Small-Scale Biomass Gasifiers for Heat and Power: A Global Review". World Bank Technical Paper No. 296, Energy Series.

Statistics Niue. Utility Statistics - Electric Power Supply: Fuel Consumed and Power Generated, 1980-1992.

http://www.spc.int/prism/country/nu/stats/Nu Utilities Comm/Power.xls (Retrieved 16th of March 2006).

Stuart, K. (2006). "Energizing the Island Community: A review of Policy Standpoints for Energy in Small Island States and Territories". Sustainable Development Vol.14, pp. 139-146.

http://www3.interscience.wiley.com/cgi-bin/fulltext/112471085/PDFSTART

(Retrieved 4th of October 2006).

Technology and Policy Assessment of the United Kingdom Energy Research Centre (March 2006). "The costs and impacts of intermittency: an assessment of the evidence on the costs and impacts of intermittent generation on the British electricity network". Imperial college of London.

The Republic of Palau, European Community (2002). Country Strategy Paper and National Indicative Programme for the period 2002-2007. 
Thorpe, T.W. (1992). A Review of Wave Energy. ESTU report R-72.

Thorpe, T.W. (1999). "An Overview of Wave Energy Technologies, Status, Performance and Cost". Seminar Wave Power: Moving Towards Commercial Viability, 30 November 1999, Broadway House, Westminster, London.

Tonga, European Community (2001). Country Strategy Paper and National Indicative Programme for the Period 2002-2007.

Tuvalu, European Community (2001). Country Strategy Paper and National Indicative Programme for the Period 2002-2007.

United Nations Development Programme (2005). Human Development Report 2005. Oxford University Press, New York.

Van der Linden, N.H. et al (2005). "Review of International Experience with Renewable Energy Obligation Support Mechanisms” ECN.

Viscusi, K., Vernon, J.M., Harrington, J.E. (2000). Economics of Regulation and Antitrust. Third Edition, Cambridge, MA: The MIT Press, 2000.

Wade, H. et al. (2005). "Pacific Regional Energy Assessment 2004: An Assessment of the Key Energy Issues, Barriers to the Development of Renewable Energy to Mitigate Climate Change, and Capacity Development Needs to Removing the Barriers". Prepared for the Secretariat of the Pacific Regional Environment Programme: Pacific Islands Renewable Energy Project, Vol. 1-16.

http://www.sprep.org/climate change/pirep.htm (Retrieved 10th of March 2006).

Weisser, D. (2003). "Costing Electricity Supply Scenarios: A Case Study of Promoting Renewable Energy Technologies on Rodriguez, Mauritius”. Renewable Energy Vol. 29 (2004), pp. 1319-1347.

http://www.sciencedirect.com/science? ob=MImg\&_imagekey=B6V4S-4BRP4G6-1-

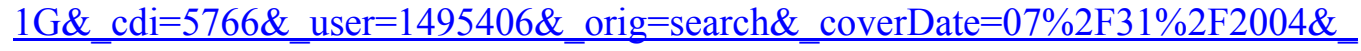




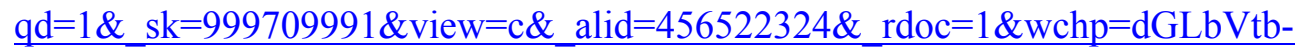

zSkzS\&md5=720225d89bf708e1ae8b6f3e7df8503d\&ie=/sdarticle.pdf (Retrieved 2nd of October 2006)

Weisser, D. (2004). "On the Economics of Electricity Consumption in Small Island Developing States: a role for Renewable Energy Technologies?” Energy Policy Vol. 32, Issue 1, pp. 127-140.

Weisser, D. (2004). "Power Sector Reform in Small Island Developing States: What Role for Renewable Energy Technologies?" Renewable and Sustainable Energy Reviews Vol. 8, pp.101-127.

http://www.sciencedirect.com/science?_ob=MImg\&_imagekey=B6VMY-4B28N7N$\underline{2-}$

$\underline{\mathrm{C} \& \text { cdi }=6163 \& \text { user }=1495406 \& \text { orig }=\text { search \& coverDate }=04 \% 2 \mathrm{~F} 30 \% 2 \mathrm{~F} 2004 \& \text { q }}$ $\mathrm{d}=1 \&$ sk=999919997\&view $=\mathrm{c} \&$ alid $=461360106 \&$ rdoc $=1 \& w \mathrm{w} \mathrm{ch}=\mathrm{dGLzVlz}-$ zSkzS\&md5=b710e3c369c2ca4e7ec5ed9d0689c344\&ie=/sdarticle.pdf (Retrieved 3rd of October 2006)

Wiser, R., Bolinger, M. (September 2004). "The Value of Renewable Energy as a Hedge Against Fuel Price Risk".

www.oe.energy.gov/DocumentsandMedia/wrec_hedge_final_sept_2004.pdf

(Retrieved 20th of September 2006)

Wiser, R., Hamrin, J., Wingate, M. (June 2002). "Renewable Energy Policy Options for China: A Comparison of Renewable Portfolio Standards, Feed-in Tariffs, and Tendering Policies". Prepared for the Center for Renewable Energy Development, Energy Research Institute, State Development Planning Commission.

Wiser, R. Lewis, J. (2005). "Fostering a Renewable Energy Technology Industry: An International Comparison of Wind Industry Policy Support Mechanisms". Ernest Orlando Lawrence Berkely National Laboratory, Environmental Energy Technologies Division. Paper \# LBNL- 59116. 
Wohlgemuth, N., Madlener, R. (2000). "Financial Support of Renewable Energy Systems: Investment vs. Operating Cost Subsidies". Proceedings of the Norwegian Association for Energy Economics (NAEE) Conference, Towards an Integrated European Energy Market. Bergen/Norway, 31 august-2 September 2000.

World Bank (1992). Pacific Regional Energy Assessment. Vol. 1-13. http://wwwwds.worldbank.org/servlet/WDSContentServer/WDSP/IB/1999/09/17/000009265 39 61001182906/Rendered/PDF/multi page.pdf (Retrieved on the 22nd of March 2006).

World Bank Operations Evaluation Department (2005). Evaluation of World Bank Assistance to Pacific Member Countries, 1992-2002. World Bank Report No. 31940.

World Council for Renewable Energy (2004). Asia Pacific Renewable Energy and Sustainable Development Agenda.

http://www.gdrc.org/uem/energy/renewable-energy-agenda-2004.html (Retrieved 1st of October 2006)

Yu, X., Glimour, A., Tapling, R. (1996). "Current Limitations on Further Introduction of renewable Energy Systems in the South Pacific”. Energy Policy, Vol. 24 no. 8, pp. 697-711.

Yu, X. and Tapling, R. (1997). "Policy Perspectives: Environmental Management and Renewable Energy in the Pacific Islands”. Journal of Environmental Management Vol. 51, pp. 107-122. 


\section{Websites consulted}

American Samoa Power Autorithy www.aspower.com

Electricité de Tahiti www.edt.pf

Elyo www.elyo.com

Guam Statistics - Utilities

http://www.spc.int/prism/country/gu/Stats/Utilities/Utilities.htm\#PH4

Guam Power Authority www.guampowerauthority.com

Hawaiian Electric Company www.heco.com

Japan International Cooperation Agency (JICA) www.jica.go.jp/english

Kiribati Statistics Office

http://www.spc.int/prism/Country/KI/Stats/OtherStatistics/utuli.htm

Marshall Energy Company www.mecrmi.com

Ocean Power Delivery www.oceanpd.com

Solomon Islands Statistics Office http://www.spc.int/prism/country/sb/stats

World Bank Renewable Energy Toolkit

www.srpnet.com/competition/terms 
